UNIVERSIDADE DE SÃO PAULO

FFCLRP - DEPARTAMENTO DE PSICOLOGIA E EDUCAÇÃO

PROGRAMA DE PÓS-GRADUAÇÃO EM PSICOBIOLOGIA

\title{
A estrutura do espaço visual e a percepção de colinearidade no campo aberto: análise de procedimentos, teste de modelos e aspectos cognitivos
}

Javier Enrique Santillán

Tese apresentada à Faculdade de Filosofia, Ciências e Letras de Ribeirão Preto da USP, como parte das exigências para a obtenção do título de Doutor em Ciências, Área: Psicobiologia

Ribeirão Preto - SP 

JaVier EnRique SANTILlán

\section{A estrutura do espaço visual e a percepção de colinearidade no campo aberto: análise de procedimentos, teste de modelos e aspectos cognitivos}

Tese apresentada à Faculdade de Filosofia, Ciências e Letras de Ribeirão Preto da USP, como parte das exigências para a obtenção do título de Doutor em Ciências, Área: Psicobiologia

Orientador: Prof. Dr. José Aparecido Da Silva 
Autorizo a reprodução e divulgação total ou parcial deste trabalho, por qualquer meio convencional ou eletrônico, para fins de estudo e pesquisa, desde que citada a fonte.

Santillán, Javier Enrique

A estrutura do espaço visual e a percepção de colinearidade no campo aberto: análise de procedimentos, teste de modelos e aspectos cognitivos.

/ Javier Enrique Santillán;

orientador José Aparecido Da Silva - Ribeirão Preto, 2009

176 p. : il.

Inclui Bibliografia.

Tese (Doutorado)-Universidade de São Paulo, 2009

1 - Percepção Visual 2 - Percepção de distância 3 - Colinearidade

I - Da Silva, José Aparecido II - Universidade de São Paulo, FFCLRP

III - A estrutura do espaço visual e a colinearidade no campo aberto: análise de procedimentos, teste de modelos e aspectos cognitivos. 
Nome: SANTILLÁN, Javier Enrique

Título: A estrutura do espaço visual e a percepção de colinearidade no campo aberto: análise de procedimentos, teste de modelos e aspectos cognitivos.

Tese apresentada à Faculdade de Filosofia, Ciências e Letras de Ribeirão Preto da USP, como parte das exigências para a obtenção do título de Doutor em Ciências, Área: Psicobiologia

Aprovado em:

\section{Banca Examinadora}

Prof. Dr.

Instituicao:

Julgamento:

Assinatura:

Prof. Dr.

Instituicao:

Julgamento:

Assinatura:

Prof. Dr.

Instituicao:

Julgamento:

Assinatura:

Prof. Dr.

Instituicao:

Julgamento: Assinatura: 



\section{Dedicatória}

A minha filinha Florencia del Rosario, que mudou nossa percepção do mundo e das distâncias, iluminando tudo com uma nova luz.

E a Teresita, meu amor, por fazê-lo possível. 



\section{Agradecimentos}

Ao Prof. Dr. José Aparecido Da Silva, pela oportunidade de participar do Fechner Day 2002 e do Simpósio The mind-Body problem: old question and new answers, na Faculdade de Filosofia, Ciências e Letras de Ribeirão Preto. Foi este gesto que me permitiu conhecer um grupo de pessoas excepcional e um campo do saber sumamente interessante, a partir do qual não só fiquei tentado de fazer meu doutorado na Psicobiologia, senão que derivou também num projeto internacional de colaboração e intercâmbio institucional com o Departamento de Luminotecnia, Luz y Visión, da Faculdade de Ciências Exatas e Tecnologia (FACET) da Universidade Nacional de Tucumán (UNT), apoiado pela CAPES e a SPU Argentina. Obrigado também pelo completo apóio (que foi fundamental nos primeiros tempos em Ribeirão Preto), pela orientação e por fornecer a infra-estrutura necessária para o desenvolvimento deste trabalho.

Ao Prof. Dr. César Alexis Galera, pelo assessoramento constante durante a marcha deste trabalho.

À Prof. Dra. Susi Lippi Marques Oliveira, que me ensinou os segredos do trabalho no campo aberto, conselhos a partir dos quais também nasceu uma amizade que transcendeu as fronteiras. Ainda, muito obrigado pelas discussões e sugestões sobre a maioria dos temas incluídos nesta tese. A seu esposo, o Dr. Herenilton Paulino Oliveira, pela inestimável colaboração para os experimentos.

Ao Prof. Dr. Luiz Marcelino de Oliveira (in memoriam), pela confiança e por sempre ter tido uma palavra de apoio.

Aos professores da Pós-graduação em Psicobiologia, pelos ensinamentos que já formam parte da minha bagagem.

Ao Igor Douckin, pelas idéias e dicas técnicas e, principalmente, pela amizade e os momentos de descontração.

Aos todos os colegas e amigos da Psicobiologia, pelo companheirismo.

A Odair Batistão e Paulo Aparecido Ambrósio, funcionários da Oficina de Precisão da PCARP, por construir os aparelhos utilizados nas pesquisas e solucionar todos os 
problemas técnicos com criatividade e celeridade.

Aos funcionários da Jardinagem da FFCLRP por manter a área experimental em condições.

À Renata Vicentini, pelas dicas e a paciência para me ajudar a resolver as questões relacionadas com o doutorado.

Às funcionárias da secretaria de Pós-Graduação, especialmente a Maria Inês Joaquim, pelo carinho na atenção e ajuda prestados durante o curso.

À Prof. Dra. Elisa Colombo e meus colegas e amigos do Departamento de Luminotecnia, Luz y Visión (FACET-UNT), por compreender minha ausência e me apoiar nesta etapa da minha formação.

A todos os observadores, especialmente ao pessoal da Química, pela desinteressada participação.

À CAPES, pelo apoio financeiro na forma de bolsa de estudo ProEx.

A Mirta Jaén e Diego Corregidor, com quem trabalhamos no Projeto "Configuraciones espaciales y temporales de luminancia que inducen stress visual" do Conselho de Investigações da UNT, pela caracterização do filtro empregado no Experimento V.

A minha família e a de Teresita, minha família política, pelo apoio desde a distância. Especial menção para meu cunhado "Pepe", cuja incondicional ajuda facilitou cada retorno nosso a Tucumán.

A minhas esposa e filha, por estar a meu lado me dando todo o amor e força necessários para trilhar este caminho até o final.

Aos brasileiros em geral, obrigado pelo afeto constante. Por abrir, para mim e minha família, as portas de este lindo pais -que sem dúvida aprendemos a querer como nosso- e que sempre terá um lugar especial em nossos corações. 
"São vãs e estão pragadas de erros as ciências que não têm nascido do experimento, mãe de toda certeza."

LEONARDo DA VINCI (1452-1519) 



\title{
Resumo
}

\author{
SANTILLÁN, J. E. A estrutura do espaço visual e a percepção de colinearidade no \\ campo aberto: análise de procedimentos, teste de modelos e aspectos cognitivos. \\ 2009. 176 p. Tese (Doutorado) - Faculdade de Filosofía, Ciências e Letras de Ribeirão \\ Preto, Universidade de São Paulo, São Paulo, 2009.
}

O propósito do presente trabalho foi investigar, a partir de uma configuração espacial de estímulos colineares no campo aberto, a acurácia e estabilidade dos ajustes e estimativas de distância. Para isso foram analisados os aspectos referidos ao emprego de uma tarefa de ajuste de colinearidade e os dados confrontados com o fenômeno perceptual de anisotropia do espaço percebido. Adicionalmente, os resultados foram ajustados a partir de diferentes modelos, avaliando suas implicações para a geometria do espaço visual. Ainda, foram considerados os aspectos cognitivos vinculados a este tipo de tarefa quando empregadas no campo aberto, especialmente, em relação à visualização mental e a correção cognitiva. Participaram do estudo, como voluntários nos diferentes experimentos, 96 observadores, com idade média de 26 anos para mulheres e 28 anos para os homens. Na coleta de dados experimentais foram utilizados recursos técnicos implícitos - apontamento exocêntrico e, também, recursos diretos estimativa verbal de distância em campo aberto. Os resultados revelaram que os observadores apresentaram um bom desempenho na tarefa de colinearidade, com erros variando sistematicamente em função da distância egocêntrica do alvo. Os alinhamentos de colinearidade foram similares aos encontrados na literatura e não apresentaram variações quando agregado mais um alvo marcando o centro da configuração espacial de estímulos. Os julgamentos de distância egocêntrica e exocêntrica foram ajustados usando diferentes modelos teóricos (linear, função de potência, Generalizado, Tangle). O melhor ajuste foi obtido pelo Tangle, o modelo não linear de Foley, Ribeiro-Filho e Da Silva (2004) (RMSE=0,29m para distância egocêntrica e $0,31 \mathrm{~m}$ para distância exocêntrica). Neste modelo ficou evidenciado que a desigualdade do triângulo foi cumprida para ângulos que variavam desde 67 até 101 graus, enquanto a soma dos segmentos das linhas de colinearidade não igualou o valor da distância entre seus pontos extremos. A anisotropia do espaço visual encontrada, nos experimentos, foi coerente com a reportada na literatura, aparecendo como um fenômeno difícil de ser representado geometricamente. As evidências apresentadas nesta tese, apontam à relevância dos processos cognitivos no momento de realizar tarefas espaciais como: o ajuste de colinearidade, a visualização mental ou a estimação de distância, tendo um aumento das correções cognitivas se incrementada a complexidade do ambiente visual. Foram encontradas diferenças nos julgamentos segundo o sexo dos observadores, com variações dependentes das tarefas consideradas. Sumariando, o trabalho experimental apresentado permitiu agregar informações para área temática desta pesquisa, contribuindo com uma análise ampliada sobre procedimentos baseados no ajuste de colinearidade, à aplicação do modelo de Foley, Ribeiro-Filho e Da Silva (2004) em estimativas baseadas neste tipo de tarefas no campo aberto, e sobre os aspectos cognitivos intervenientes.

Palavras-chave: Percepção visual. Percepção espacial. Percepção de distância. Psicofísica. 



\title{
Abstract
}

\author{
SANTILLÁN, J. E. The structure of visual space and the perception of collinearity \\ in open field: analysis of procedures, model testing and cognitive aspects. 2009. \\ 176 p. Tese (Doutorado) - Faculdade de Filosofía, Ciências e Letras de Ribeirão Preto, \\ Universidade de São Paulo, São Paulo, 2009.
}

The purpose of the present work was to investigate, using a spatial configuration of collinear stimuli in the open field, the accuracy and stability of the adjustments and distance estimates. Aspects related with the collinearity task were analyzed and the data confronted with the phenomenon of the anisotropy of perceived space. In addition, the results were fitted using different theoretical models, assessing their implications for the geometry of the visual space. The cognitive aspects related with this kind of task, when used in the open field, were also considered, particularly these referred to mental visualization and cognitive correction. 96 volunteers participated in the different experiments of this study, with a mean age of 26 years old for women and 28 for the men. In the collection of the experimental data, indirect measures were used, in particular a kind of exocentric pointing task, and, also, direct measures, like verbal judgments. The result shows that the observers achieved a good performance in the collinearity task, with errors varying systematically in function of the egocentric distance to the target. The results of the collinearity task were analogous to those found in the literature, and they didn't show significant variations when one more target, indicating the center of the spatial configuration of stimuli, was added on. The egocentric and exocentric distance judgments were adjusted using different theoretical models (lineal, power function, Common model, Tangle). The best fit was obtained by the Tangle, the non-linear model of Foley, Ribeiro-Filho and Da Silva (2004) (with RMSE=0,29m for egocentric distances and 0,31m for exocentric distances). In this model it was evidenced that the inequality of the triangle was accomplished for angles that varied from 67 to 101 degrees, while the sum of the segments of the collinearity lines didn't equal the value of the total distance among their extreme points. The anisotropy of the visual space found in the experiments, was coherent with the reports in the literature, appearing as a phenomenon difficult of being represented geometrically. The evidences presented in this work point to the relevance of the cognitive processes when performing spatial tasks such as: collinearity adjust, mental visualization, distance estimation, with the cognitive corrections increasing as the complexity of the visual environment grown. They were also found differences in the judgements according to the observers' sex, with variations depending on the considered tasks. Summarizing, the present experimental work contributed to this area of research, with an analysis about the procedures based on the adjust of collinearity, the application of the theoretical model of Foley, Ribeiro-Filho and Da Silva (2004) in estimatives based on this kind of tasks in the open field, as well on the related cognitive aspects.

Key-words: Visual perception. Space perception. Distance perception. Psychophysics. 



\section{Sumário}

\section{Lista de Figuras}

Lista de Tabelas

$\begin{array}{lr}\text { Apresentação } & \text { p. } 29\end{array}$

1 O espaço visualmente percebido $\quad$ p.33

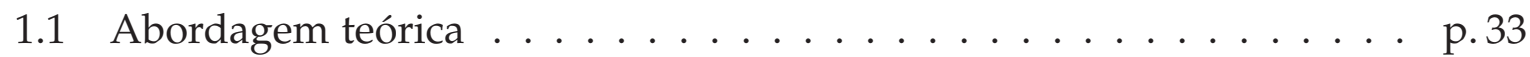

1.2 O espaço visual $\ldots \ldots \ldots \ldots \ldots \ldots \ldots \ldots$. . . . . . . . . . . . . . . .

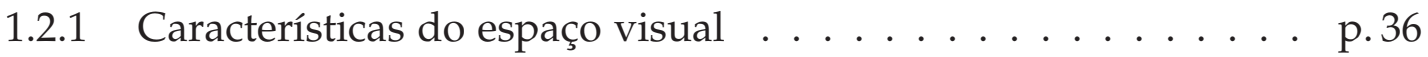

1.2.2 A anisotropia do $\mathrm{EV}^{3} \ldots \ldots \ldots \ldots$. . . . . . . . . . . .

1.2.3 A geometria do espaco visual . . . . . . . . . . . p.38

1.3 Interagindo com o espaço visual . . . . . . . . . . . p. 39

1.3.1 As distâncias percibidas . . . . . . . . . . . . . p. 39

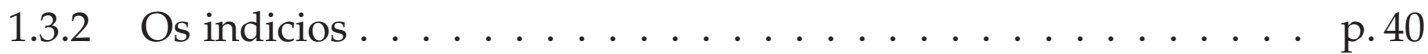

1.3 .3 Os ambientes .............................. 41

1.3.4 Acerca das tarefas . . . . . . . . . . . . . . p. 42

1.4 Relevância do estudo do Espaço Visual . . . . . . . . . . . . . . p p.43

1.4.1 Implicações cognitivas . . . . . . . . . . . . . . p.43

1.4.2 Implicações psicobiológicas . . . . . . . . . . . . . p. 44

1.4.3 Implicações filosóficas . . . . . . . . . . . . . p.45

2 Modelagem da percepção de distância exocêntrica $\quad$ p.47 
2.1 A perspectiva geométrica: o ângulo visual . . . . . . . . . . p. p 47

2.2 O ângulo visual percebido . . . . . . . . . . . . . p. 49

2.3 Modelagem da percepção exocêntrica de distância . . . . . . . . . . . p. p.50

2.4 O modelo de Foley, Ribeiro-Filho e Da Silva (2004) . . . . . . . . p. p.58

2.4.1 Testagem do modelo "Tangle" . . . . . . . . . . . p. 61

3 Objetivos a serem atingidos p.65

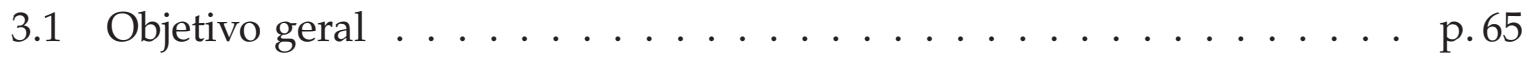

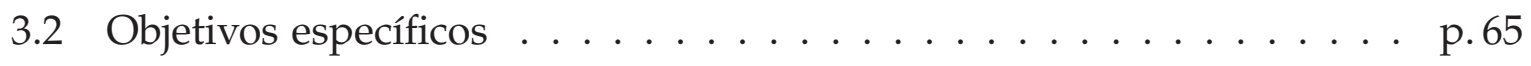

4 Delineamento do Projeto p. $\quad$ p.

4.1 Percepção de colinearidade em campo aberto . . . . . . . . . . . p p.67

4.1.1 Percepção de distância e orientação exocêntrica em campo aberto .............................. 68

4.1.2 Apontamento exocêntrico e colinearidade . . . . . . . . . p. 69

4.1.3 Tarefas de colinearidade em campo aberto . . . . . . . . p.71

4.1.4 Acerca dos estímulos e seu posicionamento . . . . . . . . p.72

4.2 Experimento I . . . . . . . . . . . . . . p. 74

4.2 .1 Método............................ 74

4.2.1.1 Participantes .................. p. 74

4.2.1.2 Ambiente experimental . . . . . . . . p. 76

4.2.1.3 Equipamentos e materiais .......... p. 76

4.2.1.4 Planejamento experimental . . . . . . . . . p. p. 79

4.2.1.5 Procedimento ............... p. 80

4.2.2 Resultados .................... p. 80

4.2 .3 Discussão . . . . . . . . . . . . . . p. 87

4.3 Experimento II . . . . . . . . . . . . . . p. 91

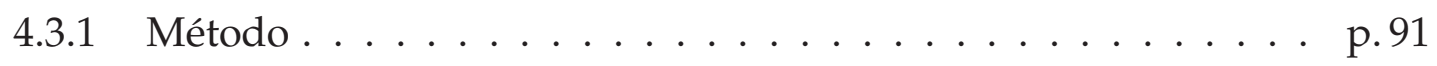


4.3.1.1 Participantes ................... p. 91

4.3.1.2 Ambiente experimental . . . . . . . . . p. 92

4.3.1.3 Equipamentos e materiais ........... . p.92

4.3.1.4 Planejamento experimental . . . . . . . . . p.92

4.3.1.5 Procedimento ................. p. 92

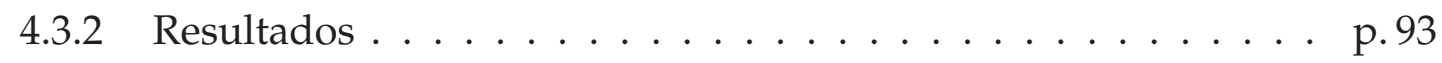

4.3 .3 Discussão . . . . . . . . . . . . . . . p. 95

4.4 Discussão Experimentos I e II . . . . . . . . . . . . . . . . p p.98

5 Testagem de modelos teóricos p.103

5.1 Modelo de Foley et al. (2004) e suas conseqüências . . . . . . . . . . . p. 103

5.2 Experimento III . . . . . . . . . . . . . . . p. 104

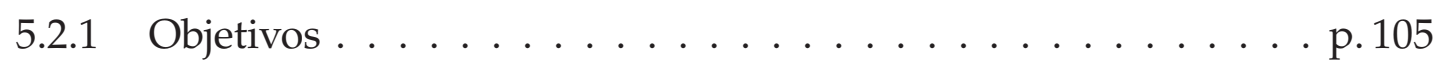

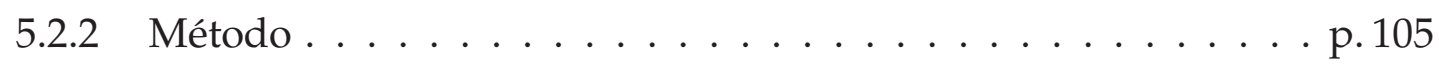

5.2.2.1 Participantes ....................... 105

5.2.2.2 Ambiente experimental . . . . . . . . . . p. 105

5.2.2.3 Equipamentos e materiais . . . . . . . . . p. 105

5.2.2.4 Planejamento experimental . . . . . . . . . p. 106

5.2 .3 Resultados . . . . . . . . . . . . . p. 106

5.2.3.1 Distâncias egocêntricas . . . . . . . . . . p. 106

5.2.3.2 Distâncias exocêntricas . . . . . . . . . . p. p. 112

5.2.3.3 Análise das apreciações subjetivas . . . . . . . . p. 118

5.2.3.4 Ajuste e modelagem dos dados . . . . . . . . . . p. 119

5.2.4 Discussão Experimento III . . . . . . . . . . . . . . . . . . . p. p.121

5.3 Modelando os dados com o 'Tangle' . . . . . . . . . . . . . . . p. 122

5.4 Analisando as conseqüências do 'Tangle' . . . . . . . . . . . . . p. 124

5.4.1 Da desigualdade do triângulo . . . . . . . . . . . p. 126 
5.4.2 Da suma dos segmentos vs. a distância total . . . . . . . . . . . p. 127

5.5 Discussão . . . . . . . . . . . . . . . . . . . . . . p. 128

6 Abordando aspectos cognitivos p.133

6.1 Visualização mental no campo aberto . . . . . . . . . . . . . p.133

6.2 Experimento IV . . . . . . . . . . . . . . . . . . . p. 135

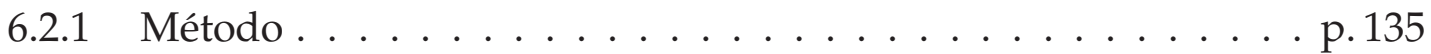

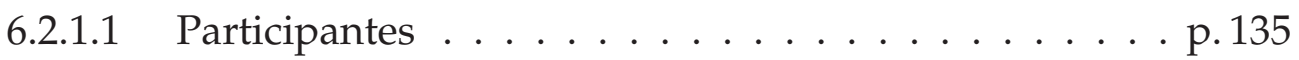

6.2.1.2 Ambiente experimental . . . . . . . . . . . p. 135

6.2.1.3 Equipamentos e materiais . . . . . . . . . p. 135

6.2.1.4 Planejamento experimental . . . . . . . . . . p. 135

6.2.1.5 Procedimento .................. . . 137

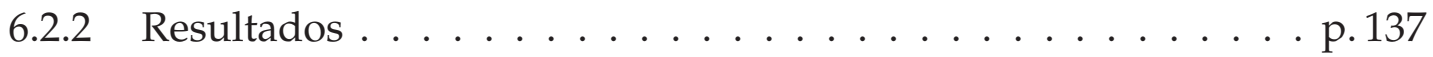

6.2 .3 Discussão . . . . . . . . . . . . . . . . . p. 139

6.3 Comparando o fator 'sexo do observador' nos Experimentos I, II, III e IV . . . . . . . . . . . . . . . . . . . . . p. 142

6.4 Percepção de colinearidade com visibilidade reduzida . . . . . . . . . p. 143

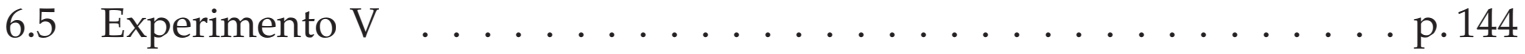

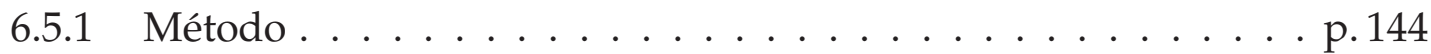

6.5.1.1 Participantes ...................... 144

6.5.1.2 Ambiente experimental . . . . . . . . . . p. 145

6.5.1.3 Equipamentos e materiais . . . . . . . . . . p. 145

6.5.1.4 Planejamento experimental . . . . . . . . . . . p. 145

6.5.1.5 Procedimento .................... 146

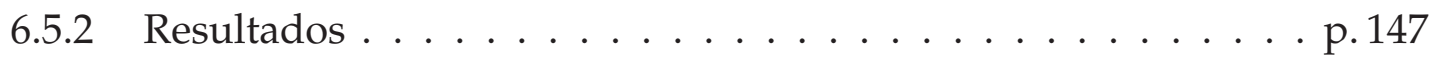

6.5 .3 Discussão . . . . . . . . . . . . . . . . . . . p. 147 
6.6 Importância de se considerar conjuntamente os aspectos visual, perceptual e cognitivo . . . . . . . . . . . . . . . . . . . p. . . . . . . . . . . . .

7 Discussão Geral p.151

$\begin{array}{ll}\text { Referências } & \text { p.155 }\end{array}$

Apêndice A - Termo de Consentimento Livre e Esclarecido p. 165

Apêndice B - Instruções Experimento I p.167

$\begin{array}{ll}\text { Apêndice C - Protocolo coleta Exp. I } & \text { p. } 169\end{array}$

Apêndice D - Instruções Experimento II $\quad$ p.171

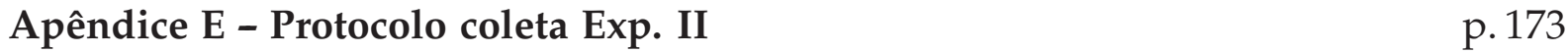

Anexo A - Protocolo Comite Etica p. 175 



\section{Lista de Figuras}

1 Espaço Físico e sua correspondência com o Espaço Visual . . . . . . . p.35

2 Geometria do ângulo visual . . . . . . . . . . . . . p. 48

3 Sistema de coordenadas proposto por Wagner (1985) para o cálculo de distância exocêntrica . . . . . . . . . . . . . . . p. 53

4 Parâmetros do modelo de Transformação proposto por Baird e Wagner (1991) para o processamento da percepção de distância exocêntrica p.56

5 Diagrama ilustrando a proposta de Foley (1980) . . . . . . . . . . p.57

6 Modelos 'generalizado' e 'Tangle' de percepção de tamanho . . . . . . . p.59

7 Configuração física empregada por Foley, Ribeiro-Filho e Da Silva

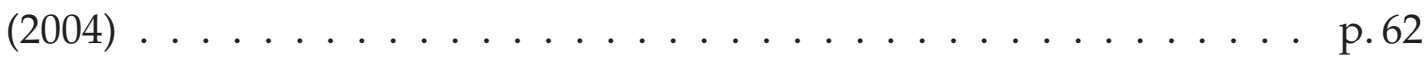

8 Esquema da proposta experimental com os ângulos subtendidos pelos estímulos . . . . . . . . . . . . . . . . p. 75

9 Fotos da Área experimental . . . . . . . . . . . . . . p. 77

10 Esquema a escala da distribuição dos estímulos no campo aberto . . . p.78

11 Esquema dos estímulos e convenção de sinais empregada na codificação dos resultados . . . . . . . . . . . . . . . . . . p.81

12 Experimento I. Boxplot dos erros no ajuste de colinearidade . . . . . . p. 83

13 Experimento I. Histograma dos erros . . . . . . . . . . . p. 84

14 Experimento I. Gráfica da média dos erros de ajuste de colinearidade segundo posição espacial . . . . . . . . . . . . . . p. 85

15 Experimento I. Erros de colinearidade e retas de regressão . . . . . . . p.86

16 Experimento I. Erros angulares em função da distância egocêntrica relativa entre os estímulos . . . . . . . . . . . . p. 88

17 Experimento I. Orientações mais freqüentes dos estímulos . . . . . . . p.90 
18 Experimento II. Boxplot dos erros no ajuste de colinearidade, sem estímulo central . . . . . . . . . . . . . . . . p. 94

19 Experimento II. Boxplot dos erros no ajuste de colinearidade, com estímulo central . . . . . . . . . . . . . . . p. 95

20 Experimento II. Interação Estímulo Móvel * Ponto início da medição p. 96

21 Experimento II. Médias dos erros e seus respectivos intervalos de confidência para ambas condições. . . . . . . . . . . . . p. p7

22 Experimento II. Orientações mais freqüentes dos estímulos na condição CE . . . . . . . . . . . . . . . . . . . . p. 99

23 Segunda implicação do modelo de Foley, Ribeiro-Filho e Da Silva (2004)p. 104

24 Experimento III. Médias dos erros constantes para os julgamentos das distâncias egocêntricas nas duas Diagonais . . . . . . . . . p.108

25 Experimento III. Médias dos erros constantes para os julgamentos das distâncias egocêntricas dos estímulos pertencentes à Diagonal 1 • p.110

26 Experimento III. Médias dos erros constantes para os julgamentos das distâncias egocêntricas dos estímulos pertencentes à Diagonal 2 • p.111

27 Experimento III. Médias dos erros constantes para os julgamentos das distâncias exocêntricas nas duas Diagonais . . . . . . . . . . . . . . p. 114

28 Experimento III. Médias dos erros constantes para os julgamentos das distâncias exocêntricas dos estímulos pertencentes à Diagonal 1 . p.116

29 Experimento III. Médias dos erros constantes para os julgamentos das distâncias exocêntricas dos estímulos pertencentes à Diagonal 2 • p. 117

30 Experimento III. Percentagens de observadores que modificariam o alinhamento dos estímulos empregados . . . . . . . . . . . p.118

31 Experimento III. Médias das estimativas egocêntricas de distância em função das distâncias físicas e ajustes linear e não linear dos dados . p. 120

32 Experimento III. Médias das estimativas exocêntricas de distância em função das distâncias físicas e ajustes linear e não linear dos dados . . p. 120

33 Médias das distâncias egocêntricas reportadas versus as predições do Modelo Generalizado . . . . . . . . . . . . . . . . . . . . . . . . . p. 121 
34 Médias das distâncias egocêntricas percebidas e ajuste com a 'Função de Distância Egocêntrica' do Tangle . . . . . . . . . . . . . . . . . . . . p.123

35 Ângulo visual efetivo para o cálculo da distância excêntrica em função do ângulo visual . . . . . . . . . . . . . . . . . . . . . . . . . p. 124

36 Médias das distâncias egocêntricas reportadas versus as predições do modelo Tangle . . . . . . . . . . . . . . . . . . . . . . . p. 125

37 Médias das distâncias exocêntricas percebidas desenhadas em função dos tamanhos físicos dos segmentos da Diagonal 1 . . . . . . . . . p. 129

38 Médias das distâncias exocêntricas percebidas desenhadas em função dos tamanhos físicos dos segmentos da Diagonal 2 . . . . . . . . . p. 129

39 Experimento IV. Configuração espacial e esquema da tarefa para o Grupo 1. . . . . . . . . . . . . . . . . . . . . p. 136

40 Experimento IV. Configuração espacial e esquema da tarefa para o Grupo 2. . . . . . . . . . . . . . . . . . . . . p. 136

41 Experimento IV. Distribuição dos resultados dos julgamentos disgregados por 'Tipo de tarefa' e por 'Sexo' . . . . . . . . . . . . . . . . . . . p. 138

42 Experimento IV. Comparação das médias dos julgamentos segundo o 'Tipo de tarefa' . . . . . . . . . . . . . . . . . . . . . . . p.138

43 Experimento IV. Comparação das médias dos julgamentos segundo o 'Sexo dos observadores' . . . . . . . . . . . . . . . . . . . p.139

44 Experimento IV. Médias dos julgamentos considerando a interação 'Tipo de tarefa $*$ Sexo' . . . . . . . . . . . . . . . . . . . . . p. 140

45 Experimento V. Caracterização do filtro difusor empregando a Função de Dispersão de Ponto $(P S F)$. . . . . . . . . . . . . . . . . . . . p.146

46 Experimento V. Erros cometidos no ajuste de colinearidade Sem e Com visibilidade reduzida vs. posição espacial . . . . . . . . . . . . . p.148 



\section{Lista de Tabelas}

1 Distâncias entre os estímulos da reta de colinearidade que passaria

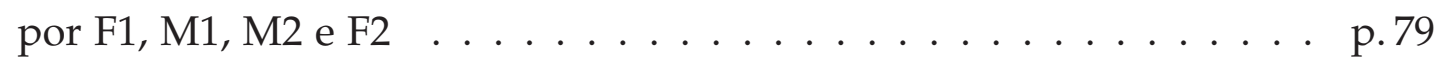

2 Distâncias entre os estímulos da reta de colinearidade que passaria por F3, M3, M4 e F4 . . . . . . . . . . . . . . . . p.79

3 Experimento I. Erros de colinearidade $\ldots \ldots \ldots \ldots \ldots \ldots$ p. 82

4 Experimento I. Ângulos visuais subtendidos pelos pares de estímulos p.87

5 Experimento II. Erros de colinearidade com os dados dos observadores nas duas condições: Sem e Com estímulo central . . . . . . . p p.93

6 Experimento II. Resultados dos erros de colinearidade para ambas condições expressados em valores angulares . . . . . . . . . . p.97

7 Experimento III. Resultados dos julgamentos de distância egocêntrica para os estímulos da Diagonal 1 nas duas condições: Sem e Com referência . . . . . . . . . . . . . . . . . . . . p. 107

8 Experimento III. Resultados dos julgamentos de distância egocêntrica para os estímulos da Diagonal 2 nas duas condições: Sem e Com referência . . . . . . . . . . . . . . . . . . . . p. 107

9 Experimento III. Resultados dos julgamentos de distância exocêntrica para os estímulos da Diagonal 1 nas duas condições: Sem e Com referência . . . . . . . . . . . . . . . . . . . p.113

10 Experimento III. Resultados dos julgamentos de distância exocêntrica para os estímulos da Diagonal 2 nas duas condições: Sem e Com referência . . . . . . . . . . . . . . . . . . . . . p.113

11 Comparação do ajuste aos dados experimentais dos modelos Generalizado e Tangle . . . . . . . . . . . . . . . . . . p.125 
12 Médias das distâncias egocêntricas e exocêntricas físicas e percebidas para os diferentes triângulos formados pelo observador $(\mathrm{O})$ e os estímulos nas Diagonais 1 e $2 \ldots \ldots$. . . . . . . . . . . . 126

13 Distâncias egocêntricas e exocêntricas estimadas pelo Tangle para os diferentes triângulos formados pelo observador $(\mathrm{O})$ e os estímulos nas Diagonais 1 e $2 \ldots \ldots$. . . . . . . . . . . . . . . 127

14 Médias das distâncias exocêntricas percebidas para os diferentes segmentos da Diagonais $1 \ldots \ldots$. . . . . . . . . . . . . . . 128

15 Médias das distâncias exocêntricas percebidas para os diferentes segmentos da Diagonais $2 \ldots \ldots$. . . . . . . . . . . . . . . 128

16 Experimento V. Resultados dos ajustes de colinearidade nas duas condições: Sem e Com filtro . . . . . . . . . . . . . . . . . . . p. 147 


\section{Apresentação}

"A Psicofísica é definida comumente como o dominio quantitativo do estudo da percepção, examinando as relações entre o estímulo observado e as respostas e as razões para essas relações. Esta é, sem embargo, uma visão muito estreita da influência que ela tem tido em grande parte da psicologia..." (BAIRS; NOMA, 1978)

A Visão apresenta várias características admiráveis, sendo sem dúvida o mais extraordinário de nossos sentidos. A particularidade responsável desta preeminência é a capacidade de detectar estímulos a distância, sem requerer contato entre o objeto ou espaço físico e o observador. Igualmente surpreendente é sua imediação: se as condições do médio ambiente são adequadas, uma pessoa sem déficits visuais nem motores consegue deslocar-se nele, e incluso realizar uma ampla variedade de tarefas, sem problemas e com impressionante precisão. Ainda mais admirável é o fato que a maior parte de essas atividades são realizadas de forma inconsciente, pois geralmente a prática terminou não só aperfeiçoando-as, senão também automatizando-as. Assim caminhar pelo centro da cidade ou dirigir um carro são, normalmente, tarefas executadas sem esforço, embora requeiram que uma importante quantidade de informação seja processada a cada instante.

Eis a dificuldade no estudo da percepção visual, pois essa imediação mascara a complexidade do Sistema Visual. Como nosso cérebro consegue entender a partir da imagem bidimensional projetada na retina o vasto mundo tridimensional que nos rodeia e, ademais, desempenhar-se adequadamente nele, continua estimulando investigações ao redor do mundo todo. Devido a que esse processamento de informação involucra vários níveis complexamente interligados, é preciso o aporte de especialidades tão diversas como fisiologia, anatomia, bioquímica, biofísica, computação, biologia, psicologia, etc., tornando as "Ciências da Visão" um campo de ativa pesquisa interdisciplinar. Sua produtividade situa esta área de pesquisa entre as mais férteis 
das últimas décadas, sendo esta afirmação confirmada pelas múltiplas possibilidades de aplicação dos resultados, que nos últimos tempos vem despertando o interesse de disciplinas associadas à alta tecnologia tais como bioengenharia, cirurgia e diagnóstico por imagens, Realidade Virtual, robótica, e aplicações militares como os sistemas de pontaria, simulação e 'Realidade Aumentada' (Augmented Reality) em ambientes amplos e abertos.

O estudo da percepção do espaço e o entendimento acerca da percepção de distância, assim como os processos subjacentes, são problemas fundamentais no campo da psicobiologia dos processos perceptivos. Mas, apesar de uma longa história de investigação -que se remonta a tempos prévios aos inícios da psicologia experimental definida como tal-, ainda não estão completamente elucidados. Neste contexto se encontrou enquadrado o presente trabalho de tese, o qual continuou a linha de pesquisa que soube destacar o Laboratório de Psicofísica e Percepção na FFCLRP da USP em Ribeirão Preto, caracterizada pela aplicação de metodologias psicofísicas ao estudo da percepção do espaço.

A tese foi organizada em seções, cada uma focada num dos aspectos do problema estudado.

Certamente, um dos aspectos que tem chamado a atenção dos pesquisadores é o evidente contraste entre o bom desempenho no espaço físico e as inadequações na sua percepção, que se manifestam em fenômenos como a compressão da distância e a falta de homogeneidade no espaço percebido. Na Seção 1 se apresenta o arcabouço teórico no qual está baseado o trabalho experimental realizado. São introduzidos alguns conceitos e termos específicos usados na literatura sobre percepção espacial, especialmente focando os aspectos relativos ao espaço visualmente percebido e a percepção de distância, assim como as dificuldades para seu estudo.

A investigação das diferenças entre as distâncias exocêntricas físicas e percebidas é, sem dúvida, uma área específica de pesquisa no campo da percepção visual. Como resultado destas investigações, vários modelos têm sido sugeridos com o propósito de representar matematicamente estas relações. Na Seção 2 se apresentam alguns destes modelos, analisando em detalhe a proposta de Foley, Ribeiro-Filho e Da Silva (2004), pensada para descrever melhor os resultados experimentais involucrando julgamentos de distância e tamanho.

Como o propósito principal dos experimentos foi investigar a performance dos observadores na percepção de distâncias no campo aberto, especificamente quando 
empregada uma tarefa que exigisse efetuar julgamentos de colinearidade em condições de indícios múltiplos e com ângulos visuais amplos, os resultados obtidos foram analisados e modelados, dando especial ênfase ao modelo criado por Foley, RibeiroFilho e Da Silva (2004), investigando logo suas conseqüências, como fica estabelecido na Seção 3.

Na Seção 4 se apresentam os resultados de investigar experimentalmente o desempenho dos observadores numa original tarefa de colinearidade no campo aberto. Como se tratou de uma nova variante de tarefa de apontamento exocêntrico, e este tipo de metodologia recém está começando a ser usada, foi realizada uma revisão na literatura e uma cuidadosa análise sobre o posicionamento dos estímulos empregados. Os Experimentos I e II permitiram comparar a performance dos observadores em duas configurações espaciais de estímulos.

A partir dos resultados do Experimento I foi realizado o Experimento III, baseado numa tarefa de julgamento verbal de distâncias percebidas como colineares, considerando duas condições: com e sem referência de tamanho. Na Seção 5, os dados obtidos foram analisados, dando continuidade ao ajustamento usando o modelo de Foley, Ribeiro-Filho e Da Silva (2004). Na seqüência os resultados foram comparados com os obtidos usando outras alternativas. Finalmente, foram examinadas as implicações estabelecidas pelos autores do modelo.

Na construção do espaço visualmente percebido existiria um processamento cognitivo subjacente, o qual estaria presente em cada julgamento de distância. Este processamento pode incluir processos conscientes, dirigidas a produzir uma resposta em particular ou manipulações específicas nas representações do espaço, por exemplo mediante "imagens mentais". Contudo, também existiriam outros fatores que não estão explicitamente disponíveis na consciência, mas que influiriam em igual o maior grau nas estimativas efetuando, por exemplo, "correções cognitivas" nos ajustes de distância realizados em condições de estímulos reduzidos ou em circunstâncias que limitam a visão. Estes aspectos foram considerados na Seção 6.

Finalmente, na Seção 7, foram sumariados os resultados experimentais e considerados os aportes do trabalho realizado. A modo de conclusão, indicam-se possíveis pontos de investigação futura. 


\section{O espaço visualmente percebido}

“O problema da percepção do espaço apresenta um longo e prestigioso pedigree [intelectual]" (WAGNER, 2005, 4)

Esta breve revisão tem como objetivo apresentar o contexto teórico no qual estaria baseado o trabalho experimental realizado, fundamentalmente o referido ao espaço visual e a percepção de distância.

\subsection{Abordagem teórica}

Entre as perspectivas teóricas que discutem nossa relação com o ambiente mediante a percepção visual encontram-se a ecológica e a representacionista. Segundo Gibson (1986), principal proponente da perspectiva ecológica, as propriedades do mundo são detectadas sem a mediação de processos cognitivos abstratos, sugerindo que a interação não se encontra mediada por processos mentais. Para este autor o aspecto fundamental seria entender quais informações disponíveis para o observador são efetivamente percebidas e contribuem na regulação de suas atividades, desconsiderando a idéia de "construção interna" da informação. Nesta perspectiva o próprio estímulo especificaria o ambiente e, portanto, nenhuma elaboração seria necessária, defendendo, assim, a percepção como sendo um processo de captação direta de informação a partir do que ele chama "arranjo óptico do ambiente" onde a informação estaria na luz e não nos impulsos nervosos. Esta assunção implica que o input sensorial no precisa ser enriquecido e que a luz estaria invariavelmente vinculada às suas fontes, estando o sistema visual dedicado a captar essas propriedades estáveis e invariáveis que se interpõem a nossa experiência e que são chamadas por Gibson de "invariantes". Assim, as configurações de estímulos forneceriam as condições para 
que o sistema visual extraísse a informação espacial a partir dos indícios presentes e sem invocar mecanismos cognitivos. Como outra alternativa nesta linha de pensamento, foi sugerido por Neisser (1994), o qual não nega a intervenção de mecanismos cognitivos, contudo sustenta a idéia que a percepção espacial não estaria baseada em representações, senão num sistema específico para o qual existiria evidência de suas funções de mediação.

Como outra forma de interpretação, a perspectiva representacionista sustenta a idéia que não há informação suficiente no ambiente e que, portanto, são necessários processos cognitivos e representações mentais para lograr uma correta interação com o meio através da percepção visual ou, segundo a interpretação de Gibson (1986), que o input sensorial se agruparia com as imagens armazenadas na memória gerando um novo input. Nesta perspectiva a percepção visual seria um processo que nos permite construir uma representação interna dos objetos e superfícies a partir da capacidade do sistema visual para determinar a direção e composição da luz que os objetos no ambiente emitem, refletem ou transmitem. O produto dessa atividade seria um 'percepto', que é uma síntese da informação externa e de aspectos internos do observador, um composto consistindo de sensação e memória (WEINLAND, 1984) que seria logo utilizado na seleção e execução das ações. Centrado nesse processamento de informação, Marr (1982) destaca em sua teoria a natureza inferencial e construtiva da percepção, sustentando que a percepção visual não deve apenas ater-se à extração de aspectos relevantes do meio que nos rodeia, senão também à formação de representações internas que possam servir de base para a interação com o ambiente.

Considera-se que as representações da cena visual podem facilitar a percepção da distribuição dos estímulos, provindo superfícies e pontos de referência (landmarks) que ajudem a definir relações de distância durante os processamentos subseqüentes (SANOCKI, 2003). Isto poderia aumentar a velocidade no processamento da informação espacial e contribuir à adequada navegação pelos ambientes.

\subsection{O espaço visual}

No campo da percepção espacial, a representação interna do ambiente construída a partir da percepção da configuração física e a informação cognitiva têm sido denominada de "espaço visual" (visual space) ou "espaço visualmente percebido". O conceito de 'percepto' ficaria aqui mais protegido, fazendo referência especificamente 


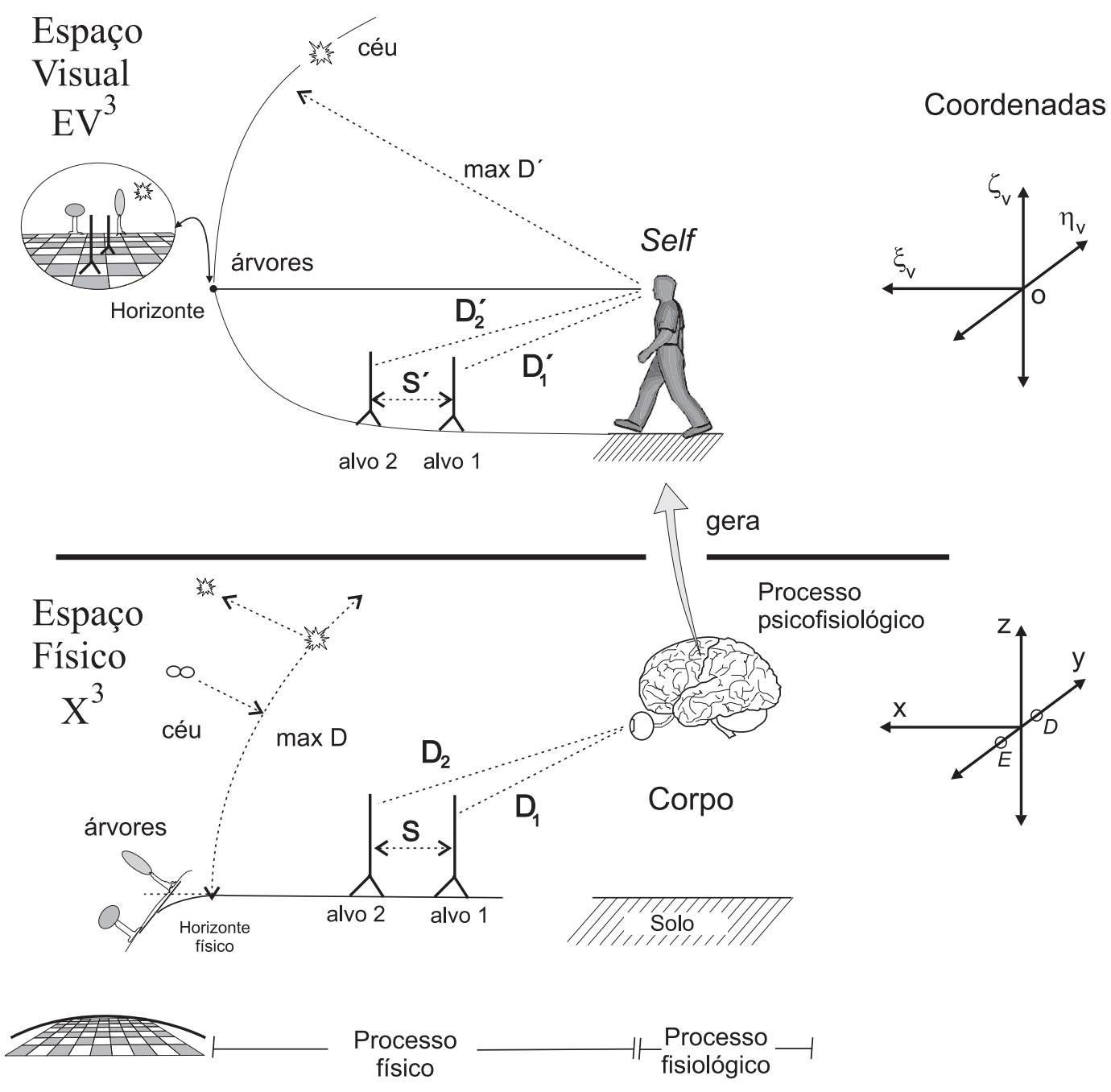

Figura 1 - Espaço Físico $\left(\mathrm{X}^{3}\right)$ e sua correspondência com o Espaço Visual $\left(\mathrm{EV}^{3}\right)$. [Modificado a partir de Indow (2004a)].

à configuração espacial visualmente percebida (HABER, 1985).

O espaço visual seria o resultado final de uma série de processos que permitiriam construir a representação que experimentamos como a configuração espacial de objetos e superfícies que existiriam independentemente de nós. Como pode ser observado na Figura 1, o primeiro processo é físico, e se refere à captação da luz emitida e refletida pelos objetos e como ela seria enfocada na retina. O segundo processo é fisiológico e vai da retina ao cérebro. Estes dois processos ocorrem no Espaço Físico (X). O terceiro processo é psicofisiológico, ocorre no cérebro, e gera o Espaço Visual (EV) como uma entidade coerente e consciente (INDOW, 2004a). Ambos espaços apresentam dimensionalidade, denotada como $\left(\mathrm{X}^{3}\right)$ e $\left(\mathrm{EV}^{3}\right)$ e indicada pelas respectivas 
coordenadas Cartesianas $(x, y, z)$ e $(\xi \mathrm{v}, \eta \mathrm{v}, \zeta \mathrm{v})$. O espaço visual estaria formado pelos perceptos dos objetos em $\mathrm{X}^{3}$, os fundos (background) e o self, que seria o percepto do corpo. Como só podemos ver algumas partes de nosso próprio corpo, o self é parcialmente visual, mas incluiria também processos proprioceptivos e vestibulares. Esta representação seria de fundamental importância, pois atua como a origem a partir da qual se estende o $\mathrm{EV}^{3}$ nas três direções.

\subsubsection{Características do espaço visual}

Indow $(1999,2004 a)$ destaca algumas características relevantes do espaço visual, as quais serão resumidas a continuação.

- Ser estável e coerente. Embora as imagens retinais estejam mudando constantemente e o campo visual seja limitado, nossa representação do mundo é ampla e estável. Isto implicaria que o espaço visual seria resultado de um processo construtivo que sumaria a informação de múltiplas visões.

- Estar hierarquicamente estruturado. Os perceptos são localizados em relação a um marco de referência. O self seria o mais importante, mas não o único, sendo ele mesmo situado a partir de outra referência externa (por exemplo, o solo).

- Ser finito. O espaço físico é infinito, contudo, no espaço visual há sempre um percepto aparecendo a uma distância finita, denotada na Figura 1 por max $D^{\prime}$. Assim, os objetos no infinito em $\mathrm{X}^{3}$ apareceriam em $\mathrm{EV}^{3}$ no horizonte à altura da linha de visão do self. Quando o horizonte é invisível no $X^{3}$, o sistema visual deriva o lugar do ponto de convergência extrapolando as linhas de fuga paralelas até o infinito (OOI; WU; HE, 2001).

- Ser dinâmico. Para poder ter uma estrutura, o espaço visual precisa que o padrão complexo de luzes proveniente dos estímulos e superfícies seja formado corretamente na retina. Por isso, se os olhos são expostos a uma iluminação homogênea de baixa intensidade se produze uma indeterminação e temos a sensação de estar rodeados por uma espécie de neblina luminosa (fenômeno conhecido como "Ganzfeld" na literatura (AVANT, 1965)). Quando as condições de iluminação e visão são suficientes, percebemos os padrões de luz como linhas, superfícies, pontos, etc., indicando que o espaço visual seria geométrico em sua natureza. 
- Na vizinhança do self, a estrutura do espaço visual seria isomórfica respeito à estrutura do espaço físico. Se afirma que nessas condições o espaço visual é verídico. Isto permitiria guiar através do $\mathrm{EV}^{3}$ o corpo no $\mathrm{X}^{3}$, possibilitando realizar ações como manipular objetos, alcançá-los, evitá-los, etc., tornando o desempenho adequado no espaço físico. Mas ao aumentar a distância, perde-se este isomorfismo, o que será considerado em detalhe no tópico seguinte.

\subsubsection{A anisotropia do $\mathrm{EV}^{3}$}

A ocorrência de distorções sistemáticas no espaço visual vem intrigando os investigadores há mais de um século. Já em 1902 Hillebrand tinha notado que os sujeitos não conseguiam emparelhar corretamente a separação horizontal de pares de objetos distantes, e que, apesar de perceber as distâncias como eqüidistantes, não avaliavam elas como linhas retas ou paralelas (HILLEBRAND, 1902). Um dos achados mais concisos da investigação em percepção de distância é que a extensão percebida entre dos pontos do $X^{3}$ varia muito de acordo com a posição no espaço e a orientação dos mesmos. Quando os estímulos estão orientados no plano frontal ao observador, a separação percebida $\left(\mathrm{S}^{\prime}\right)$ tende a ser maior que a distância física entre eles (S). Mas, quando orientados em profundidade, isto é, no sentido da linha de visão do observador, a distância percebida tende a ser menor que a distância física (WAGNER, 1985; HIGASHIYAMA; UEYAMA, 1988; TOYE, 1986; LOOMIS; DA SILVA; FUJITA; FUKUSIMA, 1992; NORMAN; TODD; PEROTTI; TITTLE, 1996), fenômeno que já tinha sido notado por Blumenfeld (1913) no começo do século passado.

As evidências mostram que este fenômeno perceptual é um dos mais robusto e intrigantes no campo da percepção, onde também é conhecido como "anisotropia" do espaço visual. Este termo parece ser emprestado das ciências exatas, onde é utilizado em contraposição a 'isotropia', que indicaria a particularidade de um material de ser fisicamente homogêneo, apresentando as mesmas propriedades independentemente da direção considerada.

Desta maneira, a anisotropia do $\mathrm{EV}^{3}$ indicaria que as dimensões percebidas variariam de magnitude em função da direção ou orientação da distância indicada em $\mathrm{X}^{3}$. 


\subsubsection{A geometria do espaco visual}

Muitas pesquisas têm sido feitas tentando determinar quais e o quanto são preservadas as propriedades do $\mathrm{X}^{3}$ quando mapeado em $\mathrm{EV}^{3}$, procurando especificar também a geometría ou modelo matemático que melhor descreve esta transformação. Esta não é uma tarefa fácil, pois aparentemente determinadas propriedades são satisfeitas numa geometria mas não em outras. Portanto, os modelos apresentados são estáticos e não dinâmicos.

Os achados de Blumenfeld (1913) questionaram a suposição de que o espaço visualmente percebido estava baseado numa geometria Euclidiana, axiomática que tinha sido considerada durante vários séculos como a única alternativa razoável para descrever as relações espaciais tridimensionais. Mas desde a publicação em 1913, o problema não foi considerado matematicamente por varias décadas, até que Luneburg (1947), um físico conhecido pelos seus aportes no campo da óptica e o eletromagnetismo, apresentara uma elaborada teoria baseada na percepção binocular do espaço físico. As duas hipóteses básicas deste autor foram: a) que o espaço visual podia ser representado por uma métrica Riemanniana, e $b$ ) que apresentava uma curvatura Gaussiana constante.

A geometria do espaço visual atualmente continua em discussão. Desde a proposta de Luneburg em meados do século passado, muitos pressupostos foram elaborados sobre o problema em questão. Alguns autores subscreveram à proposta de Luneburg (1947) e tentaram melhorá-la (BLANK, 1953; ESCHENBURG, 1980) ou modificá-la (SCHELLING, 1956). Outros consideram que a geometria Euclidiana poderia dar conta do fenômeno de anisotropia se empregadas as transformações necessárias (HABER, 1985). Da mesma forma foram sugeridas propostas matemáticas mais complexas, por exemplo, que mesclam a geometria Euclidiana no plano frontoparalelo e a Hiperbólica no plano de profundidade (INDOW, 2004b), ou até explicações probabilísticas (YANG; PURVES, 2003). Mas também, têm autores que consideram o espaço visual como contextualmente variável e, portanto, a definição dependeria do que estiver presente nele num momento determinado (KOENDERINK et al., 2008). Outros mostram-se céticos sob a possibilidade de conseguir definir uma geometria específica para o espaço visual (GOGEL, 1965; FOLEY; RIBEIRO-FILHO; DA SILVA, 2004). Sumariando, a explanação deste tópico não teve a intenção de ser exaustivo em expor as idéias dos autores considerados, senão a de apresentar alguns exemplos que permitiriam entender a magnitude do problema. 


\subsection{Interagindo com o espaço visual}

Reconhecida a relevância do estudo do espaço visual para a compreensão do desempenho espacial humano e as dificuldades impostas para a sua caracterização, um outro problema significativo seria: como medir as distâncias percebidas?. Isto se deve ao fato de que as distâncias percebidas compartilham a característica de construto do espaço visual, e, como todo construto psicológico, este remete a variáveis internas que só podem ser acessadas através do comportamento. No contexto da percepção espacial, qualquer medida comportamental é considerada como um indicador (PHILBECK, 1997). Contudo, este indicadores podem ser influenciados por outras variáveis (condições visuais, instruções, as tarefas, os métodos psicofísicos empregados, intervalo de distâncias, idade dos observadores, etc. (AZNAR-CASANOVA; DA SILVA; RIBEIRO-FILHO; SANTILLÁN, 2009)) no momento da medição e, portanto, podem conduzir a valores diferentes da distância percebida. Posto isto, dado à relevância destas variáveis que interferem na métrica do espaço visual, alguns aspectos relevantes serão expostos na seqüência.

\subsubsection{As distâncias percibidas}

Uma suposição fundamental, na qual se baseia o conceito de espaço visual é a capacidade de poder localizar nele um ponto (percebido) específico a partir de uma referência. Quando essa referência é o próprio observador, a distância entre ambos é chamada de egocêntrica. Na Figura 1, as distâncias egocêntricas físicas estão indicadas como $D_{1}$ e $D_{2}$, enquanto que as egocêntricas percebidas como $D_{1}^{\prime}$ e $D_{2}^{\prime}$.

De modo contrário, se a referência é externa ao sujeito, então, a distância é chamada exocêntrica, em alusão ao fato de que a distância considerada é entre dos pontos alheios ao observador. A distância exocêntrica física entre os alvos está indicada na Figura 1 como $S$, e a distância exocêntrica percebida como $S^{\prime}$. Neste trabalho de investigação os termos "extensão" e "tamanho" serão empregados como equivalentes a "distância exocêntrica" já que ambos se referem à separação entre dois pontos específicos.

A terminologia direção exocêntrica refere-se à orientação de um objeto no espaço, portanto, estes termos serão considerados sinónimos. 


\subsubsection{Os indicios}

Algumas pesquisas têm provado que a acurácia nos julgamentos de tamanho e distância dependem das condições de iluminação e da disponibilidade de indícios visuais (KÜNNAPAS, 1968; CUTTING; VISHTON, 1995; CUTTING, 1997).

Há inúmeros indícios disponíveis para o sistema perceptual humano, os quais podem fornecer informação de distância relativa, (exocêntrica), ou distância absoluta (egocêntrica), informando sobre as relações entre os diferentes objetos no mundo e entre eles e o observador. No caso da visão, a informação contida na imagem e nas relações espaciais dos elementos das cenas que são projetadas na retina, fornece indícios conhecidos como pictóricos. Dentro destes incluem-se a oclusão, a altura no campo visual, o gradiente de textura, a perspectiva linear, o tamanho relativo, a perspectiva aérea, o tamanho familiar e o sombreamento.

A distância egocêntrica percebida tende a variar com os indícios oculomotores, que são a convergência, a acomodação, a vergência, e o paralaxe de movimento.

Por um outro lado, a distância exocêntrica percebida se encontra vinculada a indícios como o movimento de paralaxe relativo, o tamanho relativo e a disparidade binocular.

É a partir destes indícios e suas inter-relações que o sistema visual constrói marcos de referência para determinar as características do espaço. Marcos estes cuja referência principal é o próprio corpo (self) do observador são considerados egocêntricos, enquanto que àqueles onde as referências principais são externas ao observador são considerados exocêntricos (MATSUSHIMA; RIBEIRO-FILHO, 2003).

Cutting e Vishton (1995) dividem $X^{3}$ em três zonas: espaço peripessoal ou manipulatôrio (dentro do alcance dos braços, $D<2 \mathrm{~m})$, espaço de ação $(2<D \leq 30 \mathrm{~m})$ e o espaço em perspectiva ou vista espaço $(D>30 \mathrm{~m})$. A eficiência dos diferentes indícios varia dentro de cada um destes espaços, produzindo diferenças na distância $D^{\prime}$ desde o self até o percepto em $\mathrm{EV}^{3}$. Por exemplo, indícios egocêntricos como a convergência seriam efetivos somente no espaço peripessoal. A disparidade binocular e a perspectiva de movimento seriam efetivas na zona seguinte, o espaço de ação. Em grandes distâncias, ou seja no 'vista espaço', só a oclusão, o tamanho relativo, o tamanho familiar, a perspectiva aérea e o gradiente de textura afetariam $D^{\prime}$. É importante notar que esta classificação de Cutting e Vishton (1995) está baseada na mudança na correspondência entre $\mathrm{X}^{3}$ e $E V^{3}$, mas não intervêm na estrutura interna do $\mathrm{EV}^{3}$, pois 
não percebemos nenhuma descontinuidade no espaço visual quando algum destes indícios é modificado (INDOW, 1999).

\subsubsection{Os ambientes}

A estrutura do espaço visual depende do ambiente no qual ele é mensurado, pois o contexto é normalmente usado como marco externo de referência (SCHOUMANS; KAPPERS; KOENDERINK, 2002). A precisão da distância percebida parece depender das propriedades do entorno imediato (LAPPIN; SHELTON; RIESER, 2006), uma vez que investigações psicofísicas indicam que o ambiente no qual os julgamentos de distância são realizados afeta, de alguma maneira, o valor médio dos parâmetros da função de correlação no modelado dos dados. Trabalhos como os de Teghtsoonian e Teghtsoonian (1969) mostraram que em ambientes interiores, a distância julgada é uma função acelerada da distância física. Pesquisas em ambientes exteriores em condições naturalísticas, como às de Da Silva (1985), evidenciam que o espaço visual torna-se mais comprimido conforme aumenta a distância de observação, sendo a distância julgada uma função desacelerada da distância física.

No estudo da percepção visual do espaço, assim como da distância, há duas vertentes históricas abordando a diferença de ambientes: no laboratório (em condições artificiais), e no exterior (sob condições naturais). Nestes últimos anos, com o avanço da tecnologia, os "ambientes sintéticos" produzidos mediante sistemas de realidade virtual tem se tornado mais uma alternativa no desenho de experimentos.

Os trabalhos no laboratório caracterizam-se pelo uso de condições com indícios visuais reduzidos e estímulos simplificados ou empobrecidos (GOGEL, 1990; AZNARCASANOVA et al., 2008).

Em condições naturais o ambiente pode ser enfocado como sendo de dois tipos: a percepção do mundo real e em situações naturalísticas.

Nas pesquisas onde o mundo real é o contexto, toma-se o ambiente natural de maneira direta, o que significa que as estimativas ou julgamentos são realizados em cenas de nossa vida diária, tais como ruas, prédios, áreas esportivas, paisagens urbanas ou rurais, etc. e onde objetos de grande tamanho e grandes distâncias podem estar presentes (BIEDERMAN, 1972; PEELEN; FEI-FEI; KASTNER, 2009). Por outro ângulo, as investigações realizadas em ambientes naturalísticos são caracterizadas pela construção de cenas que apresentam configurações de estímulos especificamente dese- 
nhadas, tais como as encontradas em laboratórios, mas realizadas em locais que se aproximem a uma cena natural, plena de múltiplos indícios (DA SILVA, 1985; PREDEBON, 1990; LOOMIS; DA SILVA; FUJITA; FUKUSIMA, 1992; FUKUSIMA; LOOMIS; DA SILVA, 1997; KELLY; BEALL; LOOMIS, 2002; NORMAN; CRABTREE; CLAYTON; NORMAN, 2005). Haber (1985) foi um dois primeiros pesquisadores a utilizar este tipo de metodologia, onde os estímulos foram distribuídos sobre a superfície de um terreno de maneira intencional seguindo uma certa geometria, e denominou-a de "configuração espacial de estímulos".

\subsubsection{Acerca das tarefas}

Loomis, Da Silva, Fujita e Fukusima (1992) distinguem entre dos tipos de ações nos experimentos de percepção visual. As ações guiadas visualmente, nas quais uma vez iniciada a ação a mesma é concluída sem ajuda da visão, e as ações dirigidas visualmente, onde todo o percurso da ação é realizado baixo o feedback da informação visual.

Usando estes tipos de ações, diferentes procedimentos têm sido desenvolvidos para a avaliação da distância percebida. O julgamento verbal e a estimação de magnitude são dois dos métodos tradicionais empregados no campo aberto (uma comparação de alguns destes estudos pode ser encontrada em Loomis e Philbeck (2008)). Os dados obtidos por estes métodos, geralmente, são bem ajustados por funções lineares com 0 na origem, mas a inclinação da reta normalmente fica num valor aproximado a 0.80. Estes métodos 'explícitos' tem sido questionados pela possível introdução de fatores tais como: o conhecimento ou crenças do observador (GOGEL, 1974). Uma alternativa para sanar esta questão tem sido os chamados métodos 'implícitos' ou 'indiretos', os quais fazem uso de um outro tipo de julgamentos que podem ser menos sensíveis à intrusão de fatores cognitivos (GOGEL; NEWTON, 1976). Nestes métodos a indicação de distância é implícita e envolve uma ação como, por exemplo, caminhar em direção a um objeto ou atirar um alvo à distância de um objeto, a qual indicaria indiretamente a distância que o observador acredita estar percebendo (DA SILVA; AZNAR-CASANOVA; RIBEIRO-FILHO; SANTILLÁN, 2006).

Uma outra possibilidade de medir a distância percebida mediante um método indirecto seria o julgamento de colinearidade, o qual estaria baseado na percepção da direção exocêntrica. Este tipo de julgamento é especialmente relevante nos procedimentos médicos auxiliados por imagens, tais como a inserção de sondas ou agulhas guiados 
por ultrasonografia. Nesse sentido Wu, Klatzky, Shelton e Stetten (2005) mostram uma metodologia psicofísica baseado na triangulação por apontamento (triangulationby-pointing) para medir a distância percebida a um ponto específico, visível só usando o sensor ultra-sônico, e comparam os resultados obtidos com visão monocular e binocular. Na condição monocular, seus dados mostram que se produz uma atenuação da informação de profundidade cuja conseqüência seria uma compressão sistemática na percepção da distância sagital, aparecendo uma tendência do observador a compensar dita falta de informação aumentando o movimento da sonda. Os autores consideram estes resultados similares aos obtidos em experimentos em maior escala usando ambientes ricos e pobres em indícios, tais como o estudo de Philbeck (1997). No tópico considerado na Seção 4, serão apresentadas em detalhe as características das tarefas baseada no apontamento exocêntrico.

\subsection{Relevância do estudo do Espaço Visual}

A importância da investigação do espaço visualmente percebido e da percepção de distância pode ser considerada a partir de suas implicações cognitivas (cognição espacial), psicobiológicas (os sistemas específicos no processamento da informação visual), e filosóficas (o espaço visual entendido como espaço fenomenológico).

\subsubsection{Implicações cognitivas}

Segundo Indow (2004), a assunção mais aceitada respeito do espaço visual e que estaria estruturado da mesma maneira para todos nós, e que devido a isso, temos um substrato comum em nosso comportamento e pensamento. Dito de outro modo, a forma em que criamos essa representação analógica do mundo que nos rodeia, o espaço visual, afeta e "constringe" (SHEPARD, 1994) nossa maneira de pensar. Isto ficaria evidente na dificuldade que experimentamos quando tratamos de pensar algo que não pode ser representado em $\mathrm{EV}^{3}$, ou seja, com mais de três dimensões. Este conhecimento do espaço, ou cognição espacial, embora possa limitar alguns aspectos de nosso pensamento, também nos libera do concreto, permitindo que interagirmos em ambientes que lembramos ou visualizamos, inclusive estando de olhos fechados. 


\subsubsection{Implicações psicobiológicas}

A idéia de um processamento visual composto por um sistema único há tempo não é sustentável. Além da evidência experimental irrefutável, sempre se reconheceu que existiam alguns processos visuais acontecendo subyacentes ao nível perceptivo. A divisão entre processos inferiores (como a localização) e superiores (como o reconhecimento) é uma das formas de pensar a visão como a sinergia de dois sistemas paralelos, vinculados, mas independentes.

Uma teoria proposta por Loomis, Da Silva, Fujita e Fukusima (1992) sugere que o espaço físico é mapeado em espaço visual, gerando medidas muito acuradas quando considerada a distância dos objetos até o observador, mas não das distâncias entre dois o mais objetos externos, ou seja, quando a referência é externa. Loomis e colaboradores usaram este padrão de resultados para argüirem que a percepção visual e a ação visualmente dirigida delineiam-se sobre os mesmos indícios perceptuais (DA SILVA; AZNAR-CASANOVA; RIBEIRO-FILHO; SANTILLÁN, 2006), presumindo a existência de um sistema unificado entre a percepção visual e a percepção visuo-motora.

Uma outra teoria, que inicialmente pareceria contradizer a proposição de Loomis, Da Silva, Fujita e Fukusima (1992), é a proposta por Goodale e Milner, os quais mostraram várias evidências neurológicas e comportamentais para uma separação entre as vias corticais conduzindo à percepção visual consciente, e àquelas levando à percepção para a ação visualmente dirigida (GOODALE; MILNER, 1992; MILNER; GOODALE, 1995). Segundo estes autores, a via ventral transformaria a informação visual em representações perceptuais que incorporariam as características dos objetos e suas relações espaciais. Estas representações nos permitiriam "resolver" a cena visual e pensar sobre os objetos e eventos no mundo visual. Por outro lado, a via dorsal mediaria o controle visual das ações dirigidas aos objetos no mundo. Para isso, registraria momento a momento a informação visual do objetivo, transformando-a nas coordenadas apropriadas para serem usadas pelo sistema efetor. As diferenças funcionais incluiriam um processamento diferente da informação, especialmente da visão central, que estaria amplificada na via ventral e reduzida na dorsal (MILNER; GOODALE, 2008).

Esta sugestão de separar as vias visuais e visuo-motoras implica na dissociação do espaço visual em dois. Esta separação e fortemente atacada desde na perspectiva ecologista, pois a suposição de um fluxo de processamento de informação puramente perceptual vai contra o hermético acoplamento entre percepção e ação advogado pe- 
los psicólogos ecologistas como sustenta Michaels (2000). Mas, apesar desta objeção, a maioria dos pesquisadores em percepção acha a suposição de Goodale e Milner irrepreensível. É importante notar que, embora estas duas teorias pareçam ser conflitantes, nenhuma exclui, de fato, a outra.

\subsubsection{Implicações filosóficas}

O problema da percepção, e especialmente a percepção visual, sempre ocupou um lugar preeminente na filosofia. No caso da filosofia ocidental, segundo Ferrater Mora (1994), a noção de percepção oscilou entre duas vertentes: como "percepção sensível", isto é, ligada à sensação, e a percepção como "percepção mental". Ou seja, por um lado vinculada a captar as propriedades dos objetos em $\mathrm{X}^{3} \mathrm{e}$, por outro, às representações dos mesmos (como aconteceria no $\mathrm{EV}^{3}$ ).

É desde esta perspectiva que Hatfield (2003) coloca o problema do espaço visual, a partir de considerá-lo como um espaço fenomenológico. Segundo este autor, para explicar como percebemos o espaço, deveria se proceder no sentido oposto ao utilizado tradicionalmente. Em vez de partir do objeto tridimensional no espaço físico e analisar como é representado pelo cérebro a partir da projeção bidimensional na retina (o problema direto), os estudos deveriam partir do padrão de estimulação cortical gerado pela distribuição espaço-temporal da energia eletromagnética captada pela retina e inferir (reconstruir) o que há no mundo exterior (o problema inverso). Desde esta perspectiva, perceber seria "resolver o problema inverso". Mas, como nota Epstein (1995), este não é um problema simples de resolver, principalmente devido a que toda projeção bidimensional é inerentemente ambígua. E, possivelmente, resolver o problema inverso não seria a solução definitiva. Se for assim, baixo condições de constância, o espaço visual não deveria apresentar compressão nem outras anomalias, como parecem indicar os resultados experimentais.

Pode se dizer que tanto o objeto de estudo, como os resultados das pesquisas sobre o espaço visual e a percepção de distância, transcendem os limites da psicologia da percepção, e que suas questões mais relevantes ainda continuam estimulando investigações nas mais importantes instituições de pesquisa ao redor do mundo. 


\title{
2 Modelagem da percepção de distância exocêntrica
}

\author{
"As relações espaciais não seriam \\ outra coisa que sensações particula- \\ res de linhas, ângulos, e formas de \\ transição..." (JAMES, 1950, 152)
}

De que maneira as propriedades dos objetos contidas na imagem retínica bidimensional (o "arranjo óptico", segundo Gibson (1986)) são transmitidas e convertidas numa informação espacial tridimensional estável, e como as distâncias percebidas se relacionam às distâncias físicas, são perguntas que vêm despertando o interesse dos "perceptólogos". Há muito tempo, estas indagações constituem, sem dúvida, um dos problemas mais antigos da psicologia experimental. Neste sentido, pode se dizer que os estudos abordando as diferenças entre as distâncias exocêntricas físicas e percebidas são, per se, uma área específica de pesquisa no campo da percepção visual. Como resultado destas investigações, vários modelos têm sido sugeridos com o propósito de representar matematicamente estas relações.

\subsection{A perspectiva geométrica: o ângulo visual}

Dentro da perspectiva matemática, a relação geométrica entre a extensão física, o ângulo compreendido e as distâncias dos pontos extremos até o observador permitiria, fixados dois destes valores, calcular o terceiro. Cabe ressaltar o conceito de ângulo visual (que fora definido na Seção prévia) já que relaciona as respectivas distâncias egocêntricas ao objeto, com seu tamanho no campo visual, segundo pode ser observado na Figura 2.

Considerando $S$ a distância entre os pontos $r$ e $i, D_{r}$ e $D_{i}$ suas distâncias ao ob- 


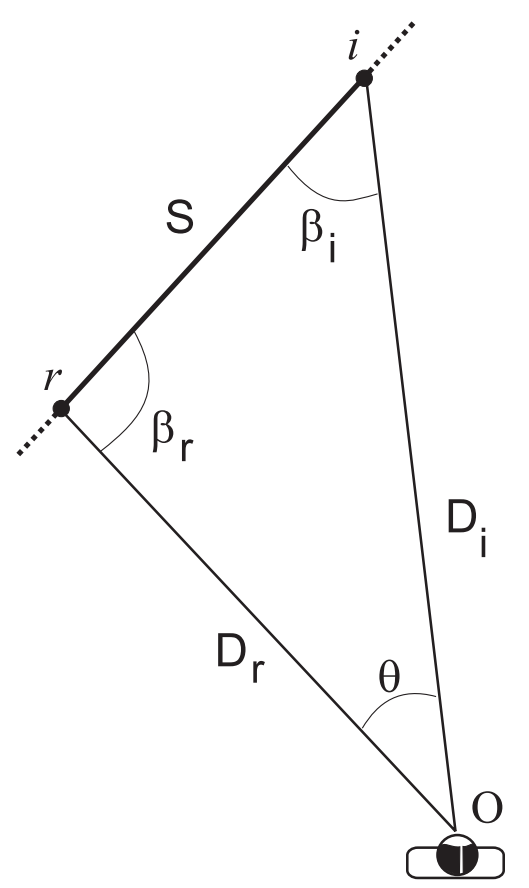

Figura 2 - Geometria do ângulo visual. A extensão $S$ subtende o ângulo visual $\theta$ quando observada do ponto $O . D_{r}$ e $D_{i}$ são as distâncias dos pontos extremos $r$ e $i$ ao origem $O ; \beta_{r}$ e $\beta_{i}$ são os respectivos ângulos compreendidos por estas distâncias à extensão $S$. 
servador $(O)$, e $\beta_{r}$ e $\beta_{i}$ os ângulos compreendidos, o ângulo $\theta$ poderia ser calculado a partir da relação dos senos,

$$
\frac{S}{\sin \theta}=\frac{D_{r}}{\sin \beta_{i}}=\frac{D_{i}}{\sin \beta_{r}}
$$

como:

$$
\theta=\arcsin \left[\left(\frac{S}{D_{r}}\right) \sin \beta_{i}\right]=\arcsin \left[\left(\frac{S}{D_{i}}\right) \sin \beta_{r}\right]
$$

ou, aplicando o teorema do coseno, como:

$$
\theta=\arccos \left(\frac{D_{r}^{2}+D_{i}^{2}-S^{2}}{2 D_{r} D_{i}}\right)
$$

Dois casos específicos são de especial interesse. O primeiro, quando o tamanho de $S$ é pequeno respeito à distância de observação, tornando as diferenças entre $D_{r}$ e $D_{i}$ e entre $\beta_{r}$ e $\beta_{i}$ insignificantes $\left(D_{r} \approx D_{i} \approx D\right.$ e $\left.\beta_{r} \approx \beta_{i} \approx \beta\right)$, fazendo com que o ângulo $\theta$ se aproxime ao valor de seu seno:

$$
\theta \approx\left(\frac{S}{D}\right) \sin \beta
$$

e, o segundo, quando mais a extensão física é perpendicular à linha de visão do observador, faria com que o ângulo $\beta$ fosse igual a $90^{\circ}$, simplificando a equação já que seu seno seria 1.

$$
\theta \approx\left(\frac{S}{D}\right) \quad \text { quando } \beta=90^{\circ}
$$

Esta equação expressaria a relação geométrica entre o tamanho e a distância egocêntrica, a qual indicaria que o ângulo visual subtendido por uma dada distância exocêntrica é diretamente proporcional a sua extensão e inversamente proporcional à distância ao olho do observador.

Mas a experiência parece indicar que o tamanho percebido dos objetos não corresponde ao seu tamanho físico, pois, os objetos parecem menores quando afastados do que quando estão mais próximos do observador.

\subsection{O ângulo visual percebido}

O ângulo visual diminui de tamanho proporcionalmente à distância do objeto, fato que já foi descrito corretamente por Kepler em 1604. Não obstante, os dados indicam que o tamanho percebido diminui muito menos do que o previsto por esta 
relação. Anos depois, em 1674, Malebranch notou que o tamanho percebido dependia da distância percebida (PASTORE, 1971), consideração que tornava importante o aspecto subjetivo assim como a influência das condições de observação. Em condições adequadas de iluminação e considerando distâncias curtas, o tamanho percebido se altera muito pouco com o aumento da distância física. Mas quando estes fatores são alterados a situação muda drasticamente.

Considerando que $S^{\prime}$ seja a distância exocêntrica percebida, $D^{\prime}$ seria a distância egocêntrica percebida escalonada segundo o ângulo subtendido $\theta$. Relação que é conhecida como a "lei da imagem retinal" (GILINSKY, 1951) e expressa como:

$$
\theta=\frac{S}{D}=\frac{S^{\prime}}{D^{\prime}}
$$

Esta equação permite derivar a relação entre o tamanho percebido e a distância:

$$
S^{\prime}=D^{\prime} \cdot \frac{S}{D}
$$

onde $S^{\prime}$ seria o tamanho percebido, $D^{\prime}$ a distância percebida, $S$ a distância física e $D$ a distância física (ver Figura 6A). Segundo esta equação, o tamanho percebido é influenciado proporcionalmente pela percepção errônea da distância, sendo a razão entre eles igual à razão entre as magnitudes físicas.

\subsection{Modelagem da percepção exocêntrica de distância}

A relação entre o tamanho ou distância exocêntrica entre dois pontos e suas respetivas distâncias egocêntricas não é simples e vem apresentando dificuldades para a correta modelagem matemática.

Uma das primeiras propostas que relacionam os indícios de distância egocêntrica com os de distância exocêntrica foi a de Brunswik (1929), quem no começo do século passado criou um índice para medir como a distância percebida diferia da respectiva distância física, empregando como parâmetro o tamanho da imagem retinal. A fórmula proposta por Brunswik seria:

$$
B_{\text {ratio }}=\frac{S^{\prime}-R}{S-R}
$$

onde $S^{\prime}$ é o tamanho percebido, $S$ o tamanho físico, e $R$ o tamanho da imagem retinal ou valor de comparação. A proporção varia de 1 (quando R coincide com S), até zero 
(quando R iguala o valor de $S^{\prime}$ ).

Em 1931, Thouless (1931) apresentou uma alternativa baseada numa transformação logarítmica da proporção de Brunswik, chamada por ele "índice de regressão fenoménica" e cuja expressão é:

$$
T_{\text {ratio }}=\frac{\log S^{\prime}-\log R}{\log S-\log R}
$$

Não obstante a forma seja similar, o logaritmo é aplicado antes de calcular a proporção. A vantagem desta fórmula seria que o resultado não depende do valor fixado como referência, o que afetaria dramaticamente o cálculo usando a proporção de Brunswick na comparação de distâncias exocêntricas percebidas.

O interessante da proposta de Thouless é que sua equação pode ser escrita de uma forma que a relaciona com a função potência de Stevens (1975), a qual tem grande valor na psicofísica experimental, sendo aplicada com sucesso na modelagem dos dados de percepção de distância (ver Da Silva (1985) para uma comparação). Assim, segundo Myers (1980), a proporção de Thouless pode ser re-escrita da seguinte maneira:

$$
\frac{S^{\prime}}{R}=\left(\frac{S}{R}\right)^{n}
$$

Sedgwick (1986) aponta que tanto a proporção de Brunswik como a de Thouless foram criticadas por não fornecer uma base tão uniforme para as comparações como aparentavam. O problema é que assumem que o valor de comparação estaria sempre entre os limites do valor tamanho físico e o percebido, quando não é incomum que nos experimentos dito valor seja ajustado substancialmente fora desse intervalo. Sem embargo, apesar das críticas, ambos índices, e sobretudo o de Brusnwik, continuam sendo muito empregados.

Gilinsky (1951) num trabalho muito interessante, tentou derivar, desde diferentes perspectivas, uma função relacionando a percepção de tamanho e de distância. Partindo da equação 2.4 e da "constância de tamanho", que determinaria $S^{\prime} / S=A / A$ (e faria $S^{\prime}=S$ independente da distância), compõe a equação:

$$
\frac{S^{\prime}}{S}=\frac{A+\delta}{A+D}
$$

onde $S^{\prime}$ e o tamanho percebido, $S$ o tamanho físico, $D$ a distância física, e $\delta$ a distância normal de observação. A autora simplifica as fórmulas, reduzindo todas as variáveis 
vinculadas ao observador e ao experimento a um só parâmetro $A$. Este parâmetro indicaria o valor assintótico da distância percebida. Quando $A=0$, a equação 2.9 seria equivalente à equação 2.4 , entanto que quando $A=\infty$ se transformaria na equação da constância de tamanho. A magnitude de $A$ seria entonces, segundo Gilinsky e usando a terminologia de Thouless, uma medida da "regressão ao tamanho real" . No caso que o valor de $D$ seja muito menor que o de $A$, o tamanho percebido estaria perto da constância, com diferenças pequenas ao ponto de resultar não significativas. Com valores de $D$ muito maiores que os de $A$ a equação indica que o tamanho percebido se aproxima à lei do tamanho retinal (Equação 2.4). Testando a fórmula com medidas experimentais, mostra que os observadores julgam, em forma independente e com acurácia, os tamanhos físicos e retinais quando avaliados em condições plenas de indícios.

Stevens (1975) demonstrou que julgamentos de estímulos unidimensionais podem ser ajustados, quase universalmente, por uma função de potência. É por isso que esta relação é também conhecida como "Lei de Stevens", sendo expressada da seguinte forma:

$$
R=k \cdot E^{n}
$$

onde $R$ seria a magnitude da sensação ou resposta, $E$ a intensidade do estímulo, $n$ o expoente da função de potência, e $k$ o módulo. O expoente refletiria a sensibilidade perceptiva do sujeito ao contínuo sensorial, sendo a constância perceptiva (ou relação lineal) indicada pelo valor 1 . Valores menores expressariam uma subconstância (que a sensibilidade do observador seria menor à dimensão sensorial do estímulo), entanto que valores maiores expressariam uma superconstância (ou hipersensibilidade à dimensão sensorial em relação à amplitude de respostas). O módulo ${ }^{1}$, embora fora considerado por Stevens como menos relevante que o expoente (STEVENS, 1975), apresenta um caráter multiplicativo, pelo que deve ser igual à unidade para obter um ajuste perfeito, já que valores diferentes indicariam a compressão ou expansão das respostas por um fator constante. Mediante medições psicofísicas Stevens demonstrou a validade desta função em diversos contínuos sensoriais. No caso da percepção de distâncias, a Lei de Stevens conseguiu descrever adequadamente estimativas de estímulos posicionados tanto no plano frontal como em profundidade e numa vasta ordem de magnitudes (ver Da Silva (1985) para uma comparação).

\footnotetext{
${ }^{1} \mathrm{O}$ termo 'módulo' é preferido para descrever $k$ frente a outros termos como 'fator escalar', 'constante escalar', 'constante da medida', que são claramente inapropriados para descrever um parâmetro que varia em função das condições de observação (Wagner, 1985).
} 
Embora Stevens argumentava que as estimativas eram bem ajustadas indiferentemente do método empregado, investigações posteriores demonstraram que distintos valores do expoente eram obtidos quando o método variava. Assim, como estabelecera Wagner (1985), os parâmetros $k$ e $n$ não seriam, necessariamente, os mesmos para todas as posições e orientações. Este autor propôs que na estimação da distância, a posição do alvo deveria estar definida por quatro coordenadas: a distância do observador $(D)$ ao ponto mais próximo $r$, o ângulo polar que esta direção subtende com um eixo arbitrariamente definido $(\theta)$, a orientação do segmento $S$ respeito ao plano frontal do observador $(\phi)$ e a distância euclidiana entre os pontos $r$ e $i$ que definem dito segmento (ver Figura 3).

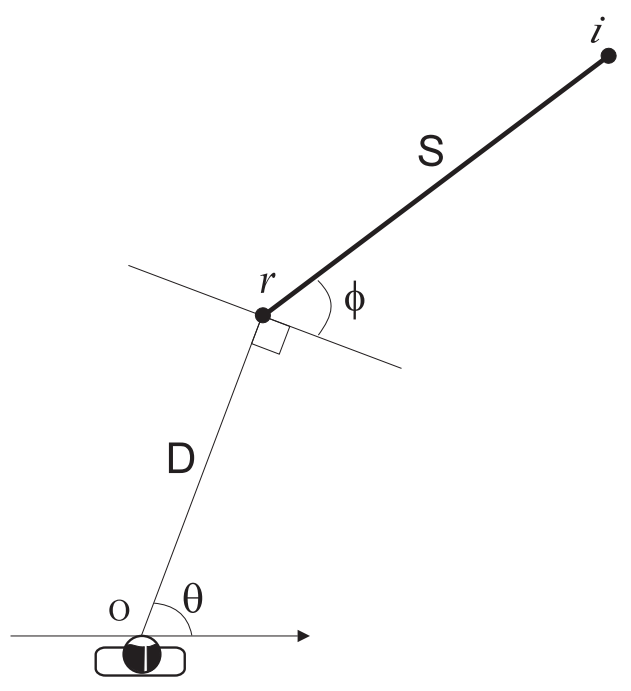

Figura 3 - Sistema de coordenadas proposto por Wagner (1985) para o cálculo de distância exocêntrica. $D$ indicaria a distância ao ponto $r$ quando observada do ponto $O ; S$ seria a distância física entre os pontos extremos $r$ e $i ; \theta$ seria o ângulo subtendido por $D$ num eixo arbitrariamente definido e $\phi$ o ângulo entre o segmento $S$ e o plano frontal do observador. [Adaptado de Wagner (1985)]

De esta maneira a Equação 2.10 ficaria especificada quando definidos os parámetros para cada caso particular:

$$
J=k(D, \theta, \phi) \cdot S^{n(D, \theta, \phi)}
$$

onde $J$ seria a distância julgada e $D, S, \theta$ e $\phi$ as coordenadas mencionadas acima.

Os dados de Wagner (1985), usando uma configuração complexa de estímulos em condições plenas de indícios, mostraram que o expoente médio da função de potência 
era igual à unidade com o módulo variando sistematicamente com a orientação da distância exocêntrica. Os valores alcançavam os valores máximos para orientações alinhadas aos planos frontais, enquanto que os valores mínimos eram encontrados nas orientações em profundidade. Assim, a proposta de Wagner (1985) é de que esta relação poderia ser modelada como uma 'projeção $a$ fim' $^{\prime}$, onde distâncias e ângulos do plano seriam sistematicamente distorcidos numa direção específica, que, segundo os dados experimentais, seria a dimensão de profundidade. Esta contração poderia ser expressada como:

$$
y^{\prime}=c \cdot y
$$

onde $y$ seria a 'coordenada física $y^{\prime}, y^{\prime}$ a coordenada ' $y$ 'percebida, e $c$ a constante de contração. Pode ser notado que esta equação seria igual à Equação 2.10 com o expoente igual à unidade. Mas, segundo o autor, se bem que o "Modelo de Contração Afim" (Affine Contraction Model) ajusta adequadamente os dados, apresenta o problema de estar definido em termos de um sistema Cartesiano, quando dificilmente percebamos o mundo baseando-nos nesse tipo de coordenadas. A solução foi dividir o vetor $\vec{S}$ (definido pelos dois pontos $r$ e $i$ ) em duas componentes: uma orientada frontalmente $\left(\vec{V}_{1}\right)$ e outra orientada em profundidade $\left(\vec{V}_{2}\right)$, estando suas orientações relacionados pelo ângulo $\phi$ subtendido pelas posições de $r$ e $i$ respeito do observador. Então, $\vec{V}_{1}=S \cos \phi$ e $\vec{V}_{2}=S \sin \phi$. A componente em profundidade $\vec{V}_{2}$ é contraída numa quantidade constante para obter a componente percebida $\vec{V}_{2}^{\prime}$, todavia a componente visual $\vec{V}_{1}^{\prime}$ não é alterada. O "Modelo de Contração Vetorial" (Vector Contraction Model) de Wagner poderia ser escrito como:

$$
J=\sqrt{\left(\vec{V}_{1}^{\prime}\right)^{2}+\left(\vec{V}_{2}^{\prime}\right)^{2}}
$$

ou, a partir da distância inter-estímulos e o ângulo subtendido:

$$
J=S \cdot \sqrt{(\cos \phi)^{2}+(c \sin \phi)^{2}}
$$

equação que pode ser generalizada à forma da função de potência:

$$
J=k\left[S \cdot \sqrt{(\cos \phi)^{2}+(c \sin \phi)^{2}}\right]^{n}
$$

Alguns anos depois, Baird e Wagner (1991) propuseram a "Teoria da Transformação" (Transformation Theory) para o processamento da percepção de tamanho. Estes autores assumem que o cérebro realiza um processo de transformação inversa da imagem retinal para recuperar, a partir dos ângulos entre os pontos específicos, os tama- 
nhos originais dos objetos. Estes autores consideram que para lograr este propósito a informação do ângulo visual, a distância egocêntrica e a orientação são os parâmetros relevantes, segundo pode ser observado no seu modelo (ver Figura 4):

$$
S^{\prime}=\frac{\sin (\theta) \sqrt{h^{2}+d^{* 2}}}{\sin \left(\phi^{*}-\theta+\delta\right)}
$$

onde $S^{\prime}$ é o tamanho percebido, $\delta=\tan ^{-1}\left(h / d^{*}\right)$, entanto $\phi^{*}$ e $d^{*}$ são as orientação e distâncias 'efetivas' aplicadas na transformação para recuperar a distância física original. Dois aspectos devem ser notados nesta proposta. O primeiro, que uma transformação única não pode ser aplicada a todas as partes do objeto, senão que o sistema perceptual precisaria aplicar uma transformação particular a cada uma das partes. Como o número de transformações necessárias para conseguir uma percepção acurada de todas as partes da imagem poderia ser infinito, o sistema escolheria transformações apropriadas para algumas extensões e orientações, mas que não se mostrariam adequadas quando aplicadas extensivamente a outras. As diferenças entre as distâncias e orientações aplicadas (efetivas) e os valores corretos seriam responsáveis das distorções sistemáticas no tamanho percebido. Valores efetivos (aqueles aplicados na transformação inversa) muito pequenos $\left(d^{*}<d\right)$ levariam à subestimação do tamanho percebido e valores grandes $\left(d^{*}>d\right)$ à superestimação. O segundo aspecto é que a orientação e tamanhos usados na transformação inversa são chamados de 'efetivos' ou 'aplicados' em contraposição a 'percebido' ou 'julgados', pois não é possível assumir que as orientações ou distâncias são errôneas quando os julgamentos de tamanho estão errados. De fato, os valores efetivos refletiriam as caraterísticas do contexto experimental onde as distâncias foram estimadas.

A perspectiva clássica implicava que para perceber a distância de um objeto era suficiente fixar a vista nele com ambos olhos. Assim, objetos que requeiram diferentes graus de vergência para serem enfocados estão situados a diferentes distâncias. Sem embargo os fatos mostram que esta informação não produz uma percepção acurada de distância, sendo também preciso a disparidade binocular, isto é a diferença entre as imagens retinais de ambos olhos. Segundo Foley (1980), a distância exocêntrica percebida dependeria dos paralaxes binoculares aos alvos, sendo, portanto, uma função da distância egocêntrica percebida. Assim, como mostra a Figura 5, a distância entre dois pontos $r$ e $i$ implicaria dois paralaxes $\gamma_{r}=\left(I / D_{r}\right) \cos \theta_{r}$ e $\gamma_{i}=\left(I / D_{i}\right) \cos \theta_{i}$, com os respectivos paralaxes efectivos (percebidos) $\gamma_{r}^{\prime}=\left(I / D_{i}^{\prime}\right) \cos \theta_{i}$ e $\gamma_{i}^{\prime}=\left(I / D_{r}^{\prime}\right) \cos \theta_{r}$ (onde $D^{\prime}$ é a distância radial percebida), sendo a disparidade binocular efectiva de $i$ 


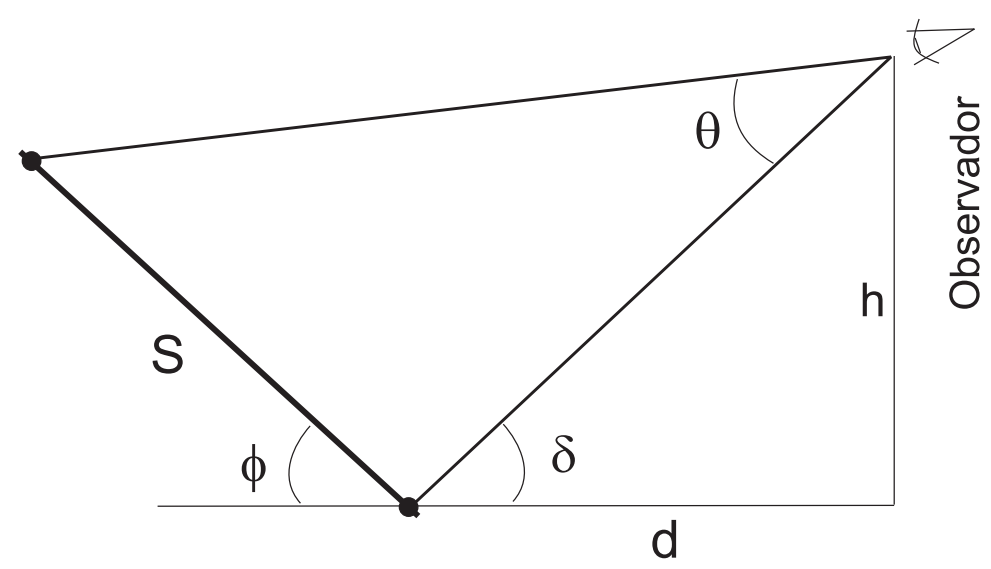

Figura 4 - Parâmetros do modelo de Transformação proposto por Baird e Wagner (1991) para o processamento da percepção da distância exocêntrica. O tamanho físico estaria indicado por $S$, sendo $h$ a altura do ponto de observação, $d$ a distância até $S$, e $\phi$ a orientação do alvo em relação ao chão. [Adaptado de Baird e Wagner (1991)]

em relação a $r$ igual a $\Gamma_{i r}^{\prime}=\gamma_{i}^{\prime}-\gamma_{r}^{\prime}$. Para dados no plano frontoparalelo, a relação entre $\gamma_{r}^{\prime}$ e $\gamma_{r}$ seria aproximadamente linear.

Assim, a distância ao ponto de referência $r$ é determinada por um sinal egocêntrica de distância. Mas as distâncias egocêntricas percebidas geralmente são diferentes das respectivas distâncias físicas, com os objetos próximos aparecendo mais distantes e os objetos distantes aparecendo como mais próximos do que eles realmente estão. Se o ponto $r$ na Figura 5 é percebido como mais distante, quaisquer que seja o paralaxe efectivo $\gamma_{r}^{\prime}$ dessa posição, o paralaxe efectivo do outro ponto $\gamma_{i}^{\prime}$ diferira de $\gamma_{r}^{\prime}$ pelo mesma quantidade que ambos paralaxes binoculares diferem. Isto implicaria que o paralaxe binocular do ponto de referência e de todas as disparidades com respeito a esse ponto sofrem uma transformação linear que produz o paralaxe binocular efectivo e a disparidade binocular efectiva, magnitudes que são combinadas aditivamente para obter a distância exocêntrica percebida.

A teoria de Foley implicaria que, para processar adequadamente a distância exocêntrica, primeiro se deve extrair a informação de distância egocêntrica de cada ponto, para logo converter as disparidades binoculares e as paralaxes binoculares em suas magnitudes efetivas. Dessa maneira as distâncias exocêntricas seriam processadas como uma função das distâncias egocêntricas percebidas. Esta idéia deu origem ao modelo de percepção de tamanho (FOLEY; RIBEIRO-FILHO; DA SILVA, 2004), o qual cal- 


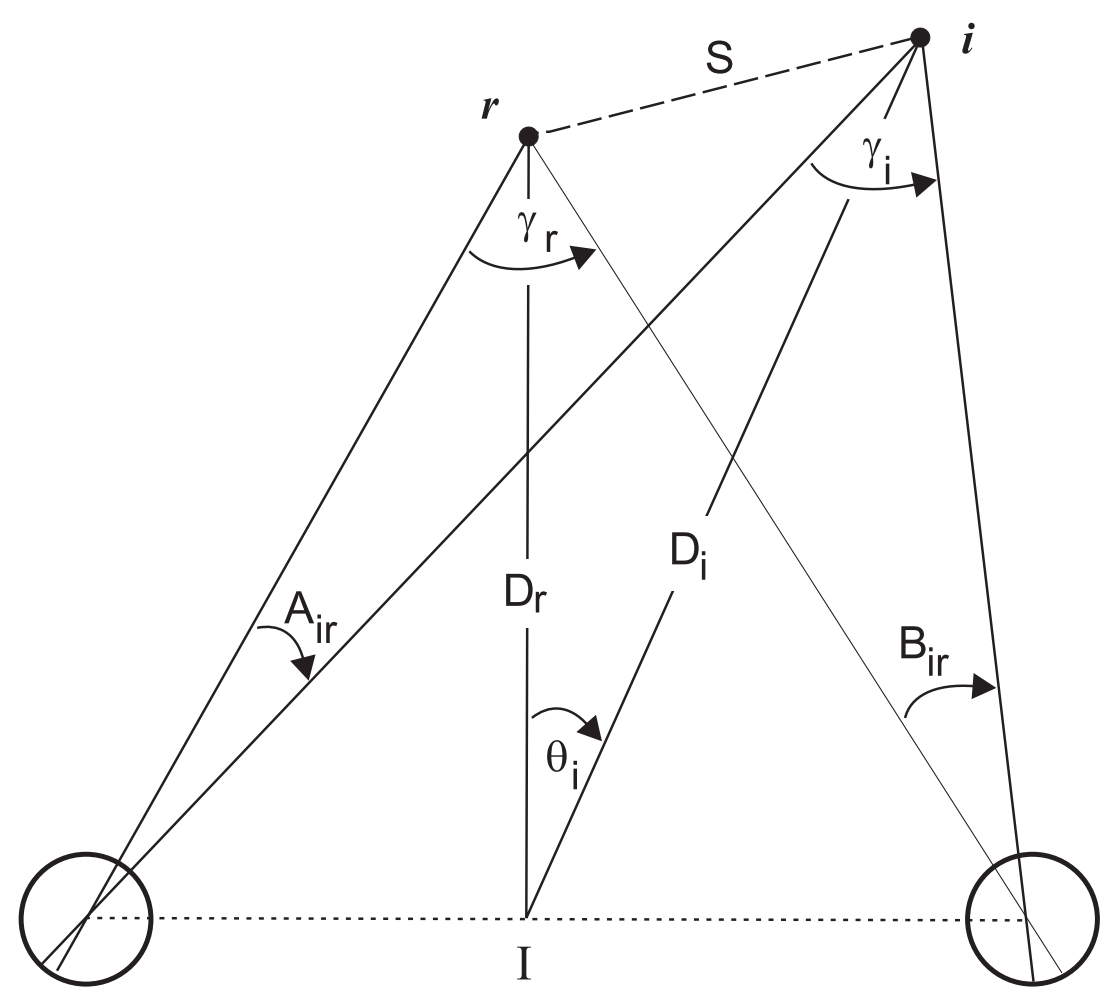

Figura 5 - Diagrama ilustrando a proposta de Foley (1980). I é a distância entre os centros de rotação dos olhos; $D_{i}$ a distância radial; $A_{i r}$ e $B_{i r}$ são os ângulos subtendidos pelos pontos $r$ e $i$ da distância física $S ; \theta_{i}$ é a direção horizontal; $\gamma_{i}$ e $\gamma_{r}$ são os paralaxes binoculares dos pontos $i$ e $r$, respectivamente. A disparidade binocular geométrica de $i$ com respeito a $r$ é: $\Gamma_{i r}=\gamma_{i}-\gamma_{r}=$ $A_{i r}-B_{i r}$. [Adaptado de Foley (1980)] 
cula a distância Euclidiana entre dois pontos num plano expressadas em coordenadas polares, assumindo que o ângulo visual efetivo sofre uma transformação que o aumenta.

\subsection{O modelo de Foley, Ribeiro-Filho e Da Silva (2004)}

Em 2004, Foley, Ribeiro-Filho e Da Silva apresentaram um modelo alternativo, o qual poderia descreve melhor os resultados de vários dos estudos envolvendo julgamentos de distância e tamanho, tendo eles sido realizados em diversas condições experimentais de observação. Devido às características intrínsecas do mesmo o nomearam de "Tangle', que seria uma redução de "ângulo transformado" ou transformed angle em inglês. Basicamente, este modelo deveria satisfazer dois achados experimentais: o primeiro, que a relação entre o tamanho -ou extensão percebida- e a distância percebida é invariante para um tamanho angular $\theta$ constante; e segundo, que o tamanho deveria variar com a orientação e o ângulo visual. Este modelo envolveria as seguintes equações:

$$
\left\{\begin{array}{l}
\theta_{i j}^{\prime \prime}=\theta_{i j}+Q \theta_{i j}^{p} \\
S_{i j}^{\prime}=\left(\left(R_{i}^{\prime}\right)^{2}+\left(R_{j}^{\prime}\right)^{2}-2 R_{i}^{\prime} R_{j}^{\prime} \cos \theta_{i j}^{\prime \prime}\right)^{0.5} \\
R_{i}^{\prime}=R_{i} /\left(F+G R_{i}\right)
\end{array}\right.
$$

e cuja dedução faremos referência na continuação.

Segundo pode ser observado na Figura 6A, um objeto localizado na frente de um observador compreende um tamanho angular $\theta$, pelo que então temos:

$$
\frac{S}{D}=2 \tan \left(\frac{\theta}{2}\right)
$$

Se torna evidente que ângulos visuais pequenos fazem que $\frac{S}{D}$ seja igual ao próprio ângulo em radianos. Mas a equação 2.17 pode ser substituída na conhecida equação 2.5 permitindo expressar $S^{\prime}$ em função de $D^{\prime}$ e $\theta$ :

$$
S^{\prime}=D^{\prime} 2 \tan \left(\frac{\theta}{2}\right)
$$

O ângulo visual indicado por $\theta$ é proporcional ao tamanho retínico, porque ambos diminuem proporcionalmente com a variação da distância. A equação 2.18 também implica que o tamanho percebido corresponderá ao ângulo visual compreendido pelo 
A

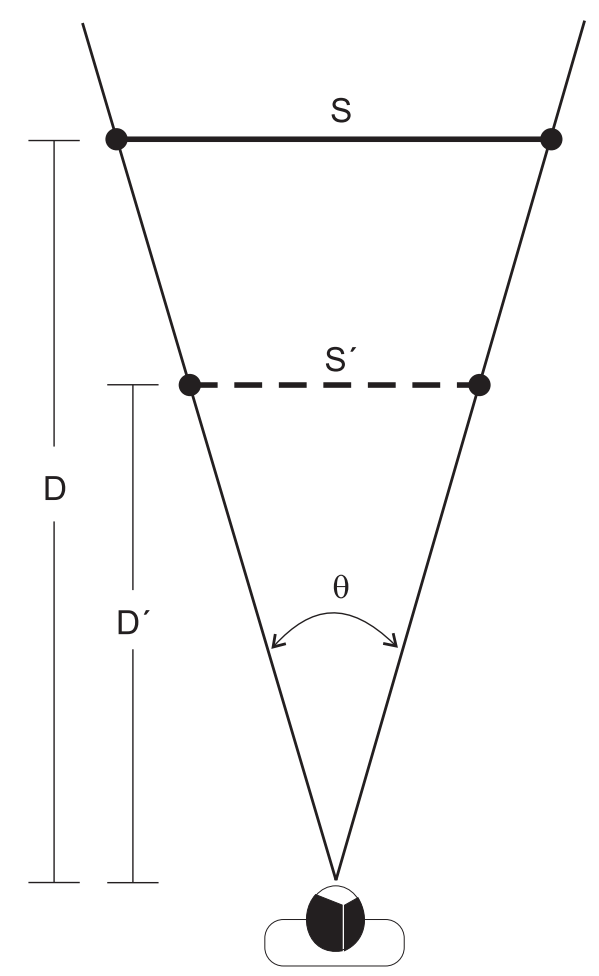

(B)

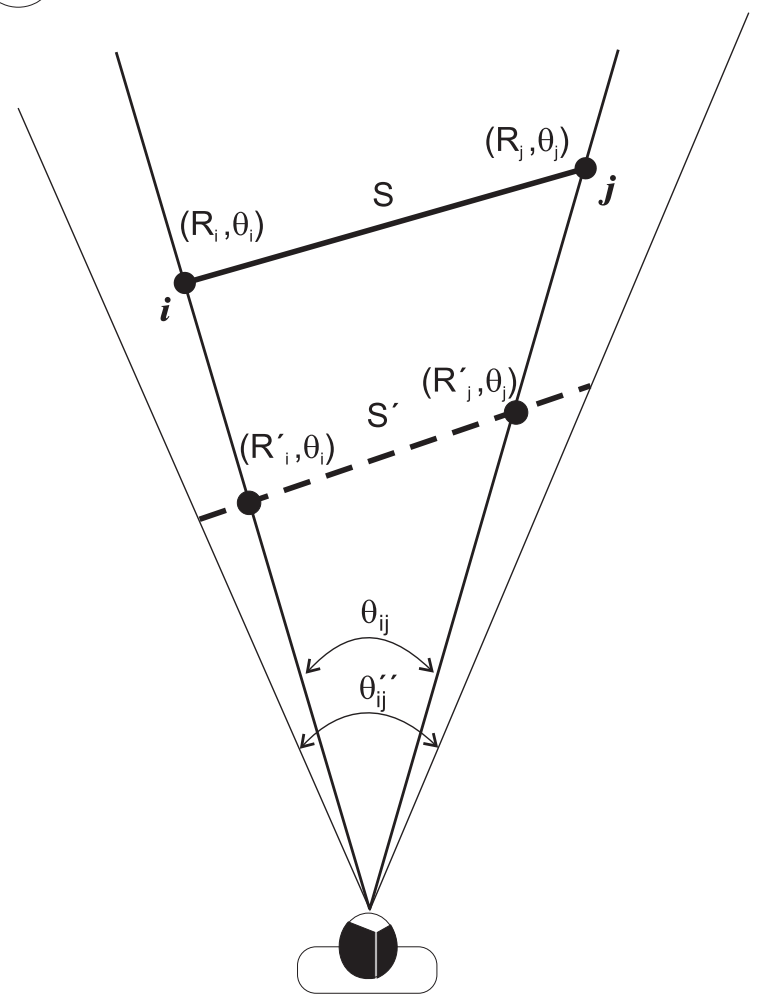

Figura 6 - (A) modelo 'generalizado' de percepção de tamanho. $\theta$ é o ângulo visual, $D$ é a distância física, $S$ é o tamanho físico, $D^{\prime}$ é a distância percebida, e $S^{\prime}$ é o tamanho percebido. Neste modelo o tamanho percebido corresponde ao ângulo visual na dada distância percebida. (B) modelo 'Tangle'. $R_{i}$ e $R_{j}$ são as distâncias egocêntricas dos pontos $i$ e $j, R_{i}^{\prime}$ e $R_{j}^{\prime}$ são as distâncias egocêntricas percebidas, $\theta_{i}$ e $\theta_{j}$ são as direções horizontais dos dois pontos, $\theta_{i j}$ é o ângulo compreendido pelos dois pontos, entanto que $\theta_{i j}^{\prime \prime}$ é o ângulo visual efetivo para o cálculo do tamanho. A linha tracejada indica a distância exocêntrica percebida. [Adaptado de Foley, Ribeiro-Filho e Da Silva (2004)] 
objeto em uma dada distância percebida. Este modelo pode ser encontrado em muitos livros de percepção, embora a maior parte dos resultados não se ajustaram a ele e nenhum desses estudos desencadenou modelos alternativos (KAUFMAN, 1974; SEDGWICK, 1986; WOODWORTH; SCHLOSBERG, 1965).

Uma situação mais realística é desenhada na Figura 6B, onde $S$ representa a extensão entre dois pontos visíveis $i$ e $j$. A simples generalização da equação 2.5 levaria à seguinte equação:

$$
S_{i j}^{\prime}=\sqrt{\left(R_{i}^{\prime}\right)^{2}+\left(R_{j}^{\prime}\right)^{2}-2 R_{i}^{\prime} R_{j}^{\prime} \cos \theta_{i j}}
$$

onde $S_{i j}^{\prime}$ representa a extensão percebida ou, o que seria o mesmo, a distância exocêntrica entre os pontos $i$ e $j$. As variáveis $R_{i}^{\prime}$ e $R_{j}^{\prime}$ são as distâncias egocêntricas percebidas dos pontos indicados, entanto que $\theta_{i j}$ o ângulo físico compreendido entre ambos pontos. Esta equação é, em essência, a expressão em coordenadas polares da distância euclidiana entre dois pontos em um plano. Como tinha sido notado anteriormente por Wagner (1985), um sistema de coordenadas polares seria mais apropriado para modelar a experiência humana. Nela as distâncias são percebidas e o ângulo visual é físico. Ao ser uma generalização da equação 2.5, também falha na descrição da distância exocêntrica, produzindo uma subestimação da extensão percebida entre os pontos, com o erro aumentando com o ângulo visual compreendido entre os pontos. Tentando solucionar este problema, Foley, Ribeiro-Filho e Da Silva (2004) propuseram uma forma diferente de transformação similar à equação 2.19, mas onde, baseados nos resultados de Foley (1991), o ângulo $\theta$ é substituido por $\theta^{\prime \prime}$ que é uma função crescente de $\theta$. Expressado matematicamente ficaria:

$$
\theta_{i j}^{\prime \prime}=\theta_{i j}+Q \theta_{i j}^{P}
$$

onde $\theta_{i j}^{\prime \prime}$ é o ângulo efetivo para computar o tamanho percebido. Isto explicaria a necessidade da primeira equação no Sistema 2.16. Note-se que o conceito de 'efetivo' é empregado aqui de maneira similar que no modelo de Baird e Wagner (1991). Assim, substituindo a equação 2.20 na 2.19 teremos que a extensão percebida é dada pela equação:

$$
S_{i j}^{\prime}=\left(\left(R_{i}^{\prime}\right)^{2}+\left(R_{j}^{\prime}\right)^{2}-2 R_{i}^{\prime} R_{j}^{\prime} \cos \theta_{i j}^{\prime \prime}\right)^{0.5}
$$

Para os autores, esta equação satisfaria as duas exigências que foram estabelecidas no começo, sendo o segundo componente do modelo (sistema 2.16, equação (b)). Então $\theta_{i j}^{\prime \prime}$ não é o ângulo visual percebido senão o ângulo determinado como função da separação dos pontos, sendo necessário, para poder calcular a extensão percebida, 
determinar as distâncias egocêntricas percebidas.

A dificuldade emergente é que a relação entre a distância egocêntrica física e a percebida é complexa e apenas parcialmente conhecida, sendo esta complexidade devida aos efeitos do contexto (PHILBECK; LOOMIS, 1997), os quais variam em função do ambiente considerado. Experimentos realizados em laboratório, em condições de indícios reduzidos, mostraram uma dependência crítica entre os estímulos, porque a adição, subtração ou modificação da posição de um deles alterava a distância egocêntrica percebida de todos os outros (FOLEY, 1980, 1985). Em condições naturais ou naturalísticas, com boa iluminação e plenas de indícios visuais, a situação é ainda mais complicada, pois aumenta a dificuldade para determinar o peso ou influência de cada um dos indícios, assim como, de suas interações (CUTTING; VISHTON, 1995; GUILLIAM, 1995). Segundo Foley (1977), na maior parte das situações a distância egocêntrica percebida pode ser descrita adequadamente por uma função com dois parâmetros:

$$
R_{i}^{\prime}=\frac{R_{i}}{F+G R_{i}}
$$

Modificações no contexto produzem alterações nos valores das constantes $F$ e $G$. Para distâncias curtas $R_{i}^{\prime}$ apresenta uma variação lineal com uma inclinação de $1 / F$ e, a medida que a distância aumenta, se torna asintótica a uma distância de $1 / G$. Esta equação completaria o modelo de distância exocêntrica percebida proposto por Foley, Ribeiro-Filho e Da Silva (2004).

\subsubsection{Testagem do modelo "Tangle"}

Foley e colaboradores (2004) asseguram que o mesmo descreve adequadamente a distância exocêntrica entre dois pontos de luz observados num quarto escuro obtendo, nesse caso, para os parâmetros os valores: $G>0, F>1, Q>0$ e $P<1$. A partir da equação 2.20, pode-se deduzir que $\theta_{i j}^{\prime \prime}>\theta_{i j}$, o que indicaria um aumento no tamanho percebido, enquanto que a equação 2.22 indicaria uma subconstância na distância egocêntrica percebida. Esta anisotropia do espaço percebido (DA SILVA, 1985; HABER, 1985; TOYE, 1986; LOOMIS; PHILBECK, 1999) ocorre também em situações iluminadas plenas de indícios visuais para as quais $F \leq 1$. Foley, Ribeiro-Filho e Da Silva (2004) testaram os modelos expostos nas Equações 2.19 e 2.21 nos resultados das estimativas de distâncias egocêntricas e exocêntricas de uma configuração de estímulos complexa empregando duas posições de observação (RIBEIRO-FILHO, 1993), a qual é desenhada na Figura 7. 


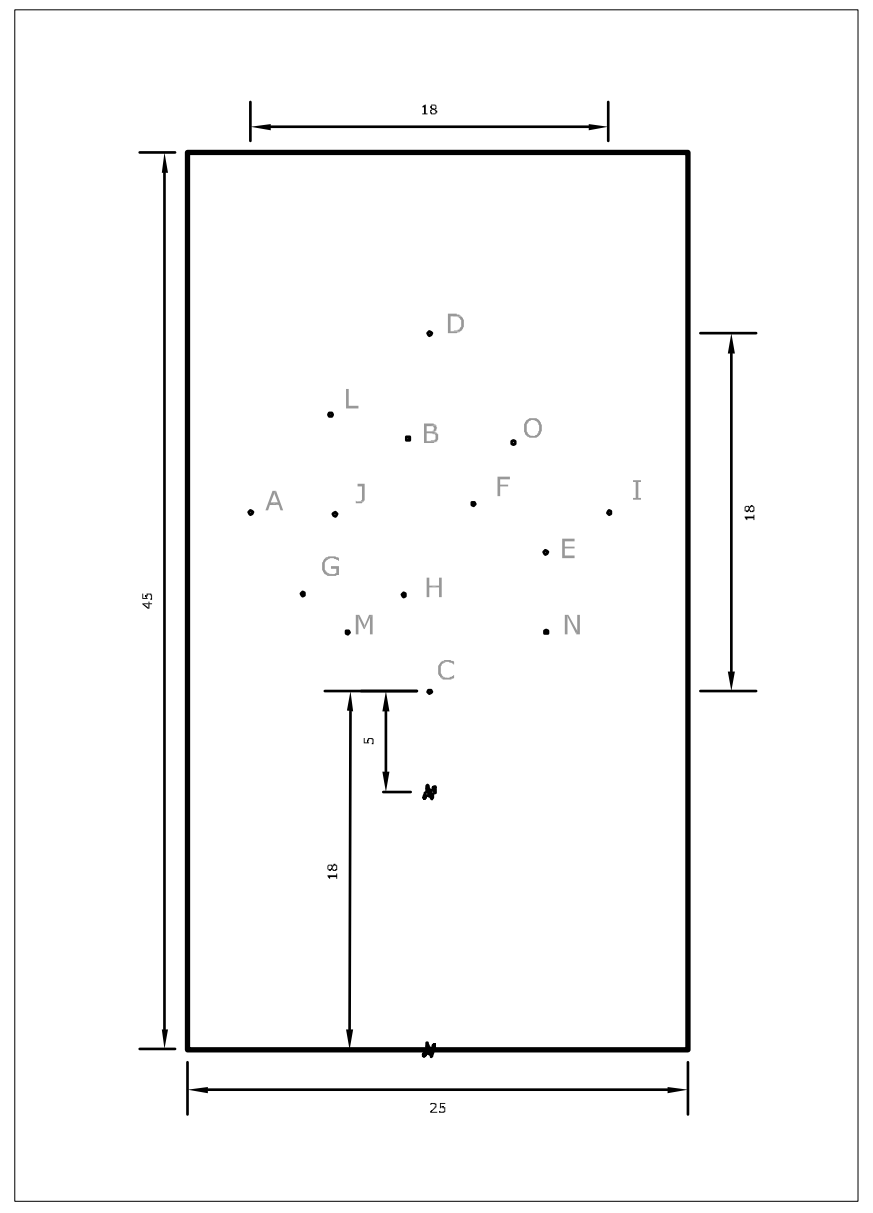

Figura 7 - Desenho na escala da configuração física empregada por Foley, RibeiroFilho e Da Silva (2004) para testar seu modelo de distância exocêntrica percebida no campo aberto. Vista superior da distribuição dos estímulos e das duas posições de observação. As distâncias estão indicadas em metros. [A partir dos dados de Foley, Ribeiro-Filho e Da Silva (2004) 
Os resultados demonstraram que a Equação 2.19 falhou em descrever os resultados, tal que a maior parte das estimativas foi maior que o predito pelo modelo (especialmente quando $\theta_{i j}>0$ ). Por outro lado, o modelo proposto na Equação 2.21 apresentou um ajuste quase perfeito $(R M S E=1,09)$, com o ângulo visual efetivo $\left(\theta_{i j}^{\prime \prime}\right)$, sendo uma função não-linear acelerada em relação ao ângulo visual físico $\left(\theta_{i j}\right)$, com parâmetros $P=0,574$ e $Q=0,314$.

O modelo foi concebido para descrever o desempenho em tarefas de igualação subjetiva (perceptual matching task), mas, segundo os dados apresentados pelos autores, consegue dar conta dos resultados obtidos mediante uma tarefa de julgamento verbal. Isto sugeriria que este tipo de tarefa estaria relacionado com a percepção da extensão.

Um dos objetivos do estudo desenvolvido nesta investigação foi analisar, à luz deste modelo, os resultados obtidos usando uma tarefa de colinearidade no campo aberto. 


\section{Objetivos a serem atingidos}

\subsection{Objetivo geral}

Investigar no campo aberto a acurácia e estabilidade dos ajustes e estimativas de distância, a partir de uma configuração espacial de estímulos colineares.

\subsection{Objetivos específicos}

O presente trabalho de tese procurou atingir os seguintes objetivos específicos:

- Avaliar o desempenho dos observadores numa original tarefa de colinearidade baseada na percepção de distância exocêntrica.

- Analisar as diferenças no desempenho quando é alterado o número de estímulos, especialmente marcando o centro da configuração espacial.

- Confrontar os resultados obtidos com o fenômeno perceptual da "anisotropia" do espaço percebido.

- Testar o modelo da percepção visual de distâncias exocêntricas proposto por Foley, Ribeiro-Filho e Da Silva (2004), comparando seus ajustes com outros modelos teórico da literatura e analisando suas implicações para a geometria do espaço visual.

- Avaliar, a partir da configuração de estímulos estudada, a suposição de Kelly, Loomis e Beall (2004) sobre a construção mental de linhas de colinearidade.

- Examinar, em condições de visão reduzida, o desempenho dos observadores na tarefa de percepção de colinearidade, considerando a hipótese da "correção cognitiva" dos ajustes. 


\section{Delineamento do Projeto}

"A habilidade do observador para perceber a distância varia com um número de circunstâncias, sendo a mais preeminente de todas o grau em que a situação experimental fornece informação de distância" (SEDGWICK, 1986, 21-8)

\subsection{Percepção de colinearidade em campo aberto}

Os estudos da percepção das propriedades geométricas do espaço e dos objetos nele posicionados mostram que, ainda em condições plenas de indícios, os observadores apresentam dificuldades para julgar adequadamente as posições dos objetos. Entanto, alguns trabalhos (GILINSKY, 1951; SEDGWICK, 1986; FUKUSIMA; LOOMIS; DA SILVA, 1997), mostram que os julgamentos de distância egocêntrica são mais acurados que as respectivas estimativas de distância exocêntrica, sugerindo uma dissociação entre os aspectos considerados ao julgar a posição, a separação e a orientação de dois objetos. Contudo, outras investigações apresentam evidência de que os indícios de base exocêntrica podem prover, de forma independente, informação mais acurada que os indícios egocêntricos (AZNAR-CASANOVA et al., 2008). Existem também posturas como as de Loomis, Philbeck e Zahorik (2002) e Foley, Ribeiro-Filho e Da Silva (2004) que tentam conciliar estes resultados.

Seguindo a perspectiva desta última linha de pesquisa, o propósito do presente estudo, disposto nesta Seção, foi investigar experimentalmente o desempenho dos observadores numa tarefa de colinearidade em campo aberto, em condições de indícios múltiplos e com ângulos visuais amplos. 


\subsubsection{Percepção de distância e orientação exocêntrica em campo aberto}

Pesquisa iniciais usando cenas naturais focaram-se em descrever a percepção de distância egocêntrica (e.g. Gilinsky (1951), Gogel (1978), Da Silva (1985)), onde o observador tinha que julgar a distância entre ele e um único alvo ou que se encontrava dentro de uma configuração. $\mathrm{O}$ interesse no estudo da percepção das distâncias interobjetais na cena e das orientações exocêntricas dos estímulos parece ter sido iniciada em meados dos anos 80 com os trabalhos de Haber (1985), Wagner (1985) e Toye (1986).

As características inovadoras do trabalho de Haber (1985) referem-se a uma investigação naturalística, empregando vários objetos (estímulos) apresentados simultaneamente e controlando as distâncias físicas entre eles. Segundo o autor, a descrição da configuração de estímulos foi observada a partir da superfície do terreno e localizadas em termos de coordenadas Euclidianas num espaço tridimensional. Por outro lado, Wagner (1985) indaga outra possibilidade empregando uma distribuição pentagonal de estímulos, onde os sujeitos efetuavam tarefas de estimação de magnitude, igualação e mapeamento. Neste caso, o objetivo foi avaliar as possíveis distorções do espaço visual. Encontrou, então, que a compressão da distância se incrementa a medida que o ângulo da distância observada passa de horizontal a radial ${ }^{1}$, com uma compressão de até 50\%. Tanto Haber como Wagner tentaram construir uma teoria sobre a forma do espaço percebido partindo da análise das relações entre as distâncias e orientações exocêntricas percebidas.

Toye (1986) realizou sua pesquisa empregando estacas distribuídas de maneira pseudo-aleatória. Seus resultados mostraram que os observadores possuem uma representação acurada da cena visual, a qual é independente do método usado nos julgamentos das distâncias, guardando as estimativas uma similaridade estatística com a cena real. Outro achado importante foi que a forma da cena visual percebida muda de acordo à posição de observação respeito à configuração, tornando relevante este parâmetro ao definir o layout experimental.

Baseados nestes trabalhos prévios, Levin e Haber (1993) investigaram a percepção de distâncias exocêntricas considerando especificamente os efeitos da aproximação e afastamento da linha de visão do observador. Mas os autores posicionaram as esta-

\footnotetext{
${ }^{1}$ Uma distância ou direção é definida como 'radial' quando esta dentro dos $30^{\circ}$ da linha de visão. É definida como 'horizontal' quando se situa dentro dos $30^{\circ}$ da perpendicular à linha entre o observador e o ponto médio da configuração (HABER, 1985).
} 
cas estímulos seguindo um critério específico para conseguir controle sob o ângulo visual e o alinhamento dos segmentos respeito à linha de visão. Na mesma época, um layout similar foi empregado em nosso laboratório com o objetivo de investigar a acurácia e estabilidade dos julgamentos verbais para estimar distâncias egocêntricas e exocêntricas em configurações espaciais no campo aberto (RIBEIRO-FILHO, 1993), e cujos dados foram modelados a posteriori no trabalho de Foley, Ribeiro-Filho e Da Silva (2004). Além de ter sido encontra uma relação lineal entre as distâncias físicas e as percebidas, Levin e Haber (1993) notaram que a distância exocêntrica apresenta uma distorção que depende do ângulo entre os objetos. Esta distorção produz uma superestimação das distâncias perpendiculares à linha de visão, mas tem pouco efeito nas distâncias paralelas à linha de visão. Ribeiro-Filho (1993) reporta resultados similares, com os julgamentos de distância exocêntrica horizontal tendendo à expansão enquanto que os julgamentos de distância exocêntrica radial tendem à compressão.

\subsubsection{Apontamento exocêntrico e colinearidade}

A diferença das tarefas empregadas nos julgamentos de distância exocêntrica que tradicionalmente usam configurações com vários estímulos-, os estudos empregando tarefas de apontamento exocêntrico se caracterizaram desde o principio por utilizar configurações espaciais baseadas somente num par de estímulos, compostos por um apontador e um alvo.

O apontamento exocêntrico bem pode ser pensado como um paradigma (KOENDERINK; VAN DOORN, 1998), pois agrupa na sua definição vários tipos de tarefas, inclusive as de paralelismo ${ }^{2}$ e de colinearidade ${ }^{3}$, as quais podem ser consideradas como casos particulares. O apontamento pode ser executado orientando um segmento a um ponto, um segmento a um outro segmento de reta, dois segmentos a um ponto. No caso do paralelismo, ambos segmentos devem estar orientados na mesma direção mas pertenecer a linhas diferentes. Na tarefa de colinearidade os três (ou mais) pontos, como os segmentos por eles definidos, devem determinar uma reta.

Uma revisão na literatura permite observar que o emprego de tarefas de apontamento para realizar julgamentos de distância exocêntrica encontram-se em estado incipiente, sendo portanto os estudos realizados concebidos como inovadores. Destacam-

\footnotetext{
${ }^{2}$ Paralelismo é uma noção que indica que dois objetos (rectas ou planos) eqüidistantes entre si estão na mesma direção e que por mais que se prolonguem não podem se encontrar.

${ }^{3}$ Colinearidade é a propriedade que indica que em um conjunto de três ou mais pontos, eles estão posicionados de tal forma que se pode traçar uma reta que contenha todos eles.
} 
se os trabalhos pioneiros do grupo de investigação liderado pelo professor Jan Koenderink na Universidade de Utrecht (nos Países Baixos).

Num dos primeiros trabalhos onde foram aplicados este tipo de tarefa, Cuijpers, Kappers e Koenderink (2000a) empregaram o apontamento exocêntrico para investigar a estrutura do espaço visual. Para executar a tarefa os observadores deveriam ajustar, mediante controle remoto, um segmento de reta em direção a um ponto específico. As medições foram realizadas no laboratório (a distâncias menores a $6 \mathrm{~m}$ ) em condições de indícios reduzidos, empregando uma distribuição radial e simétrica dos estímulos ao redor do observador. Neste experimento, os autores mostraram que a condição de visão binocular é fundamental para conseguir uma melhor performance neste tipo de tarefa baseada no apontamento de um segmento de reta. Contudo, em condição binocular os desvios foram significativos e dependeram linearmente da orientação, indicando a anisotropia no espaço percebido, a qual parece ser simétrica no sentido esquerda/direita. Por último, estes autores chamaram a atenção sobre o fato que os desvios da acurácia desaparecem quando os ângulos entre os objetos são amplos. Isto parece ser devido à falta de sensibilidade da tarefa de apontamento para julgar distâncias para este tipo de ângulos. Quando a tarefa é de paralelismo, isto é tentar ajustar um segmento de reta na direção de um outro segmento específico, os resultados também se mostraram independentes das distâncias dos estímulos ao observador (CUIJPERS; KAPPERS; KOENDERINK, 2000b). Mas ainda assim os desvios são sistemáticos e significativos. Segundo os dados obtidos, seriam maiores aos $40^{\circ}$, e apresentaram uma tendência a se incrementar linearmente em função do ângulo de separação entre os estímulos.

Empregando um layout similar ao anterior, Cuijpers, Kappers e Koenderink (2002) também investigaram o conceito de colinearidade num ambiente com indícios reduzidos. A tarefa do sujeito foi alinhar duas barrinhas no plano horizontal à altura dos olhos, de maneira que elas ficassem tangentes a uma linha reta que conectasse os centros delas. Seus resultados mostraram que a orientação destas barras depende sistematicamente da proporção da distância entre elas e a distância ao observador, sendo similar ao observado com a tarefa de apontamento a um ponto (CUIJPERS; KAPPERS; KOENDERINK, 2000a), mas não com a tarefa de paralelismo (CUIJPERS; KAPPERS; KOENDERINK, 2000b). Uma explicação possível seria que os indícios usados para realizar ambos tipos de tarefas são diferentes. Embora que na tarefa de paralelismo os julgamentos podem ser baseados pura e exclusivamente na relação entre as dimensões das barras, essa informação é insuficiente para realizar corretamente a tarefa de colineari- 
dade, onde a distância dos objetos ao observador seria um parâmetro relevante. Estas diferenças encontradas entre as tarefas de paralelismo e colinearidade levaram a estes autores a assumir que diferentes tarefas implicam diferentes operacionalizações do espaço visual.

\subsubsection{Tarefas de colinearidade em campo aberto}

Um trabalho que pode ser considerado como precursor no emprego de tarefas de apontamento exocêntrico no campo aberto foi apresentado em 1997 num Congresso sob “Visão e Ação" na Universidade de New York por Koenderink e van Doorn (1998). O objetivo era estudar os aspectos projetivos da estrutura do espaço visual de forma independente de qualquer propriedade métrica. Neste experimento o alvo e o ponteiro foram posicionados em dois dos vértices de um triângulo eqüilátero com o observador posicionado no baricentro ou centro geométrico da configuração. As distâncias variavam entre 1,5 e 24 metros. O ângulo visual subtendido entre o alvo e o ponteiro foi de $120^{\circ}$, o que forçava ao observador a mover a cabeça para conseguir ver ambos claramente. Os resultados mostram um comportamento simultáneo de compressão e expansão, variando em função das distâncias exocêntricas consideradas. Os triângulos pequenos aparecem 'inflados', excedendo a soma de seus ângulos os $180^{\circ}$ axiomatizados pela geometría Euclidiana. Contrariamente, os triângulos grandes aparecem 'desinflados', pelo que a adição de seus ângulos seria inferior aos $180^{\circ}$ Euclidianos. Segundo os autores o excesso na estimativa angular indicaria uma curvatura elíptica e o 'déficit angular' indicaria uma curvatura hiperbólica. Este resultado seria coerente com a proposta de Luneburg (1947) de um espaço visual de curvatura não constante e cuja percepção fora caracterizada pela função sugerida por Gilinsky (1951).

Uma variante interessante de tarefa de colinearidade foi a proposta por Kelly, Loomis e Beall (2004), onde a tarefa do sujeito foi observar dois alvos (com separações de 45,90 e $135^{\circ}$ e distâncias egocêntricas fixas de 5, 10, 15 e 20 m) e sinalizar um terceiro ponto na distância que fosse colinear a eles. Para isso, o observador tinha que imaginar a linha conectando os alvos e depois extrapolar dita linha imaginada até uma cerca perimetral que delimitava o campo. As respostas eram marcadas num cilindro com uma foto panorâmica de dita cerca. Estes autores encontraram um erro médio de só $7,43^{\circ}$ o que, segundo eles, indicaria a boa precisão dos julgamentos.Resultado que foi surpreendente devido aos grandes ângulos que o observador devia percorrer 
com a visão desde um extremo a outro da reta de colinearidade. A similaridade nos padrões de erros com aqueles observados nos estudos de Cuijpers, Kappers e Koenderink (2000a) leva a supor que as tarefas empregadas baseiam-se no mesmo tipo de julgamento exocêntrico.

Mais recentemente, Koenderink et al. (2008) empregaram no campo aberto uma variante da tarefa de apontamento que seu grupo de trabalho usara com sucesso no laboratório (CUIJPERS; KAPPERS; KOENDERINK, 2000a, 2002). O objetivo foi investigar a existência de um arco "pregeodésico" ${ }^{4}$-único e reto- conectando cada par de pontos do espaço, representados pelo ponteiro e o alvo e a respectiva inversão dos mesmos. Neste caso o posicionamento dos estímulos seguiu uma configuração geométrica triangular, com o ponteiro, alvo e observador em cada um dos vértices. As distâncias foram de 1, 2, 4, 8, 16 e 32 metros fixando o ângulo interior no 'egocentro' em $60^{\circ}$. O tamanho angular dos estímulos foi mantido constante em $1,8^{\circ}$ modificando o tamanho físico dos estímulos (segundo a equação 2.4). Contudo, os autores notaram que mesmo assim os observadores percebiam a diferença real de tamanho entre os estímulos próximos e distantes. Os resultados mostraram marcadas diferenças individuais, com variações muito maiores quando o ponteiro estava próximo do sujeito que quando estava longe. Embora não seja possível extrapolar os resultados para os dados obtidos nos experimentos no laboratório (CUIJPERS; KAPPERS; KOENDERINK, 2000a, 2002) devido às diferenças contextuais e metodológicas, é interessante notar que em geral a informação obtida parece mostrar a incapacidade dos observadores para estabelecer arcos simples no espaço visual.

Devido às implicações, torna-se importante aprofundar o estudo sobre nossa percepção visual ante tarefas que exijam seguir uma linha reta no espaço físico, tais como as de apontamento exocêntrico ou colinearidade, especialmente num ambiente naturalístico e pleno de indícios como é o campo aberto.

\subsubsection{Acerca dos estímulos e seu posicionamento}

A diferença no desempenho entre as orientações ortogonais e as oblíquas é conhecida e atribuída ao fenômeno chamado efeito oblíquo (APPELLE, 1972). Embora seus

\footnotetext{
${ }^{4}$ Nas matemáticas, a noção de "geodésico" é uma generalização da noção de 'linha reta' num espaço curvo. O arco "pregeodésico" é uma curva definida de forma tal que todas suas tangentes são paralelas no sentido geométrico, mas que se diferença do geodésico por não implicar uma propriedade métrica e sim projetiva. Assim um arco pregeodésico no espaço visual apareceria como uma linha reta, mas no espaço físico seria mapeado como curvo (embora possa apresentar pontos de inflexão).
} 
efeitos já foram reportados em alguns estudos empregando condições naturalísticas nos experimentos (TOYE, 1986; KOENDERINK; VAN DOORN; LAPPIN, 2003; KELLY; LOOMIS; BEALL, 2004), a pesquisa em direções exocêntricas que não sejam paralelas ou perpendiculares à linha entre o observador e o ponto médio da configuração continuam sendo de grande interesse. Tal interesse volta-se para o estudo do processamento das características do espaço tridimensional quando mapeado em espaço visual, especialmente quando aplicado no contexto da vida diária, onde é representado por uma orientação comum de muitos objetos que nos rodeiam e substancialmente importante no "espaço visual compartilhado" (KELLY; BEALL; LOOMIS, 2004). Nesse sentido, Toye (1986) estabeleceu um critério em relação à orientação dos estímulos. Partindo da linha de visão do observador quando olhando a sua frente, ele sugeriu que as orientações espaciais dos estímulos fossem consideradas sagital se o desvio a partir desta linha fosse inferior a $\pm 30^{\circ}$ e frontoparalela se o desvio fosse inferior à perpendicular $\pm 30^{\circ}$, nomes mais indicativos que os termos 'radial' e 'horizontal' quando empregados com a mesma finalidade.

Um outro aspecto importante é o ângulo visual concernente à porção da cena que pode ser capturada numa observação. Quando o ângulo é pequeno, e os estímulos se encontram alinhados com a linha de visão, não são necessários movimentos para abarcá-los de uma vez só. Mas, com ângulos visuais maiores, são precisos movimentos dos olhos e da cabeça. Segundo referenciam Levin e Haber (1993), para uma tarefa de percepção exocêntrica, uma separação de maior a $20^{\circ}$ provocaria os movimentos necessários. Por outro lado, ao avaliar o campo visual aparente em observadores normais, Koenderink, van Doorn e Todd (2009) encontram que na maioria dos casos as pessoas experimentam um campo visual percebido de aproximadamente $90^{\circ}$ (ou menos), valor bastante inferior que os $180^{\circ}$ verídicos, indicando uma redução ao $56 \%$ do valor sugerido pelo poder dióptrico do olho.

Considerando os trabalhos com tarefas de colinearidade em campo aberto, aprendese que Kelly, Loomis e Beall (2004) empregaram em seus estímulos separações de $45^{\circ}$, $90^{\circ}$ e $135^{\circ}$, notando que quando o ângulo era de $135^{\circ}$ a maioria dos observadores (70\%) falhava ao perceber corretamente as relações entre as distâncias egocêntricas e exocêntricas, mas que, quando a proporção entre as distâncias egocêntricas era extremosamente grande, os erros angulares retornavam a valores próximos a 0 (tal como acontecia quando ditas distâncias eram similares). Koenderink et al. (2008) também usaram uma configuração triangular, porém mantiveram o ângulo do egocentro fixado em $60^{\circ}$, valor aproximado com o do ponto médio do intervalo referido por 
Koenderink, van Doorn e Todd (2009), e que seria de $\approx 67^{\circ}$.

Baseados nestes trabalhos, pode-se dizer que um critério para a eleição dos ângulos entre os estímulos extremos é tentar mantê-los num valor próximo ao $50 \%$ do campo visual teórico, ou seja usar ângulos com valores próximos ou ligeiramente superiores a $90^{\circ}$. Entanto, considerar que a inclinação das retas por eles determinados poderia ser maior aos $30^{\circ}$ do critério de Toye (1986), com a finalidade de indagar experimentalmente o que acontece quando os objetos se encontram nessa orientação não encontrada com freqüência na literatura. Na Figura 8, pode ser observada a proposta de layout experimental aplicado na presente investigação, onde as retas definidas pelos estímulos extremos F1 e F2, F3 e F4, formariam ângulos de $32^{\circ}$ e $35^{\circ}$ respeito à linha de visão do observador e o ângulo $\theta$ seria maior a $90^{\circ}$ (para manter a clareza da figura não se desenha o ângulo subtendido pelos estímulos F1 e F2). As áreas cinzas indicariam os ângulos do critério de Toye (1986).

\subsection{Experimento I}

O objetivo deste experimento foi estudar o desempenho dos observadores em uma tarefa de colinearidade em grande escala no campo aberto. Em vez do posicionamento acostumado nas pesquisas de distância exocêntrica, que normalmente é radial ou horizontal respeito à línea de visão do observador (paralelo ou perpendicular aos eixos cartesianos), o arranjo dos estímulos foi estabelecido seguindo aproximadamente as duas diagonais no espaço empregado, abarcando um ângulo amplo no campo visual. Embora a geometria básica seja parecida à empregada por Koenderink et al. (2008), pode-se dizer que neste caso os triângulos se encontram de forma simultânea no espaço físico e numa reflexão não simétrica a partir do ponto central da configuração. $\mathrm{O}$ fato de cruzar as linhas de colinearidade a uma distância fixa na frente do observador também permitiria uma série de interessantes comparações.

\subsubsection{Método}

\subsubsection{Participantes}

Participaram do experimento 30 observadores (metade do sexo masculino, metade do sexo feminino), alunos de cursos de graduação e pós-graduação da FFCLRP. O intervalo de idades foi de 20 a 34 anos, com uma média para as mulheres de $25 \pm 4$ 


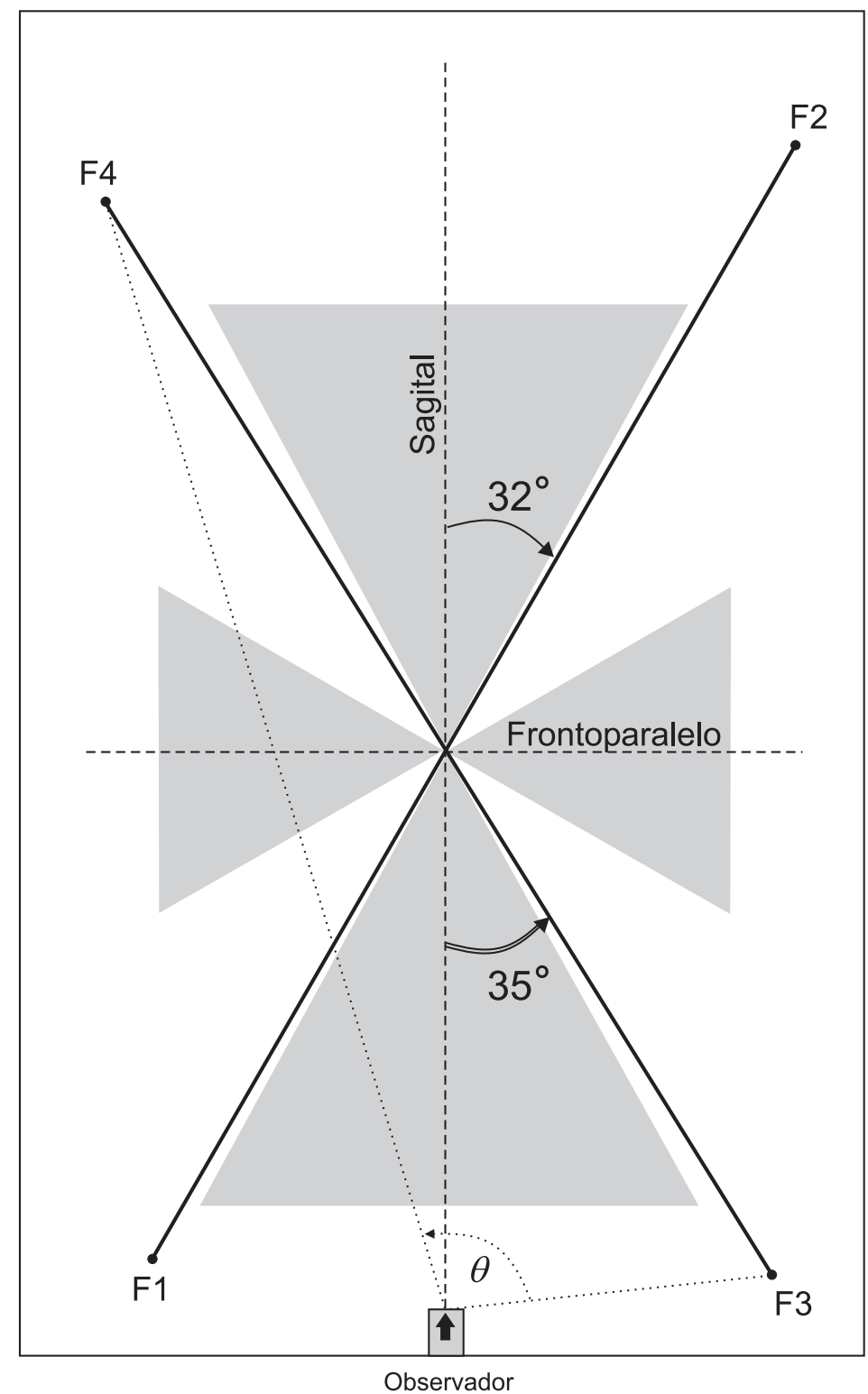

Figura 8 - Esquema da proposta experimental com os ângulos subtendidos pelas linhas determinadas pelos estímulos extremos F1 e F2, F3 e F4. As áreas cinza indicariam o critério de Toye (1986) para considerar as orientações como "sagitais" ou "frontoparalelas". 
anos e de $27 \pm 4$ anos para os homens. Todos com visão normal ou corrigida, ingênuos quanto à naturaleza do experimento, sendo sua colaboração voluntária. A proposta de estudo foi submetida e aprovada pelo Comitê de Ética da USP-RP (Protocolo CEP-FFCLRP n 224/2005 - 2005.1.1657.59.0) e pelo SINESP do Ministério de Saúde (Protocolo n ${ }^{\circ}$ 0992.0.222.000-05).

\subsubsection{Ambiente experimental}

Campo aberto plano de dimensões 20 × 30 m, onde foi realizada uma terraplanagem e coberto com uma camada uniforme de areia compactada. A área de aplicação do estudo foi delimitada por uma pequena mureta de tijolos com uma altura aproximada de $15 \mathrm{~cm}$. Em uma das laterais de $20 \mathrm{~m}$ foi construída uma base de concreto de $0,5 \times 1 \mathrm{~m}$ onde ficava o observador e onde uns parafusos (chumbados perto do lado mais interno ao campo) permitiam a correta fixação do suporte de queixo (ver Figura 9). Do local de posicionamento do observador eram visíveis à esquerda e na frente algumas árvores e mato. Já à direita podiam ser avistadas algumas árvores, existindo também uma rua interna transitada ocasionalmente por veículos e pedestres. No período de coleta de dados o clima foi ótimo com condições de sol pleno em quase todas as medições. As sessões de coleta foram realizadas, na sua totalidade, no período da manhã com o propósito de que alguns indícios (por exemplo as sombras) ficassem na mesma orientação e mantidos para todos os participantes.

\subsubsection{Equipamentos e materiais}

De forma similar a Foley, Ribeiro-Filho e Da Silva (2004), os estímulos foram estacas de alturas variáveis (desde 1,10 a 1,70 m com uma média de 1,32 m) e diâmetro de $1,25 \mathrm{~cm}$, todas pintadas na cor branca (Figura 9B). Os estímulos de posição ajustável foram montados sobre uma base móvel encarrilhada em trilhos invisíveis ao observador do seu ponto de observação. Os trilhos foram posicionados perpendicularmente à extensão entre os pontos terminais que eram fixos (F1 e F2, F3 e F4), como pode ser observado na Figura 10. Os trilhos foram posicionados descentralizados em relação à linha de colinearidade, de jeito que ela não passasse pelo centro de equilíbrio do trilho, evitando assim que esta proporção pudesse ser empregada como referência na hora do observador realizar os ajustes. A distribuição dos estímulos no campo buscou manter certa simetria a partir do ponto central da configuração (localizado a $12 \mathrm{~m}$ na frente do sujeito), mas as distâncias inter-estímulos e o posicionamento foram ligei- 

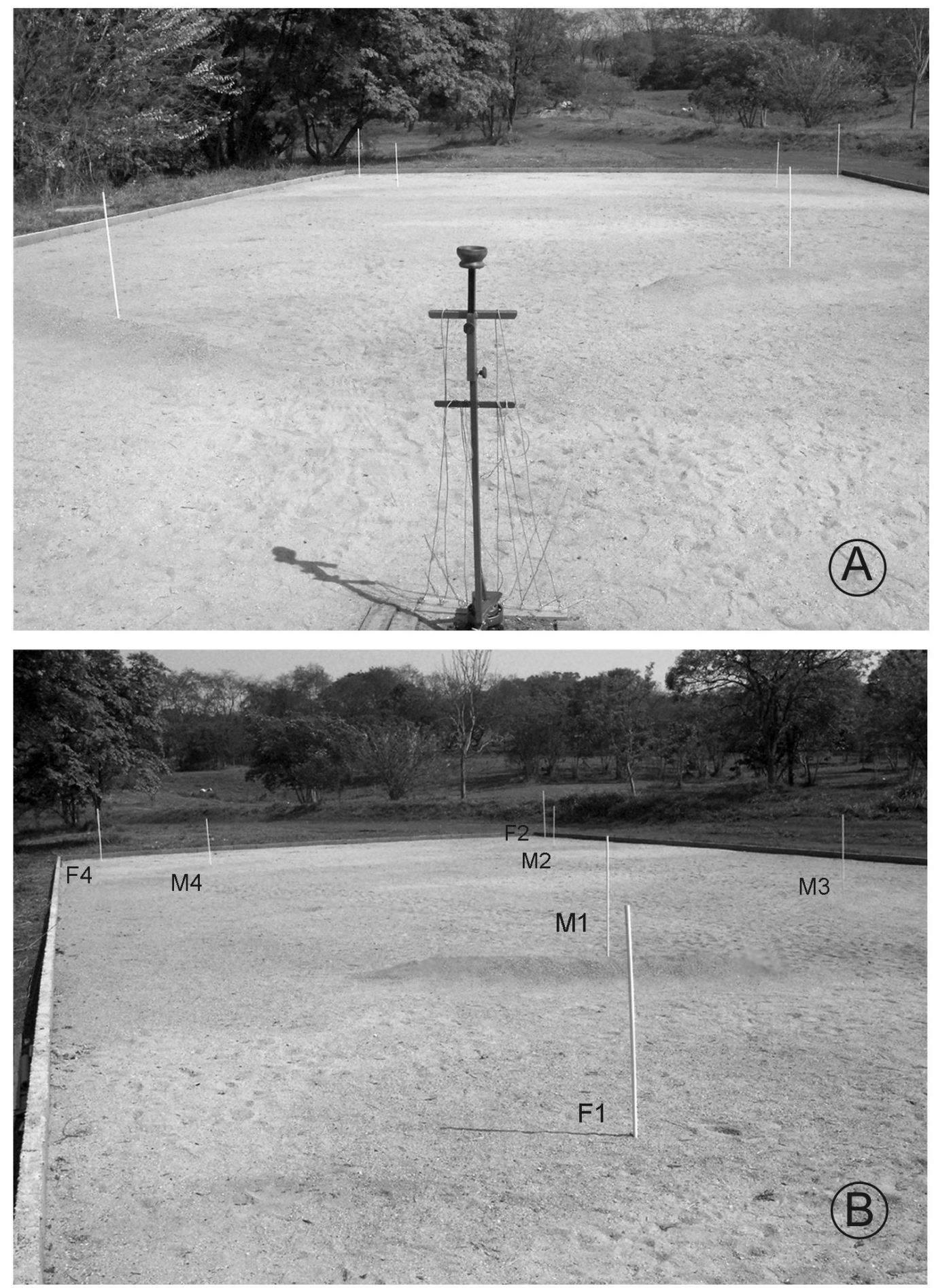

Figura 9 - Fotos da área experimental. (A) Desde a posição do observador, onde se observa o suporte de queixo e os fios usados para ajustar os estímulos móveis (sistema que ficava dissimulado na areia). (B) Visão desde parte inferior esquerda, onde se pode observar desde outra posição a configuração de estímulos. 


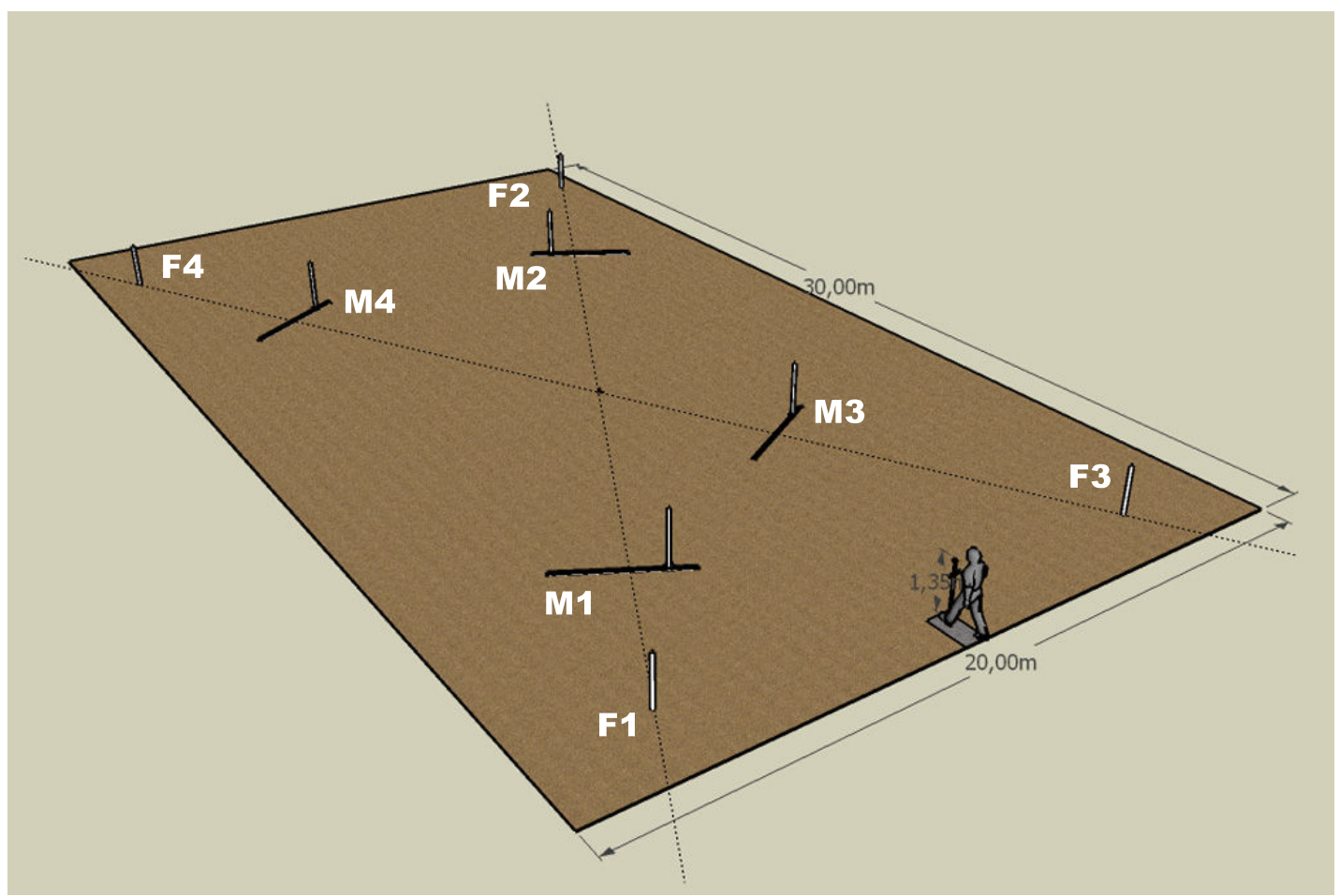

Figura 10 - Esquema a escala da distribuição dos estímulos no campo aberto $(\mathrm{M}=$ móvel, $\mathrm{F}=$ fixo) em perspectiva aérea. Disposição das linhas de colinearidade para cada serie de alvos e a posição do sujeito com o suporte de queixo.

ramente diferentes em cada quadrante para evitar que dita regularidade fosse usada como referência por parte do observador.

Os estímulos móveis (M1, M2, M3 e M4) foram ajustados através de um sistema de controle à distância, mediante fios dissimulados no solo que permitiam mover os pólos verticais de um extremo ao outro do trilho. Como o erro na fixação do trilho na sua posição foi de $0,5 \mathrm{~cm}$, no levantamento das medições se considerou este valor como a precisão do sistema. As Tabelas 1 e 2 sumariam as distâncias entre os estímulos de cada diagonal e entre cada um deles e o ponto de observação $O$, determinado pelo centro do suporte de queixo, ou distância egocêntrica física. Os valores estimados (ver seção 2.1) para os ângulos visuais entre F1 e F2, e entre F3 e $\mathrm{F} 4$ foram de $\theta_{F 1 F 2}=94^{\circ}$ e $\theta_{F 3 F 4}=101^{\circ}$, respectivamente. Estes valores foram confirmados com medições no campo, com um erro aproximado de $\pm 2^{\circ}$ devido ao sistema empregado.

Pelo fato de os alvos serem facilmente identificáveis na sua localização espacial, para simplificar o aspecto visual da configuração de estímulos não foram utilizadas placas de identificação, evitando-se também introduzir no campo objetos que pode- 
Tabela 1 - Distâncias entre os estímulos da reta de colinearidade que passaria por F1, M1, M2 e F2. Se indica também a distância de cada estímulo ao ponto $\mathrm{O}$ (distância egocêntrica).

\begin{tabular}{cccccc}
\hline & F1 & M1 & M2 & F2 & O \\
\hline F1 & - & 4,25 & 22,80 & 29,25 & 6,00 \\
M1 & 4,25 & - & 18,55 & 25,05 & 6,10 \\
M2 & 22,80 & 18,55 & - & 6,50 & 21,56 \\
F2 & 29,25 & 25,05 & 6,50 & - & 28,23 \\
\hline
\end{tabular}

Tabela 2 - Distâncias entre os estímulos da reta de colinearidade que passaria por F3, M3, M4 e F4. Se indica também a distância de cada estímulo ao ponto $\mathrm{O}$ (distância egocêntrica).

\begin{tabular}{cccccc}
\hline & F3 & M3 & M4 & F4 & O \\
\hline F3 & - & 8,00 & 23,25 & 29,25 & 6,00 \\
M3 & 8,00 & - & 15,25 & 21,25 & 8,05 \\
M4 & 23,25 & 15,25 & - & 6,00 & 21,71 \\
F4 & 29,25 & 21,25 & 6,00 & - & 27,54 \\
\hline
\end{tabular}

riam servir como referência de tamanho.

Um suporte de queixo fixado a uma altura de 1,35 $\mathrm{m}$ foi empregado para restringir os movimentos do observador, especialmente no sentido vertical e translacional de paralaxe, mas podia ser girada a cabeça com liberdade permitindo-se o movimento de vai-e-vem (paralaxe rotacional) necessário para abarcar todos os estímulos. Assim sendo, a totalidade dos sujeitos observaram a configuração de estímulos do mesmo ângulo de visão.

\subsubsection{Planejamento experimental}

Foi empregado um planejamento fatorial de um fator intra-sujeitos, duas direções de ajustamento (partindo de Dentro ou partindo de Fora ${ }^{5}$ ) e duas séries de estimativas, considerando como variável dependente o erro no ajuste de colinearidade. Na análise dos dados foram consideradas também como variáveis de interesse a posição espacial dos estímulos móveis (devido às diferenças próprias do campo aberto e da configuração de estímulos), e o sexo dos observadores.

\footnotetext{
${ }^{5}$ Entendendo aqui por 'Fora' ou 'Dentro' se o alvo móvel era posicionado para começar os ajustes na metade externa ou interna do trilho, separação definida a partir do ponto 0 onde ele era cruzado pela linha de colinearidade.
} 


\subsubsection{Procedimento}

Após a aceitação para participar, o observador era conduzido até o local de pesquisa. Todos os observadores assinaram um termo de consentimento livre e esclarecido. Em seguida, eram acomodados numa posição à parte do campo experimental onde eram lidas as instruções, do tipo objetiva, que solicitavam que os observadores ajustassem a posição dos estímulos móveis M1 e M2 de modo que ficassem colineares à extensão compreendida entre F1 e F2, seguindo o mesmo esquema para os estímulos M3 e M4 mantendo-os colineares à extensão compreendida entre F3 e F4. As instruções incluíam figuras com esquemas da tarefa a ser realizada e enfatizavam que as posições poderiam ser ajustadas o quanto desejassem. Era esclarecida também qualquer dúvida que surgia no momento, e permitida uma breve prática na movimentação dos estímulos móveis (Instruções em Anexos).

Durante os ajustamentos o observador ficava em pé e com a cabeça apoiada no suporte de queixo. Os controles dos estímulos ficavam perto das mãos e organizados de acordo à posição dos mesmos, mas era permitido ao observador acomodá-los de outra forma se ele achasse que isso lhe facilitava seu uso e/ou manuseio.

Iniciado o experimento, o observador virava de costas e o experimentador posicionava adequadamente os estímulos no ponto de início (aleatório) indicado pelo protocolo. Então, o observador começava a tarefa de ajuste dos alvos. Após cada série de ajustes dos quatro estímulos móveis, os observadores viravam de costas durante o período de medição das posições dos estímulos ajustáveis, de forma que não pudessem utilizar o corpo do experimentador como um referencial de tamanho e de distância.

Os erros na colinearidade foram medidos em centímetros a partir do ponto 0 de cada trilho, que era onde passava a linha reta que unia todos os estímulos em cada diagonal $(\overline{F 1 F 2}$ e $\overline{F 3 F 4})$. O erro era considerado negativo no sentido proximal ao observador e positivo no sentido oposto, segundo esquematizado na Figura 11.

\subsubsection{Resultados}

Os dados oriundos dos ajustes de colinearidade foram codificados em termos de desvio em centímetros da linha de colinearidade.

Os resultados, organizados por estímulo móvel, sexo dos observadores, ponto de 


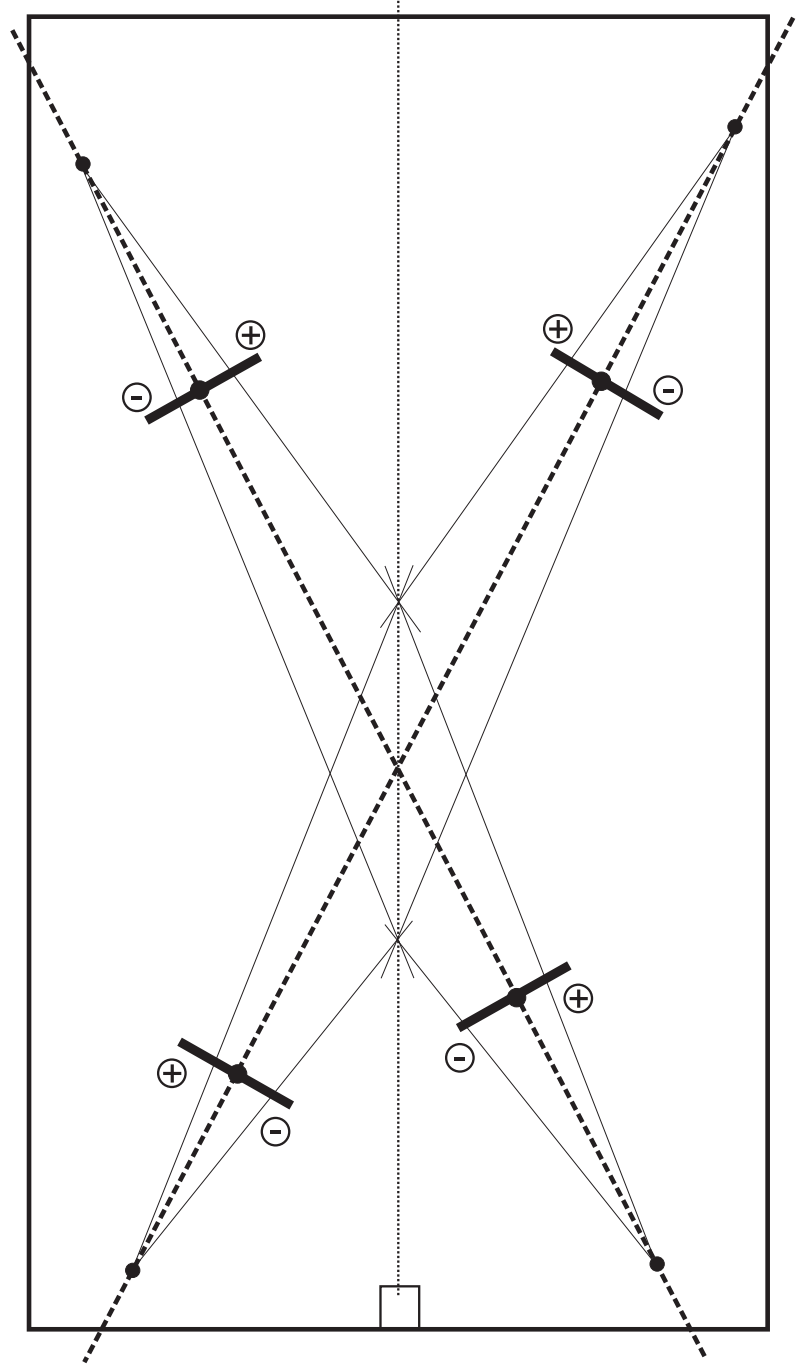

Figura 11 - Esquema dos estímulos e da convenção de sinais empregada na codificação dos resultados (O desenho não é a escala). 
Tabela 3 - Erros de colinearidade relativos ao Experimento I $(\mathrm{N}=480)$. Erros médios e desvios-padrão, medianas e intervalo interquartílico, expressados em centímetros. Os resultados estão discriminados por Estímulo Móvel (1 a 4), Sexo do observador ( $\mathrm{M}$ ou F) e Ponto de Inicio da medição (Fora ou Dentro).

\begin{tabular}{ccccccc}
\hline E. Móvel & Sexo & Inicio & Média & SD & Mediana & RIQ \\
\hline 1 & M & F & $-10,03$ & 35,29 & $-7,75$ & 46,00 \\
1 & M & D & $-14,75$ & 38,51 & $-7,50$ & 45,38 \\
1 & F & F & 2,68 & 37,31 & 6,00 & 51,50 \\
1 & F & D & $-1,45$ & 34,38 & $-3,00$ & 54,38 \\
2 & M & F & $-41,72$ & 20,61 & $-42,50$ & 24,13 \\
2 & M & D & $-30,85$ & 23,08 & $-32,00$ & 37,00 \\
2 & F & F & $-54,37$ & 30,95 & $-46,00$ & 45,38 \\
2 & F & D & $-42,70$ & 38,63 & $-44,50$ & 61,75 \\
3 & M & F & 16,08 & 35,68 & 20,25 & 47,13 \\
3 & M & D & $-1,72$ & 33,94 & 8,50 & 38,38 \\
3 & F & F & 12,47 & 42,04 & 15,50 & 46,13 \\
3 & F & D & 9,27 & 43,09 & 16,25 & 51,25 \\
4 & M & F & $-34,85$ & 25,82 & $-42,00$ & 26,25 \\
4 & M & D & $-23,88$ & 22,71 & $-20,75$ & 30,50 \\
4 & F & F & $-34,71$ & 31,99 & $-41,75$ & 28,13 \\
4 & F & D & $-22,07$ & 30,27 & $-25,50$ & 41,38 \\
\hline All Groups & & & $-16,90$ & 38,09 & $-20,00$ & 56,50 \\
\hline
\end{tabular}

início da medição, encontram-se sumariados na Tabela 3.

Uma primeira inspecção, considerando o conjunto dos dados, indicaria um erro de colinearidade negativo com Média $=-16,91$ e Mediana $=-20,00$. Pode ser observado que tanto as médias $(-17,64$ nos homens, $-16,16$ nas mulheres) como as medianas ( $-20,00$ nos homens, $-20,75$ nas mulheres) dos erros são negativas para ambos sexos. Consideram-se aqui as medianas como dado relevante devido ao fato que alguns dos observadores realizaram julgamentos aparentemente fora da distribuição normal dos demais e essa medida de tendência central é menos afetada pelos outliers. De forma similar a Koenderink et al. (2008), ao olhar os dados discriminados por observador, encontramos marcas das diferenças individuais.

Na Figura 12 foram representadas as medianas e os intervalos interquartílicos. O boxplot permitiu identificar os outliers (Indicados com um ' $*$ ' na figura), definidos aqui como aqueles valores cuja distancia à mediana é $>1,5$ vezes o intervalo interquartílico. Devido ao fato de que estes valores extremamente inusuais afetariam a divisão dos dados e sua remoção não altera a média significativamente -já que a mu- 


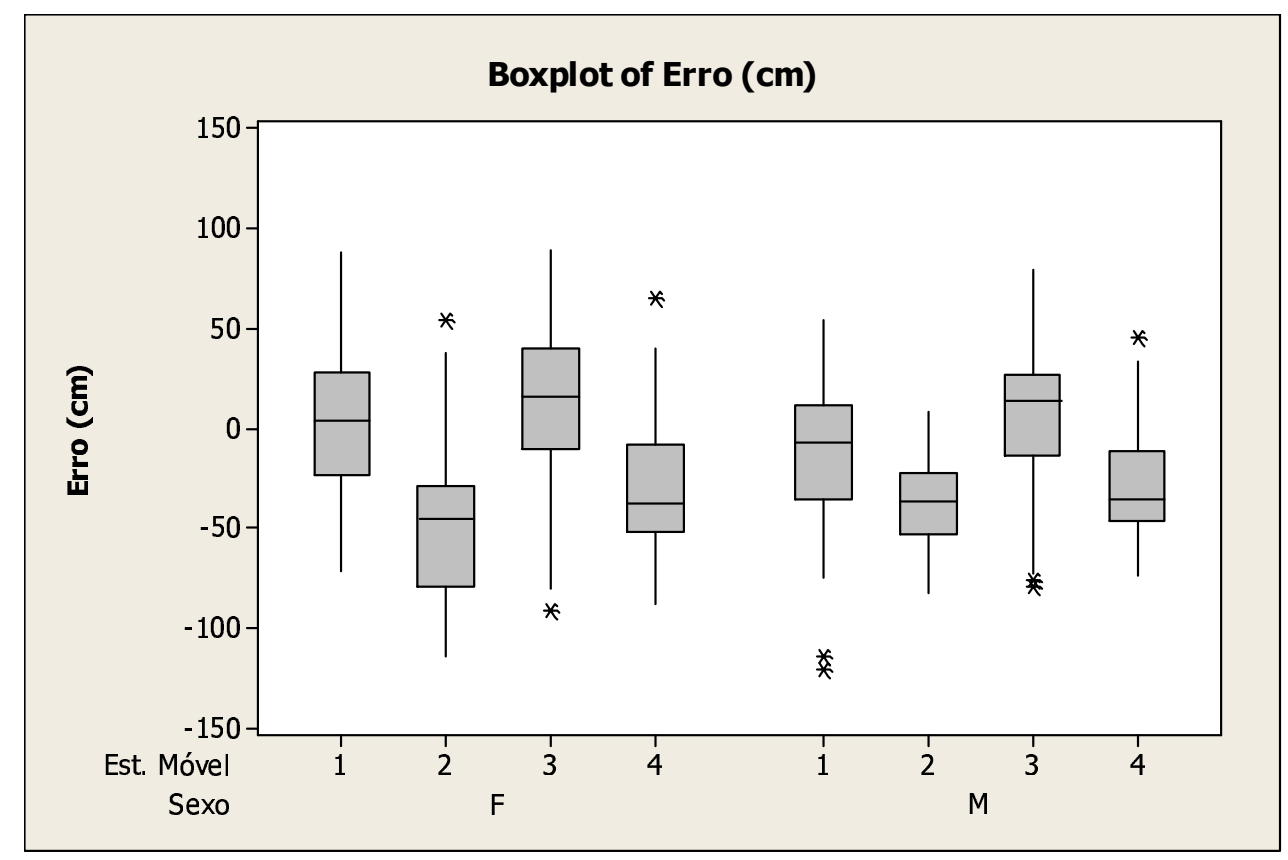

Figura 12 - Boxplot dos erros (em centímetros) cometidos no ajuste de colinearidade separados por posição espacial (estímulo móvel) e por sexo do observador. Os outliers são indicados com um ' $*$ '.

dança esta na casa do erro de medição $(0,5 \mathrm{~cm})$-, foram removidos dos dados antes da análise estatística das diferenças entre os grupos de observações. Como a posição espacial é um dos fatores de maior interesse em nossa pesquisa o desempenho foi descriminando segundo os estímulos móveis. Assim, observa-se que as mulheres têm erro positivo no M1 (embora não seja significativo por ser da mesma ordem de magnitude do erro de medição), entanto que ambos sexos apresentam erros positivos no estímulo M3.

Na Figura 13, o histograma apresenta a distribuição dos erros em todas as observações. Segundo pode ser observado, o 67\% das observações têm valores negativos, ficando mais da metade dos resultados (55\%) categorizados entre 0 e $-50 \mathrm{~cm}$. Tal como indicara a diferença entre ambas medidas de tendência central, a distribuição dos erros mostra uma leve assimetria para o lado esquerdo. Isto é confirmado pela análise de obliqüidade (skewness) que mostra um valor de 0,11, o que sugeriria uma tendência muito pouco acentuada em sentido dos valores acima da média (para o lado esquerdo, que neste caso a mesma é negativa). A análise de normalidade foi realizada usando o teste de Kolmogorov-Smirnov ( $D=0,447, p>0,05)$ o qual indica que a distribuição dos erros segue um padrão similar à curva normal.

Uma vez analisada a normalidade das observações, realizou-se um estudo sobre a igualdade na variância dos erros segundo a posição espacial (estímulo móvel), o sexo 


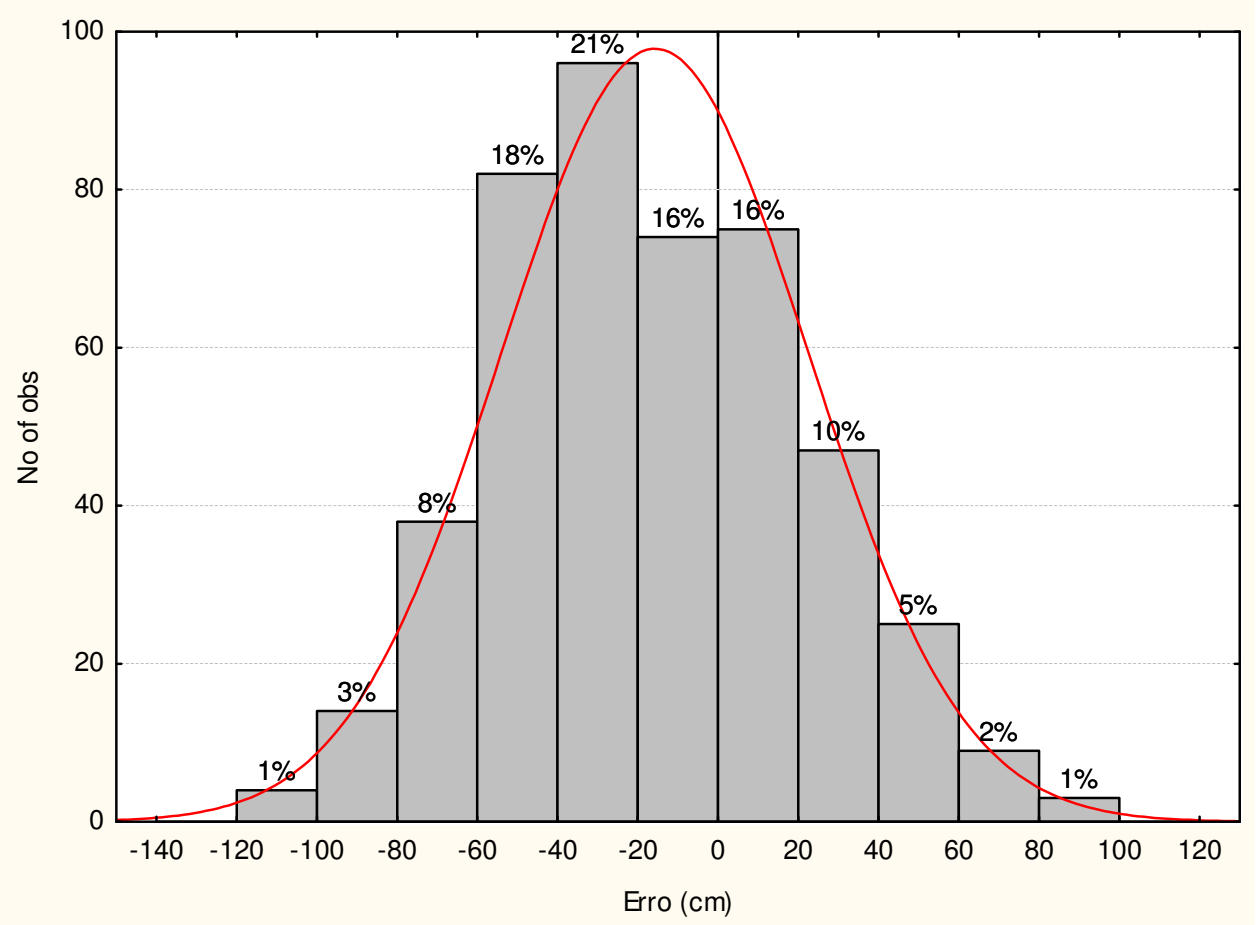

Figura 13 - Histograma dos erros (em centímetros) cometidos no ajuste de colinearidade.

do observador e o ponto de início (fora (F) ou dentro (D)) das mesmas empregando o teste de Levene. Em todos os casos não houve diferenças entre as variâncias e o teste revelou homogeneidade em todos os casos com $p>0,05$.

Dando continuidade, foi realizada uma análise de variância (ANOVA) fatorial sobre os erros de colinearidade, considerando os fatores principais Alvo Móvel, Ponto de início da medição (Fora o Dentro), Sexo do observador, Ordem da medida (primeira ou segunda). A análise revelou somente efeito significativo para o fator 'Estímulo Móvel' com $F_{(3,473)}=69,86, p<0,001$. O estudo das interações entre os efeitos principais denota como significativa a interação entre 'Estímulo Móvel' e o 'Ponto de Início da medição', $F_{(3,448)}=3,413, p<0,05$.

Nas duas variáveis onde o ANOVA resultou em valores significativos de $F$ foi realizada uma análise pós-hoc. No caso do fator Estímulo Móvel, o teste de Newman-Keuls encontra diferenças significativas $(p<0,05)$ para as quatro posições espaciais, entretanto que para a interação 'Estímulo Móvel $*$ Ponto inicio medição' a diferença significativa se encontra no estímulo M4.

Na Figura 14, foram traçados os erros em função da distância egocêntrica ao ponto de colinearidade de cada um dos estímulos. Indicam-se as relações entre os estímulos, 


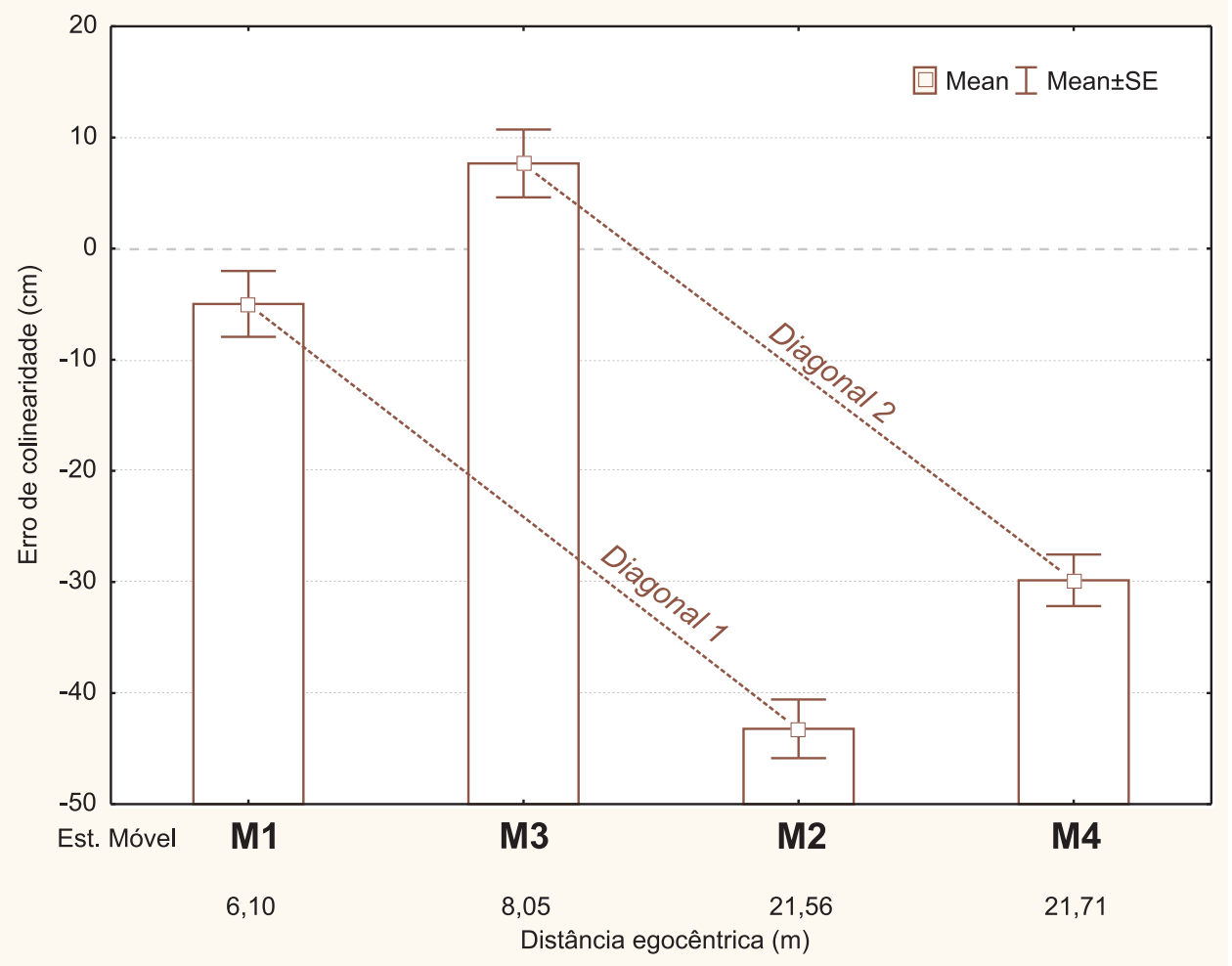

Figura 14 - Gráfica da média dos erros de ajuste de colinearidade (em centímetros) separados por posição espacial (estímulo móvel) e distância ao observador do ponto de colinearidade física. Se indicam as Diagonais do sistema de estímulos. As barras verticais indicam o erro padrão da média (SE).

o seja sua pertença a cada uma das diagonais do sistema de estímulos. Além das diferenças já apontadas pela ANOVA, nota-se uma sistemática na distribuição dos erros. Para investigar a mesma, foi realizada uma análise empregando regressão linear dos resultados obtidos, separados por sua vinculação espacial.

Assim, como pode observar-se na Figura 15, as duas retas de regressão são quase paralelas. A reta de regressão produz um ajuste dos dados numa função linear do tipo $y=a x+b$, onde o parâmetro $a$, ou inclinação, se refere à precisão do ajuste entre as respostas dos dois estímulos e o parâmetro $b$, ou interseção, indicaria um erro constante, associado ao ajuste de colinearidade e independente da distância física do alvo ao observador. Para os estímulos M1 e M2 a reta de regressão seria $y=10,11-2,47 x$ $(R=-0,53, p<0,001)$, entretanto que para o par M3 e M4 a reta de regressão seria $y=29,78-2,74 x(R=-0,53, p<0,001)$, existiendo uma diferença de 0,3 na inclinação de ambas retas, indicando que o mesmo fenômeno de compressão estaria presente nas estimativas realizadas sob ambas Diagonais. Desta maneira, o parâmetro a mostra que a medida que aumenta a distância física ao estímulo, aumenta também a subestimação da distância egocêntrica percebida. $\mathrm{O}$ parâmetro $b$ exibe um erro 


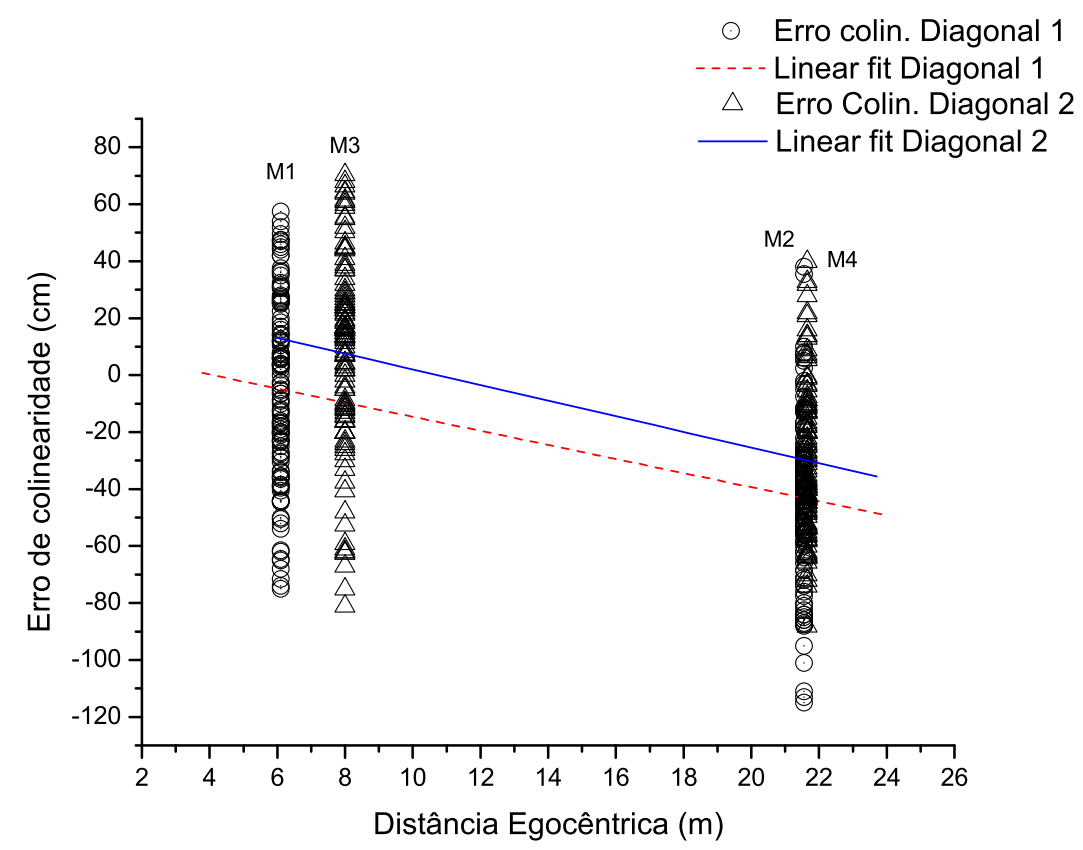

Figura 15 - Erros de colinearidade (em centímetros) separados por posição espacial (estímulo móvel) e distância egocêntrica ao ponto de colinearidade física. As retas de regressão linear estão tracejadas para cada par de estímulos.

constante de $\approx 10 \mathrm{~cm}$ para a Diagonal 1 , mas no caso da Diagonal 2 o valor é três vezes mais $(\approx 30 \mathrm{~cm}$ ) o que poderia estar indicando que os observadores estariam considerando as diferenças espaciais entre ambas séries de estímulos e sua posição (egocentro) ao efetuar seus julgamentos.

Tomando como segmentos orientados as porções de reta determinados pelos pares de estímulos, para analisar a distância exocêntrica foi considerado o ângulo visual subtendido por eles (ver seção 2.1) nas posições de colinearidade geométrica e depois comparada com os valores médios dos ajustes efetuados pelos observadores os quais indicariam a colinearidade perceptual. Os resultados se encontram resumidos na Tabela 4.

Como poder ser notado, as diferenças angulares foram pequenas. No caso dos segmentos extremos (os determinados pelos estímulos fixos e os móveis), a média das diferenças seria de $\approx-1^{\circ}$ e, quando convertidas em distâncias, as ditas diferenças mostrariam uma subconstância na percepção da distância. Apreende-se que os erros constantes são dez vezes menores que os encontrados ao avaliar as distâncias egocêntricas. Considerando os segmentos médios (os determinados pelos estímulos móveis), as média dos erros das diferenças também são de $\approx 1,5^{\circ}$, mas se convertidos 
Tabela 4 - Ângulos visuais subtendidos pelos pares de estímulos nas posições de colinearidade geométrica e segundo a média dos valores ajustados pelos observadores. Todos os valores estão indicados em graus $\left(^{\circ}\right)$.

\begin{tabular}{cccc}
\hline Segmento & Ângulo visual & Âng. visual Ajuste & $\Delta_{a n g}$ \\
\hline F1-M1 & 41,116 & 41,379 & 0,263 \\
M2-F2 & 3,624 & 2,173 & $-1,451$ \\
F3-M3 & 67,606 & 67,092 & $-0,514$ \\
M4-F4 & 3,323 & 1,075 & $-2,248$ \\
M1-M2 & 53,097 & 54,112 & 1,015 \\
M3-M4 & 29,716 & 31,696 & 1,979 \\
\hline
\end{tabular}

em distâncias, estes erros indicam uma expansão na percepção do tamanho de ambos segmentos centrais.

\subsubsection{Discussão}

Embora pareça uma tarefa simples seguir uma linha reta no espaço físico, tais como exigido pelas tarefas de apontamento exocêntrico, os resultados mostram que, ainda num ambiente naturalístico e pleno de indícios como é o campo aberto, realizar este tipo de atividade apresenta certa dificuldade, a qual parece manifestar-se nas pronunciadas diferenças individuais (KOENDERINK et al., 2008). Mas, coerentemente com o observado na literatura (CUIJPERS; KAPPERS; KOENDERINK, 2000a, 2000b, 2001, 2002; KELLY; LOOMIS; BEALL, 2004; KOENDERINK et al., 2008), as medidas de tendência central dos resultados obtidos coincidem e revelam evidencias de respostas surpreendentemente acuradas no ajuste de colinearidade, sobretudo considerando a magnitude das distâncias involucradas.

Nesse sentido, evidência-se uma forte dependência dos erros em função da distância egocêntrica aos alvos do segmento considerado. Cuijpers, Kappers e Koenderink (2000a) encontraram que tanto o tamanho como a orientação dos erros angulares são altamente dependentes da proporção entre às distâncias egocêntricas dos alvos considerados.

Kelly, Loomis e Beall (2004) reportaram erros similares com uma média de 7,43, com a máxima para proporções entre alvos ao redor de 0,75 e a mínima para proporções ao redor de 1,3. Em nosso caso, obtivemos proporções similares e, de igual maneira, os valores maiores nos erros angulares foram reportados para as propor- 


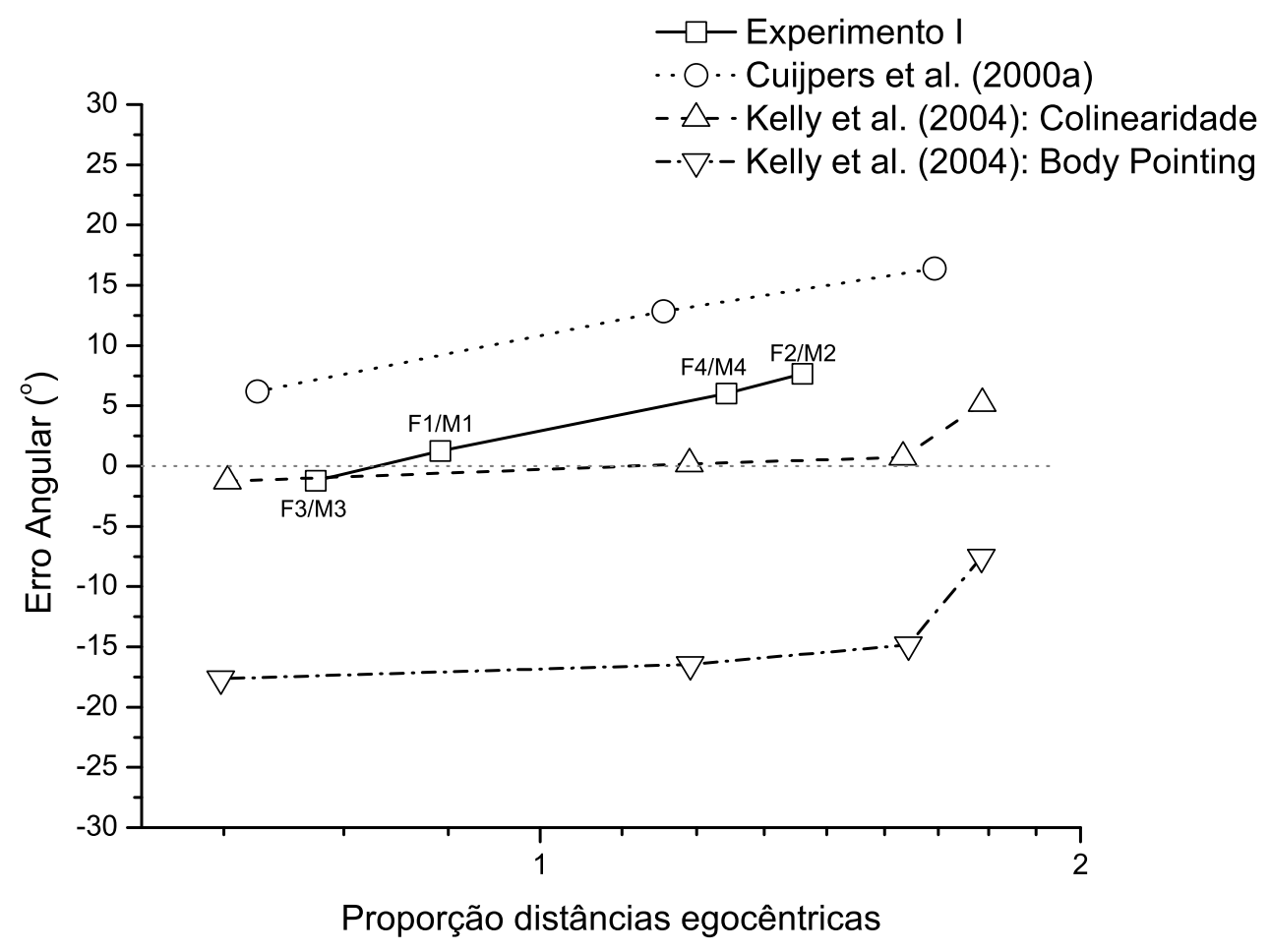

Figura 16 - Média dos erros angulares (em graus) em função da proporção das distâncias egocêntricas entre os estímulos. Disposição comparativa dos dados de Cuijpers, Kappers e Koenderink (2000a) e Kelly, Loomis e Beall (2004) para esse intervalo de proporções. 
ções de distâncias maiores. Assim, quando calculados os erros angulares da mesma forma que estes autores (considerando também o sinal na orientação dos vectores), temos para os segmentos proximais: $\frac{F 1}{M 1}=0,88$ e erro angular de 1,$34 ; \frac{F 3}{M 3}=0,75$ e erro angular de $-1,10$; e para os segmentos distais: $\frac{F 2}{M 2}=1,33$ e erro angular de 7,$20 ; \frac{F 4}{M 4}=1,27$ com um erro angular de 5,70. Na Figura 16 são representados estes valores e, para comparação, os dados de Kelly, Loomis e Beall (2004) para esse intervalo de proporções entre distâncias egocêntricas. Pode observar-se a similaridade com o padrão de erros no experimento de Cuijpers, Kappers e Koenderink (2000a) usando a tarefa de apontamento exocêntrico, onde estes autores obtiveram erros maiores provavelmente devido às condições de indícios reduzidos empregadas. Por outro lado, talvez as diferenças em relação aos resultados de Kelly, Loomis e Beall (2004) se devam às características próprias implícitas em cada tarefa. No caso destes últimos autores, os observadores consideravam dois alvos fixos e projetavam mentalmente a linha de colinearidade até um terceiro ponto. Diferentemente, da tarefa empregada por nós, onde os sujeitos tinham que alinhar quatro estímulos mexendo na posição de dois deles, o que implicaria um grau de dificuldade diferente por ser uma tarefa guiada visualmente.

Segundo indicam os dados, em nosso experimento a variação nas proporções das distâncias egocêntricas estaria relacionada com o ângulo na orientação dos estímulos, observando-se erros constantes específicos para cada diagonal, de acordo com Levin e Haber (1993). Estes notaram que a distância exocêntrica apresenta uma distorção que depende do ângulo entre os objetos considerados. Assim, enquanto Cuijpers, Kappers e Koenderink (2000a) encontraram uma simetria direita-esquerda na anisotropia do espaço visual, na presente investigação apreende-se que os erros são similares por diagonal e não por metade do campo visual (Figura 15). Ainda, estes autores asseguraram que os desvios da acurácia se reduzem quando os ângulos entre os objetos são amplos. Isto parece dever-se à falta de sensibilidade da tarefa de apontamento exocêntrico para julgar distâncias com este tipo de ângulos, obtendo dados similares com tarefa de paralelismo (CUIJPERS; KAPPERS; KOENDERINK, 2000b). De forma similar, encontramos uma relação inversamente proporcional entre os ângulos visuais e os erros de colinearidade cometidos. Mas é importante notar que no layout utilizado as posições dos estímulos levam à existência de uma dependência do ângulo visual entre pares de estímulos com as respectivas distâncias egocêntricas.

As pequenas variações na distância exocêntrica percebida e a relação dos erros cometidos com as distâncias egocêntricas indicariam que o marco de referência eliciado 


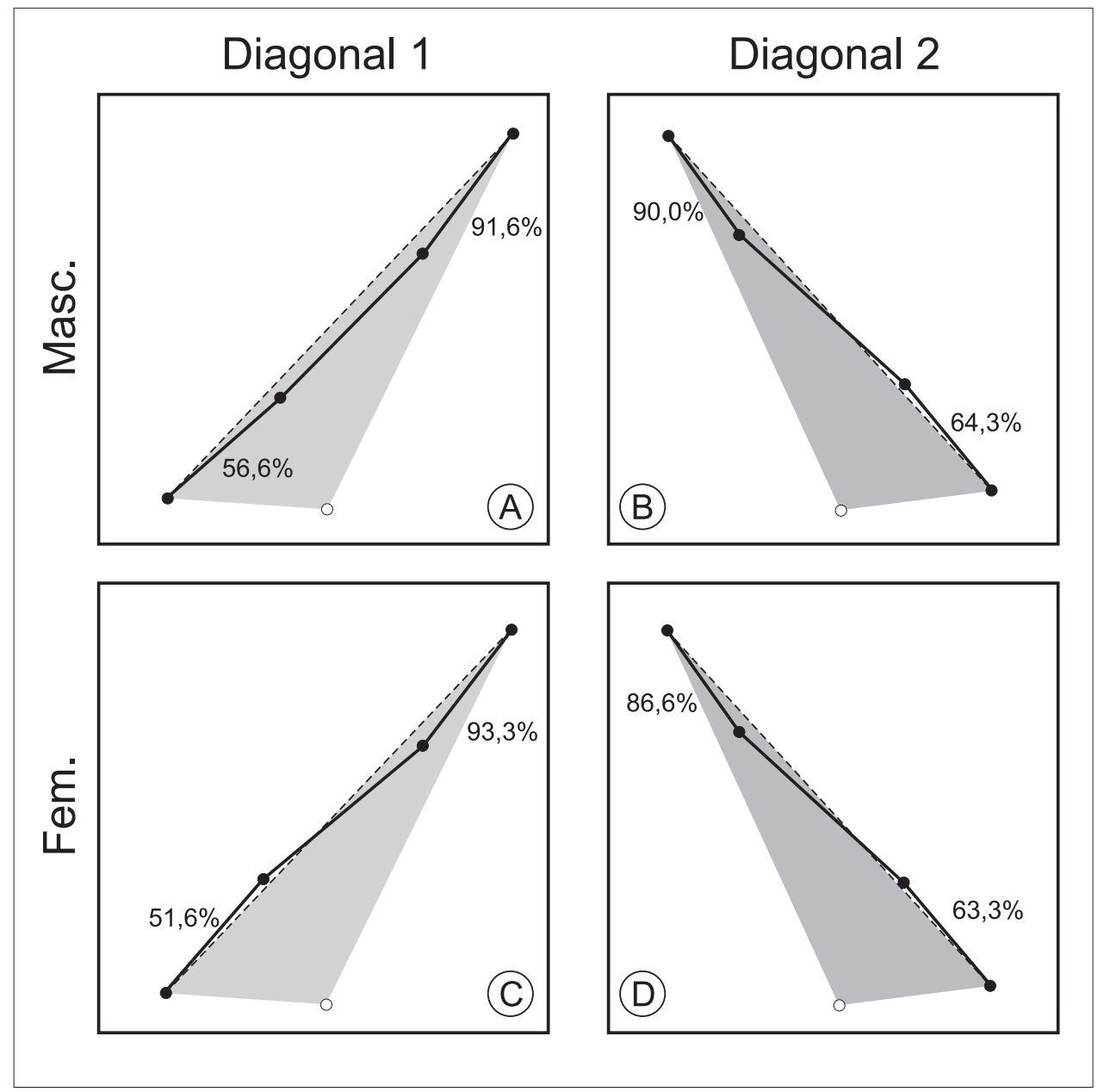

Figura 17 - Orientações mais freqüentes dos estímulos em função da linha de colinearidade e do sexo do observador. Os círculos preenchidos representam os estímulos, e o círculo vazado a posição do observador.

por esta configuração de estímulos, embora possa estar baseado nos indícios exocêntricos, é escalado por um fator egocêntrico, como encontrado por Aznar-Casanova et al. (2008), e fora proposto por Foley (1980) e Foley, Ribeiro-Filho e Da Silva (2004). Isto também indicaria que nosso sistema visual não precisa processar a informação de distância exocêntrica para produzir estimações de orientação exocêntrica quando a informação de perspectiva está presente (caso contrário ver Aznar-Casanova, Matsushima, Da Silva e Ribeiro-Filho (2008)).

Além das diferenças individuais entre os observadores ${ }^{6}$, assim como Koenderink et al. (2008) encontramos que, em geral, os pares de posições determinadas com os estímulos móveis falham em definir um arco simples, isto é, um arco cuja curvatura não muda de sinal. Pelo contrário, a tendência é de aparecer um ponto de inflexão entre

\footnotetext{
${ }^{6}$ Também notadas em outros tipos de tarefas 3D no campo aberto, ver por exemplo os trabalhos de Norman, Todd, Perotti e Tittle (1996), Norman, Crabtree, Clayton e Norman (2005)
} 
os pontos extremos do arco apresentado um formato de "S". Estes autores acharam que as médias dos posicionamentos na maioria dos casos (91\%) estabelecem arcos com o segmento próximo ao observador apontando no sentido oposto a ele e com o segmento distante apontando para ele. Os resultados de nosso experimento mostram um padrão similar para os ângulos e distâncias empregados. Na Figura 17 se desenham, a modo de exemplo, as orientações mais freqüentes. Empregam-se segmentos retos para simplificar. Pode ser observado que na maioria dos casos as porcentagens indicam a característica configuração em forma de " $\mathrm{S}$ " (obviamente são possíveis outras combinações de orientações além das representadas). O gráfico (A) mostra o caso onde os segmentos estão orientados do mesmo lado -ou forma de " $\mathrm{C}$ "-, entretanto, os gráficos (B), (C) e (D) apresentam alternâncias que derivam na forma de " $\mathrm{S}$ ".

A alta percentagem de arcos pregeodésicos encontrados (KOENDERINK et al., 2008) (que apareceriam na Figura 17 como linhas quebradas) mostrariam a anisotropia do espaço visual, apoiando a hipótese da não homogeneidade do mesmo.

Uma pergunta óbvia que aparece ao olhar a configuração de estímulos empregada seria: "Que aconteceria se aumentado o número de segmentos, e introduzida ao mesmo tempo, uma referência relevante no layout?". Tal indagação foi testado e desenvolvida no Experimento II.

\subsection{Experimento II}

Este experimento mostra-se similar ao Experimento I. Os observadores determinaram a colinearidade de dois conjuntos de estímulos espalhados no campo aberto, mas neste caso em particular, o centro da configuração foi marcado com um alvo fixo. O objetivo, portanto, foi avaliar se esta informação ajudava no momento de efetuar os ajustes de colinearidade. Além de representar uma referência importante, este estímulo produziria uma redução no tamanho virtual dos segmentos $\overline{M 1 M 2}$ e $\overline{M 3 M 4}$ ao dividi-los em dois e fornecer um ponto de equilíbrio entre eles.

\subsubsection{Método}

\subsubsection{Participantes}

Do número total de observadores $(\mathrm{N}=30)$ que participaram do Experimento I, 18 destes colaboradores (nove mulheres e nove homens) foram escolhidos aleatoriamente 
(em função de protocolos marcados por um sorteio prévio, efetuado no momento de delinear os Experimentos I e II) e eram solicitados a realizar a posteriori o Experimento II.

\subsubsection{Ambiente experimental}

Foi utilizado o mesmo ambiente experimental do Experimento I.

\subsubsection{Equipamentos e materiais}

Os estímulos móveis e fixos foram os mesmos do Experimento I, adicionalmente foi agregado mais um alvo fixo marcando o centro da configuração, sendo este instalado a 12 m na frente do observador (ver Figuras 10 e 11).

\subsubsection{Planejamento experimental}

Foi empregado um planejamento fatorial similar ao do Experimento I, pois o objetivo foi comparar os resultados de ambos padrões de estímulos. Assim, foram empregados um fator intra-sujeitos, duas direções de ajustamento (ponto de inicio) e duas séries de estimativas, considerando como variável dependente o erro no ajuste de colinearidade.

\subsubsection{Procedimento}

Concluído o Experimento I, os observadores realizavam uma outra tarefa breve. Logo, após de um intervalo de descanso para evitar o efeito "carry-over" (ATKINSON, 1966), os observadores foram solicitados a repetir a tarefa do experimento I. Foi explicitado que o novo alvo fixo marcava o centro da configuração e que a tarefa continuava sendo alinhar os alvos móveis de forma que ficassem colineares com os alvos fixos.

As análises mostraram no Experimento I que o efeito de ordem nas medições não foi significativo, portanto, repetir de novo a tarefa não deveria ser afetado pelos julgamentos prévios. Embora possa existir um efeito da prática por parte dos observadores, tal efeito poderia se manifestar no tempo de execução da tarefa mais que na precisão dos ajustes. Acredita-se que por ser esta uma tarefa guiada visualmente, o fator memória não teria tanto peso, ainda mais que a introdução de um novo elemento 
Tabela 5 - Erros de colinearidade relativos ao Experimento II ( $\mathrm{N}=288$ ) com os dados dos observadores nas duas condições: Sem e Com estímulo central. Reportam-se os erros médios, desvios-padrão e medianas, todos expressados em centímetros. Os resultados estão discriminados por Estímulo Móvel (1 a 4), Ponto de Inicio da medição (Fora ou Dentro) e Sexo do observador (M ou F).

\begin{tabular}{|c|c|c|c|c|c|c|c|c|}
\hline \multirow[b]{2}{*}{ E. Móvel } & \multirow[b]{2}{*}{ Inicio } & \multirow[b]{2}{*}{ Sexo } & \multicolumn{3}{|c|}{ Sem Estímulo } & \multicolumn{3}{|c|}{ Com Estímulo } \\
\hline & & & Média & SD & Mediana & Média & SD & Mediana \\
\hline 1 & $\mathrm{~F}$ & M & $-5,97$ & 40,40 & $-9,25$ & 7,50 & 22,31 & 4,00 \\
\hline 1 & $\mathrm{~F}$ & $\mathrm{~F}$ & 1,90 & 41,59 & 12,25 & 3,15 & 30,35 & $-7,75$ \\
\hline 1 & $\mathrm{D}$ & M & $-1,75$ & 45,86 & 5,50 & 2,59 & 29,30 & $-0,25$ \\
\hline 1 & $\mathrm{D}$ & $\mathrm{F}$ & $-13,00$ & 33,12 & $-18,50$ & $-10,05$ & 22,73 & $-16,75$ \\
\hline 2 & $\mathrm{~F}$ & M & $-41,47$ & 11,53 & $-41,50$ & $-38,50$ & 28,57 & $-40,25$ \\
\hline 2 & $\mathrm{~F}$ & $\mathrm{~F}$ & $-57,50$ & 25,48 & $-50,50$ & $-45,65$ & 27,23 & $-52,50$ \\
\hline 2 & $\mathrm{D}$ & M & $-33,28$ & 21,34 & $-34,25$ & $-33,28$ & 23,69 & $-40,75$ \\
\hline 2 & $\mathrm{D}$ & $\mathrm{F}$ & $-51,88$ & 33,01 & $-52,50$ & $-44,70$ & 20,33 & $-47,25$ \\
\hline 3 & $\mathrm{~F}$ & M & 19,47 & 42,77 & 12,75 & 11,44 & 26,69 & 10,00 \\
\hline 3 & $\mathrm{~F}$ & $\mathrm{~F}$ & $-0,10$ & 42,74 & 8,50 & 27,26 & 25,03 & 25,25 \\
\hline 3 & $\mathrm{D}$ & M & 14,00 & 47,46 & 12,50 & 3,34 & 26,08 & 0,50 \\
\hline 3 & $\mathrm{D}$ & $\mathrm{F}$ & 0,80 & 46,38 & 7,25 & 7,93 & 23,87 & 14,50 \\
\hline 4 & $\mathrm{~F}$ & $\mathrm{M}$ & $-32,13$ & 28,09 & $-34,75$ & $-33,94$ & 22,52 & $-34,50$ \\
\hline 4 & F & $\mathrm{F}$ & $-37,30$ & 32,47 & $-44,50$ & $-41,73$ & 10,95 & $-39,25$ \\
\hline 4 & $\mathrm{D}$ & $\mathrm{M}$ & $-30,47$ & 20,16 & $-35,50$ & $-24,22$ & 23,87 & $-25,50$ \\
\hline 4 & $\mathrm{D}$ & $\mathrm{F}$ & $-26,58$ & 28,95 & $-30,00$ & $-29,33$ & 19,70 & $-29,00$ \\
\hline All Groups & & & $-18,95$ & 41,34 & $-24,25$ & $-15,08$ & 33,32 & $-18,00$ \\
\hline
\end{tabular}

estaria mudando a configuração espacial de estímulos e, possivelmente, a estratégia de resolução adotada anteriormente.

\subsubsection{Resultados}

Os dados encontram-se dispostos na Tabela 5, onde foram codificados em termos do desvio (em centímetros) da linha de colinearidade para as duas condições: Sem o Estímulo central (SE) e Com Estímulo central (CE).

Ao considerar todos os dados, pode observar-se um erro de colinearidade negativo indicando uma compressão geral da distância percebida, tanto na condição $\mathrm{SE}$ (média $=-18,95$, mediana $=-24,25)$ como na condição $\mathrm{CE}$ (média $=-15,08$, mediana $=-18,00)$. Os resultados dos dados desagregados por trilho e sexo dos observadores estão sumariados nas Figuras 18 e 19, ambas desenhadas na mesma escala 


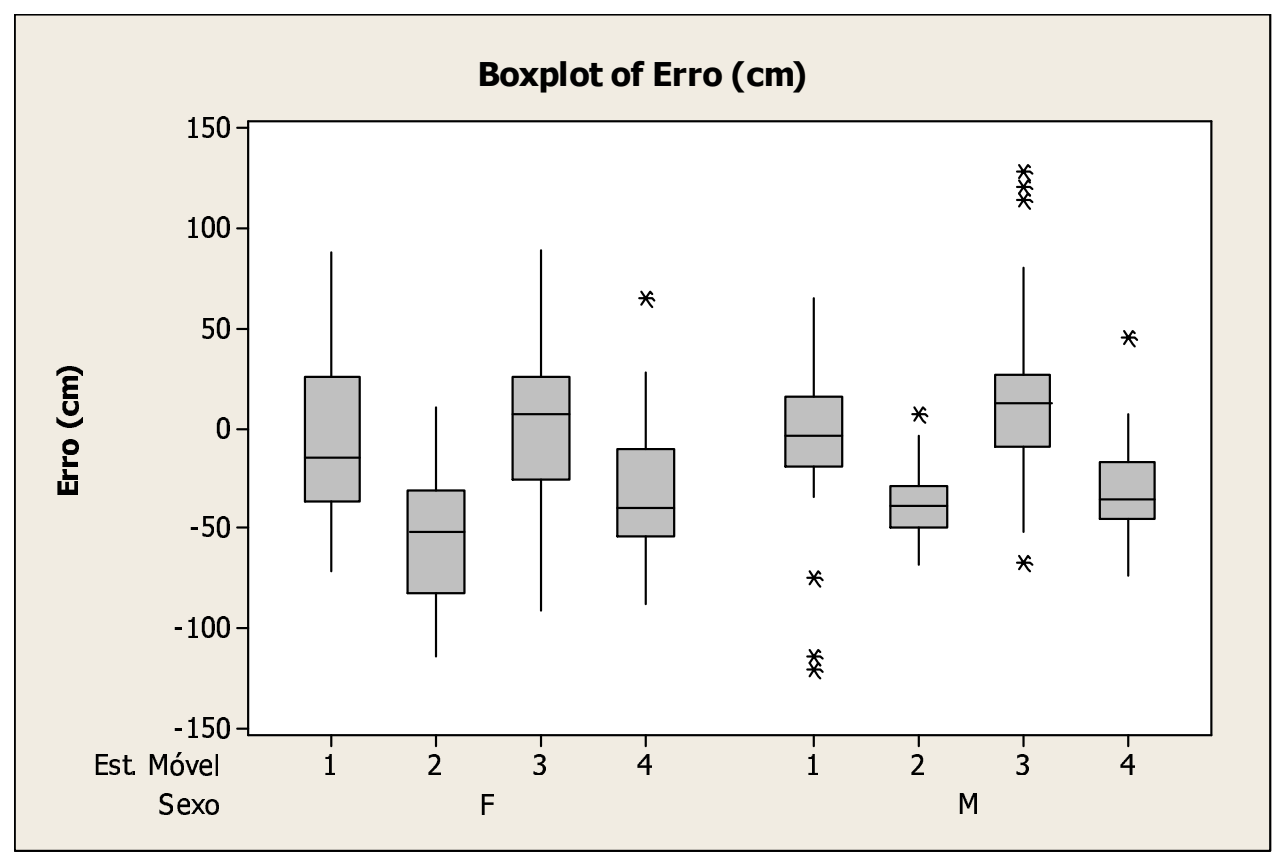

Figura 18 - Boxplot dos erros (em centímetros) cometidos no ajuste de colinearidade sem estímulo central, separados por posição espacial (estímulo móvel) e por sexo do observador. $(\mathrm{N}=18)$

que a Figura 12.

O boxplot permitiu identificar os outliers (Indicados com um ' $*$ ' nas figuras) no grupo para ambas condições (SE e CE), os quais foram removidos dos dados antes da análise estatística aplicando o mesmo critério do Experimento I. É importante notar que, entanto na condição SE os outliers se distribuem em positivos e negativos, na condição CE os outliers só apresentam sinal positivo. Uma vez analisada a normalidade das observações (condição SE: Kolmogorov-Smirnov $D=0,06, p>0.20$; condição CE: Kolmogorov-Smirnov $D=0,07, p<0,20)$ se realizou um estudo sobre a igualdade na variância dos erros segundo trilho, o sexo do observador e o ponto de início das mesmas empregando intervalos de Bonferroni do 95\%. Em todos os casos não houve diferenças entre as variâncias $(p>0.05)$.

No caso da condição SE, a ANOVA sobre os dados obtidos, isto é os erros na colinearidade do sub-grupo, considerando o planejamento Estímulo Móvel (1 a 4) x Sexo do observador (M ou F) x Ponto de inicio da medição (Fora ou Dentro), encontra efeitos significativos para os fator principal Estímulo Móvel $\left(F_{(3,272)}=34,88, p<0,001\right)$, coerentemente com o que acontecia no grupo maior considerado no Experimento I. Mas aparecem aqui diferenças devido ao Sexo do observador $\left(F_{(1,272)}=4,58\right.$, $p<0,05)$. As interações entre os fatores não reportaram efeitos significativos. Para o fator 'Estímulo Móvel', o teste de Newman-Keuls apontou diferenças significativas 


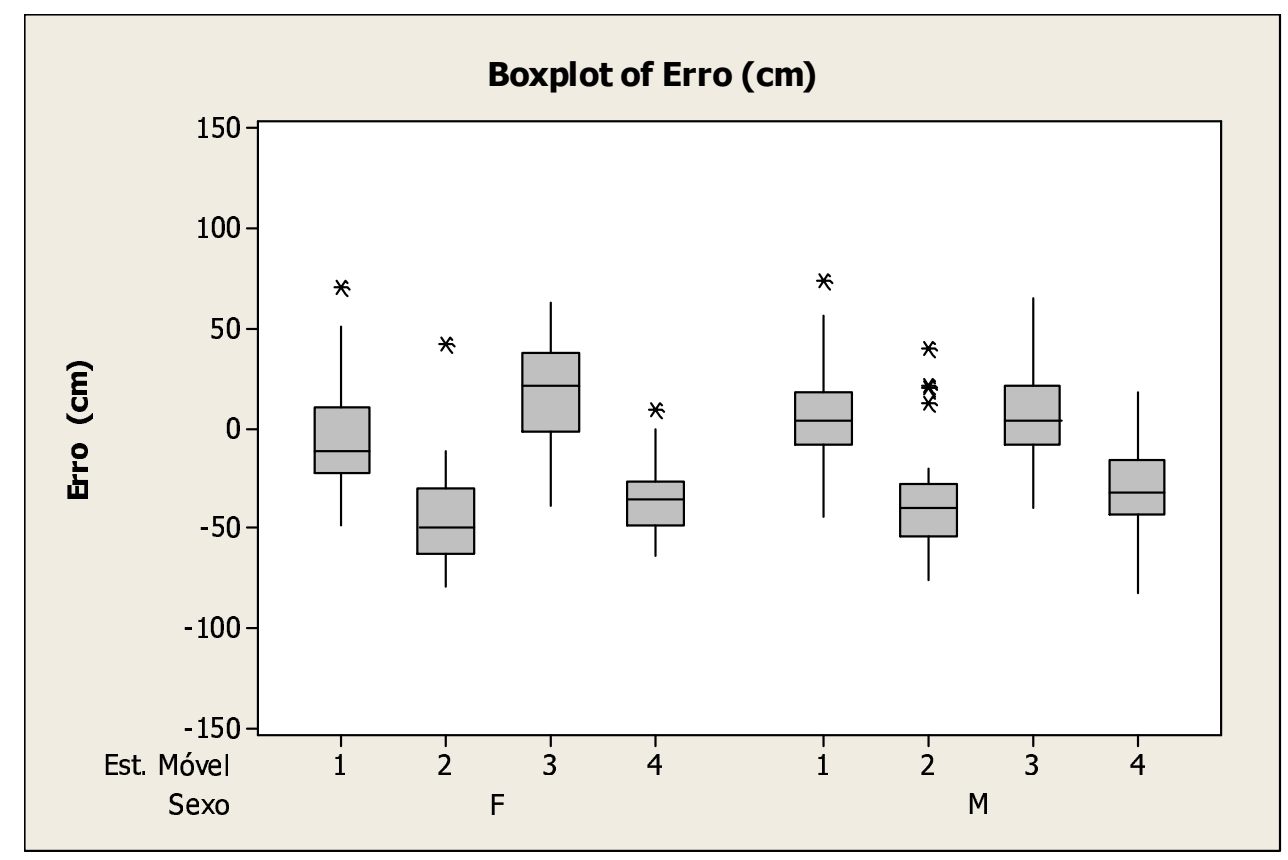

Figura 19 - Boxplot dos erros (em centímetros) cometidos no ajuste de colinearidade com estímulo central, separados por posição espacial (estímulo móvel) e por sexo do observador. $(\mathrm{N}=18)$

entre todas as condições $(p<0,05)$, e para o fator 'Sexo do observador' a diferença significativa entre os julgamentos de homens e mulheres se encontra no Estímulo Móvel $2(p<0,05)$.

Para a condição CE, a ANOVA sobre os dados obtidos -considerando o mesmo planejamento que na condição anterior-, revelou a presença de efeitos significativos só para o fator principal 'Estímulo Móvel' $\left(F_{(3,272)}=78,99, p<0,001\right)$ e para a interação 'Estímulo Móvel*Ponto Inicio' $\left(F_{(3,272)}=3,87, p<0,01\right)$. Uma análise póshoc, usando o teste de Newman-Keuls indicou diferenças significativas entre todas as posições $(p<0,05)$-como sucedia na condição SE-, e no caso da interação 'Estímulo Móvel*Ponto Inicio' as diferenças significativas foram evidenciadas para os Estímulos posicionados na Diagonal 2, o seja, no Estímulo M3 ( $p<0,01)$, e no Estímulo M4 $(p<0,05)$, segundo pode ser observado na Figura 20.

\subsubsection{Discussão}

Os resultados indicariam uma redução na magnitude do erro na condição CE, a qual seria levemente inferior à observada no Experimento I. O fato mais interessante é a redução nos desvios padrão, o que indicaria uma melhora na acurácia dos ajustes. Ainda assim, realizando uma comparação usando a prova $t$ para mostras dependentes 


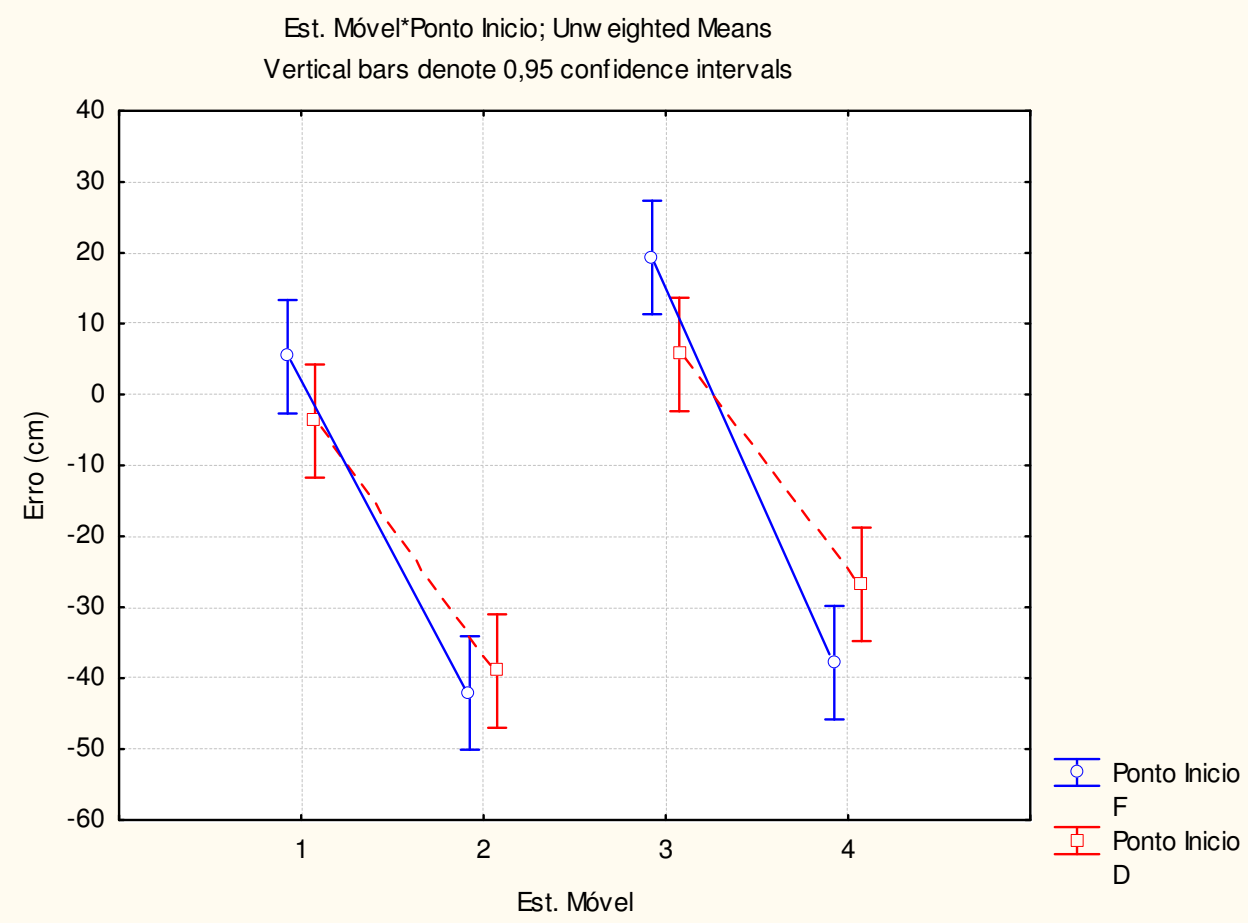

Figura 20 - Médias dos erros (em centímetros) cometidos no ajuste de colinearidade separados por posição espacial (Estímulo Móvel) e por Ponto de Início da medição (Fora ou Dentro). As barras verticais denotam o intervalo de confidência do $95 \%$.

obtemos que as diferenças não são significativas estadísticamente $(t=-1,858, p>$ 0,05), o que pode ser observado na Figura 21.

Se comparados com os dados do Experimento I, a presença do pólo marcando o centro da configuração não contribui em grande medida, talvez porque os observadores já estiveram realizando a tarefa a partir das referências brindadas pelos estímulos extremos da reta. Pôde ser notado nos resultados que os sujeitos organizam a configuração de estímulos em função da proximidade entre os estímulos fixos e móveis, seguindo o principio da proximidade expressado pela teoria da Gestalt (KOFFKA, 1975), o que aparentemente não é alterado pela presença do estímulo central.

Assim, o aumento do número de segmentos determinados pelas estacas não complicou o esquema, pelo contrário, a marca no centro da configuração ajudou a melhorar os julgamentos, o que pode ser notado na redução dos desvios padrão, desaparecendo, também, a diferença entre os julgamentos de homens e mulheres encontrado na condição SE para o segmento posicionado na parte distal direita. Por outro lado, parece que devido a este novo elemento o Ponto de Início (onde era situado o alvo móvel no início da medição) passa a ter relevância ao posicionar os estímulos móveis 


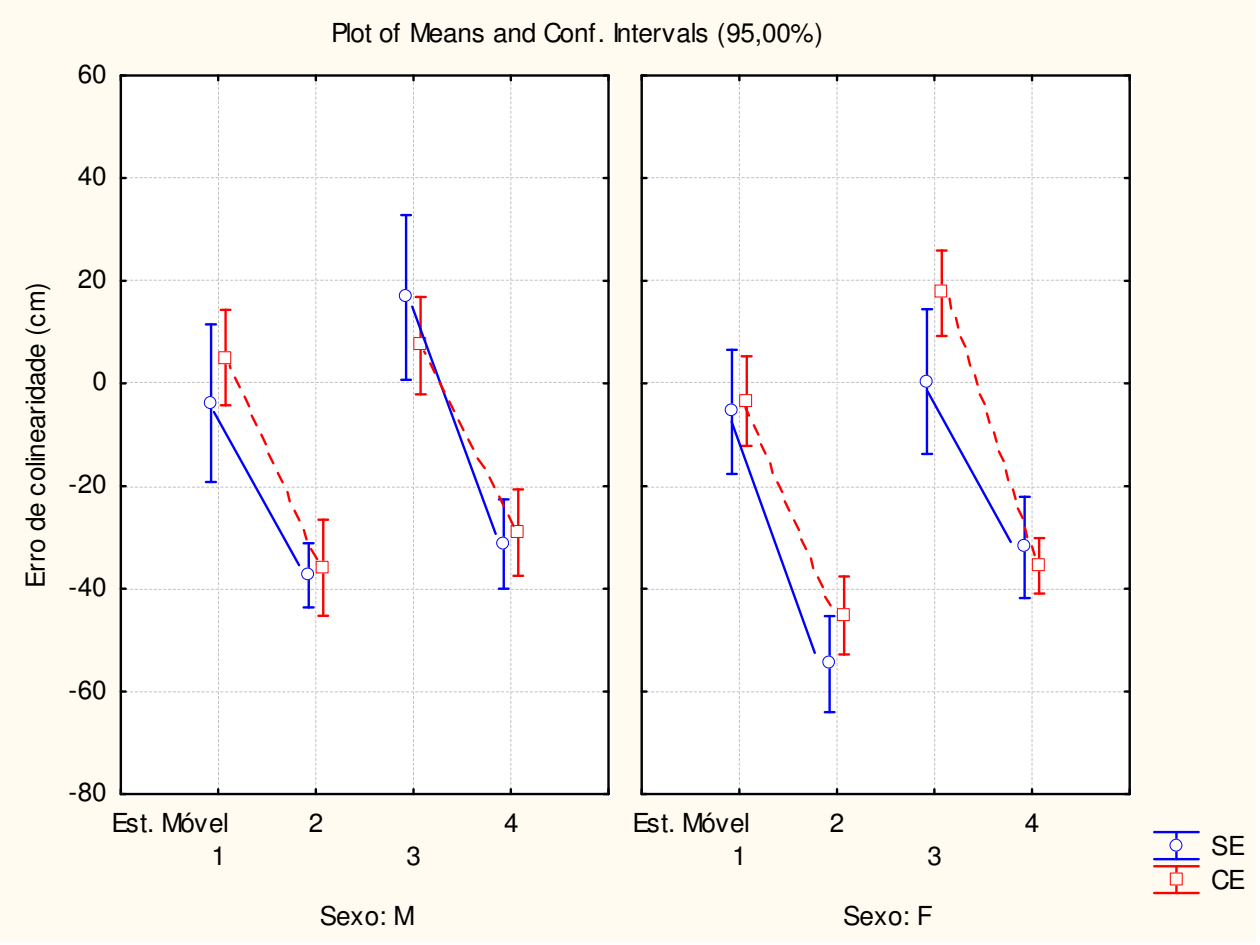

Figura 21 - Médias dos erros (em centímetros) e seus respectivos intervalos de confidência (barras verticais) separados por posição espacial (Est. Móvel) e por Sexo dos observadores nas duas condições avaliadas (SE e CE).

da Diagonal 2, cometendo erros menores ao começar de Dentro, especialmente no estímulo M3.

Ao calcular os erros angulares dos segmentos orientados do mesmo modo que Kelly, Loomis e Beall (2004) (ver página 87), observamos que os valores das condições $\mathrm{SE}$ e CE são muito próximos (com uma $\Delta_{\text {ang }}$ média de $0,7^{\circ}$ ), segundo pode ser apreciado na Tabela 6, com as diferenças menores para os estímulos da Diagonal 2. Esta semelhança também foi notada quando comparados com os valores do Experimento I.

Tabela 6 - Resultados dos erros de colinearidade para ambas condições expressados em valores angulares (graus) seguindo a convenção de cálculo de Kelly, Loomis e Beall (2004)

\begin{tabular}{cccc}
\hline Est. Móvel & Erro s/estímulo $\left(^{\circ}\right)$ & Erro c/estímulo $\left({ }^{\circ}\right)$ & $\Delta_{\text {ang }}$ \\
\hline 1 & 1,27 & 0,22 & 1,48 \\
2 & 7,65 & 6,75 & 0,90 \\
3 & $-1,22$ & $-1,79$ & 0,57 \\
4 & 6,01 & 6,15 & $-0,14$ \\
\hline
\end{tabular}


Quando analisadas as posições dos estímulos na configuração CE, seguindo a proposta de Koenderink et al. (2008), apareceram duas possibilidades interessantes. A primeira, aparece no caso que os estímulos móveis ficaram ajustados em lados opostos da reta de colinearidade geométrica. Esta situação torna evidente a necessidade do modelar a linha de colinearidade usando 'arcos pregeodésicos' com o ponto de inflexão situado no alvo central, o que pode ser observado na Figura 22. A segunda possibilidade emerge quando os estímulos móveis foram ajustados do mesmo lado da linha de colinearidade. A análise neste caso, aparece mais complicada, cabendo duas alternativas: a) o arco apresenta uma forma de " $\varepsilon$ ", unindo todos os estímulos mas é preciso usar mais de um ponto de inflexão para lograr o ajuste; ou b) devem ser considerados dois arcos, um para cada extremo da reta, cada qual passando por os dois estímulos e se juntando no alvo central.

\subsection{Discussão Experimentos I e II}

Nesta Seção foi investigado o desempenho dos observadores numa nova variante de tarefa de apontamento exocêntrico baseada na colinearidade. O ambiente experimental escolhido foi o campo aberto, sem restrições de indícios, com todos os estímulos presentes simultaneamente e estabelecendo ângulos visuais que abarcavam o campo visual efetivo dos sujeitos (KOENDERINK; VAN DOORN; TODD, 2009).

A similaridade dos padrões de erro encontrados nos experimentos com os descritos por outros autores (p.e. Cuijpers, Kappers e Koenderink (2000a, 2002), Kelly, Loomis e Beall (2004), Koenderink et al. (2008)) sugere que a tarefa utilizada neste trabalho estaria baseada no mesmo tipo de julgamento exocêntrico de direção. Kelly, Loomis e Beall (2004) destacaram a simplicidade como uma das vantagens deste tipo de tarefa de colinearidade, mas encontraram na determinação do ponto final um problema potencial de seu método. No nosso caso, além da configuração ter definido o ponto final, o que permite uma melhor e mais confiável análise dos dados, o método baseado no ajuste da posição dos estímulos móveis foi de extrema simplicidade. Isto daria aos sujeitos bom controle da sua resposta, tal como aconteceu com o sistema empregado por Koenderink et al. (2008), contudo sem ter o problema enfrentado por eles com o escalonamento no tamanho dos ponteiros e alvos. Nossas observações, coletadas de maneira informal ao final das medições, indicaram que nenhum dos observadores encontrou dificuldade em realizar a tarefa e que todos acharam interessante o sistema para indicar sua resposta. Em casos onde a percepção de distância 


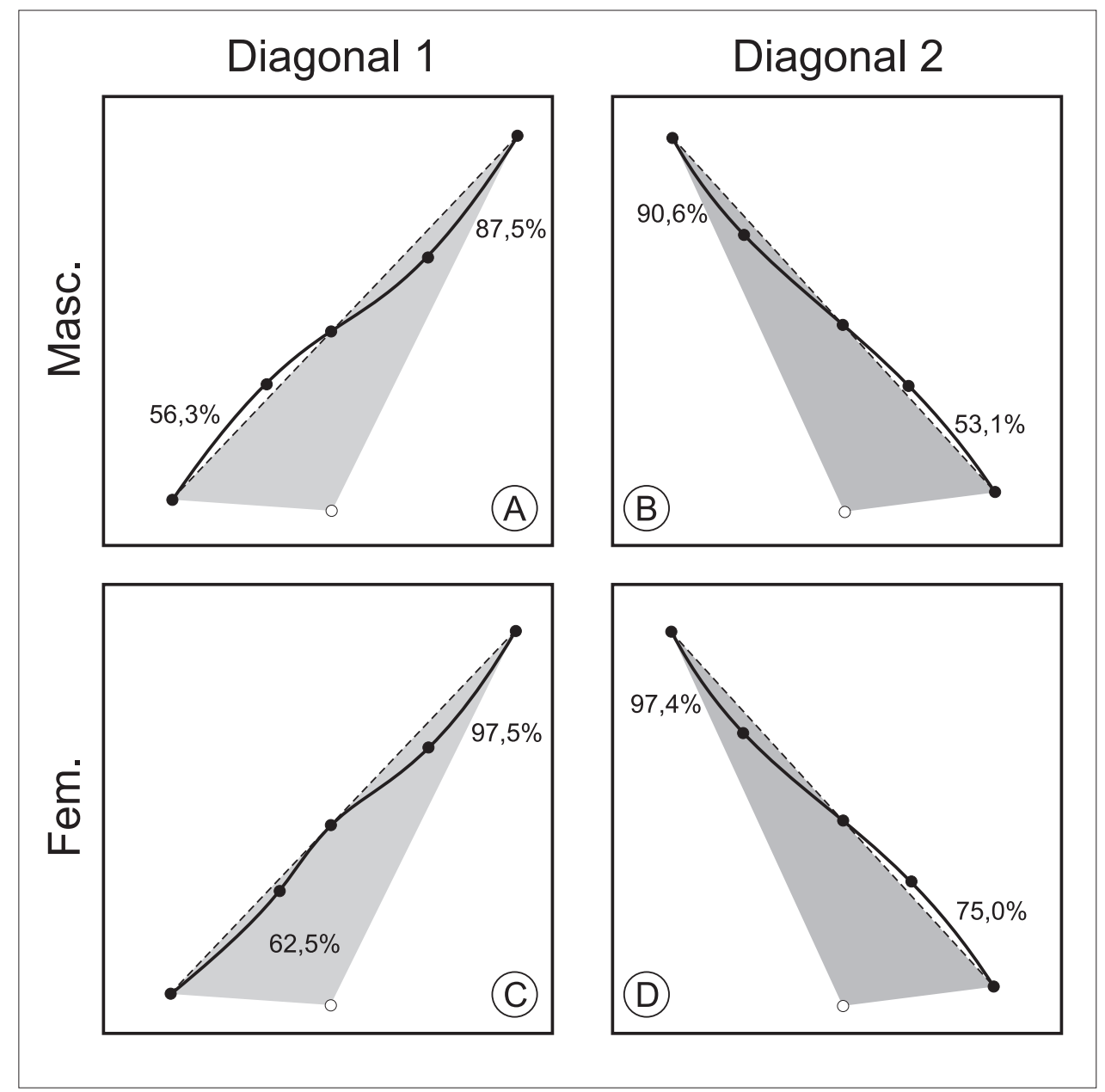

Figura 22 - Orientações mais freqüentes dos estímulos para a condição CE, em função da pertença à linha de colinearidade e do sexo do observador. Os círculos preenchidos representam os estímulos, e o círculo vazado a posição do observador. Empregam-se arcos 'pregeodésicos' para modelar as linhas de colinearidade percebida (KOENDERINK et al., 2008) em (A), (B), (D). No gráfico $(\mathrm{C})$ precisa-se de mais de um ponto de inflexão para conseguir o ajuste. 
é escalada linearmente (como acontece em ambientes plenos de indícios visuais), os julgamentos baseados em colinearidade se projetam como o método mais promissório de resposta para avaliar a direção exocêntrica percebida (KELLY; LOOMIS; BEALL, 2004). Mais experimentos serão necessários para definir os alcances e as limitações desta metodologia, tanto no campo aberto como no laboratório.

Em ambos Experimentos I e II foi evidenciada uma forte dependência dos erros em função da distância egocêntrica considerada, no entanto, agregar mais um estímulo fixo -com a conseqüente redução das distâncias exocêntricas interestímulosnão produz diferenças significativas nos resultados, aparecendo só uma melhora na acurácia dos ajustes. Por outro lado, as diferenças significativas (em ambos experimentos) dos erros segundo a Posição do estímulo móvel, isto é sua dependência de uma das Diagonais, poderia estar indicando a influência do contexto no julgamento da direção exocêntrica, o que já havia sido demonstrado experimentalmente por Schoumans, Koenderink e Kappers (2000). Assim, o padrão de erros nos Experimentos I e II sugeriria que o marco de referência eliciado por esta configuração de estímulos poderia estar baseado nos indícios exocêntricos, mas estar sendo escalado por um fator egocêntrico tal como proposto por Foley (1980) e Foley, Ribeiro-Filho e Da Silva (2004) e confirmado pelos dados de Aznar-Casanova et al. (2008). A possibilidade de que nosso sistema visual calcule o ajuste grosso da distância a partir da distância absoluta (egocêntrica) e o ajuste fino usando as distâncias relativas (exocêntricas) sinalizaria que, em primeira instância, não precisaria da distância exocêntrica para produzir julgamentos de orientação exocêntrica quando a informação de perspectiva esta presente (AZNAR-CASANOVA; MATSUSHIMA; DA SILVA; RIBEIRO-FILHO, 2008), tal como acontece com a disposição de estímulos empregada.

Embora a maior parte dos dados de Cuijpers e colaboradores tenham sido coletados em distâncias inferiores aos 6 m (CUIJPERS; KAPPERS; KOENDERINK, 2000a, 2000b, 2002), Kelly, Loomis e Beall (2004) encontraram resultados similares ao do estudo discutido empregando julgamentos exocêntricos no campo aberto com distâncias entre 5 e 20 m, o que é confirmado pelos dados de Koenderink et al. (2008) com distâncias até $32 \mathrm{~m}$. Nossos resultados, empregando distâncias entre 6 e $28 \mathrm{~m}$ e uma configuração espacial de estímulos diferente dos trabalhos citados previamente, reforçariam esta mesma tendência achada tanto no laboratório como no campo aberto, observando-se uma compressão geral da distância percebida. Quando considerados os estímulos mais distantes ao observador, estas respostas de sub constância mostram uma freqüência alta, segundo os dados geralmente maior ao $87 \%$. 
Esta anisotropia do espaço visual encontrada nos presentes Experimentos é similar à reportada por Koenderink et al. (2008), mostrando que os ajustes de colinearidade (linhas retas) resultam em violações à hipótese da existência de arcos geodésicos simples entre dois pontos quaisquer, aparecendo no espaço físico como linhas retas quebradas ou arcos pré-geodésicos com pontos de inflexão de posição variável. Este fato é de considerável interesse, pois levaria a descartar geometrias constantes para modelar o espaço visual, tal como aconteceria com a proposta de Luneburg (LUNEBURG, 1947), ou inclusive poder ser caracterizado exclusivamente por uma geometria particular (LUKAS, 2001; NORMAN; CRABTREE; CLAYTON; NORMAN, 2005). A proposta de Koenderink et al. (2008) seria de postular o espaço como 'contextual' (dependente do que estaria presente nele), ou 'momentâneo' (dependente de onde o observador esta posicionado no espaço), ou 'dependente da tarefa' (o que já tinha sido notado por Norman, Crabtree, Clayton e Norman (2005)), ou talvez de combinações destas possibilidades. Foley, Ribeiro-Filho e Da Silva (2004) também concluíram no seu estudo que "mesmo que a percepção da posição e de extensão estejam relacionadas, não estão por uma geometria Euclidiana ou por qualquer geometria métrica".

Sem embargo, a noção do espaço visual variando em função das condições de visão e das exigências da tarefa não é paradoxal, especialmente, considerando os dados psicobiológicos que mostram a estrutura anisotrópica do sistema visual, a falta de uniformidade no campo visual (FUKUSIMA; FAUBERT, 2001; SAKAGUCHI, 2003) e a capacidade do sistema visual de atribuir pesos diferentes a uma mesma fonte de informação para situações diferentes de disponibilidade de indícios visuais (CUTTING; VISHTON, 1995; GUILLIAM, 1995; PHILBECK; LOOMIS, 1997). De acordo com a perspectiva representacionista, um espaço visual isomórfico e homogêneo só poderia derivar de uma construção no percurso do tempo, incluindo nesta montagem as variações instantâneas de direções de observação devido a movimentos oculares, da cabeça, do corpo, dos objetos na cena, etc. Esta construção discreta e serial necessariamente involucraria processos de memória e cognitivos (HOLLINGWORTH; HOLLINGWORTH, 2004; PERTZOV; AVIDAN; ZOHARY, 2009). 


\section{$5 \quad$ Testagem de modelos teóricos}

"Modelagem é um processo que envolve observação de um fenômeno, conjeturando relacionamentos, aplicando análises matemáticas [...], obtendo resultados matemáticos, e reinterpretando o modelo" (LINGEFJÄRD, 2006, 96)

\subsection{Modelo de Foley et al. (2004) e suas conseqüências}

O modelo de distâncias exocêntricas percebidas proposto por Foley, Ribeiro-Filho e Da Silva (2004) (resumido no apartado 2.4) apresenta duas importante implicações para a geometria do espaço visual: a primeira refere-se à "desigualdade do triângulo" e, a segunda, à propriedade de que a distância exocêntrica entre pontos adjacentes, percebidos como colineares, não corresponde à distância percebida entre os pontos extremos.

A primeira implicação diz respeito a uma propriedade fundamental de qualquer métrica espacial, onde dado um triângulo de arestas $a, b$ e $c$, sendo $a$ a aresta mais longa, temos:

$$
a \leq b+c
$$

Se a Equação 2.20 estiver correta e o ângulo visual efetivo $\left(\theta_{i j}^{\prime \prime}\right)$ for suficientemente maior ao ângulo visual físico $\left(\theta_{i j}\right)$, haverá uma violação desta propriedade para triângulos nos quais a compreenda um ângulo visual grande e $b$ e $c$ ângulos visuais pequenos. Na prática, isto pode ser pensado como um triângulo onde o observador fica num vértice e o ângulo visual maior é subtendido por os dois outros pontos. No experimento referido por Foley, Ribeiro-Filho e Da Silva (2004) o maior ângulo visual 
empregado foi de 68, $7^{\circ}$ e a Equação 5.1 foi satisfeita. Entretanto, Kelly, Loomis e Beall (2004) encontraram violações da desigualdade para ângulos maiores que $90^{\circ}$. Dado que a violação da desigualdade do triângulo excluiria todas as geometrias do espaço visual baseadas em geometrias métricas, tanto euclidianas como riemannianas, é fundamental testar esta conseqüência do modelo.

A segunda implicação se refere ao fato de que, dado um conjunto de três ou mais objetos no ambiente os quais estejam arranjados de modo a serem percebidos como colineares, a soma das distâncias exocêntricas percebidas determinadas pelos segmentos de reta adjacentes não se igualaria à distância exocêntrica percebida entre os pontos mais extremos (Figura 23).

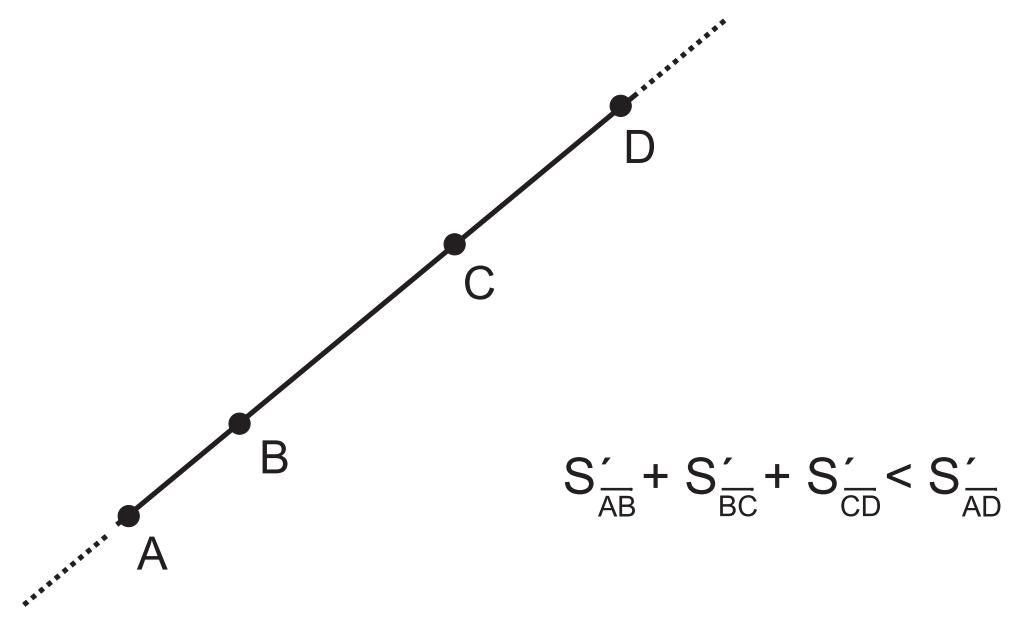

Figura 23 - Para pontos perceptualmente colineares, $A, B, C$ e $D$, a soma das distâncias percebidas entre os segmentos determinados pelos pares de pontos $\overline{A B}, \overline{B C}, \overline{C D}$, não é igual à distância percebida entre os pontos extremos $A$ e $D$ (segmento $\overline{A D}$ ).

\subsection{Experimento III}

O propósito deste experimento foi fornecer mais informação sobre as anisotropias do espaço visual encontradas nos Experimentos I e II, usando a mesma configuração de estímulos.

Neste experimento, os observadores estimaram verbalmente as distâncias egocêntricas e exocêntricas dos estímulos da configuração espacial resultante do Experimento I. Como discutido na seção 4.4, existem várias possibilidades de linhas de 
colinearidade perceptual. Frente ao exposto, consideramos os ajustes indicados como os estatisticamente mais prováveis.

\subsubsection{Objetivos}

Os objetivos foram: a), examinar as respostas e o desempenho dos observadores ante dita configuração de estímulos; b), logo de modelar os dados usando o Tangle, verificar se houve violação das implicações do modelo proposto por Foley, RibeiroFilho e Da Silva (2004).

\subsubsection{Método}

\subsubsection{Participantes}

Vinte observadores (metade do sexo masculino, metade do sexo feminino), alunos de cursos de graduação e pós-graduação da FFCLRP, participaram do experimento. O intervalo de idades foi de 22 a 35 anos, com uma média para as mulheres de $25 \pm 3$ anos e de $28 \pm 4$ anos para os homens, dando uma média geral de $26 \pm 4$ anos. Todos eram ingênuos quanto à naturaleza do experimento e não tinham participado dos Experimentos anteriores. Igualmente, todos apresentavam visão normal ou corrigida a normal.

\subsubsection{Ambiente experimental}

Foi utilizado o mesmo ambiente experimental do Experimento I.

\subsubsection{Equipamentos e materiais}

Todos os estímulos se encontravam fixos. Os situados nos extremos das duas linhas de colinearidade (F1 e F2, F3 e F4) foram os mesmos do Experimento I, entretanto que os estímulos M1, M2, M3 e M4 foram fixados nas centróides resultantes dos ajustes realizados em dito experimento. Lembramos que para simplificar, nos referiremos às duas linhas de estímulos (perceptualmente) colineares como "Diagonais", estando a Diagonal 1 composta pelos estímulos F1, M1, M2 e F2, e a Diagonal 2 pelos estímulos F3, M3, M4 e F4, respectivamente.

Para a condição Com Referência era colocado a 1,5 m na frente do observador um 
par de segmentos de acrílico colorido, cada um de $1 \mathrm{~m}$ de comprimento, formando um ' $\mathrm{T}$ ' invertida. A comparação das estimativas com um padrão (standard) conhecido é relevante, e estaria em conformidade com a metodologia aplicada por Foley, RibeiroFilho e Da Silva (2004).

Com o intuito de assegurar que todos os observadores vissem a configuração de estímulos do mesmo ângulo de visão, foi empregado o mesmo suporte de queixo do Experimento I ajustado a uma altura de 1,35 m.

\subsubsection{Planejamento experimental}

A distância física, seja egocêntrica ou exocêntrica e a condição de observação foram os fatores intra-sujeitos, considerando como variável dependente as estimativas verbais de distância egocêntrica de cada estímulo (totalizando 8 estimativas), de distância exocêntrica dos pares de estímulos para cada diagonal (8 estimativas) e entre os estímulos de ambas no plano frontoparalelo (4 estimativas), realizadas nas duas condições Sem ou Com Referência de distância. As distâncias foram aleatorizadas dentro de cada serie de estimativas. Igualmente, os observadores foram divididos aleatoriamente em duas metades, realizando uma delas primeiro a tarefa Sem referência e depois Com referência, enquanto que a outra metade as realizou na ordem inversa. $\mathrm{O}$ sexo dos observadores foi considerado como fator inter-sujeitos nas análises.

\subsubsection{Resultados}

\subsubsection{Distâncias egocêntricas}

Os resultados dos julgamentos de distância egocêntrica foram sumariados nas Tabelas 7 e 8, onde encontram-se indicam as médias, os desvio-padrão e as medianas, agrupados para cada serie de estímulos. Ao lado do nome de cada estímulo se encontra a respectiva distância física em metros.

Pode-se observar para ambas condições (Sem e Com referência), uma compressão das estimativas. Da mesma maneira que reportam Foley, Ribeiro-Filho e Da Silva (2004), todas as medianas das estimativas apresentaram valores menores que as respectivas distâncias físicas. Aparecem, também, em ambas condições erros sistemáticos, os quais indicam um aumento da variabilidade com o incremento da distância física. 
Tabela 7 - Médias, desvios-padrão (SD) e medianas (todos em metros) dos resultados dos julgamentos de distância egocêntrica para os estímulos da Diagonal 1 nas duas condições: Sem e Com referência. Os resultados estão discriminados por Estímulo (distância egocêntrica física entre parênteses) e Sexo do observador (M ou F).

\begin{tabular}{lcccccccc}
\hline & & \multicolumn{3}{c}{ Sem Referência } & & \multicolumn{3}{c}{ Com Referência } \\
\cline { 8 - 9 } Estímulo & Sexo & Média & SD & Mediana & & Média & SD & Mediana \\
\hline F1 $(6,00)$ & M & 5,05 & 1,71 & 5,00 & & 5,25 & 1,83 & 5,00 \\
F1 $(6,00)$ & F & 3,37 & 0,70 & 3,10 & & 4,42 & 1,05 & 4,75 \\
M1 $(6,03)$ & M & 5,10 & 1,87 & 4,75 & & 5,40 & 1,85 & 5,00 \\
M1 (6,03) & F & 3,40 & 0,84 & 3,00 & & 4,25 & 0,59 & 4,00 \\
M2 (21,43) & M & 17,40 & 6,17 & 15,50 & & 16,45 & 6,39 & 17,00 \\
M2 (21,43) & F & 10,05 & 3,85 & 9,00 & & 11,35 & 3,00 & 11,00 \\
F2 (28,23) & M & 21,90 & 7,20 & 19,50 & & 22,00 & 7,76 & 20,25 \\
F2 $(28,23)$ & F & 13,25 & 4,39 & 12,75 & & 15,15 & 3,09 & 15,00 \\
\hline
\end{tabular}

Tabela 8 - Médias, desvios-padrão (SD) e medianas (todos em metros) dos resultados dos julgamentos de distância egocêntrica para os estímulos da Diagonal 2 nas duas condições: Sem e Com referência. Os resultados estão discriminados por Estímulo (distância egocêntrica física entre parênteses) e Sexo do observador (M ou F).

\begin{tabular}{lcccccccc}
\hline & & \multicolumn{3}{c}{ Sem Referência } & & \multicolumn{3}{c}{ Com Referência } \\
\cline { 8 - 9 } Estímulo & Sexo & Média & SD & Mediana & & Média & SD & Mediana \\
\hline F3 $(6,00)$ & M & 4,55 & 1,32 & 4,50 & & 5,68 & 1,83 & 5,00 \\
F3 (6,00) & F & 3,30 & 1,18 & 3,00 & & 4,70 & 0,79 & 4,50 \\
M3 (8,12) & M & 7,05 & 2,54 & 6,50 & & 7,12 & 2,32 & 6,50 \\
M3 (8,12) & F & 4,55 & 1,36 & 4,25 & & 6,15 & 0,82 & 6,00 \\
M4 (21,55) & M & 17,75 & 6,79 & 17,50 & & 16,95 & 4,73 & 17,50 \\
M4 (21,55) & F & 10,85 & 4,55 & 10,50 & & 11,70 & 2,75 & 11,00 \\
F4 (27,54) & M & 22,10 & 8,33 & 21,00 & & 21,80 & 7,04 & 20,75 \\
F4 (27,54) & F & 13,70 & 4,72 & 13,50 & & 15,05 & 3,02 & 15,00 \\
\hline
\end{tabular}




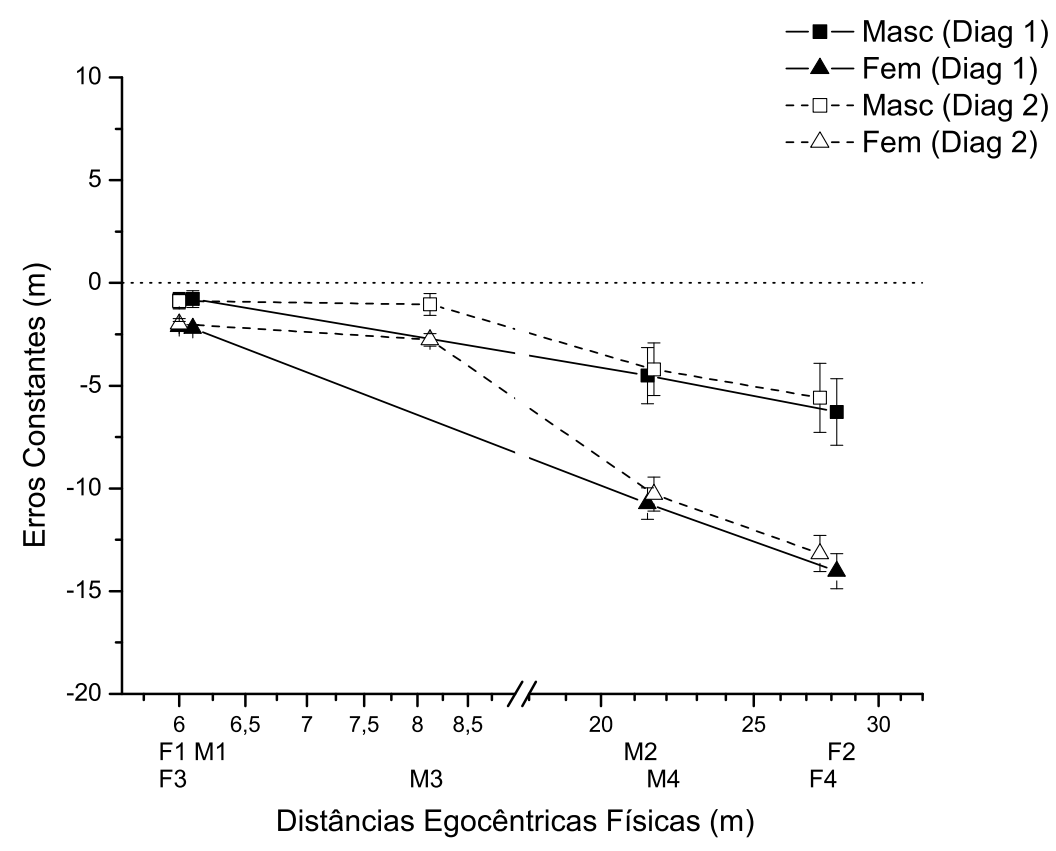

Figura 24 - Médias dos erros constantes (em metros) para os julgamentos das distâncias egocêntricas dos estímulos pertencentes a ambas Diagonais. Os quadrados representam os resultados para os observadores do sexo masculino e os triângulos para os observadores do sexo feminino. As marcas cheias indicam a pertença à Diagonal 1, entanto que as esvaziadas a à Diagonal 2. As barras verticais representam os desvios padrão da média. A linha pontilhada representa a reta de acurácia perfeita da estimativa em relação aos estímulos físicos.

Para uma melhor comparação, as médias das estimativas verbais foram transformadas em erros constantes, que é a diferença entre o valor da distancia percebida $\left(D^{\prime}\right)$ e o valor da distancia física $(D)$ :

$$
\Delta_{\text {constante }}=D^{\prime}-D
$$

onde o sinal negativo nos resultados indicaria que os observadores estariam subestimando as distancias físicas, e, caso seja positivo, que estariam superestimando-as.

A partir da Equação 5.2, na Figura 24 encontram-se desenhados os erros constantes para cada série de estímulos, discriminados por Diagonais (1 e 2) e sexo dos observadores.

Como pode ser notado, os estímulos de distâncias físicas similares, ainda que pertencentes a Diagonais diferentes, produzem julgamentos similares. Por outro lado, evidencia-se as diferenças entre os julgamentos dos observadores de ambos gêneros, 
assim como a diferença nas respectivas taxas de incremento no erro sistemático. Isto é confirmado pela ANOVA fatorial, que não revela diferenças significativas nos julgamentos realizados em ambas Diagonais $\left(F_{(1,288)}=0,088, p=0,766\right)$ nem entre os julgamentos Sem e Com referência $\left(F_{(1,288)}=1,913, p=0,167\right)$. Por outro lado, a ANOVA indica como significativos os fatores 'Posição do Estímulo' $\left(F_{(7,288)}=36,192\right.$, $p<0,001)$, 'Sexo' do observador $\left(F_{(1,288)}=83,287, p<0,001\right)$ e a interação 'Posição do Estímulo $*$ Sexo' $^{\prime}\left(F_{(7,288)}=5,503, p<0,001\right)$.

Estes resultados indicam que os observadores foram coerentes ao estimar as distâncias egocêntricas de estímulos posicionados em distâncias físicas semelhantes, ainda que se encontrem em posições espaciais diferentes e pertençam a séries de estímulos diferentes. Isto é confirmado pelo teste pós-hoc de Newman-Keuls que, por exemplo, mostra que não há diferenças entre os julgamentos dos estímulos proximais F1, M1, M3, e F3, o que também acontece com os estímulos intermediários M2 e M4 e os distais F2 e F4 ( $p>0,05$ para todas as comparações). O efeito significativo para o fator 'Posição do Estímulo' indica que os sujeitos foram capazes de discriminar entre os diferentes estímulos que constituiam as Diagonais. A análise com o teste de Newman-Keuls indicou precisamente que as diferenças significativas na interação 'Posição do Estímulo * Sexo' apareceram para estímulos mais distantes, isto é, para os estímulos M2 e F2 da Diagonal 1, e para os estímulos M4 e F4 da Diagonal 2 (com $p>0,05$ para todas as comparações).

Para refinar estas análises, nas Figuras 25 e 26 foram representado os erros constantes médios das estimativas para cada Diagonal, discriminados segundo as condições de observação (Sem e Com referência) e Sexo do observador. Os valores foram expressos em metros. Fica mais claro o comportamento observado nos dados das Tabelas 7 e 8, especialmente como se diferençam os julgamentos de homens e mulheres. Pode ser notado que, no caso das mulheres, a curva dos julgamentos usando a referência se encontra acima da curva sem referência tanto na Diagonal 1 como na 2, o que indicaria uma redução regular no erro constante.

Uma ANOVA fatorial aplicada aos dados da Diagonal 1 (Figura 25) revelou resultados similares aos observados no quadro geral, com diferenças significativas para o fatores principais 'Posição espacial do Estímulo' $\left(F_{(3,144)}=47,711, p<0,05\right)$ e 'Sexo do observador' $\left(F_{(1,144)}=42,785, p<0,05\right)$, assim como para a interação 'Posição espacial do estímulo * Sexo' $\left(F_{(3,144)}=6,801, p<0,05\right)$. As comparações múltiplas usando o teste de Newman-Keuls indicaram que não há diferença entre os julgamen- 


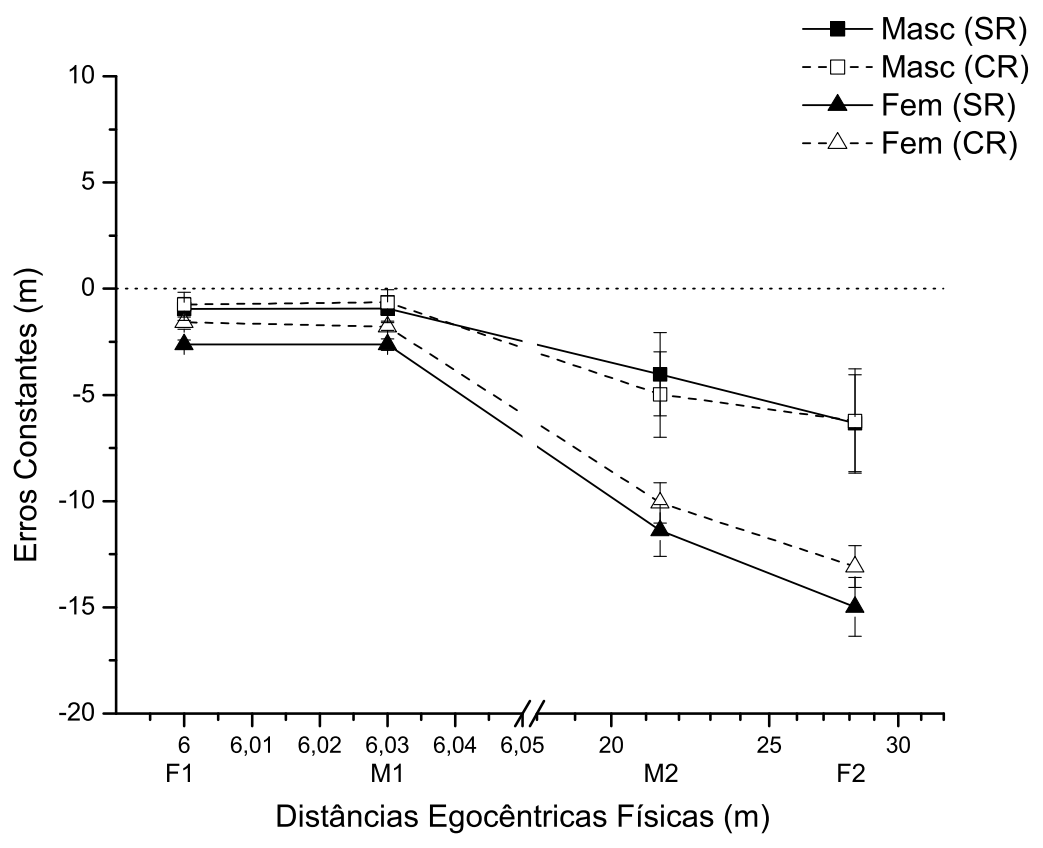

Figura 25 - Médias dos erros constantes (em metros) para os julgamentos das distâncias egocêntricas dos estímulos pertencentes à Diagonal 1. Os quadrados representam os resultados para os observadores do sexo masculino e os triângulos para os observadores do sexo feminino. As marcas cheias representam a condição Sem referência (SR) entanto que as esvaziadas a condição Com referência (CR). As barras verticais representam os desvios padrão da média. A linha pontilhada representa a reta de acurácia perfeita da estimativa em relação aos estímulos físicos. 


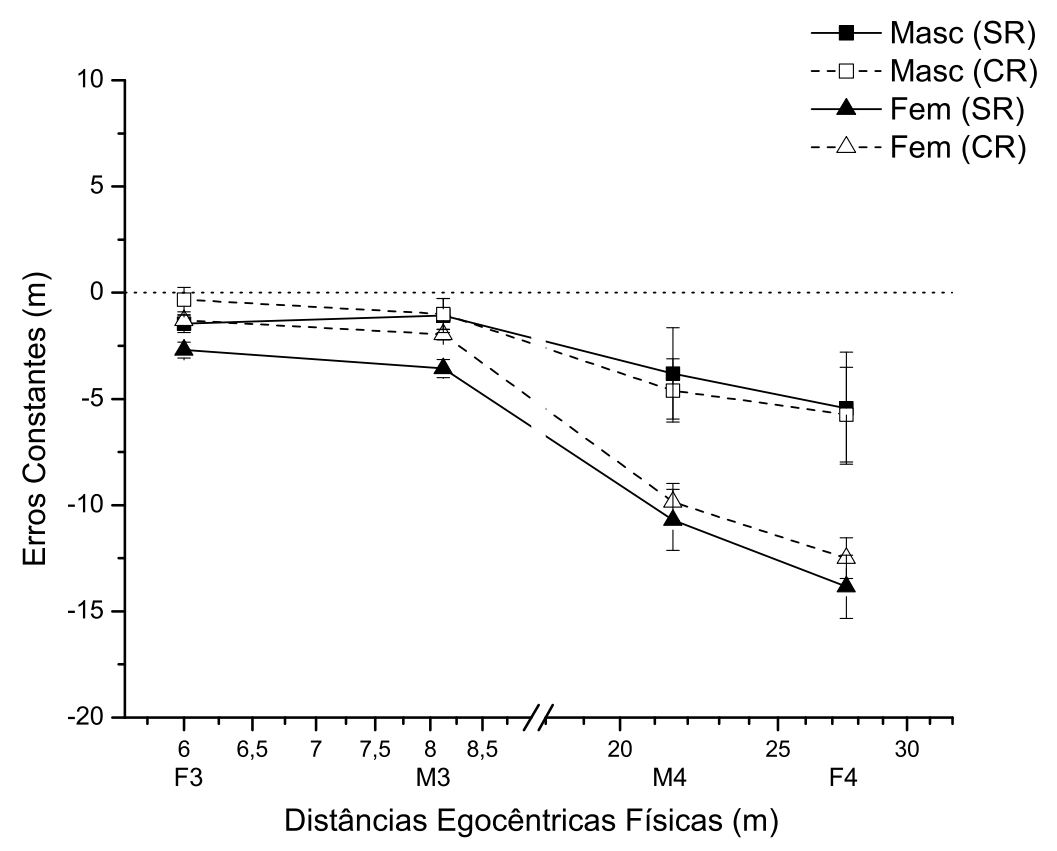

Figura 26 - Médias dos erros constantes (em metros) para os julgamentos das distâncias egocêntricas dos estímulos pertencentes à Diagonal 2. Os quadrados representam os resultados para os observadores do sexo masculino e os triângulos para os observadores do sexo feminino. As marcas cheias representam a condição Sem referência (SR) entanto que as esvaziadas a condição Com referência (CR). As barras verticais representam os desvios padrão da média. A linha pontilhada representa a reta de acurácia perfeita da estimativa em relação aos estímulos físicos. 
tos dos estímulos F1 e M1, entretanto, os estímulos M2 e F2 apresentaram diferenças significativas na totalidade das comparações, sendo a interação 'Estímulo * Sexo' significativa somente para esses dois estímulos ( $p<0,05$ em todos os casos).

De igual forma, uma ANOVA fatorial aplicada aos dados da Diagonal 2 (Figura 26) mostrou resultados semelhantes, embora estes estímulos estivessem posicionados diametralmente opostos aos da Diagonal 1. Deste modo, encontrou-se diferenças significativas para os fatores principais 'Posição do Estímulo' $\left(F_{(3,144)}=36,867\right.$, $p<0,001)$, 'Sexo do observador' $\left(F_{(1,144)}=40,543, p<0,001\right)$, assim como para a interação destes fatores $\left(F_{(3,144)}=6,051, p<0,001\right)$. O teste de Newman-Keuls indica que, no caso do fator 'Posição do Estímulo', as diferenças nos erros constantes se devem aos estímulos posteriores, enquanto que F3 e M3 produzem estimativas similares. Com respeito à interação 'Estímulo * Sexo', a análise encontrou que os julgamentos dos observadores de ambos sexos foram similares para os estímulos proximais, indicando que as diferenças significativas nas estimativas foram originadas nos estímulos M4 e F4 $(p<0,001)$.

\subsubsection{Distâncias exocêntricas}

Os resultados dos julgamentos de distância egocêntrica foram resumidos nas Tabelas 9 e 10, indicando-se as médias, os desvio-padrão e as medianas, agrupados para cada serie de estímulos. Ao lado do nome de cada estímulo se encontra a respectiva distância física. Pode-se observar, tal como aconteceu nos julgamentos das distâncias egocêntricas, uma compressão das estimativas para ambas condições (Sem e Com referência). A exceção estaria dada pelos julgamentos dos observadores do sexo masculino para os pares de estacas mais próximos F1-M1 e F3-M3 onde a mediana da condição 'Com referência' praticamente toma o valor da distância física. De maneira similar ao reportado por Foley, Ribeiro-Filho e Da Silva (2004), as medianas das estimativas mostraram valores menores que as respectivas distâncias físicas. Aparecendo também em ambas condições erros sistemáticos, indicando um aumento da variabilidade a medida que aumenta a distância física.

Como pode ser percebido na Figura 27, distâncias físicas similares $(\overline{F 2 M 2}$ e $\overline{M 4 F 4}$, ou $\overline{F 1 F 2}$ e $\overline{F 3 F 4}$ ), produziram julgamentos similares, ainda encontrando-se em Diagonais diferentes. Por outro lado, novamente foram notórias as diferenças entre os julgamentos dos observadores de ambos gêneros, tendo mais relevância este fator que a localização dos estímulos em uma Diagonal específica. De fato, a ANOVA fa- 
Tabela 9 - Resultados dos julgamentos de distância exocêntrica para os estímulos da Diagonal 1 nas duas condições: Sem e Com referência. Reportam-se as médias, desvios-padrão (SD) e medianas, todos expressados em metros. Os resultados estão discriminados segundo o par de estímulos considerado (distância física entre parênteses) e Sexo do observador (M ou F).

\begin{tabular}{|c|c|c|c|c|c|c|c|}
\hline \multirow[b]{2}{*}{ Estímulos } & \multirow[b]{2}{*}{ Sexo } & \multicolumn{3}{|c|}{ Sem Referência } & \multicolumn{3}{|c|}{ Com Referência } \\
\hline & & Média & SD & Mediana & Média & SD & Mediana \\
\hline F1-M1 $(4,25)$ & $\mathrm{M}$ & 4,17 & 1,23 & 4,25 & 4,55 & 1,07 & 4,25 \\
\hline F1-M1 $(4,25)$ & $\mathrm{F}$ & 2,68 & 0,55 & 2,50 & 3,59 & 0,94 & 3,45 \\
\hline M1-M2 $(18,55)$ & M & 16,20 & 8,09 & 12,50 & 13,80 & 5,27 & 13,50 \\
\hline M1-M2 $(18,55)$ & $\mathrm{F}$ & 8,45 & 2,48 & 8,00 & 10,85 & 2,96 & 12,00 \\
\hline M2-F2 $(6,5)$ & M & 4,00 & 1,70 & 3,25 & 4,75 & 2,40 & 4,00 \\
\hline M2-F2 $(6,5)$ & $\mathrm{F}$ & 2,42 & 0,52 & 2,50 & 3,80 & 1,95 & 3,25 \\
\hline F1-F2 $(29,25)$ & M & 25,80 & 9,66 & 23,00 & 25,25 & 8,11 & 24,00 \\
\hline F1-F2 $(29,25)$ & $\mathrm{F}$ & 13,90 & 3,63 & 14,50 & 17,15 & 2,83 & 17,50 \\
\hline
\end{tabular}

Tabela 10 - Resultados dos julgamentos de distância exocêntrica para os estímulos da Diagonal 2 nas duas condições: Sem e Com referência. Reportam-se as médias, desvios-padrão (SD) e medianas, todos expressados em metros. Os resultados estão discriminados segundo o par de estímulos considerado (distância física entre parênteses) e Sexo do observador (M ou F).

\begin{tabular}{|c|c|c|c|c|c|c|c|}
\hline \multirow[b]{2}{*}{ Estímulos } & \multirow[b]{2}{*}{ Sexo } & \multicolumn{3}{|c|}{ Sem Referência } & \multicolumn{3}{|c|}{ Com Referência } \\
\hline & & Média & SD & Mediana & Média & SD & Mediana \\
\hline F3-M3 (8) & M & 6,65 & 2,44 & 6,00 & 7,65 & 2,10 & 7,75 \\
\hline F3-M3 (8) & $\mathrm{F}$ & 4,30 & 1,46 & 4,00 & 5,72 & 1,02 & 6,00 \\
\hline M3-M4 $(15,25)$ & M & 13,00 & 5,77 & 12,50 & 12,65 & 3,76 & 12,50 \\
\hline M3-M4 $(15,25)$ & $\mathrm{F}$ & 7,75 & 2,63 & 7,25 & 10,00 & 3,13 & 9,50 \\
\hline M4-F4 (6) & M & 3,55 & 1,30 & 3,00 & 3,90 & 1,15 & 3,50 \\
\hline M4-F4 (6) & $\mathrm{F}$ & 2,45 & 0,50 & 2,50 & 3,25 & 1,09 & 3,50 \\
\hline F3-F4 $(29,25)$ & M & 25,70 & 10,15 & 22,50 & 25,30 & 8,30 & 23,50 \\
\hline F3-F4 $(29,25)$ & $\mathrm{F}$ & 13,85 & 3,87 & 14,50 & 16,90 & 3,21 & 16,50 \\
\hline
\end{tabular}


torial não encontrou diferenças significativas quando considerado o fator 'Diagonal' $\left(F_{(1,288)}=0,019, p=0,888\right)$, nem o fator 'Condição' $\left(F_{(1,288)}=3,469, p=0,067\right)$, referido ao emprego ou não da referência de distância. Dita análise indicou como significativos os fatores 'Par de Estímulos' $\left(F_{(7,288)}=21,371, p<0,001\right)$, 'Sexo' do observador $\left(F_{(1,288)}=83,512, p<0,001\right)$, da mesma forma que as interações 'Par de Estímulos $*$ Sexo' $\left._{\left(F_{(7,288)}\right.}=8,031, p<0,001\right)$ e 'Sexo $*$ Condição' $\left(F_{(7,288)}=4,760\right.$, $p<0,05)$.

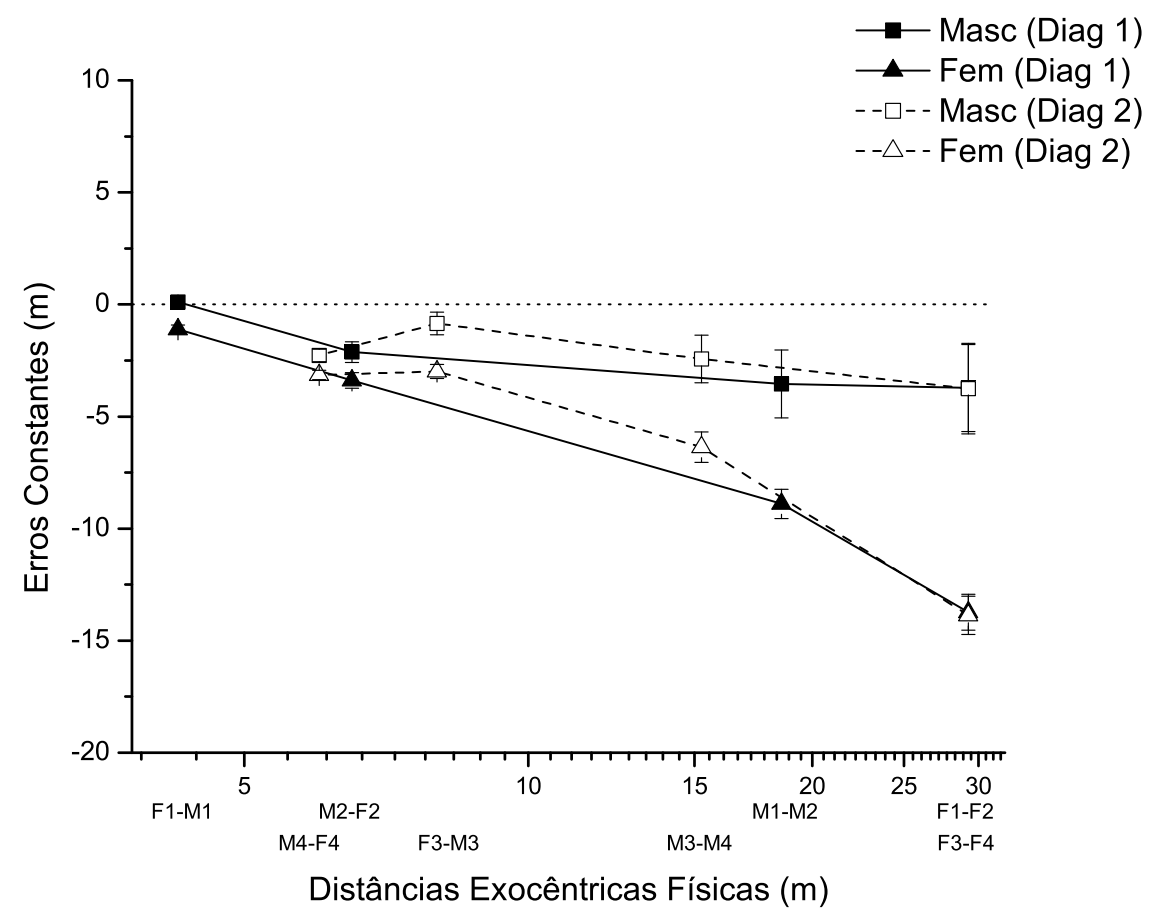

Figura 27 - Médias dos erros constantes (em metros) para os julgamentos das distâncias exocêntricas dos estímulos pertencentes a ambas Diagonais. Os quadrados representam os resultados para os observadores do sexo masculino e os triângulos para os observadores do sexo feminino. As marcas cheias indicam a Diagonal 1, enquanto que as esvaziadas a Diagonal 2. As barras verticais representam os desvios padrão da média. A linha pontilhada representa a reta de acurácia perfeita da estimativa em relação aos pares de estímulos físicos.

Os resultados obtidos a partir dos julgamentos exocêntricos apontaram na mesma direção que os dados dos julgamentos das distâncias absolutas, ou seja que os observadores foram coerentes em suas apreciações. Pode ser notado que as estimativas das distâncias inter-estímulos semelhantes, embora posicionadas em localizações espaciais diferentes, foram similares. O teste de Newman-Keuls deixou em evidência as diferenças óbvias entre os pares de estímulos, porém foram mais interessantes as si- 
militudes. Assim a análise pós-hoc mostrou que não aparecem diferenças significativas entre os julgamentos das distâncias determinadas pelos segmentos proximais $(\overline{F 1 M 1}$ e $\overline{F 3 M 3})$, intermédios $(\overline{M 1 M 2}$ e $\overline{M 3 M 4})$ e posteriores $(\overline{M 2 F 2}$ e $\overline{M 4 F 4})$ de ambas Diagonais, mesmo que entre os julgamentos respeito do tamanho das duas Diagonais $(\overline{F 1 F 2}$ e $\overline{F 3 F 4})$. No caso das interações, as diferenças significativas para 'Par de estímulos $*$ Sexo' do observador apareceram nos segmentos $\overline{M 1 M 2}$ e os de tamanho maior, quando considerada a Diagonal toda $(\overline{F 1 F 2}$ e $\overline{F 3 F 4})$. Para a interação 'Sexo do observador $*$ Condição' o teste de Newman-Keuls mostrou que para os observadores do sexo feminino apareceram diferenças nos julgamentos $(p<0,05)$ quando usam a referência de distância.

Nas Figuras 28 e 29 se representaram os erros constantes médios das estimativas exocêntricas para cada Diagonal, discriminados segundo as condições de observação (Sem e Com referência) e Sexo do observador. Todos valores foram indicados em metros.

A ANOVA fatorial, a partir dos dados da Diagonal 1, mostrou como significativos os fatores 'Par de Estímulos' $\left(F_{(3,144)}=27,857, p<0,001\right)$, 'Sexo' do observador $\left(F_{(1,144)}=41,735, p<0,001\right)$, e a interação de estes dois fatores $\left(F_{(3,144)}=9,119\right.$, $p<0,001)$, não havendo diferença entre o emprego ou não da referência de distância $\left(F_{(1,144)}=1,227, p=0,269\right)$. A análise pós-hoc com o teste de Newman-Keuls indicou que os observadores julgaram como diferentes todos os segmentos considerados. Por outro lado, na interação 'Par de estímulos $*$ Sexo do observador' as diferenças se encontraram nos julgamentos dos segmentos de maior tamanho, ou seja $\overline{M 1 M 2}$ e $\overline{F 1 F 2}$.

De igual maneira, a ANOVA fatorial nos dados da Diagonal 2 distinguiu como significativos os fatores 'Par de Estímulos' $\left(F_{(3,144)}=21,728, p<0,001\right)$, 'Sexo' do observador $\left(F_{(1,144)}=41,819, p<0,001\right)$, e também sua interação $\left(F_{(3,144)}=9,630\right.$, $p<0,001)$, sem encontrar diferença para os julgamentos Sem e Com referência de distância $\left(F_{(1,144)}=2,360, p=0,126\right)$. Interessantemente, o teste de Newman-Keuls mostrou que no caso da Diagonal 2 os segmentos de tamanho parecido foram julgados como similares, devendo-se as diferenças significativas no ANOVA às comparações com o par F3-F4. A análise também salientou que na interação 'Par de estímulos * Sexo do observador' os segmentos de maior tamanho ( $\overline{M 3 M 4}$ e $\overline{F 3 F 4})$ foram julgados de forma diferente pelos observadores de ambos sexos. Embora não significativa na ANOVA, a interação 'Condição $*$ Sexo do observador' apresentou diferenças entre os 


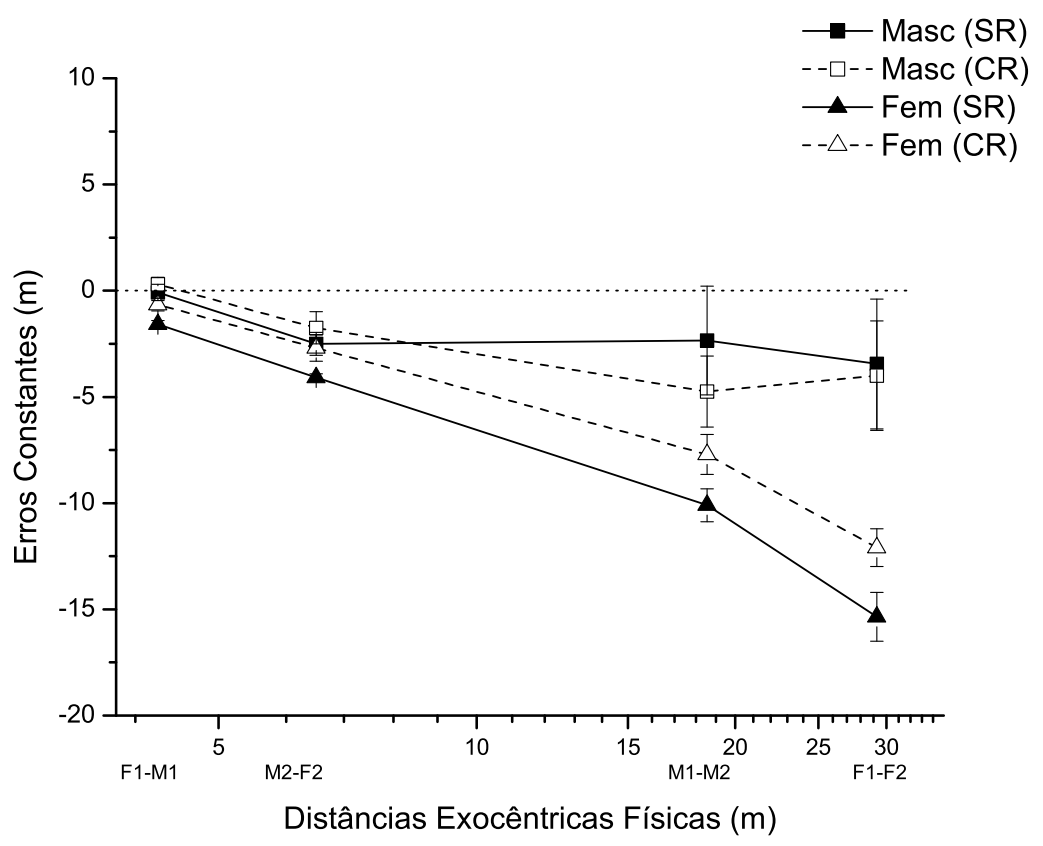

Figura 28 - Médias dos erros constantes (em metros) para os julgamentos das distâncias exocêntricas dos estímulos pertencentes à Diagonal 1. Os quadrados representam os resultados para os observadores do sexo masculino e os triângulos para os observadores do sexo feminino. As marcas cheias representam a condição Sem referência (SR) entanto que as esvaziadas a condição Com referência (CR). As barras verticais representam os desvios padrão da média. A linha pontilhada representa a reta de acurácia perfeita da estimativa em relação aos pares de estímulos físicos. 


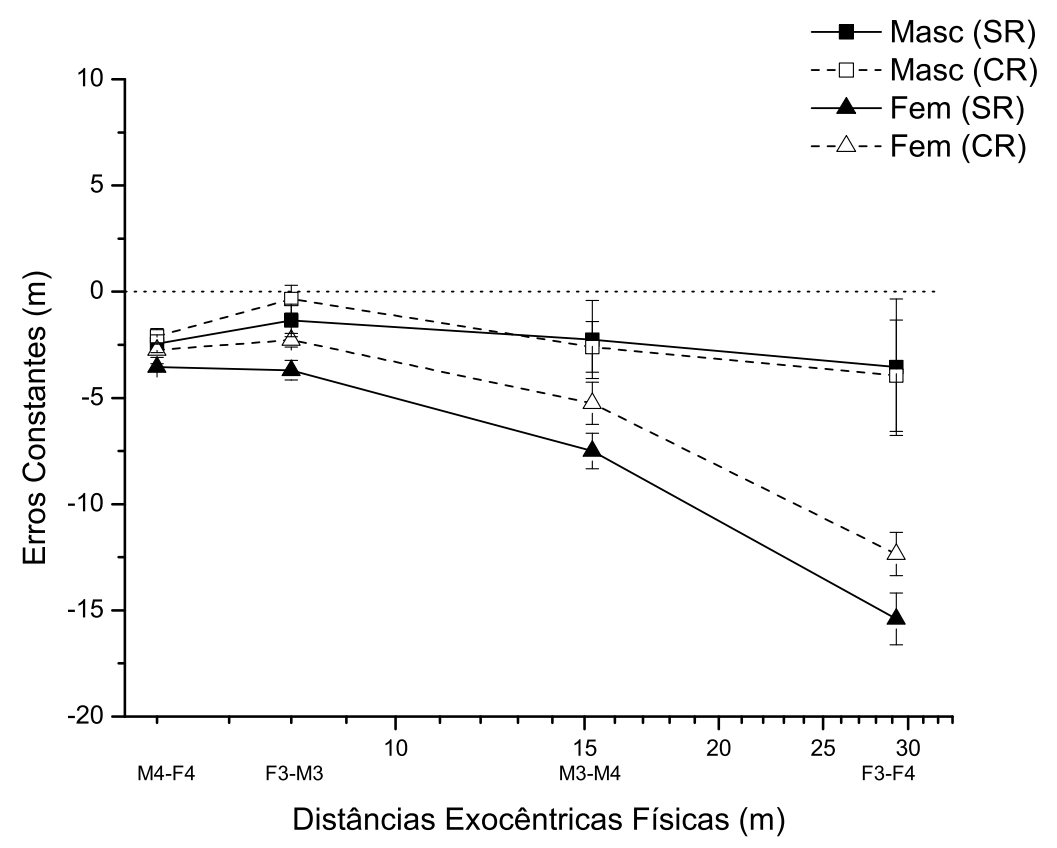

Figura 29 - Médias dos erros constantes (em metros) para os julgamentos das distâncias exocêntricas dos estímulos pertencentes à Diagonal 2. Os quadrados representam os resultados para os observadores do sexo masculino e os triângulos para os observadores do sexo feminino. As marcas cheias representam a condição Sem referência (SR) entanto que as esvaziadas a condição Com referência (CR). As barras verticais representam os desvios padrão da média. A linha pontilhada representa a reta de acurácia perfeita da estimativa em relação aos pares de estímulos físicos. 
julgamentos sem e com a referência de distância no caso dos observadores do sexo feminino $(p<0,05)$.

\subsubsection{Análise das apreciações subjetivas}

Terminada a fase dos julgamentos verbais de distância, os observadores foram interrogados sobre se eles perceberam as séries de estímulos como colineares. Devido às características peculiares do posicionamento dos alvos, baseado nas médias dos ajustes de colinearidade do Experimento I, era interessante saber se eles concordavam em perceber os estímulos como alinhados.

Os resultados das apreciações subjetivas indicaram que a maioria dos sujeitos considerou os estímulos como colineares. Em média, só o $15 \%$ dos observadores achou que o alinhamento ficaria melhor reposicionando um o mais estímulos. Na Figura 30 se indicaram as percentagens de observadores que moveriam cada um dos diferentes estímulos num dado sentido. Cabe destacar que só foi indagado a orientação do ajuste e não a magnitude do mesmo. Como pode ser notado, a maior parte das correções aconteceu nos estímulos proximais M1 e M3. Isto é coerente com a ambigüidade já observada alhures, na análise dos resultados do Experimento I (ver Figura 17).

Diagonal 1

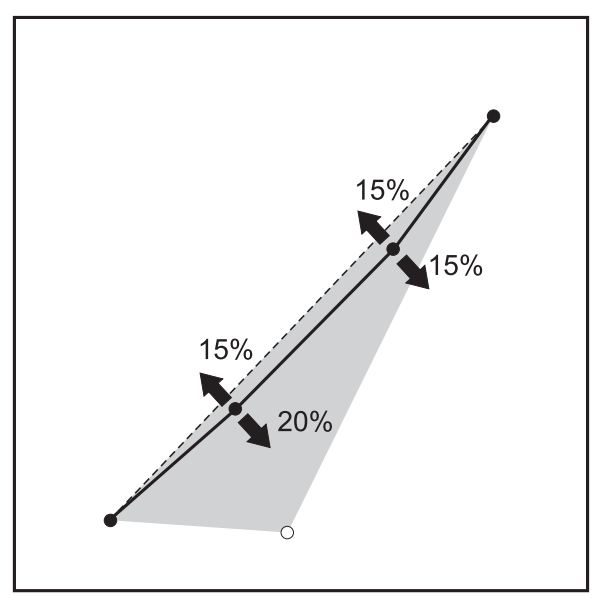

Diagonal 2

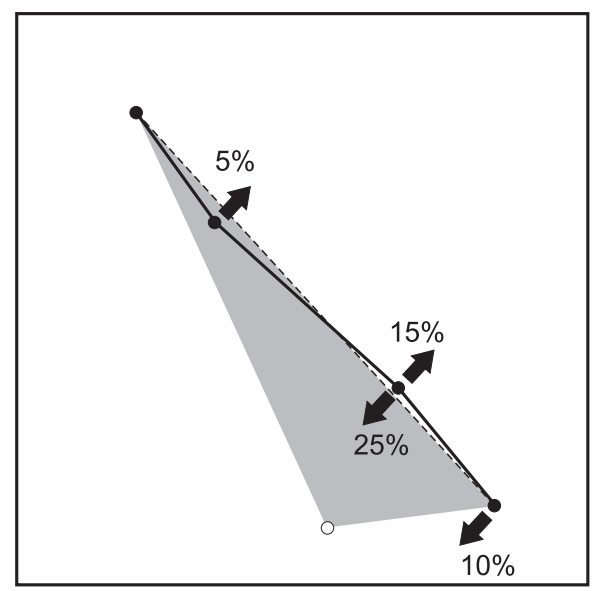

Figura 30 - Percentagens de observadores que modificariam a posição dos estímulos empregados para que ficassem perceptualmente colineares para eles. Em cada estímulo se indicam a direção na qual deveria ser realizado o ajuste e a percentagem de observadores que o sugeriram.

No caso dos estímulos da Diagonal 1, 45\% dos observadores alterariam só a posição de um deles, entanto que 10\% dos observadores acharam necessário mexer em 
dois estímulos simultaneamente para melhorar o ajuste de colinearidade. Para a Diagonal 2, também $45 \%$ dos observadores reajustaria unicamente a posição de um estímulo, e só $5 \%$ o faria com dois deles. O 45\% dos sujeitos consideraram que os estímulos eram colineares na Diagonal 1 e 50\% acharam o mesmo dos estímulos da Diagonal 2.

\subsubsection{Ajuste e modelagem dos dados}

Para a modelagem, tanto dos resultados egocêntricos como exocêntricos, foram considerados os dados de todos os observadores. Como as diferenças nas duas condições não foram significativas estatisticamente, ambos resultados foram incluídos nos ajustes, tal como fizeram Foley, Ribeiro-Filho e Da Silva (2004) em seu trabalho. Embora nossos dados mostraram diferenças significativas devidas ao sexo dos observadores, a maioria dos trabalhos na literatura não consideram dita variável nas análises ou, no melhor dos casos, simplesmente balancearam nas amostras a quantidade de observadores masculinos e femininos. Adotaremos aqui esta opção para poder comparar os resultados obtidos nos ajustes com os provenientes de outros estudos.

As distâncias reportadas pelos observadores, tanto egocêntricas como exocêntricas, foram ajustadas por uma função linear com interseção na origem. Os dados egocêntricos foram modelados por uma reta de inclinação $0,66 \pm 0,01\left(R^{2}=0,997\right.$, $R M S E=0,53 \mathrm{~m})^{1}$, e os exocêntricos por uma reta de inclinação $0,70 \pm 0,01\left(R^{2}=\right.$ 0,989, $R M S E=0,66 \mathrm{~m}$ ), como pode ser observado nas Figuras 31 e 32. Em ambos casos os resultados apresentaram um ajuste muito bom, segundo os indicadores de bondade no ajuste.

A continuação foram estimados os parâmetros para a função de potência, expressada na Equação 2.10. Para os julgamentos egocêntricos obteve-se $k=0,91 \pm 0,06$ e $n=0,90 \pm 0,02\left(R^{2}=0,998, R M S E=0,28 \mathrm{~m}\right)$, e para os exocêntricos $k=0,65 \pm 0,01$ e $n=1,01 \pm 0,05\left(R^{2}=0,989, R M S E=0,46 \mathrm{~m}\right)$, sendo ambas curvas desenhadas nas Figuras 31 e 32, respectivamente. Os coeficientes de determinação indicaram, para ambos casos, a ótima adequação da função de potência no modelado da relação entre as distâncias físicas dos estímulos e as distâncias reportadas pelos sujeitos.

Por último, os dados obtidos neste Experimento foram aplicados na Equação 2.19, representativa do 'Modelo Generalizado', e cujo resultado é plotado na Figura 33.

\footnotetext{
${ }^{1}$ Empregaremos a sigla RMSE (do inglês Root Mean Squared Error) para referir-nos à a Raiz do Erro Quadrático Médio.
} 


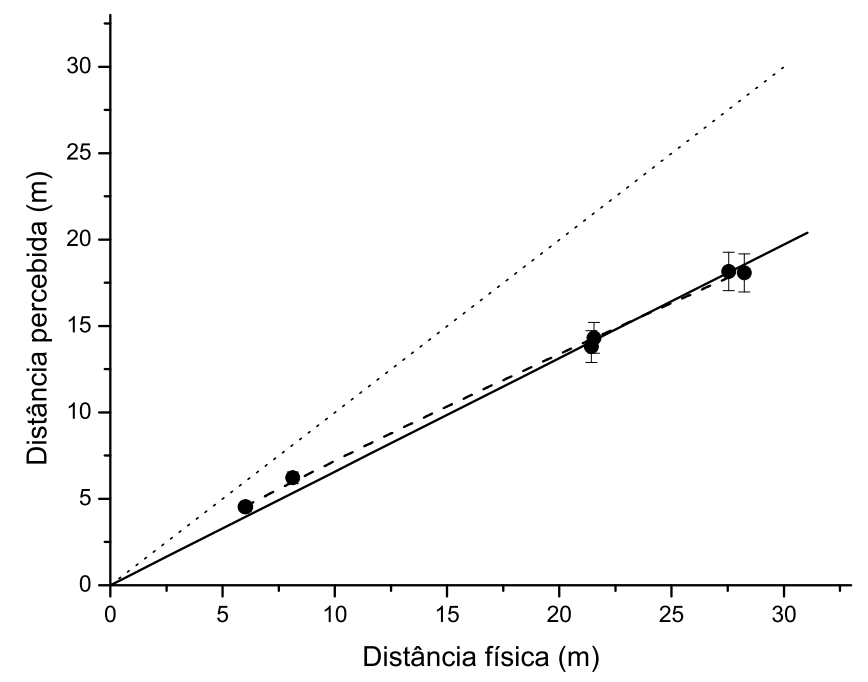

Figura 31 - Médias das estimativas egocêntricas de distância em função das distâncias físicas, em metros. As barras verticais indicam o erro padrão da média. A linha pontilhada representa a reta de acurácia entre as distâncias percebidas e os estímulos físicos. A linha sólida indica o resultado do ajuste linear, a tracejada o modelado com a função de potência.

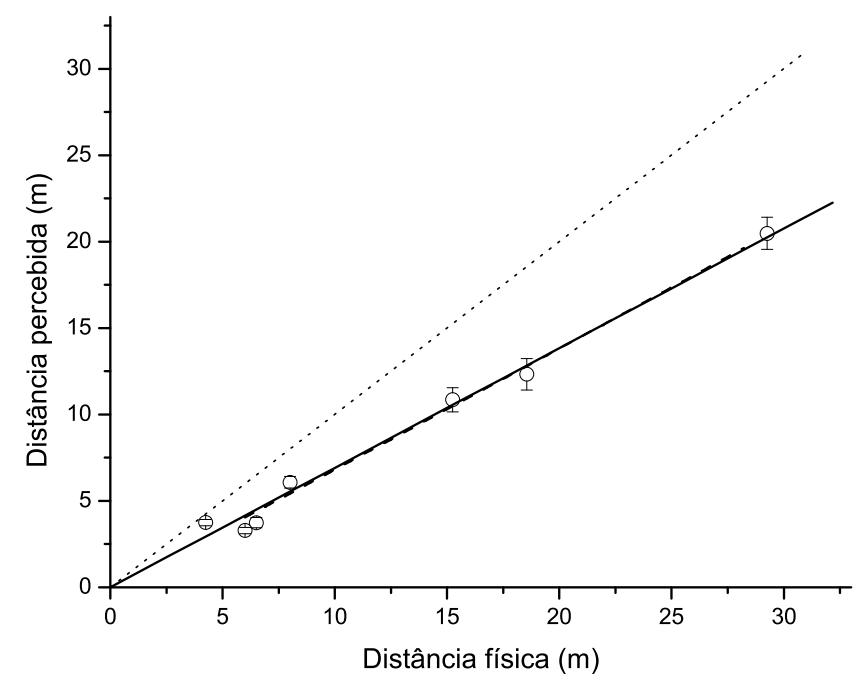

Figura 32 - Médias das estimativas exocêntricas de distância em função das distâncias físicas, em metros. As barras verticais indicam o erro padrão da média. A linha pontilhada representa a reta de acurácia entre as distâncias percebidas e os estímulos físicos. A linha sólida indica o resultado do ajuste linear, a tracejada o modelado com a função de potência. 


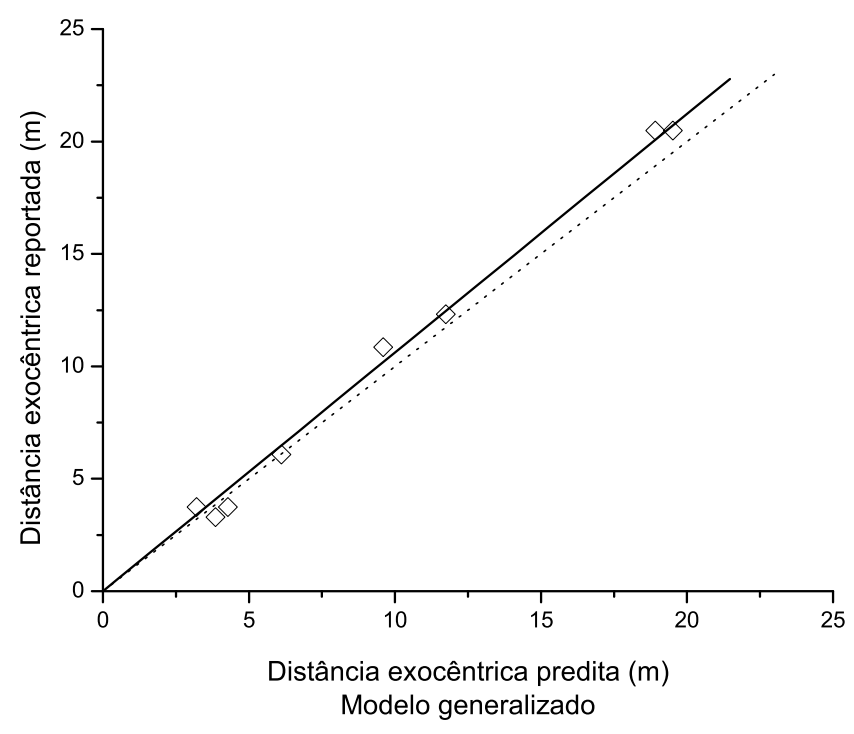

Figura 33 - Médias das distâncias egocêntricas reportadas versus as predições do 'Modelo Generalizado' (Equação 2.19). A linha pontilhada representa a reta de acurácia e a sólida indica o resultado do ajuste linear $\left(R^{2}=0,994\right.$, $R M S E=0,57 \mathrm{~m}$ )

Segundo pode ser observado, a maioria das médias das distâncias exocêntricas indicadas pelos observadores apresentaram valores superiores que os preditos por este modelo. Isto foi indicado pela reta de regressão entre ambos dados, que passa pela origem e apresenta inclinação de 1,09 $\pm 0,01$ com $R^{2}=0,994, R M S E=0,57 \mathrm{~m}$. Como notaram Foley, Ribeiro-Filho e Da Silva (2004), este modelo claramente subestimaria a extensão percebida, com o erro aumentando a medida que aumenta o ângulo entre os estímulos considerados.

\subsubsection{Discussão Experimento III}

Os resultados das estimativas dos observadores indicaram que estes foram coerentes ao estimar as distâncias egocêntricas de estímulos posicionados em distâncias físicas semelhantes, ainda que se encontraram em posições espaciais diferentes, ou seja, que estivessem colocados numa Diagonal ou na outra. As diferenças nas magnitudes dos julgamentos entre observadores de ambos sexos só aconteceram nos estímulos mais distantes, não sendo encontradas diferenças nos julgamentos dos alvos proximais. Embora não fosse considerado como significativa pela análise estatística, no caso das mulheres a curva do desempenho nos julgamentos usando a referência de distância se posicionou acima da curva sem referência, indicando uma redução 
regular no erro constante, tanto para os julgamentos dos estímulos posicionados na Diagonal 1 como na 2.

Quando consideradas os julgamentos exocêntricos das distâncias, pôde ser notado que distâncias físicas similares produziram estimativas similares, ainda encontrandose em Diagonais diferentes, o que também tinha sido observado nos julgamentos das distâncias egocêntricas. Aqui também foram notórias as diferenças entre os julgamentos dos observadores de ambos sexos, tendo mais relevância este fator que o posicionamento dos estímulos em uma Diagonal específica, indicando a coerência das apreciações dos sujeitos.

Os resultados foram similares aos reportados por outros autores (DA SILVA, 1985; WAGNER, 1985; TOYE, 1986; LOOMIS; PHILBECK, 1999; NORMAN; TODD; PEROTTI; TITTLE, 1996; RIBEIRO-FILHO, 1993; FOLEY; RIBEIRO-FILHO; DA SILVA, 2004), mostrando uma compressão das estimativas, as quais apresentaram valores menores que as respectivas distâncias físicas, indicando uma anisotropia do espaço visualmente percebido.

A modelagem dos dados egocêntricos e exocêntricos foi feita usando o ajuste linear, e a função de potência. Em ambos casos os coeficientes de determinação indicaram que os ajustes foram bem-sucedidos, apresentando a função de potência uma melhor adequação à relação entre as distâncias físicas dos estímulos e as distâncias reportadas pelos sujeitos. Entretanto, o 'modelo Generalizado' mostrou uma subestimação da extensão percebida, com o erro aumentando a medida que aumenta o ângulo entre os estímulos considerados.

Os resultados observados no modelado dos dados e o relevamento das apreciações subjetivas indicaram que a maioria dos sujeitos considerou os estímulos como colineares. Foi interessante notar que, em média, só o 15\% dos observadores encontrou que o alinhamento ficaria melhor mudando a posição de um o mais estímulos. Estas semelhanças encontradas poderiam estar relacionadas com o exposto por Indow (2004a), em referência às características compartidas pelos humanos do espaço visualmente percebido, o que leva a outros autores como Kelly, Beall e Loomis (2004) a falar de "espaço visualmente compartilhado", analisando, incluso, sua aplicação prática.

\subsection{Modelando os dados com o 'Tangle'}

Para aplicar o modelo, o primeiro passo foi ajustar os dados das distâncias egocêntricas percebidas usando a 'Função de Distância Egocêntrica' (FDE) do Tangle, 
expressada pela Equação 2.22. Os parâmetros obtidos para a mesma foram:

$$
\begin{aligned}
F & =1,29 \pm 0,06 \\
G & =0,009 \pm 0,002 \\
R^{2} & =0,998 \\
R M S E & =0,29 \mathrm{~m}
\end{aligned}
$$

e o gráfico com o ajuste da função aos dados pode ser observado na Figura 34. Os valores dos parâmetros se encontram no intervalo reportado por Foley e colaboradores (2004) para condições de observação binocular, com indícios e no campo aberto. Nessas circunstâncias eles calcularam para a FDE os valores $F=1,25, G=0,007$, $R M S E=0,93 \mathrm{~m}$.

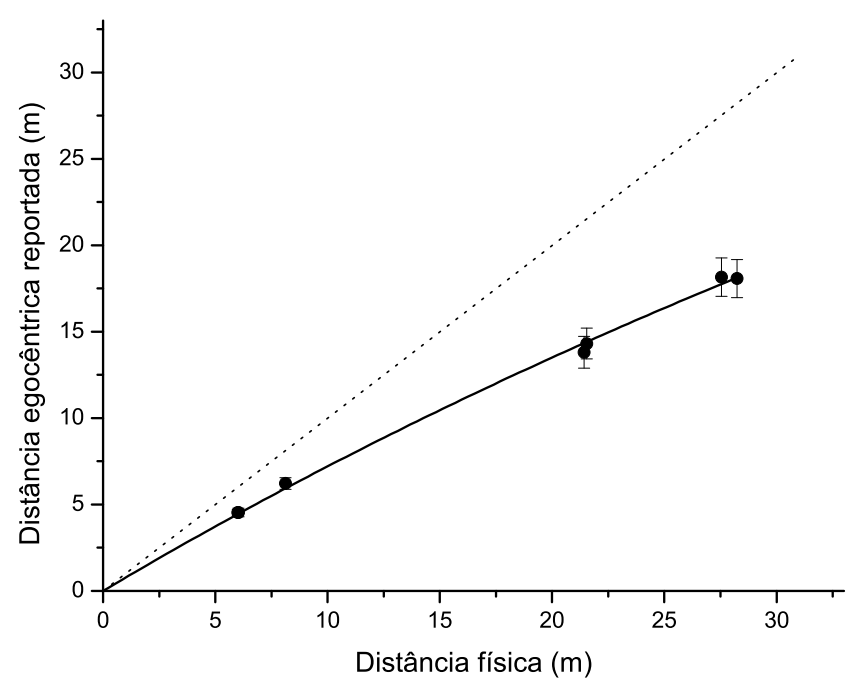

Figura 34 - Médias das distâncias egocêntricas percebidas e ajuste com a 'Função de Distância Egocêntrica' do Tangle (Equação 2.22). Consideram-se os parâmetros $F=1,29, G=0,009, R M S E=0,29 \mathrm{~m}$.

A continuação foram estimados os parâmetros $Q$ e $P$ da Equação 2.20, necessários para computar os ângulos efetivos utilizados para o modelado das distâncias exocêntricas. Os valores $Q=0,112 \pm 0,09$ e $P=2,217 \pm 0,06$ lograram o melhor ajuste $\left(R^{2}=0,987, R M S E=0,079\right)$. Na Figura 35 foi traçado o ângulo visual efetivo em função do ângulo visual. Como pode ser notado, o ângulo visual efetivo apresenta uma característica não-linear, aumentando de maneira mais rápida que o ângulo visual. Esta particularidade do modelo seria a que permitiria um melhor ajuste aos dados experimentais. 


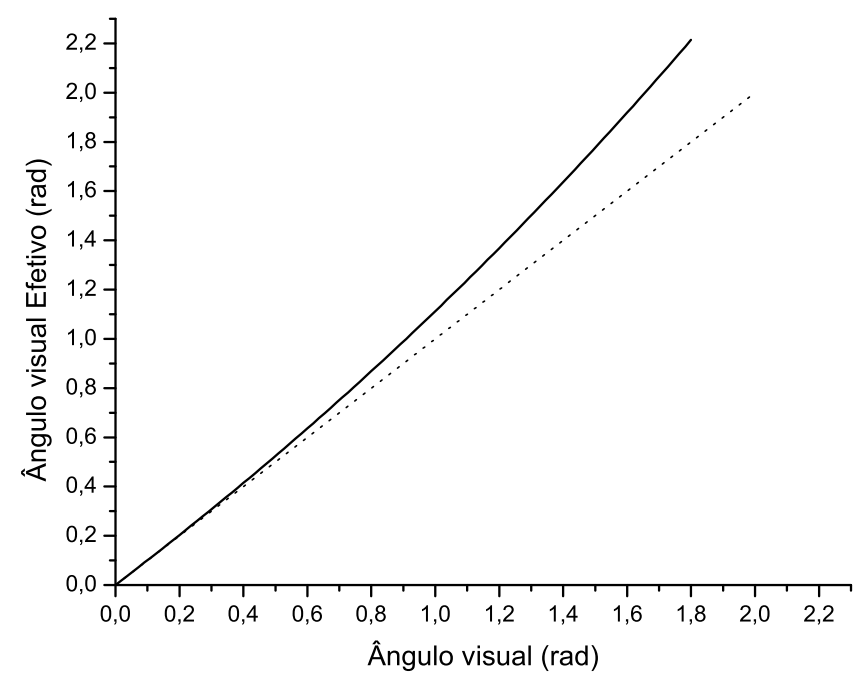

Figura 35 - Ângulo visual efetivo para o cálculo da distância excêntrica versus o ângulo visual. O resultado da estimação está baseado no ajuste do modelo Tangle aos dados do Experimento III. A linha pontilhada representaria a situação de igualdade entre os ângulos efetivo e visual.

Para a configuração espacial de estímulos empregada nos Experimentos I e III, o Sistema de Equações 2.16 ficaria parametrizado da seguinte maneira:

$$
\left\{\begin{array}{l}
\theta_{i j}^{\prime \prime}=\theta_{i j}+0,112 \cdot \theta_{i j}^{2,217} \\
S_{i j}^{\prime}=\left(\left(R_{i}^{\prime}\right)^{2}+\left(R_{j}^{\prime}\right)^{2}-2 R_{i}^{\prime} R_{j}^{\prime} \cos \theta_{i j}^{\prime \prime}\right)^{0.5} \\
R_{i}^{\prime}=R_{i} /\left(1,29+0,009 \cdot R_{i}\right)
\end{array}\right.
$$

A Figura 36 apresenta as distâncias exocêntricas reportadas pelos observadores em função das extensões preditas pelo Tangle. Como pode ser notado, a reta do ajuste linear está praticamente superposta à linha que indicaria o ajuste perfeito. Isto foi confirmado pelos coeficientes de determinação, obtendo $R^{2}=0,998$ e $R M S E=0,31 \mathrm{~m}$. A comparação com a Figura 34 e os valores dos ajustes para ambos modelos (resumidos na Tabela 11), permite observar o melhor desempenho do Tangle no modelado destes dados experimentais.

\subsection{Analisando as conseqüências do 'Tangle'}

Na seqüencia os dados obtidos foram analisados considerando as implicações do modelo de Foley, Ribeiro-Filho e Da Silva (2004), sumariadas na seção 5.1. 


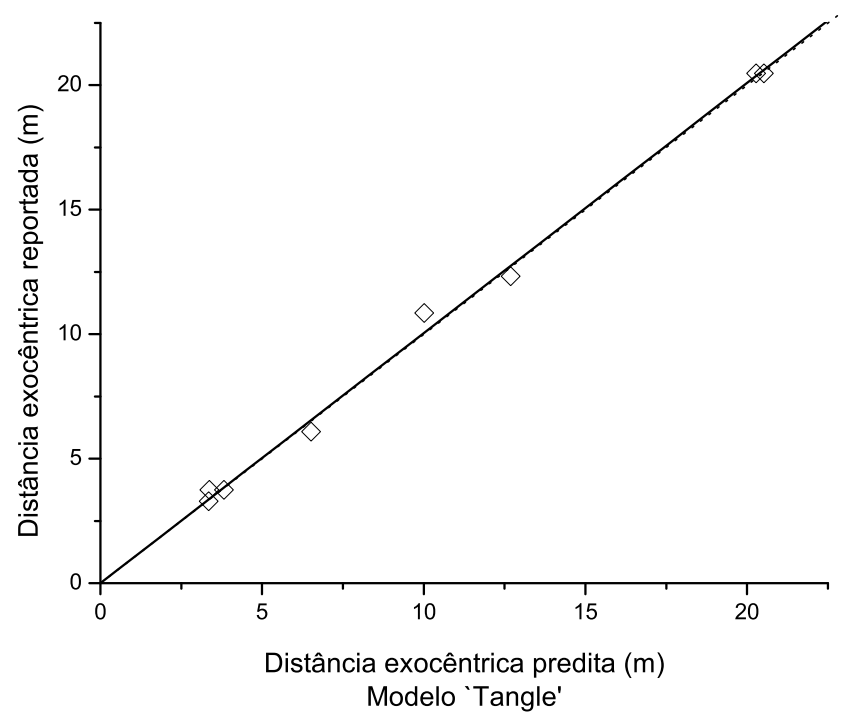

Figura 36 - Médias das distâncias egocêntricas reportadas versus as predições do modelo Tangle. A linha pontilhada representaria o ajuste perfeito aos dados e a sólida indica o resultado do ajuste linear $\left(R^{2}=0,998, R M S E=0,31 \mathrm{~m}\right)$

Tabela 11 - Comparação do ajuste aos dados dos modelos Generalizado e Tangle (ambas retas de regressão passam pela origem).

\begin{tabular}{lcc}
\hline & \multicolumn{2}{c}{ Modelo } \\
\cline { 2 - 3 } & Generalizado & Tangle \\
\hline Interseção & 0 & 0 \\
Inclinação & $1,06 \pm 0,01$ & $1,00 \pm 0,01$ \\
$R^{2}$ & 0,994 & 0,998 \\
Ad- $R^{2}$ & 0,994 & 0,998 \\
$R M S E$ & $0,57 \mathrm{~m}$ & $0,31 \mathrm{~m}$ \\
$F_{(1,7)}$ & 1120,00 & 2124,16 \\
$p$ & $<0,001$ & $<0,001$ \\
\hline
\end{tabular}




\subsubsection{Da desigualdade do triângulo}

Os dados das distâncias físicas e das distâncias egocêntricas e exocêntricas percebidas foram utilizados para testar a desigualdade do triângulo, uma propriedade fundamental de todos os espaços métricos, representada pela Equação 5.1. Estes valores podem ser observados na Tabela 12. Na análise foram considerados tanto os resultados dos julgamentos de homens como os das mulheres. Devido a que em nenhum caso houve violação da desigualdade, para simplificar a tabela foram colocadas as médias dos observadores de ambos os sexos para cada distância. Como diferentes triângulos eram possíveis para cada Diagonal, a desigualdade foi testada em todos eles. $\mathrm{O}$ triângulo $\mathrm{F}_{3} \widehat{O M}_{3}$ também foi considerado, devido à pequena diferença entre as distâncias físicas.

Tabela 12 - Médias das distâncias egocêntricas e exocêntricas para os diferentes triângulos formados pelo posição do observador e os estímulos nas Diagonais 1 e 2. $D_{1}$ e $D_{2}, D_{1}^{\prime}$ e $D_{2}^{\prime}$ indicam as respectivas distâncias egocêntricas físicas e percebidas, enquanto $\overline{D_{1} D_{2}}$ e $\overline{D_{1}^{\prime} D_{2}^{\prime}}$ as respectivas distâncias exocêntricas físicas e percebidas.

\begin{tabular}{cccccccc}
\hline Triângulo & $D_{1}$ & $D_{2}$ & $\overline{D_{1} D_{2}}$ & $D_{1}^{\prime}$ & $D_{2}^{\prime}$ & $D_{1}^{\prime}+D_{2}^{\prime}$ & $\overline{D_{1}^{\prime} D_{2}^{\prime}}$ \\
\hline$F_{1} \widehat{O M}_{2}$ & 6 & 21,43 & 22,8 & 4,21 & 13,95 & 18,16 & 15,76 \\
$\widehat{F}_{1} \widehat{O F}_{2}$ & 6 & 28,23 & 29,25 & 4,21 & 17,58 & 21,79 & 19,9 \\
$F_{3} \widehat{O M}_{3}$ & 6 & 8,12 & 8,00 & 3,93 & 5,8 & 9,73 & 5,48 \\
$F_{3} \widehat{O M}_{4}$ & 6 & 21,55 & 23,25 & 3,93 & 14,21 & 18,14 & 15,86 \\
$\widehat{F}_{3} \widehat{O F}_{4}$ & 6 & 27,54 & 29,25 & 3,93 & 17,9 & 21,83 & 19,78 \\
\hline
\end{tabular}

Encontramos que os julgamentos realizados a partir da configuração de estímulos perceptualmente colineares, os quais compreendiam ângulos visuais de aproximadamente $67^{\circ}, 94^{\circ}, 96^{\circ}, 99^{\circ}$ e $101^{\circ}$, satisfazem a desigualdade do triângulo.

Como a suposição foi que se a Equação 2.20 estiver correta, e o ângulo visual efetivo $\left(\theta_{i j}^{\prime \prime}\right)$ for suficientemente maior que o ângulo visual físico $\left(\theta_{i j}\right)$, ocorreria uma violação da desigualdade do triângulo, esta propriedade também foi testada a partir dos valores preditos pelo Tangle. Na Tabela 13 são apresentados os ângulos físico e efetivo para cada triângulo, assim como as distâncias egocêntricas e exocêntrica estimadas pelo modelo.

Pode ser observado que apesar do incremento no ângulo efetivo estimado pelo 
Tabela 13 - Distâncias egocêntricas e exocêntricas estimadas pelo Tangle para os diferentes triângulos formados pela posição do observador $(\mathrm{O})$ e os estímulos nas Diagonais 1 e 2 . $\theta_{i j}$ é o ângulo físico, $\theta_{i j}^{\prime \prime}$ é o ângulo efetivo, $R_{i}^{\prime}$ e $R_{j}^{\prime}$ as distâncias egocêntricas e $S_{i j}^{\prime}$ a distância exocêntrica estimadas pelo modelo.

\begin{tabular}{ccccccc}
\hline Triângulo & $\theta_{i j}$ & $\theta_{i j}^{\prime \prime}$ & $R_{i}^{\prime}$ & $R_{j}^{\prime}$ & $R_{i}^{\prime}+R_{j}^{\prime}$ & $S_{i j}^{\prime}$ \\
\hline$F_{1} \widehat{O M}_{2}$ & 95,5 & 104,3 & 4,44 & 4,47 & 8,91 & 3,37 \\
$F_{1} \widehat{O F}_{2}$ & 97,4 & 113 & 4,44 & 18,12 & 22,56 & 20,28 \\
$F_{3} \widehat{O M}_{3}$ & 67,1 & 76,2 & 4,44 & 5,93 & 10,37 & 6,51 \\
$F_{3} \widehat{O M}_{4}$ & 98,8 & 109,6 & 4,44 & 14,41 & 18,85 & 16,52 \\
$\widehat{F}_{3} \widehat{O F}_{4}$ & 100,7 & 123,1 & 4,44 & 17,75 & 22,19 & 20,52 \\
\hline
\end{tabular}

Tangle, os quais vão desde $76^{\circ}$ até $123^{\circ}$, os valores de distância indicados pelo modelo tampouco violam o estabelecido pela desigualdade do triângulo.

Desta maneira nossos resultados confirmam os achados de Foley, Ribeiro-Filho e Da Silva (2004) para ângulos de $\approx 68^{\circ}$, e expandem suas conclusões para ângulos visuais de até $101^{\circ}$.

\subsubsection{Da suma dos segmentos vs. a distância total}

A segunda implicação do Tangle se referia ao fato que, para um conjunto de três o mais estímulos arranjados de modo a serem percebidos como colineares, a soma das distâncias exocêntricas percebidas dos segmentos da reta não igualaria a distância exocêntrica percebida dos pontos extremos de dita reta (ver Figura 23). Para analisar isto, nas Tabelas 14 e 15 são ordenados os valores das distâncias exocêntricas percebidas dos segmentos e comparados os respectivos valores da suma versus os valores da distância percebida entre os pontos extremos de cada Diagonal.

Os resultados da comparação mostram que há diferenças segundo o fator 'Sexo do observador'. No caso das mulheres, em ambas Diagonais a suma das distâncias percebidas dos segmentos foi maior que a distância entre os pontos extremos da respectiva reta. Nos observadores homens, ocorreu o contrário, sendo em ambos casos menor a suma dos segmentos que a distância percebida da reta total. Para uma melhor comparação, nas Figuras 37 e 38 foram plotadas as médias das distâncias exocêntricas percebidas para cada série de estímulos, comparando seu tamanho com 
Tabela 14 - Médias das distâncias exocêntricas percebidas para os diferentes segmentos da Diagonais 1, considerados perceptualmente colineares.

\begin{tabular}{lcccccc}
\hline & $\overline{F 1 M 1}$ & $\overline{M 1 M 2}$ & $\overline{M 2 F 2}$ & total & $\overline{F 1 F 2}$ \\
\hline Homens & $4,36+15,00+4,37=23,73<25,53$ \\
Mulheres & $3,13+9,65+3,11=15,89>15,52$ \\
\hline Média $=$ & $3,75+12,33+3,74=19,81<20,53$ \\
\hline
\end{tabular}

Tabela 15 - Médias das distâncias exocêntricas percebidas para os diferentes segmentos da Diagonais 2, considerados perceptualmente colineares.

\begin{tabular}{cccccccc}
\hline & $\overline{F 3 M 3}$ & $\overline{M 3 M 4}$ & $\overline{M 4 F 4}$ & total & $\overline{F 3 F 4}$ \\
\hline Homens & $7,15+12,83+3,73=23,71<2$ & $<2,5$ \\
Mulheres & $5,01+8,88+2,85=16,74$ & $>15,38$ \\
\hline Média $=$ & $6,08+10,86+3,29$ & $=20,23<2,44$ \\
\hline
\end{tabular}

a respectiva distância física e com o tamanho da linha toda.

\subsection{Discussão}

Como foi notado, os resultados das estimativas verbais de distância do Experimento III mostraram uma compressão geral da distância percebida, indicando a anisotropia do espaço visualmente percebido.

Embora o modelo de Foley, Ribeiro-Filho e Da Silva (2004) fosse concebido para descrever o desempenho dos observadores em tarefas de igualação subjetiva, os resultados reportados indicariam que o mesmo consegue dar conta de dados obtidos mediante tarefas de julgamento verbal no campo aberto. Nessas condições, estes autores encontraram que a Equação 2.19 falhou na descrição dos dados do seu experimento, com a maior parte das estimativas sendo maior que as preditas pelo modelo, entanto que o Tangle logrou modelá-las perfeitamente. Em nosso caso o Modelo Generalizado conseguiu um ajuste razoavelmente bom das estimativas dos observadores, o que é demonstrado pela análise estatística do resultado. Sem embargo, o ajuste conseguido pelo Tangle foi melhor, segundo pode ser apreciado nos indicadores da bondade do ajuste obtidos. As diferenças nos ajustes de ambos modelos foram evidentes grafica- 


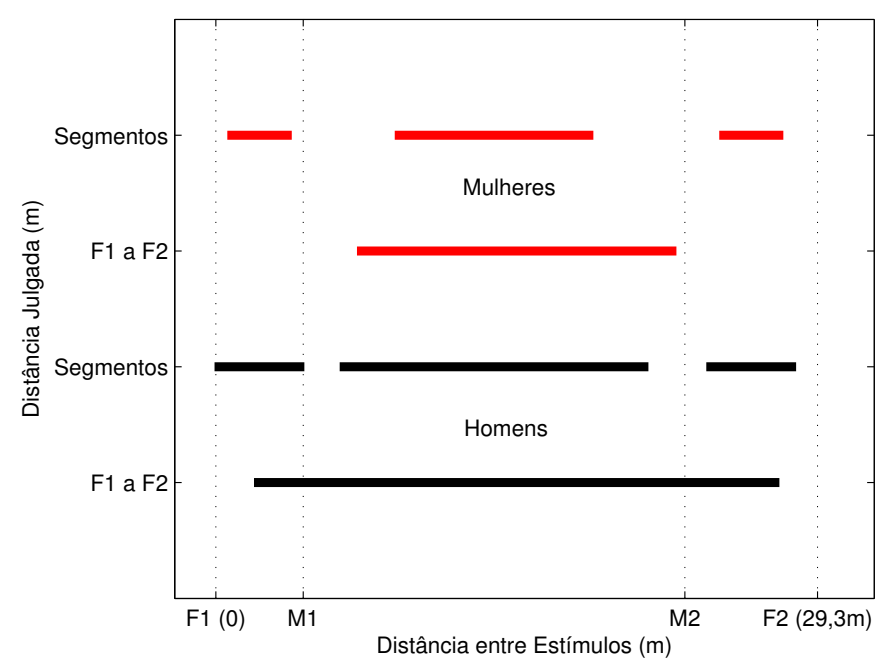

Figura 37 - Médias das distâncias exocêntricas percebidas desenhadas em função dos tamanhos físicos dos segmentos da Diagonal 1. Abaixo, tamanhos médios reportados pelos observadores homens para a diagonal toda $(\overline{F 1 F 2})$ e para os segmentos da mesma $(\overline{F 1 M 1}, \overline{M 1 M 2}$ e $\overline{M 2 F 2})$. Acima os respectivos resultados dos julgamentos dos observadores mulheres.

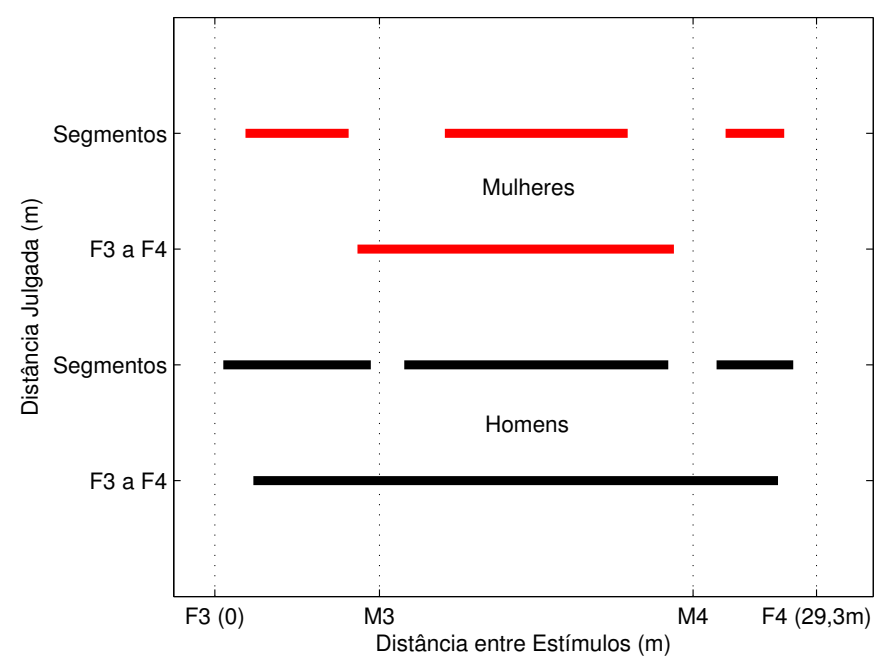

Figura 38 - Médias das distâncias exocêntricas percebidas desenhadas em função dos tamanhos físicos dos segmentos da Diagonal 2. Abaixo, tamanhos médios reportados pelos observadores homens para a diagonal toda $(\overline{F 3 F 4})$ e para os segmentos da mesma $(\overline{F 3 M 3}, \overline{M 3 M 4}$ e $\overline{M 4 F 4})$. Acima os respectivos resultados dos julgamentos dos observadores mulheres. 
mente ao comparar as Figuras 33 e 36.

Tal como estabelecido pelos autores do Tangle, os parâmetros variariam de acordo ao layout experimental. Mas no caso dos parâmetros da FDE, os valores obtidos por nós ( $F=1,29$ e $G=0,009)$ foram muito próximos aos encontrado por eles para a condição de observação binocular $(F=1,25$ e $G=0,007)$, sendo em ambos casos maiores ao valor estimado no seu trabalho para condições com boa iluminação e indícios visuais, que era $F \leq 1$. Deve ser notado que o ajuste dos julgamentos egocêntricos conseguido pela FDE foi muito melhor $(R M S E=0,29 \mathrm{~m})$ que o da função linear $(R M S E=0,53 \mathrm{~m})$ e similar ao da função de potência $(R M S E=0,28 \mathrm{~m})$.

No caso dos parâmetros $P$ e $Q$, também encontramos que ambos tomaram valores $>0$. Esta semelhança entre os parâmetros obtidos para o Tangle em duas configurações de estímulos diferentes, embora em condições de observação similares (binocular, plenas de indícios, no campo aberto) indicaria a aptitude do modelo para dar conta de dados obtidos mediante tarefas de julgamento verbal de distância exocêntrica. Isto foi confirmado pela comparação das Raízes dos Erros Quadráticos Médios obtidas nos ajustes dos diferentes modelos aos dados do Experimento III: linear (RMSE =0,66m), função de potência $(R M S E=0,46 \mathrm{~m})$, Generalizado $(R M S E=0,57 \mathrm{~m})$ e o Tangle $(R M S E=0,31 \mathrm{~m})$. Claramente o melhor ajuste foi conseguido por este último modelo, seguido depois pela função de potência.

As características "adaptativas" do Tangle parecem ser responsáveis desta superioridade nos ajustes. Quando a distância egocêntrica é subestimada, o modelo segue este padrão de função desacelerada, logrando estimativas melhores que as computadas segundo a métrica Euclidiana. Nas situações nas quais a configuração produz uma superestimação das distâncias egocêntricas, o modelo compensa as distâncias excêntricas derivadas dessas apreciações.

Ao analisar as conseqüências do modelo Tangle a partir da desigualdade do triângulo, encontramos, ao comparar os resultados das estimativas dos observadores com as predições do modelo, que em ambos os casos não houve violação desta propriedade. Nossos achados apóiam aqueles de Foley e colaboradores para ângulos de aproximadamente $68^{\circ}$. Ainda, a configuração espacial de estímulos empregada permitiu testar vários ângulos com valores entre $90^{\circ}$ e $101^{\circ}$, o quais foram indicados pela pesquisa de Koenderink, van Doorn e Todd (2009) como limites do campo visual efetivo.

A desigualdade do triângulo foi satisfeita em todas as distâncias e ângulos con- 
siderados a partir desta configuração espacial de estímulos, definida a partir dos resultados do Experimento I. Contudo, a média da suma dos segmentos das retas de colinearidade não igualou à média distância percebida entre os extremos, segundo o predito pelo modelo de Foley, Ribeiro-Filho e Da Silva (2004). Foi esta circunstância a que levou a estes autores a questionar o emprego de representações do espaço visual baseadas em geometrias métricas, tanto euclidianas (WAGNER, 1985) como riemannianas de curvatura constante (LUNEBURG, 1947) ou variável (KOENDERINK; DOORN; LAPPIN, 2000). Nossos resultados, assim como os achados apresentados na Seção 4 , apoiariam esta assunção. 


\section{Abordando aspectos cognitivos}

"A cognição espacial seria [], em outras palavras, a reflexão e reconstrução do espaço no pensamento." (HART; MOORE, 2005, 248)

Como estabelecido na Seção 1, na construção do $\mathrm{EV}^{3}$ há um processamento cognitivo subjacente, o qual estaria presente em cada processo de julgamento. Assim, é relevante estudar os possíveis fatores cognitivos involucrados nas tarefas de julgamento de distância no campo aberto.

\subsection{Visualização mental no campo aberto}

A construção do espaço visual envolve a integração de informação de diferentes fontes. É por isso que ao receber instruções, as pessoas combinam porções do espaço que são percebidas ("observe o alvos situado na sua frente") e àquelas que não ("imagine uma linha unindo os alvos apresentados"). Para derivar estas representações do espaço, a partir de tais descrições simbólicas, é preciso um processo interpretativo para traduzir-lhes em uma forma espacial e nele uma série de estratégias cognitivas são adotadas. Por isso, alguns autores se referem às representações resultantes deste processo interno de construção como "mediadas" (WU; KLATZKY; SHELTON; STETTEN, 2008).

Kelly, Loomis e Beall (2004) solicitavam a seus observadores “imaginar uma linha de um poste a outro, e continuá-la até o ponto onde esta linha imaginária interceptaria a cerca perimetral", marcando depois sua resposta numa fotografia panorâmica do campo onde as medições eram feitas ou orientando seu corpo até ficar paralelo a dita linha (no caso da tarefa de 'body pointing'). A partir desta informação, calculavam as coordenadas 
cartesianas da localização da resposta. Estes autores deduzem de seus resultados que os observadores são capazes de extrapolar uma linha imaginária ao longo de grandes distâncias e sinalizar corretamente o ponto de finalização, o que só poderia ser possível se as distâncias egocêntricas percebidas estivessem linearmente relacionadas com as distâncias físicas.

Em nosso caso, devido ao ângulo entre os pontos extremos das linhas definidas pelas séries de estímulos, o observador era incapaz de abarcar com seu campo de visão todos os alvos ao mesmo tempo. Ainda assim, a falta de diferença significativa entre os julgamentos dos Experimentos I e II, e o pequeno valor dos erros angulares cometidos, embora maiores que os obtidos por Kelly, Loomis e Beall (2004) na tarefa de colinearidade (ver Figura 16), poderia estar indicando que os observadores conseguem construir uma linha imaginária vinculando os 4 alvos e realizar a tarefa com precisão.

Consideraremos aqui a tarefa de visualização mental no sentido empregado por Shepard e Metzler (1971) quando referidos a nossa capacidade de criar "imagens mentais". Assim, a visualização mental permitiria formar uma imagem visual mental a partir de estímulos presentes (ou não) no campo visual. Depois, seria possível nelas mudar mentalmente o ponto de vista, as relações espaciais e características dos elementos, gerando incluso novas entidades. De fato, Pylyshyn (2003) destaca como uma propriedade única das imagens mentais seu caráter espacial, pois cada objeto nelas sempre apresenta algum tipo de relação espacial relativa a algum outro.

Para se obter uma melhor compreensão acerca destas representações visuais do espaço, muita investigação vêm sendo desenvolvida nestes últimos anos (DIWADKAR; MCNAMARA, 1997; KORIAT; GOLDSMITH; PANSKY, 2000; SIMONS; WANG, 1998; WANG; SIMONS, 1999), com pesquisas aplicadas demonstrando as vantagens das técnicas baseadas em visualização mental na preparação prévia a eventos de exigência física, por exemplo esportivos (JEANNEROD, 1995; RAMIRES; CARAPETA; FELGUEIRAS; VIANA, 2001) ou terapêuticos (WARNER; MCNEILL, 1988)

No contexto do estudo apresentado, o interesse por esta questão volta-se para a comparação do desempenho dos observadores frente a duas situações de estimação de distância: 1) a primeira, baseada na localização de um ponto específico, imaginado a partir da interceptação mental de duas linhas de colinearidade definida por uma série de alvos fixos e 2) a segunda, a um alvo fixo na posição física do ponto de interseção das linhas de colinearidade. 


\subsection{Experimento IV}

O propósito deste experimento foi avaliar o comportamento dos observadores frente a dois tipos diferentes de tarefas espaciais (percepção e visualização mental) aplicadas em uma situação experimental de julgamento verbal de distância em campo aberto.

\subsubsection{Método}

\subsubsection{Participantes}

Participaram do estudo 40 voluntários (metade do sexo masculino, metade do sexo feminino), com visão normal ou corrigida, todos ingênuos quanto ao propósito do experimento. Foram divididos simetricamente em dois grupos independentes. $\mathrm{O}$ GRUPo 1 (10 mulheres, 10 homens) com idade média de 27 \pm 7 anos, e Grupo 2 (10 mulheres, 10 homens) com idade média de $28 \pm 5$ anos. Devido às características do experimento, cada grupo realizou só uma tarefa para evitar o viés nas respostas que ocorreria se julgaram em ambas configurações.

\subsubsection{Ambiente experimental}

Foi utilizado o mesmo ambiente experimental do Experimento I.

\subsubsection{Equipamentos e materiais}

Os estímulos empregados foram as mesmas estacas brancas de alturas variáveis, conforme apresentadas no Experimento I. O estímulo fixo empregado para a tarefa do Grupo 1 respeitava as características dos conjunto, com uma altura de 1,30 m.

Em ambas condições foi empregado um suporte de queixo fixado a uma altura de 1,35 m para restringir os movimentos do observador. Assim, todos os sujeitos observaram ambas as configurações de estímulos pelo mesmo ângulo de visão.

\subsubsection{Planejamento experimental}

Duas condições experimentais foram empregadas. Para o Grupo 1, que realizava a tarefa puramente perceptual, o único alvo estava fixado no ponto de cruzamento 


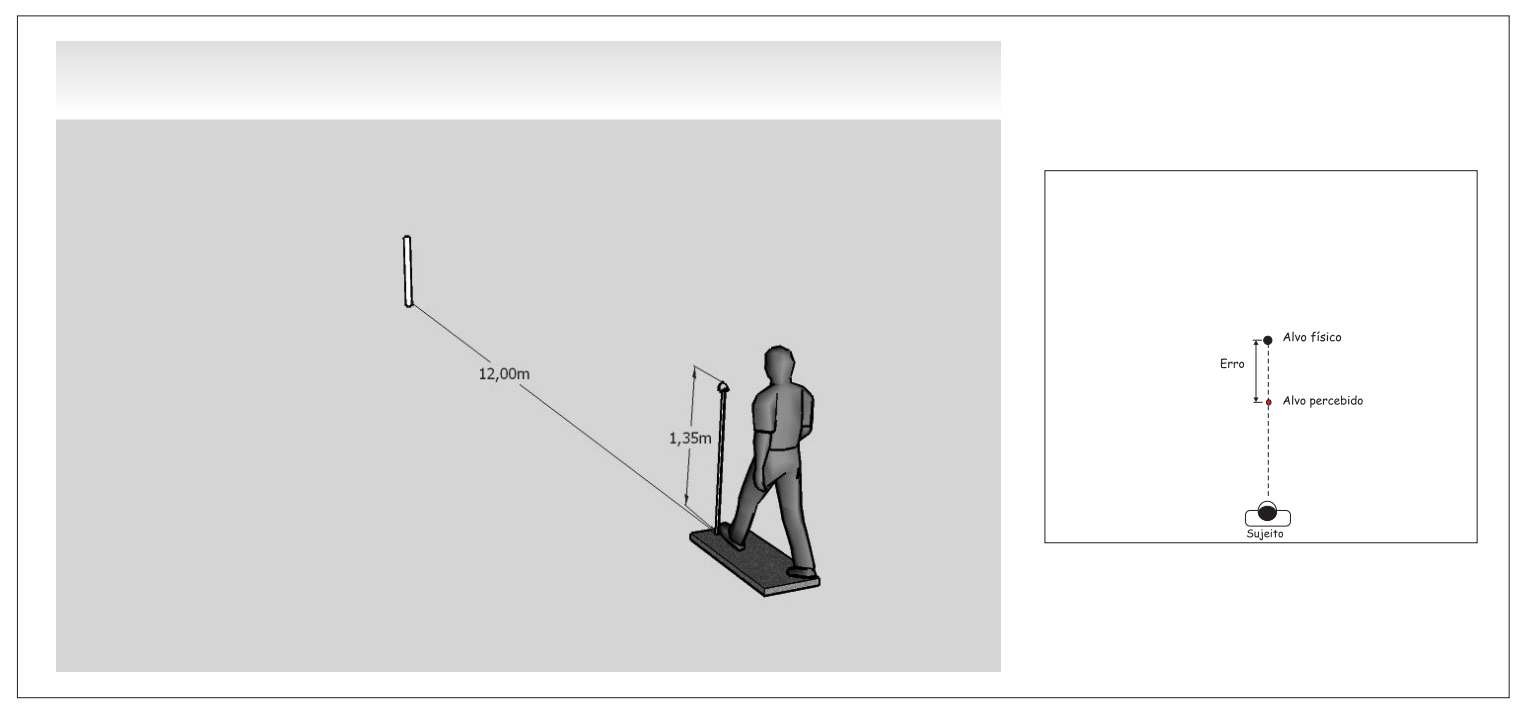

Figura 39 - Configuração espacial e esquema da tarefa (simples) para o Grupo 1.

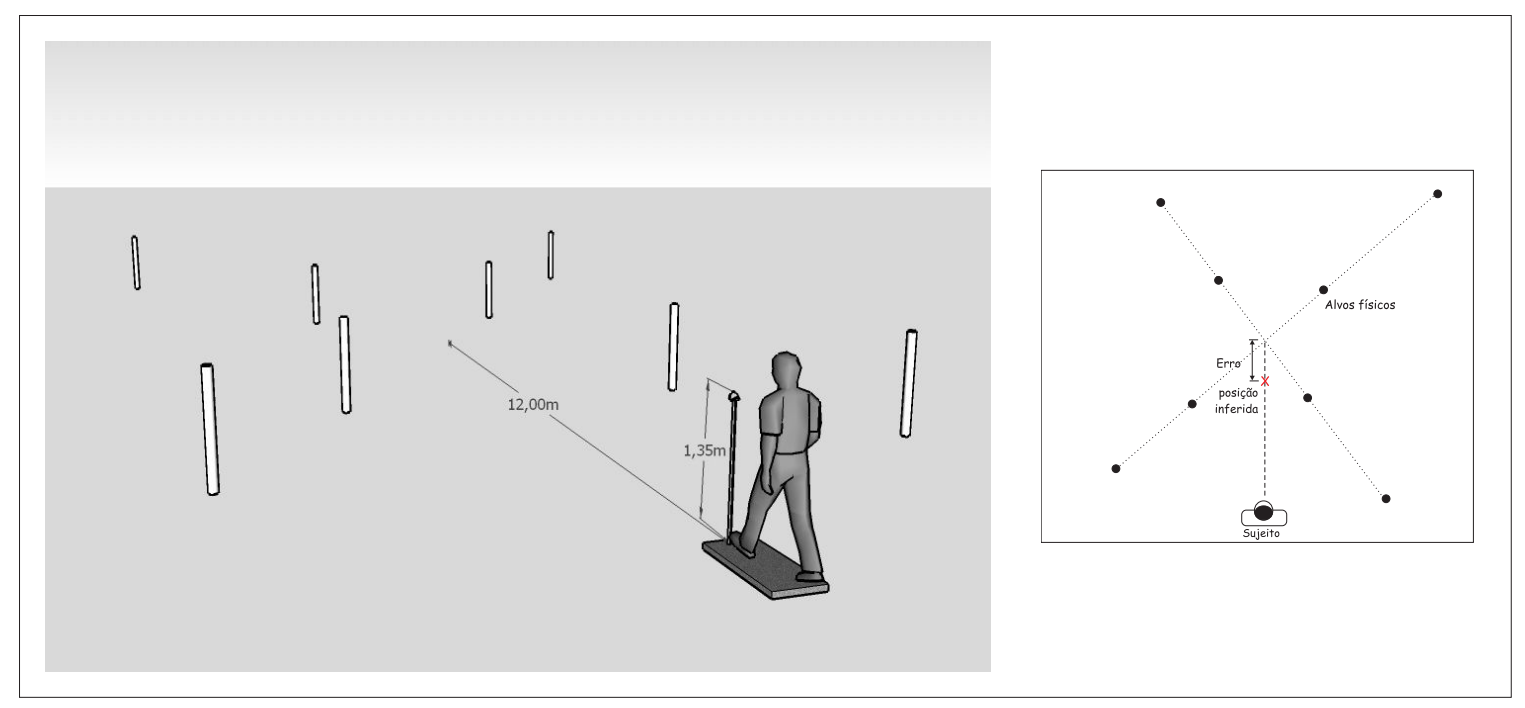

Figura 40 - Configuração espacial e esquema da tarefa (complexa) para o Grupo 2.

das retas de colinearidade da configuração de estímulos definida para o Experimento I, o qual se encontrava a $12 \mathrm{~m}$ na frente do observador (Figura 39). Para o Grupo 2, que efetuava a tarefa de "visualização mental", os oito estímulos foram situados nos pontos de colinearidade geométrica da configuração de estímulos empregada no Experimento I. O centro a $12 \mathrm{~m}$ era o mesmo ponto onde ficava o alvo da tarefa da primeira condição (Figura 40). Assim, a estimativa verbal da distância e o gênero do observador foram as variáveis analisadas. 


\subsubsection{Procedimento}

Todos os observadores assinaram o termo de consentimento livre e esclarecido, sendo logo conduzidos até o local de pesquisa. Em seguida, eram acomodados numa posição à parte do campo experimental (relativamente distante) onde eram lidas as instruções, do tipo objetiva, sobre a tarefa que deveriam executar. Em seguida, os sujeitos eram conduzidos ao ponto de observação da configuração.

O Grupo 1 (perceptual) realizou o julgamento de distância egocêntrica a partir do alvo fixo posicionado a $12 \mathrm{~m}$ na sua frente. A tarefa do sujeito foi indicar verbalmente em metros e centímetros quão longe estava o alvo a partir de ele.

O Grupo 2 (visualização mental) enfrentou uma tarefa mais complexa, pois devia inferir, a partir dos oito alvos fixos, o ponto de cruzamento das duas linhas determinadas por eles e julgar a distância egocêntrica até dito ponto, que era o mesmo local onde ficava o alvo para o Grupo 1. Cada observador teve que estimar, verbalmente, em metros e centímetros a distância dele até esse ponto que estava visualizando mentalmente.

\subsubsection{Resultados}

Na Figura 41, foram apresentados os dados obtidos. Em cada grupo os observadores foram discriminados por sexo.

Após a análise estatística dos dados, decidiu-se desconsiderar os outliers nas análises posteriores, seguindo o mesmo critério que nos Experimentos I e II.

Como pode ser observado na Figura 42, os resultados mostraram que existe subconstância em ambos tipos de tarefas, encontrando na ANOVA diferenças significativas entre os alvos físico e inferido $\left(F_{(1,34)}=19,3, p<0,001\right)$.

Embora em ambos sexos há subestimação em ambas tarefas, ocorre uma diferença significativa entre as médias das estimativas dos observadores homens e mulheres $\left(F_{(1,34)}=17,6, p<0,001\right)$, como fica evidenciado na Figura 43.

Uma ANOVA aplicada à média das estimativas revelou que a interação 'Tarefa $x$ Sexo do observador' não foi estatisticamente significativa $\left(F_{(1,34)}=0,68, p=0,414\right)$, o que pode ser apreciado na Figura 44. Uma análise detalhada com o teste de Tukey permitiu vislumbrar que não há diferenças nos julgamentos das mulheres para ambos tipos de estímulos e tampouco entre homens e mulheres para o alvo inferido $(p>0,05$ 


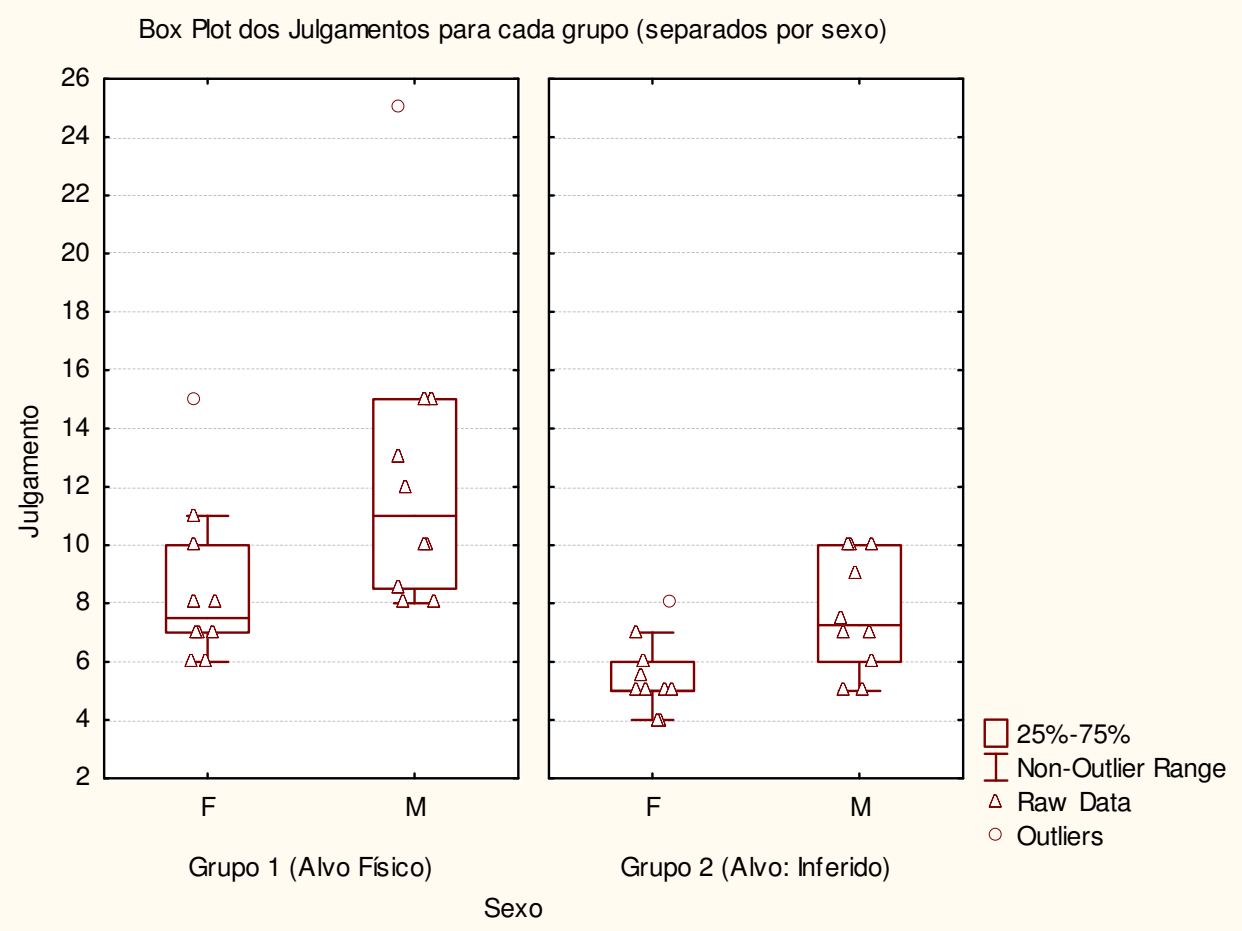

Figura 41 - Distribuição dos resultados dos julgamentos disgregados por 'Tipo de tarefa' e por 'Sexo dos observadores'.

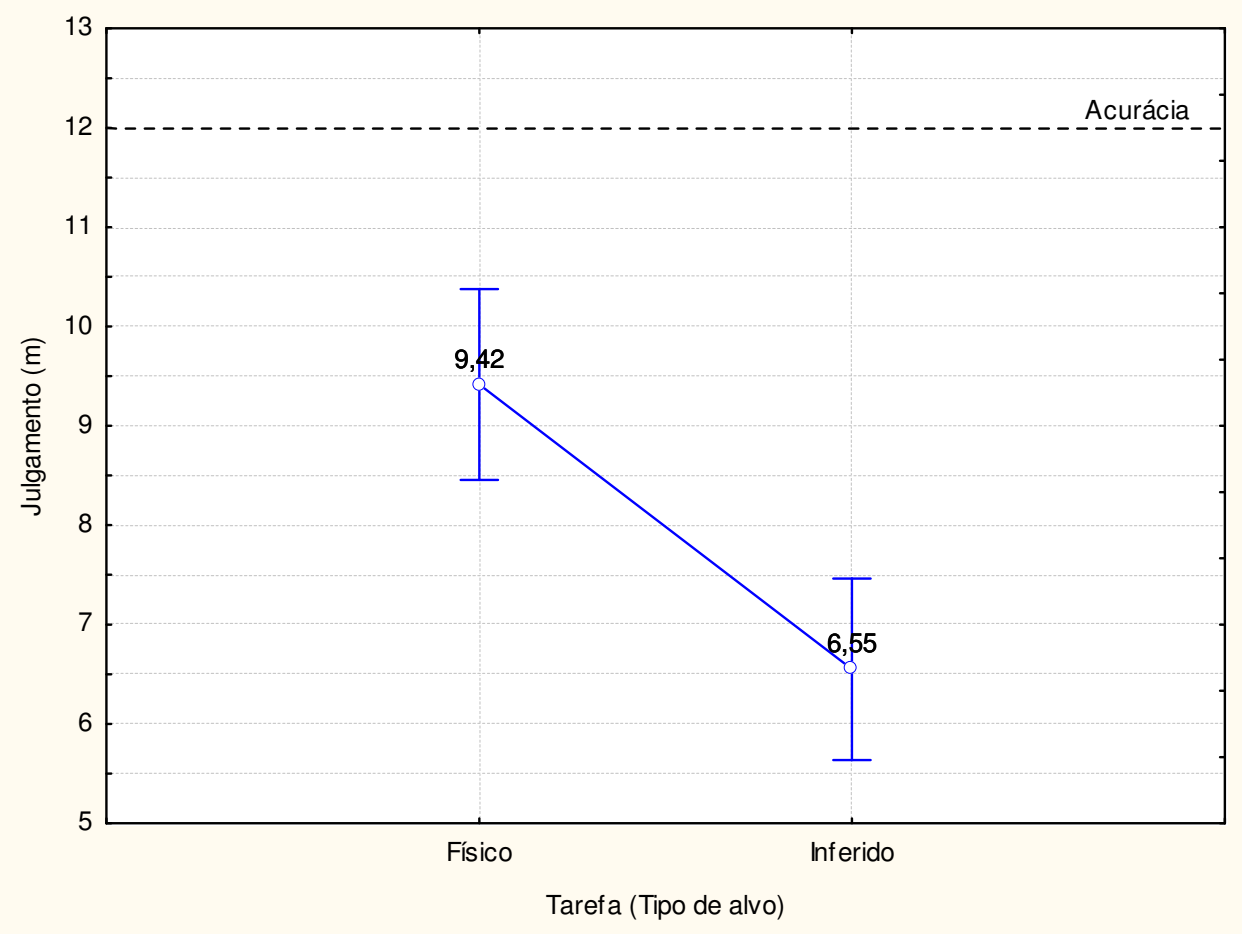

Figura 42 - Comparação das médias dos julgamentos segundo o 'Tipo de tarefa' considerando todos os observadores. 


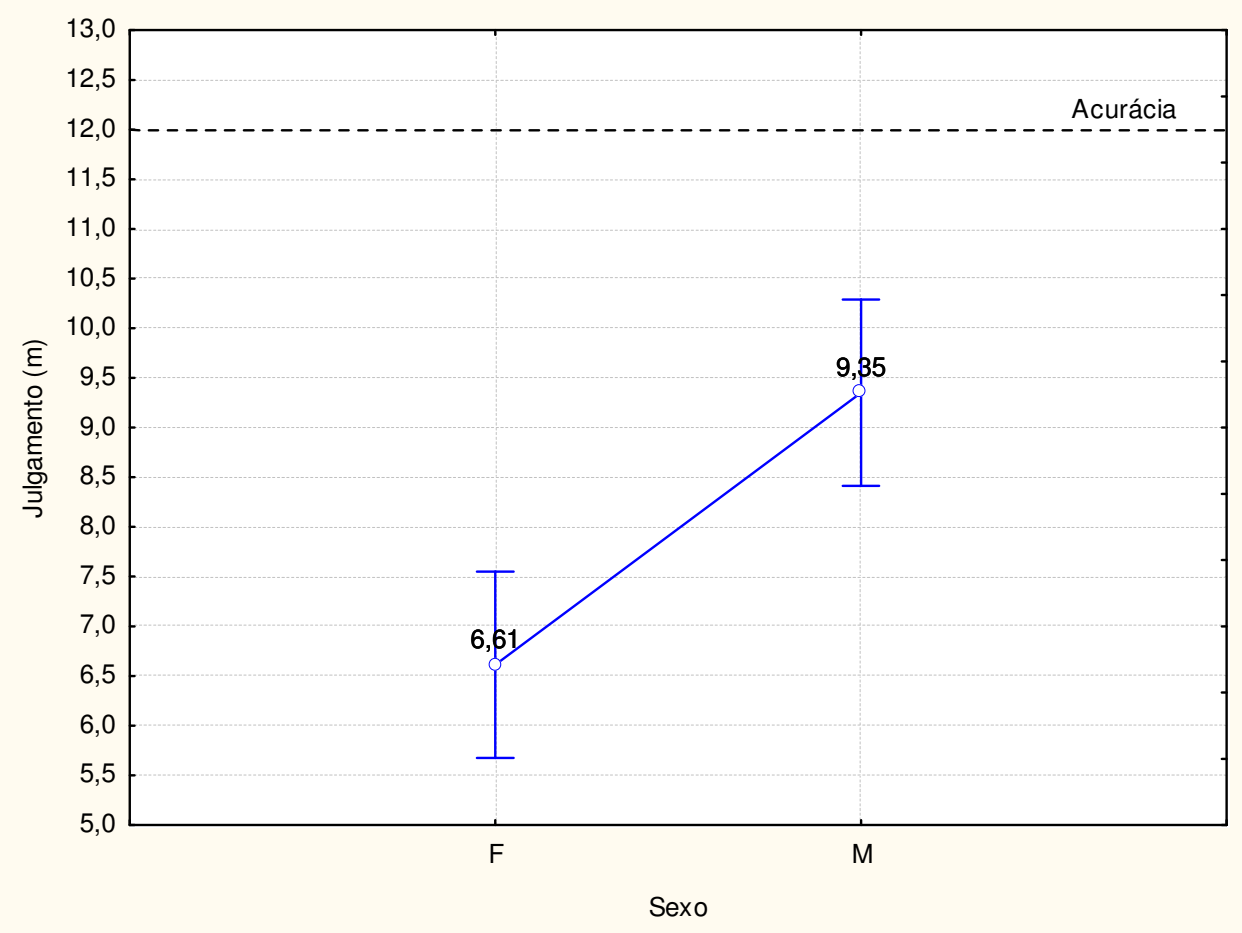

Figura 43 - Comparação das médias dos julgamentos segundo o 'Sexo dos observadores'.

em ambos casos), mas que existem diferenças significativas entre os julgamentos de homens e mulheres para o alvo físico $(p<0,05)$.

\subsubsection{Discussão}

Os resultados mostraram que no campo aberto a tarefa com um estímulo físico produziu estimativas melhores que a complexa de visualização mental, baseada na inferência da posição a partir de outros objetos. Gogel e Da Silva (1987), têm hipotetizado que os observadores adultos são conscientes da compressão (foreshortening) das distâncias egocêntricas a objetos mais distantes, e que, portanto, tentam corrigir seus julgamentos de distância a partir deste conhecimento. Possivelmente, esta correção cognitiva seja mais fácil de realizar com o estímulo físico devido ao feedback, entretanto as inferências baseadas na visualização mental se mostraram mais difíceis de alterar, o que fica evidente no maior grau de compressão nas estimativas. Sem embargo, estas seriam coerentes com os resultados encontrados no Experimento I, onde as linhas de colinearidade apresentavam deformações pré-geodésicas similar à reportada por Koenderink et al. (2008), o que faria que o ponto de interseção ficasse geralmente deslocado no sentido do observador. 


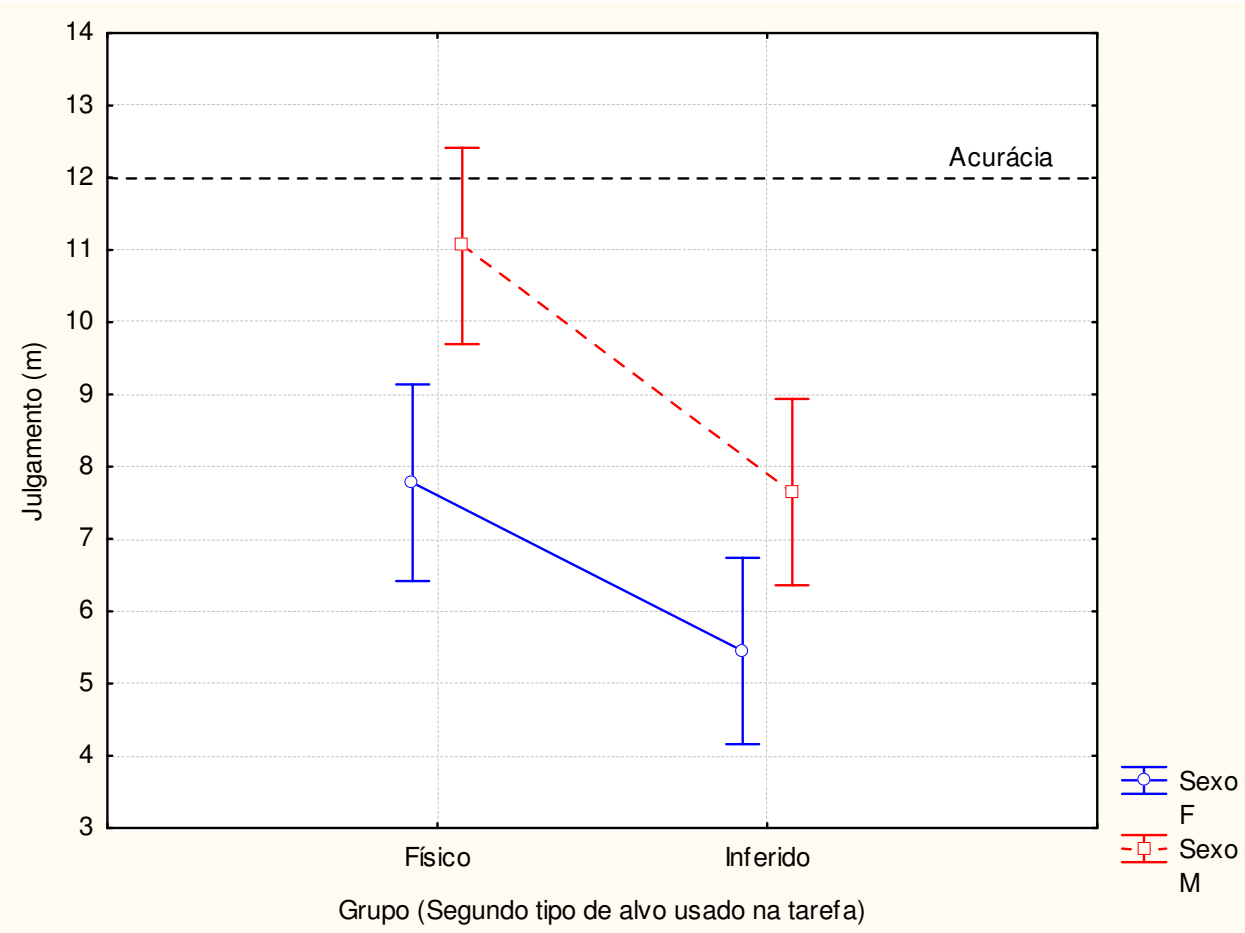

Figura 44 - Comparação das médias dos julgamentos considerando a interação 'Tipo de tarefa $*$ Sexo'.

Nos resultados de ambas tarefas pôde ser observada a anisotropia do espaço visual reportada na literatura (LEVIN; HABER, 1993; HABER, 1985; WAGNER, 1985; TOYE, 1986; KELLY; LOOMIS; BEALL, 2004) e nos Experimentos prévios, mas chama a atenção a magnitude dos erros cometidos, especialmente, quando comparados com os da tarefa de colinearidade do Experimento I. Tanto no Grupo 1 como o Grupo 2 há evidencia de erros com dimensões métricas dos julgamentos, enquanto que na tarefa do Experimento I, para alvos quase ao dobro de distância $(\approx 24 \mathrm{~m})$, os erros médios cometidos na tarefa de colinearidade sempre foram inferiores aos $50 \mathrm{~cm}$. Aplicando as retas de regressão calculadas a partir desses dados, o valor médio para o erro a uma distância egocêntrica de $12 \mathrm{~m}$ seria de $\approx 11,31 \mathrm{~cm}$, muito abaixo dos valores obtidos a partir dos registros verbais, mostrando a influência do tipo de tarefa na estimação da distância.

Os Modelos referidos no Experimento III, testados com parâmetros obtidos a partir dos dados dos julgamentos verbais de distância egocêntrica, predizem os seguintes valores para um alvo situado a 12 m do observador: Modelo linear $\Rightarrow$ 7,62 m; Função de potência $\Rightarrow 8,52 \mathrm{~m}$; e Tangle $\Rightarrow 8,6 \mathrm{~m}$. Quando comparados com os valores médios das duas tarefas utilizadas no presente Experimento, estas predições, especialmente a do Tangle, são mais aproximadas ao resultado conseguido com o alvo físico. Isto 
poderia estar indicando que os mesmos processos cognitivos estiveram subjacentes nas estimativas de distância egocêntrica realizadas em ambos experimentos, quando empregados estímulos físicos.

Kelly, Loomis e Beall (2004) enfatizaram que na sua tarefa de colinearidade os sujeitos conseguiram visualizar mentalmente uma linha de mais de $10 \mathrm{~m}$, produzindo erros angulares pequenos. Resultados similares foram obtidos com as tarefas dos Experimentos I e II. Mas as diferenças destes experimentos com os resultados da tarefa de visualização mental poderia indicar que os observadores usaram, em ambos casos, estratégias cognitivas diferentes na representação mental destas linhas de colinearidade. Outra alternativa possível seria que o registro verbal da distância ao alvo imaginado seria permeado por algum outro processo cognitivo que incrementa o grau de subestimação. Nesse sentido, autores como Struiksma, Noordzij e Postma (2009) consideram que a imagem mental seria supra-modal, ou seja, que suas propriedades espaciais excederiam o visual, incorporando características de outras modalidades perceptuais e da linguagem, não sendo sempre a ação final um produto exclusivo da percepção e da cognição (SONG; NAKAYAMA, 2009).

Tversky (2000) aponta para a importância da linguagem na aquisição do conhecimento acerca do espaço. Segundo a autora, descrições bem-feitas do espaço podem propiciar a elaboração de representações acuradas. Apreende-se, então, que tanto no momento da percepção visual do espaço/configuração espacial, quanto no acesso desta informação armazenada (representação mental) a questão verbal permeia o processo. Um exemplo disto é que os observadores, ainda sendo encorajados reiteradas vezes a falar qualquer valor de distância, por exemplo em centímetros, geralmente julgavam as distâncias dos alvos usando valores inteiros em metros ou, em caso de aproximação de valor, usavam $\frac{1}{2}$ metro. A título de exemplo, de um total de 400 julgamentos verbais, $23,25 \%$ apresentaram o formato " $(x x) \pm \frac{1}{2} \mathrm{~m}$ ", e só $0,5 \%$ usaram para aproximar um valor distinto ao $\frac{1}{2} \mathrm{~m}$.

Por último, foram encontradas diferenças significativas relativas ao fator 'Sexo do observador'. Estas se manifestaram de forma geral na magnitude do erro nos julgamentos, com uma diferença entre as médias de homens e mulheres de 2,74 m (Figura 43). Quando considerado o estímulo empregado, as mulheres não apresentaram diferencias estatisticamente significativas, enquanto que para os observadores homens fez diferença se o estímulo era físico ou visualizado mentalmente (Figura 44). É interessante notar que na tarefa com maior componente cognitivo não existiu dife- 
renças significativas entre homens e mulheres. Dentro deste contexto, na seqüência será considerada a questão dos efeitos do fator 'Sexo do observador' nos experimentos realizados.

\subsection{Comparando o fator 'sexo do observador' nos Expe- rimentos I, II, III e IV}

Como foi estabelecido, as habilidades espaciais envolvem perceber e manipular mentalmente objetos e imagens. As diferenças devidas ao sexo ${ }^{1}$ nestas habilidades têm sido consideradas entre as diferenças cognitivas mais importantes e controvertidas (CRAWFORD; CHAFFIN; FITTON, 1995), sendo a principal razão de ter sido balanceado o sexo dos observadores em todos os experimentos desta tese. Observações informais no momento da coleta de dados já indicavam algumas diferenças nas estimativas e julgamentos dos observadores de ambos os sexos, por isto este fator foi considerado em todas as análises dos resultados.

Nos Experimentos I e II as diferenças entre os observadores homens e mulheres aparecem sobretudo nos valores dos desvios padrão, mas as diferenças na magnitude dos erros não foram estatisticamente significativas. Todavia, podem ser notadas diferenças em relação às orientações mais freqüentes dos estímulos (confrontar as Figuras 17 e 22). Segundo a literatura, a assimetria entre as duas diagonais é um fenômeno cognitivo intrigante pelo fato de não poder ser reduzido a assimetrias entre os hemicampos direito e esquerdo (KOSSLYN, 1987), ou superior e inferior (CHRISTMAN, 1993), pois se estendem da direita à esquerda e de acima para abaixo por todo o campo visual. Ainda, Avrahami, Argaman e Weiss-Chasum (2004) encontraram evidência de que essa assimetria estaria relacionada ao gênero, intervindo nos julgamentos perceptuais e preferências estéticas dos observadores, como pode ser notado nos resultados de seus experimentos. Contrariamente, no Experimento III as diferenças significativas entre os julgamentos dos observadores aparecem relacionados com o valor do erro constante e não com a Diagonal considerada, acontecendo tanto para as distâncias egocêntricas como exocêntricas.

É interessante notar que no Experimento III o rendimento dos observadores do

\footnotetext{
${ }^{1}$ No contexto da Psicologia Experimental, na qual está enquadrado o presente trabalho, os termos 'Sexo' e 'Gênero' são utilizados como sinônimos. Mas a Psicologia Feminista, quando considera a cognição no contexto social, faz uma distinção conceptual entre ambos (CRAWFORD; CHAFFIN; FITTON, 1995). $\mathrm{O}$ 'Sexo' é definido como as diferenças biológicas na composição genética e na anatomia reprodutiva e funcional, e o 'Gênero' é o que a cultura faz com o "material cru" do sexo biológico.
} 
sexo feminino melhora na condição Com referência, isto é, quando empregado um padrão de comparação. No Experimento IV, o rendimento de ambos os sexos foi similar na tarefa de visualização mental. Nossos achados concordam com Feingold (1988), quando ele postula que as diferenças entre observadores de diferentes gêneros desaparecem quando empregadas tarefas complexas.

Em relação às diferenças devidas ao sexo nas habilidades espaciais, existem autores que consideram que as origens poderiam ser advindas dos efeitos dos hormônios (KIMURA, 1996; TORRES et al., 2006), enquanto outros apontam para diferentes áreas do cérebro involucradas (COMMITTERI et al., 2004) e até diferenças sensoriais (WAGNER; FINK; ZADNIK, 2008).

Novas investigações acerca do tema devem ser conduzidas para identificar e esclarecer similaridades e diferenças devida ao gênero nos processos de percepção e representação mental da informação visuo-espacial, especialmente a referida a condições naturais de observação.

\subsection{Percepção de colinearidade com visibilidade redu- zida}

As distorções sistemáticas do espaço visual, produzidas pela presença ou ausência de fontes de informações visuais, são produto dos processos decisórios ao longo das diferentes etapas perceptivas (referidas na Seção 1 e representadas na Figura 1), sendo caracterizadas por dois tipos de estimulação: a proximal, baseada nos receptores visuais e mecanismos cerebrais, e pela estimulação distal, que é registrada a nível do objeto externo ao observador (GOGEL, 1973). Estas estimulações estariam associadas diretamente aos indícios visuais de distância, seguindo os objetos mais próximos a norma da estimulação proximal e, os mais distantes, podem ter a ação dos indícios visuais reduzidos, produzindo julgamentos que dar-se-ão a nível da subjetividade (RIBEIRO-FILHO, 1993).

Gogel (1974) considera que em condições reduzidas de indícios os observadores tendam melhorar as estimativas usando correções cognitivas, que ele chamou de "tendências do observador". A tendência da distância específica ocorreria em situações de redução de fontes de informação de distância egocêntrica, onde o objeto pareceria estar posicionado a uma distância entre dois e três metros do observador. A tendência eqüidistante ficaria evidente na redução de fontes de informação visual de distância 
exocêntrica, manifestada pela tendência dos objetos, ou partes deles, aparecerem na mesma distância ao observador.

A redução da visão usando pupila artificial (pinhole) nos julgamentos de distância exocêntrica no campo aberto foi empregada no trabalho de Matsushima (2003), com a intenção de limitar a informação binocular e oculomotora, especialmente, dos movimentos vergenciais. Seus resultados, restritos à orientação sagital (devido à dificuldade própria do uso da pupila artificial na observação da orientação frontoparalela esta orientação foi desconsiderada), mostraram que esta redução causou uma forte compressão dos julgamentos de distância exocêntrica, sendo similares aos obtidos com a redução dos movimentos translacionais da cabeça.

Uma outra opção interessante de redução da visão é mediante ofuscamento (blur). A primeira razão seria porque a percepção do ofuscamento é um atributo do sistema visual humano (CIUFFREDA; WANG; VASUDEVAN, 2007), que o utiliza para enfocar e conseguir imagens retinais nítidas, aproveitando, também, esta informação como indício de profundidade relativa e absoluta dos objetos no ambiente (MATHER, 1997). Uma segunda razão seria o valor ecológico dos resultados, pois estes podem ser relacionados aos produzidos por condições naturais de perda de visibilidade. Estas poderiam ser externas ao observador (distais) (CUQLOCK-KNOPP; WHITAKER, 1993), por exemplo, no caso de condições climáticas como chuva intensa ou neblina, ou internas (proximais), tal como sucede na pessoa com cataratas (FINE; RUBIN, 1999) ou miopia (ofuscamento por desenfoque (WOODS; STRANG; ATCHISON, 2000)).

\subsection{Experimento V}

O propósito deste experimento foi avaliar o desempenho dos observadores na tarefa de colinearidade realizada em condições de visão reduzidas por ofuscamento, testando a hipótese da correção cognitiva dos ajustes.

\subsubsection{Método}

\subsubsection{Participantes}

Participaram do estudo seis voluntários (metade do sexo masculino, metade do sexo feminino), com visão normal ou corrigida, todos ingênuos quanto ao propósito do experimento. A idade média dos observadores foi de $27 \pm 4$ anos. 


\subsubsection{Ambiente experimental}

Foi utilizado o mesmo layout experimental do Experimento I.

\subsubsection{Equipamentos e materiais}

Os estímulos foram as mesmas estacas brancas de alturas variáveis do Experimento I.

Foi empregado um suporte de queixo fixado a uma altura de 1,35 $\mathrm{m}$ para restringir os movimentos do observador. Assim, todos os sujeitos observaram ambas as configurações de estímulos desde o mesmo ângulo de visão.

Foi construído um par de óculos especiais para produzir uma redução da visão baseada no ofuscamento, que consistiam de óculos de proteção modificados agregando um filme auto adesivo. A caracterização difusora do filme foi realizada através dos sistemas OQAS e C-Quant ${ }^{2}$. Os resultados da Função de Dispersão de Ponto (Point Spread Function) podem ser observados na Figura 45. O valor de 'S' oscila entre 30 e 35, o que corresponderia à difusão própria de um olho de $\geq 80$ anos sem patologia ocular, ou a um de menor idade, mas com uma catarata avançada. O efeito na visão funcional do observador é de um filtro 'passa-baixo', permitindo a passagem das baixas freqüências espaciais e filtrando as altas, o que se manifestaria na perda dos detalhes finos na imagem retinal.

\subsubsection{Planejamento experimental}

Foi empregado um planejamento fatorial similar ao do Experimento I com o objetivo de comparar os resultados dos ajustes realizados pelos observadores em duas condições de visão: Sem e Com filtro. Assim foram empregados um fator intra-sujeitos, duas direções de ajustamento (ponto de inicio) e duas séries de estimativas, considerando como variável dependente o erro no ajuste de colinearidade. O sexo dos observadores foi balançado na amostra, mais não foi considerado como fator nas análises.

\footnotetext{
${ }^{2}$ No Laboratório de Óptica do “Departamento de Luminotecnia, Luz y Visión”, da Faculdade de Ciências Exatas e Tecnologia da Universidade Nacional de Tucumán, Argentina
} 


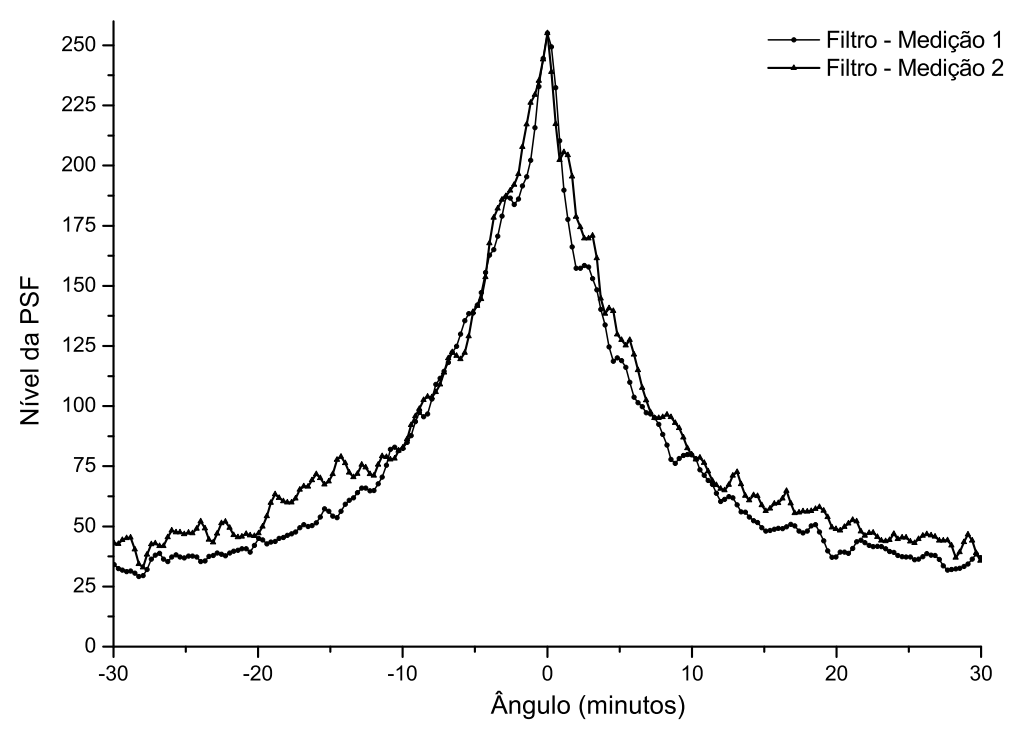

Figura 45 - Caracterização do filtro difusor empregando a Função de Dispersão de Ponto (Point Spread Function)

\subsubsection{Procedimento}

Todos os observadores assinaram um termo de consentimento livre e esclarecido, sendo logo conduzidos até o local de pesquisa. Em seguida, foram levados para uma das laterais do campo experimental relativamente afastada, onde eram lidas as instruções, do tipo objetiva, sobre a tarefa que deveriam executar.

A ordem das condições foi parcialmente randomizada no grupo, de tal forma que metade dos observadores realizaram primeiro a medição sem filtro e metade a realizaram primeiro com filtro.

Foi seguido o mesmo procedimento que nos Experimentos I e II, solicitando aos sujeitos que ajustassem a posição dos estímulos móveis M1 e M2 até que ficassem colineares à extensão compreendida entre F1 e F2, realizando logo o mesmo procedimento com os estímulos M3 e M4.

Para a medição em condições de visão reduzida, o observador virava de costas e, com ajuda do experimentador, colocava os óculos especiais ajustando-os até ficar certo. Após cada série de ajustes dos estímulos móveis, os observadores viravam de costas durante o período de medições, podendo tirar os óculos para descansar.

Os erros de colinearidade foram medidos da mesma forma que nos experimentos anteriores, usando o centímetro como unidade, e considerando negativo o sentido 
Tabela 16 - Médias, desvios-padrão (SD) e medianas dos resultados dos ajustes de colinearidade nas duas condições: Sem e Com filtro. (Unidade: $\mathrm{cm}$ ).

\begin{tabular}{cccccccc}
\hline & \multicolumn{3}{c}{ Sem Filtro } & & \multicolumn{3}{c}{ Com Filtro } \\
\cline { 2 - 3 } \cline { 6 - 8 } Estímulo & Média & SD & Mediana & & Média & SD & Mediana \\
\hline M1 & 2,46 & 34,26 & 7,00 & & 8,00 & 33,79 & 6,50 \\
M2 & $-34,96$ & 38,43 & $-35,50$ & & $-40,13$ & 43,92 & $-46,25$ \\
M3 & 8,77 & 48,43 & 16,75 & & 2,04 & 48,68 & 14,50 \\
M4 & $-25,92$ & 30,83 & $-29,50$ & & $-31,19$ & 27,63 & $-32,00$ \\
\hline All Grps & $-12,41$ & 42,23 & $-22,00$ & & $-15,32$ & 43,98 & $-24,00$ \\
\hline
\end{tabular}

proximal ao observador e positivo o sentido oposto (Figura 11).

\subsubsection{Resultados}

Os resultados estão sumariados na Tabela 16 e representados na Figura 46.

Os dados foram submetidos a uma ANOVA fatorial, incluindo medidas repetidas, sobre os erros de colinearidade, considerando os fatores principais posição espacial do Estímulo móvel, Ponto de início da medição (Fora o Dentro), Ordem da medida (primeira ou segunda). A análise revelou somente efeito significativo para o fator 'Estímulo Móvel' com $F_{(3,184)}=14,574, p<0,001$. Nenhum dos outros fatores principais ou interações foram estatisticamente significativas ( $p>0,1$ em todos os casos).

Uma análise pós-hoc com o teste de Newman-Keuls para o fator Estímulo Móvel, encontrou diferenças significativas $(p<0,05)$ entre os estímulos 1 e 4 , e entre os estímulos 2 e 3 . Colocado de outra maneira, a análise mostra que as respostas para as posições espaciais 1 e 3 (próximas ao observador) foram similares, acontecendo o mesmo para os estímulos 2 e 4 (distantes ao observador).

\subsubsection{Discussão}

Não deixa de ser surpreendente que a magnitude dos erros na condição com filtro difusor fosse similar à obtida com visão normal, especialmente considerando o nível de ofuscamento a que foram submetidos os sujeitos, sendo este um elemento limitador perceptivo. Os dados dos ajustes de colinearidade sugerem que os observadores foram capazes de melhorar os perceptos, compensando os déficits induzidos. 


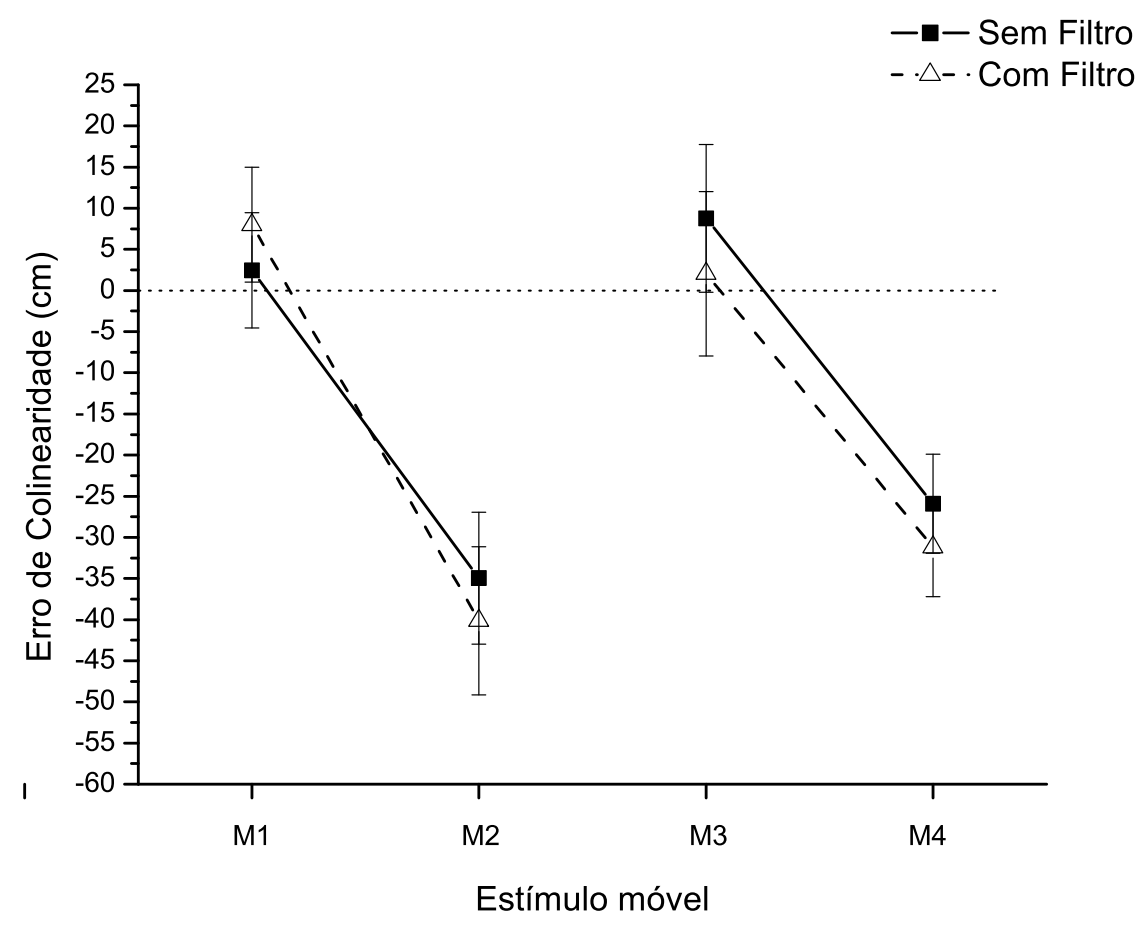

Figura 46 - Médias dos erros (em $\mathrm{cm}$ ) cometidos no ajuste de colinearidade nas condições Sem e Com visibilidade reduzida em função da posição espacial do estímulo móvel. As barras verticais representam o erro padrão da média. A linha pontilhada representa a colinearidade perfeita. 
Os processos compensatórios poderiam estar agindo tanto na estimulação proximal como distal. A compensação neural de déficits sensorial ao nível da óptica do olho (aberrações) já tinha sido referida por Artal et al. (2004). Igualmente, segundo Rajeev e Metha (2009), os mecanismos de adaptação do sistema visual compensariam os efeitos do ofuscamento, melhorando a Sensibilidade ao Contraste a partir de uns 30 minutos de exposição a estímulos em ditas condições. Como em nosso caso os observadores começavam a realizar a tarefa imediatamente colocados os óculos, e em geral terminavam antes de finalizado o lapso de tempo referido pelos autores, possivelmente não conseguiram se adaptar adequadamente à condição de visão reduzida, compensando fisiologicamente o déficit induzido. Então, outros mecanismos compensatórios foram utilizados. A hipótese da correção cognitiva (GOGEL, 1973) agindo na estimulação distal ganharia força, explicando o porquê de os erros na condição 'com filtro' serem similares aos obtidos na condição 'sem filtro'. Estes processos corretivos poderiam ser os mesmos evidenciados em outras respostas de base motora, onde transformariam o indicador (por exemplo caminhar de olhos vendados) de tal maneira que as distorções no espaço visual seriam compensadas em maior medida que nos julgamentos verbais, dando lugar assim a outputs mais acurados (PHILBECK, 1997; LOOMIS; DA SILVA; FUJITA; FUKUSIMA, 1992). Esta correção cognitiva pode incluir estratégias conscientes dirigidas a produzir uma resposta em particular, mas não precisa estar explicitamente disponível na consciência (GOGEL; DA SILVA, 1987), sendo esta particularidade a responsável da dificuldade no seu estudo.

\subsection{Importância de se considerar conjuntamente os as- pectos visual, perceptual e cognitivo}

A particularidade do espaço visual de integrar aspectos perceptuais e cognitivos abre uma perspectiva de investigação que permitiria o estudo das interações destes processos a partir de tarefas como a percepção de distância, sendo muita pesquisa desenvolvida nesta direção (POSTMA, 2005; AZNAR-CASANOVA; MATSUSHIMA; RIBEIROFILHO; DA SILVA, 2006; LOOMIS; PHILBECK, 2008; AZNAR-CASANOVA; DA SILVA; RIBEIROFILHO; SANTILLÁN, 2009).

As evidências apresentadas no contexto deste estudo experimental apontam sobre a relevância dos processos cognitivos no momento de realizar tarefas espaciais como o ajuste de colinearidade, a visualização mental ou a estimação de distância. Neste sentido, a influência de fatores como o sexo do observador devem ser considerados 
pois, dependendo da tarefa, podem produzir diferenças significativas nos resultados.

Melhoras nas metodologias e técnicas empregadas possivelmente permitiram revelar e identificar experimentalmente as fases seqüenciais da percepção, cognição, toma de decisões e resposta motora. Estudos neurofisiológicos recentes (SONG; NAKAYAMA, 2009) indicariam a existência de múltiplos processos interativos que ocorreriam simultaneamente, reduzindo a distância entre as diferentes disciplinas onde cada um destes processos tem sido investigado independentemente.

Pesquisas vinculando aspectos visuais específicos (como o ofuscamento) e tarefas com importantes componentes perceptuais e motoras (como o ajuste de colinearidade), que considerem também os aspectos cognitivos envolvidos, poderiam ajudar nas investigações desses processos.

A importância dos resultados obtidos estaria dada pela aplicação, por exemplo, na compensação das limitações visuais produzida pela catarata, patologia indicada como de grande incidência em todo o mundo pela Organização Mundial da Saúde (OMS) (WHO, 2000), ou da redução do efeitos do ofuscamento em tarefas complexas onde a percepção de distância é fundamental, como seria a direção de um veículo (HIGGINS; WOOD; TAIT, 1998; MANTYJARVI; TUPPURAINEN, 1999). 


\section{Discussão Geral}

O presente estudo considerou o espaço visual e a percepção de distância, a partir da colinearidade no campo aberto. Os aportes podem ser sumariados a partir de três aspectos: em relação ao espaço visual e a percepção de colinearidade, em relação ao modelado dos dados das distâncias percebidas e, por último, em relação aos aspectos cognitivos.

Como foi estabelecido, o espaço visual seria o resultado final de uma série de processos que permitiriam construir essa representação que experimentamos como a configuração espacial de objetos e superfícies que existiriam independentemente de nós. Mas, embora seja estável, coerente, estruturado (INDOW, 1999, 2004a), e possa ser caracterizado por algumas propriedades geométricas percebidas, tais como as distâncias egocêntricas e exocêntricas, estas não são uma transformação direta das características Euclidianas do espaço físico (HERSHENSON, 1999). Pelo contrário, o fenômeno perceptual da anisotropia do espaço visual é um dos mais robustos e intrigantes no campo da percepção, e mostra que as distâncias percebidas não guardam uma relação simples com a sua contraparte física, dependendo também de condições como o layout utilizado(LAPPIN; SHELTON; RIESER, 2006) , os indícios disponíveis nele (KÜNNAPAS, 1968; CUTTING; VISHTON, 1995; CUTTING, 1997) e o tipo de tarefa utilizada (LOOMIS; DA SILVA; FUJITA; FUKUSIMA, 1992; LOOMIS; PHILBECK, 2008). Nesse contexto, foram definidos os experimentos apresentados no presente estudo, os quais foram realizados no campo aberto, em condições de indícios múltiplos e usando tarefas baseadas na percepção de colinearidade.

O apontamento exocêntrico(KOENDERINK; VAN DOORN, 1998) aparece como uma metodologia nova, especialmente no campo aberto, pelo que foi de especial interesse o estudo de uma tarefa baseada nele. Para isso também foi necessário definir as condições na sua aplicação, especialmente no referido ao posicionamento dos estímulos empregados. O layout utilizado buscou indagar as diagonais do campo visual, áreas não utilizadas com freqüência nos experimentos encontrados na literatura. Assim, as 
séries de estímulos foram colocadas em ângulos fora do padrões definidos por Toye (1986) como sagitais ou frontoparalelos, com valores maiores aos $30^{\circ}$ indicados por este autor. Os ângulos visuais abarcados por nossa configuração de estímulos estiveram de acordo com os achados de Koenderink, van Doorn e Todd (2009) no referido ao ângulo visual efetivo. De esta maneira, as distâncias exocêntricas abarcaram ângulos desde $67^{\circ}$ até $101^{\circ}$, com vários valores rondando os $90^{\circ}$, valor também considerado no trabalho de Kelly, Loomis e Beall (2004). Assim, a geometria básica foi parecida à empregada por Koenderink et al. (2008), mas os triângulos definidos pelas estacas se encontraram de forma simultânea no espaço físico e numa reflexão não simétrica a partir do ponto central da configuração.

Os resultados dos ajustes de colinearidade apresentaram erros negativos no $67 \%$ das observações, indicando uma compressão do espaço percebido. Mas ao considerar o tamanho dos erros, as medidas de tendência central dos resultados obtidos coincidem e revelam evidencias de respostas surpreendentemente acuradas no ajuste de colinearidade, de forma similar ao indicado por outros autores que empregaram tarefas baseadas no apontamento exocêntrico (CUIJPERS; KAPPERS; KOENDERINK, 2000a, 2000b, 2001, 2002; KELLY; LOOMIS; BEALL, 2004; KOENDERINK et al., 2008). Foi encontrada uma forte dependência dos erros de colinearidade em função da distância egocêntrica aos estímulos, de maneira similar ao reportado por Cuijpers, Kappers e Koenderink (2000a) e Kelly, Loomis e Beall (2004) mas com diferenças, próprias às características implícitas nas diferentes variantes utilizadas pelos autores.

De igual maneira ao encontrado por Koenderink et al. (2008) vemos que as posiciones de colinearidade definidas pelos observadores falham em definir arcos simples, evidenciando os resultados da tarefa de colinearidade a anisotropia do espaço visual. Este fato levaria a descartar geometrias constantes para modelar o espaço visual, tal como a proposta de Luneburg (LUNEBURG, 1947), ou inclusive poder ser caracterizado exclusivamente por uma geometria particular (LUKAS, 2001; NORMAN; CRABTREE; CLAYTON; NORMAN, 2005). A alternativa proposta por Koenderink et al. (2008) seria de postular o espaço como 'contextual' ou 'momentâneo', ou 'dependente da tarefa, ou talvez de combinações destas possibilidades, destacando suas características dinâmicas e adaptativas.

O Experimento III buscou indagar mais sobre as anisotropias do espaço visual, a partir das estimativas verbais de distâncias egocêntricas e exocêntricas dos estímulos da configuração espacial que tinha sido definida no Experimento I. Os resultados das 
estimativas para ambos tipos de distâncias indicaram que estes foram coerentes, pois estímulos posicionados em distâncias físicas semelhantes, ainda que se encontravam em Diagonais diferentes, produziram julgamentos similares. Os dados mostraram uma compressão das estimativas, as quais apresentam valores menores que as respectivas distâncias físicas, indicando uma anisotropia do espaço visualmente percebido, tal como indicado na literatura (DA SILVA, 1985; WAGNER, 1985; TOYE, 1986; LOOMIS; PHILBECK, 1999; NORMAN; TODD; PEROTTI; TITTLE, 1996; RIBEIRO-FILHO, 1993; FOLEY; RIBEIRO-FILHO; DA SILVA, 2004). A modelagem dos dados, tanto egocêntricos como exocêntricos, com os diferentes modelos considerados (ajuste linear, função de potência, 'modelo Generalizado' e o 'Tangle') mostrou que todos estes modelos conseguiam ajustar bem os resultados. Sem embargo, a função de potência apresentou uma melhor adequação à relação entre as distâncias físicas dos estímulos e as distâncias reportadas pelos sujeitos, entretanto, o modelo Generalizado mostrou uma subestimação da extensão percebida, com o erro aumentando a medida que aumenta o ângulo entre os estímulos considerados. Sem dúvida o Tangle foi o modelo que melhor conseguiu ajustar os dados em ambos tipos de distâncias, desempenho devido possivelmente a suas características adaptativas (FOLEY; RIBEIRO-FILHO; DA SILVA, 2004).

Os dados das distâncias físicas e das distâncias egocêntricas e exocêntricas percebidas foram utilizados para testar a desigualdade do triângulo. Foi encontrado que os julgamentos realizados a partir da configuração de estímulos perceptualmente colineares satisfizeram dita propriedade, confirmando os achados de Foley, Ribeiro-Filho e Da Silva (2004) para ângulos de $\approx 68^{\circ}$, e expandindo suas conclusões para ângulos visuais de até $101^{\circ}$. Em relação à segunda implicação, isto é que a soma das distâncias exocêntricas percebidas determinadas pelos segmentos de reta adjacentes não se igualaria à distância exocêntrica percebida entre os pontos mais extremos, não foi cumprida pelas observações, segundo o predito pelo modelo de Foley, Ribeiro-Filho e Da Silva (2004).

Os resultados são coerentes com os encontrados nos experimentos anteriores, mostrando novamente as anisotropias do espaço visual, e levando a questionar, como fizeram Foley, Ribeiro-Filho e Da Silva (2004), o emprego de representações do espaço visual baseadas em geometrias métricas, tanto euclidianas (WAGNER, 1985) como riemannianas de curvatura constante (LUNEBURG, 1947) ou variável (KOENDERINK; DOORN; LAPPIN, 2000), e, ainda mais, rechazar a proposta de Gibson (1986) de assumir que o espaço visual seria equivalente ao espaço físico. 
Os resultados do Experimento IV mostraram que no campo aberto a tarefa com um estímulo físico produziu estimativas melhores que a complexa de visualização mental, baseada na inferência da posição a partir de varios estímulos físicos. Em ambos casos, a compressão nos julgamentos foi maior que as observadas nos experimentos prévios. Ainda que os sujeitos tentaram corrigir suas estimativas, segundo hipotetizado por Gogel e Da Silva (1987), esta correção cognitiva poderia ser mais fácil de realizar com o estímulo físico que nas inferências baseadas na visualização mental a partir de uma quantidade maior de informação. Assim, embora ambos perceptos sejam afetados pela compressão, indicando a anisotropia na representação das posições deles, a disponibilidade do alvo físico no local específico faria com que reajustar a estimativa seja mais fácil.

O Experimento $\mathrm{V}$, onde os observadores foram expostos a uma redução significativa na qualidade e quantidade dos indícios disponíveis, mostrou que os sujeitos conseguiram se sobrepor a ditas limitações, com ajustes de colinearidade que não foram estatisticamente diferentes dos realizados com visão normal. Estes resultados coincidem em mostrar a anisotropia do espaço visual, mas também ressaltam a importância dos fatores cognitivos na sua construção, onde correções cognitivas atuam constantemente para melhorar os perceptos e facilitar nosso desempenho no mundo físico.

Ainda que nos experimentos foram notadas diferencias individuais nas estimativas, assim como devidas ao sexo dos observadores, foi interessante notar também como são compartilhadas as características do espaço visual. Os resultados obtidos a partir do emprego da colinearidade no campo aberto indicaram que em geral, a maioria dos sujeitos ajustou linhas de colinearidade semelhantes, e, de igual maneira, julgaram como colineares os alvos posicionados por outras pessoas.

Como futuras investigações nesta linha de pesquisa, ficaria o considerar ângulos visuais diferentes entre os estímulos, mudar a posição de observação, avaliar o peso dos indícios presentes e aprofundar nos aspectos cognitivos subjacentes, especialmente em condições de visão reduzida.

Sumariando, o trabalho experimental apresentado permitiu agregar informações para área temática desta pesquisa, contribuindo com uma análise ampliada sobre procedimentos baseados no ajuste de colinearidade, à aplicação de modelos, especialmente o de Foley, Ribeiro-Filho e Da Silva (2004) em estimativas baseadas neste tipo de tarefas no campo aberto, e sobre os aspectos cognitivos intervenientes. 


\section{Referências}

APPELLE, S. Perception and discrimination as a function of stimulus orientation: the "oblique effect" in man and animals. Psychological bulletin, v. 78, n. 4, p. 266-278, 1972.

ARTAL, P. et al. Neural compensation for the eye's optical aberrations. Journal of Vision, v. 4, n. 4, p. 281-287, 2004.

ATKINSON, G. F. Designs for sequences of treatments with carry-over effects. Biometrics, v. 22, n. 2, p. 292-309, 1966.

AVANT, L. L. Vision in the ganzfeld. Psychological Bulletin, v. 64, n. 4, p. 246-258, 1965.

AVRAHAMI, J.; ARGAMAN, T.; WEISS-CHASUM, D. The mysteries of the diagonal: Gender-related perceptual asymmetries. Perception \& Psychophysics, v. 66, n. 8, p. 14051417, 2004.

AZNAR-CASANOVA, J. A.; DA SILVA, J. A.; RIBEIRO-FILHO, N. P.; SANTILLÁN, J. E. ¿es el espacio visualmente percibido un espacio métrico? Estudios de Psicología, v. 30, n. 3, p. 345-371, 2009.

AZNAR-CASANOVA, J. A.; MATSUSHIMA, E. H.; DA SILVA, J. A.; RIBEIRO-FILHO, N. P. Can exocentric direction be dissociated from its exocentric distance in virtual environments? Perception E Psychophysics, v. 70, n. 3, p. 541-550, 2008.

AZNAR-CASANOVA, J. A.; MATSUSHIMA, E. H.; RIBEIRO-FILHO, N. P.; DA SILVA, J. A. One-dimensional and multi-dimensional studies of the exocentric distance estimates in frontoparallel plane, virtual space, and outdoor open field. The Spanish journal of psychology, v. 9, n. 2, p. 273-284, 2006.

AZNAR-CASANOVA, J. A. et al. Interaction between egocentric and exocentric frames of reference assessed by perceptual constancy parameters. Cognitive Studies, v. 15, n. 1, p. 22-37, 2008.

BAIRD, J. C.; WAGNER, M. Transformation theory of size judgment. Journal of Experimental Psychology: Human Perception and Performance, v. 17, n. 3, p. 852-864, 1991.

BAIRS, J. C.; NOMA, E. Fundamentals of Scaling and Psychophysics. New York: John Wiley \& Sons, Inc., 1978.

BIEDERMAN, I. Perceiving real-word scenes. Science, v. 177, n. 43, p. 77-80, 1972.

BLANK, A. A. The luneburg theory of binocular visual space. Journal of the Optical Society of America, v. 43, n. 9, p. 717-727, 1953.

BLUMENFELD, W. Untersuchungen über die scheinbare Grösse im Sehraume. Zeitschrift für Psychologie, v. 65, p. 241-404, 1913. 
BRUNSWIK, E. Zur Entwicklung der Albedowahrnehmung. Zeitschrift für Psychologie, v. 109 , p. $40-115,1929$.

CHRISTMAN, S. D. Local-global processing in the upper versus lower visual fields. Bulletin of the Psychonomic Society, v. 31, p. 275-278, 1993.

CIUFFREDA, K. J.; WANG, B.; VASUDEVAN, B. Conceptual model of human blur perception. Vision Research, v. 47, n. 9, p. 1245-1252, 2007.

COMMITTERI, G. et al. Reference frames for spatial cognition: Different brain areas are involved in viewer-, object-, and landmark-centered judgments about object location. Journal of Cognitive Neuroscience, v. 16, n. 9, p. 1517-1535, 2004.

CRAWFORD, M.; CHAFFIN, R.; FITTON, L. Cognition in social context. Learning and Individual Differences, v. 7, n. 4, p. 341-362, 1995.

CUIJPERS, R. H.; KAPPERS, A. M.; KOENDERINK, J. J. Investigation of visual space using an exocentric pointing task. Perception $\mathcal{E}$ Psychophysics, v. 62, n. 8, p. 1556-1571, 2000 .

CUIJPERS, R. H.; KAPPERS, A. M.; KOENDERINK, J. J. Large systematic deviations in visual parallelism. Perception, v. 29, n. 12, p. 1467-1482, 2000.

CUIJPERS, R. H.; KAPPERS, A. M.; KOENDERINK, J. J. Visual perception of collinearity. Perception E psychophysics, v. 64, n. 3, p. 392-404, 2002.

CUIJPERS, R. H.; KAPPERS, A. M. L.; KOENDERINK, J. J. On the role of external reference frames on visual judgements of parallelity. Acta Psychologica, v. 108, n. 3, p. 283-302, 2001.

CUQLOCK-KNOPP, V. G.; WHITAKER, L. A. Spatial ability and land navigation under degraded visual conditions. Human Factors, v. 35, n. 3, p. 511-520, 1993.

CUTTING, J. E. How the eye measures reality and virtual reality. Behavior Research Methods, Instruments, and Computers, v. 29, n. 1, p. 27-36, 1997.

CUTTING, J. E.; VISHTON, P. M. Perceiving layout and knowing distances: The integration, relative potency, and contextual use of different information about depth. In: EPSTEIN, W.; ROGERS, S. J. (Ed.). Perception of Space and Motion. San Diego CA: Academic Press, 1995. p. 69-117.

DA SILVA, J. A. Scales for perceived egocentric distance in a large open field: comparison of three psychophysical methods. American Journal of Psychology, v. 98, n. 1, p. 119-144, 1985.

DA SILVA, J. A.; AZNAR-CASANOVA, J. A.; RIBEIRO-FILHO, N. P.; SANTILLÁN, J. E. Acerca da métrica da percepção do espaço visual. Arquivos Brasileiros de Oftalmologia, v. 69, n. 1, p. 127-135, 2006.

DIWADKAR, V. A.; MCNAMARA, T. P. Viewpoint dependence in scene recognition. Psychological Science, v. 8, p. 302-306, 1997. 
EPSTEIN, W. The Metatheorical Context. In: EPSTEIN, W.; ROGERS, S. J. (Ed.). Perception of Space and Motion. 2nd. ed. San Diego, CA: Academic Press, 1995. v. 2, p. $1-22$.

ESCHENBURG, J. H. Is binocular visual space constantly curved? Journal of mathematical biology, v. 9, n. 1, p. 3-22, 1980.

FEINGOLD, A. Cognitive gender differences are disappearing. American Psychologist, v. 43, p. 95-103, 1988.

FERRATER MORA, J. Diccionario de Filosofía. Barcelona: Editorial Ariel, 1994.

FINE, E. M.; RUBIN, G. S. The effects of simulated cataract on reading with normal vision and simulated central scotoma. Vision Research, v. 39, n. 25, p. 4274-4285, 1999.

FOLEY, J. M. Effect of distance information and range on two indices of visually perceived distance. Perception, v. 6, p. 449-460, 1977.

FOLEY, J. M. Binocular distance perception. Psychological Review, v. 87, n. 5, p. 411-434, 1980.

FOLEY, J. M. Binocular distance perception: egocentric distance tasks. Journal of Experimental Psychology: Human Perception and Performance, v. 11, n. 2, p. 133-149, 1985.

FOLEY, J. M. Binocular space perception. In: REGAN, D. (Ed.). Binocular vision. London: Macmillan, 1991. v. 9, p. 75-92.

FOLEY, J. M.; RIBEIRO-FILHO, N. P.; DA SILVA, J. A. Visual perception of extent and the geometry of visual space. Vision Research, v. 44, p. 147-156, 2004.

FUKUSIMA, S. S.; FAUBERT, J. Perceived length in the central visual field: evidence for visual field asymmetries. Vision research, v. 41, n. 16, p. 2119-2126, 2001.

FUKUSIMA, S. S.; LOOMIS, J. M.; DA SILVA, J. A. Visual perception of egocentric distance as assessed by triangulation. Journal of Experimental Psychology: Human Perception and Performance, v. 23, n. 1, p. 86-100, 1997.

GIBSON, J. J. The Ecological Approach to Visual Perception. New Jersey: Lawrence Erlbaum Associates, 1986. Original publicado em 1979.

GILINSKY, A. S. Perceived size and distance in visual space. Psychological Review, v. 58, n. 6, p. $460-482,1951$.

GOGEL, W. C. Equidistance tendency and its consequences. Psychological Bulletin, v. 64, p. $153-163,1965$.

GOGEL, W. C. The organization of perceived space. I. Perceptual interactions. Psychologische Forschung, v. 36, n. 3, p. 195-221, 1973.

GOGEL, W. C. Cognitive factors in spatial responses. Psychology, v. 17, p. 213-225, 1974. 
GOGEL, W. C. Size, distance and depth perception. In: CARTTERETTE, E.; FRIEDMAN, M. (Ed.). Handbook of Perception. New York: Academic Press, 1978. IX, cap. 8, p. 300-333.

GOGEL, W. C. A theory of phenomenal geometry and its applications. Perception $\mathcal{E}$ Psychophysics, v. 48, n. 2, p. 105-123, 1990.

GOGEL, W. C.; DA SILVA, J. A. A two-process theory of the response to size and distance. Perception \& Psychophysics, v. 41, n. 3, p. 220-238, 1987.

GOGEL, W. C.; NEWTON, R. E. An apparatus for indirect measurement of perceived distance. Perceptual and motor skills, v. 43, n. 1, p. 295-302, 1976.

GOODALE, M.; MILNER, A. Separate visual pathways for perception and action. Trends in Neurosciences, v. 15, n. 1, p. 20-25, 1992.

GUILLIAM, B. The perception of spatial layout from statical optical information. In: EPSTEIN, W.; ROGERS, S. J. (Ed.). Perception of Space and Motion. San Diego CA: Academic Press, 1995. p. 23-67.

HABER, R. H. Toward a theory of the perceived spatial layout scenes. Computer vision and imaging processing, v. 34, p. 282-321, 1985.

HART, R. A.; MOORE, G. T. The development of spatial cognition: A review. In: DOWNS, R.; STEA, D. (Ed.). Image \& environment: cognitive mapping and spatial behavior. New Jersey: Aldine Transaction, 2005. p. 246-288.

HATFIELD, G. Representation and constraints: the inverse problem and the structure of visual space. Acta psychologica, v. 114, n. 3, p. 355-378, 2003.

HERSHENSON, M. Visual Space Perception. Massachusetts: MIT, 1999.

HIGASHIYAMA, A.; UEYAMA, E. The perception of vertical and horizontal distances in outdoor settings. Perception \& psychophysics, v. 44, n. 2, p. 151-156, 1988.

HIGGINS, K. E.; WOOD, J.; TAIT, A. Vision and driving: selective effect of optical blur on different driving tasks. Human factors, v. 40, n. 2, p. 224-232, 1998.

HILLEBRAND, F. Theorie der scheinbaren grösse bai binocularem Sehen [Theory of apparent size in binocular vision]. Denkschrifften der Wiener Akademic. Matematisch Naturwissenschaft Klasse, v. 72, p. 255-307, 1902.

HOLLINGWORTH, A.; HOLLINGWORTH, A. Constructing visual representations of natural scenes: the roles of short- and long-term visual memory. Journal of experimental psychology. Human perception and performance, v. 30, n. 3, p. 519-537, 2004.

INDOW, T. Global structure of visual space as a united entity. Mathematical Social Sciences, v. 38, n. 3, p. 377-392, 1999.

INDOW, T. Awareness, Consciousness, and Visual Space. [S.1.], 2004.

INDOW, T. The Global Structure of Visual Space. New Jersey: World Scientific, 2004. 
JAMES, W. The principles of psychology. New York: Dover, 1950. Trabalho original publicado em 1890.

JEANNEROD, M. Mental imagery in the motor context. Neuropsychologia, v. 33, n. 11, p. 1419-1432, 1995.

KAUFMAN, L. Sight and mind: an introduction to visual perception. New York: Oxford Universitary Press, 1974.

KELLY, J. W.; BEALL, A. C.; LOOMIS, J. M. Accurate judgments of exocentric direction in large scale space. Journal of Vision, v. 2, n. 7, p. 718-718, 2002. Abstract of the Vision Sciences Society Meeting held on May 10-15, 2002.

KELLY, J. W.; BEALL, A. C.; LOOMIS, J. M. Perception of shared visual space: Establishing common ground in real and virtual environments. Presence: Teleoperators and Virtual Environments, v. 13, n. 4, p. 442-450, 2004.

KELLY, J. W.; LOOMIS, J. M.; BEALL, A. C. Judgments of exocentric direction in large-scale space. Perception, v. 33, n. 4, p. 443-454, 2004.

KIMURA, D. Sex, sexual orientation and sex hormones influence human cognitive function. Current opinion in neurobiology, v. 6, n. 2, p. 259-263, 1996.

KOENDERINK, J. J.; DOORN, A. J. van; LAPPIN, J. S. Direct measurement of the curvature of visual space. Perception, v. 29, n. 1, p. 69-79, 2000.

KOENDERINK, J. J.; VAN DOORN, A. J. Exocentric pointing. In: HARRIS, L.; JENKIN, M. (Ed.). Vision and Action. Cambridge: Cambridge University Press, 1998. p. 295-313.

KOENDERINK, J. J. et al. Exocentric pointing in depth. Vision Research, v. 48, n. 5, p. 716-723, 2008.

KOENDERINK, J. J.; VAN DOORN, A. J.; LAPPIN, J. S. Exocentric pointing to opposite targets. Acta Psychologica, v. 112, n. 1, p. 71-87, 2003.

KOENDERINK, J. J.; VAN DOORN, A. J.; TODD, J. T. Wide distribution of external local sign in the normal population. Psychological research, v. 73, n. 1, p. 14-22, 2009.

KOFFKA, K. Principios da Psicologia da Gestalt. São Paulo: Cultrix, 1975. Publicação original de 1935.

KORIAT, A.; GOLDSMITH, M.; PANSKY, A. Toward a psychology of memory accuracy. Annual review of psychology, v. 51, p. 481-537, 2000.

KOSSLYN, S. M. Seeing and imagining in the cerebral hemispheres: a computational approach. Psychological review, v. 94, n. 2, p. 148-175, 1987.

KÜNNAPAS, T. Distance perception as a function of available visual cues. Journal of Experimental Psychology, v. 77, n. 4, p. 523-529, 1968.

LAPPIN, J. S.; SHELTON, A. L.; RIESER, J. J. Environmental context influences visually perceived distance. Perception E psychophysics, v. 68, n. 4, p. 571-581, 2006. 
LEVIN, C. A.; HABER, R. N. Visual angle as a determinant of perceived interobject distance. Perception E Psychophysics, v. 54, p. 250-259, 1993.

LINGEFJÄRD, T. Faces of mathematical modeling. ZDM - The International Journal on Mathematics Education, v. 38, n. 2, p. 96-112, 2006.

LOOMIS, J. M.; DA SILVA, J. A.; FUJITA, N.; FUKUSIMA, S. S. Visual space perception and visually directed action. Journal of Experimental Psychology: Human Perception and Performance, v. 18, n. 4, p. 906-921, 1992.

LOOMIS, J. M.; PHILBECK, J. W. Is the anisotropy of perceived 3-d shape invariant across scale? Perception E Psychophysics, v. 61, p. 397-402, 1999.

LOOMIS, J. M.; PHILBECK, J. W. Measuring spatial perception with spatial updating and action. In: KLATZKY, R. L.; MACWHINNEY, B.; BEHRMANN, M. (Ed.). Embodiment, Ego-space and Action. New York: Taylor \& Francis, 2008. cap. 1, p. 1-39.

LOOMIS, J. M.; PHILBECK, J. W.; ZAHORIK, P. Dissociation between location and shape in visual space. Journal of Experimental Psychology: Human Perception and Performance, v. 28, p. 1202-1212, 2002.

LUKAS, J. Geometry of visual space. In: SMELSER, N. J.; BALTES, P. B. (Ed.). International Encyclopedia of the Social \& Behavioral Sciences. Oxford: Pergamon, 2001. p. 16274-16278.

LUNEBURG, R. K. Mathematical analysis of binocular vision. Princeton NJ: Princeton University Press, 1947.

MANTYJARVI, M.; TUPPURAINEN, K. Cataract in traffic. Graefes Arch Clin Exp Ophthalmol, v. 237, n. 4, p. 278-282, 1999.

MARR, D. Vision. New York: W. H. Freeman \& Co, 1982.

MATHER, G. The use of image blur as a depth cue. Perception, v. 26, n. 9, p. 1147-1158, 1997.

MATSUSHIMA, E. H. Anisotropia do espaço percebido e paralaxe de movimento : uma análise da orientação espacial. Tese (Doutorado) - Universidade de São Paulo, 2003.

MATSUSHIMA, E. H.; RIBEIRO-FILHO, N. P. Interações entre os sistemas de referência alocêntricos e egocêntricos: evidências dos estudos com direção percebida. Estudos e Pesquisas em Psicologia, v. 3, n. 1, p. 105-118, 2003.

MICHAELS, C. F. Information, perception, and action: What should ecological psychologists learn from Milner and Goodale (1995)? Ecological Psychology, v. 12, n. 3, p. 241-258, 2000.

MILNER, A. D.; GOODALE, M. A. The Visual Brain in Action. New York: Oxford University Press, 1995.

MILNER, A. D.; GOODALE, M. A. Two visual systems re-viewed. Neuropsychologia, v. 46, n. 3, p. 774-785, 2008. 
MYERS, A. K. Quantitative indices of perceptual constancy. Psychological Bulletin, v. 88, n. 2 , p. $451-457,1980$.

NEISSER, U. Multiple systems: A new approach to cognitive theory. European Journal of Cognitive Psychology, v. 6, p. 225-241, 1994.

NORMAN, J. F.; CRABTREE, C. E.; CLAYTON, A. M.; NORMAN, H. F. The perception of distances and spatial relationships in natural outdoor environments. Perception, v. 34, n. 11, p. 1315-1324, 2005.

NORMAN, J. F.; TODD, J. T.; PEROTTI, V. J.; TITTLE, J. S. The visual perception of three-dimensional length. Journal of Experimental Psychology: Human Perception and Performance, v. 22, p. 173-186, 1996.

OOI, T. L.; WU, B.; HE, Z. J. Distance determined by the angular declination below the horizon. Nature, v. 414, p. 197-200, 2001.

PASTORE, N. Selective history of the theories of visual perception. New York: Oxford Universitary Press, 1971.

PEELEN, M. V.; FEI-FEI, L.; KASTNER, S. Neural mechanisms of rapid natural scene categorization in human visual cortex. Nature, v. 460, n. 7251, p. 94-97, 2009.

PERTZOV, Y.; AVIDAN, G.; ZOHARY, E. Accumulation of visual information across multiple fixations. Journal of Vision, v. 9, n. 10, p. 1-12, 2009.

PHILBECK, J. W. Processes underlying paradoxical indications of extend. Tese (PhD thesis) - University of California in Santa Barbara, 1997.

PHILBECK, J. W.; LOOMIS, J. M. Comparison of two indicators of perceived egocentric distance under full-cue and reduced-cue conditions. Journal of Experimental Psychology: Human Perception and Performance, v. 23, n. 1, p. 72-85, 1997.

POSTMA, A. Space: from perception to action. Acta Psychologica, v. 118, n. 1-2, p. 1-6, 2005.

PREDEBON, J. Relative distance judgments of familiar and unfamiliar objects viewed under representatively natural conditions. Perception \& Psychophysics, v. 47, p. 342-348, 1990.

PYLYSHYN, Z. Return of the mental image: are there really pictures in the brain? Trends in Cognitive Sciences, v. 7, n. 3, p. 113-118, 2003.

RAJEEV, N.; METHA, A. Enhanced contrast sensitivity confirms active compensation in blur adaptation. Investigative ophthalmology $\mathcal{E}$ visual science, 2009. In Press.

RAMIRES, A.; CARAPETA, C.; FELGUEIRAS, F.; VIANA, M. F. Treino de modelagem e visualização mental: Avaliação dos efeitos nas expectativas de auto-eficácia e desempenho de atletas de patinagem. Análise Psicológica, v. 29, n. 1, p. 15-25, 2001.

RIBEIRO-FILHO, N. P. Percepção de configurações espaciais de estímulos em grande campo aberto. Tese (Doutorado) — Universidade de São Paulo, 1993. 
SAKAGUCHI, Y. Visual field anisotropy revealed by perceptual filling-in. Vision research, v. 43, n. 19, p. 2029-2038, 2003.

SANOCKI, T. Representation and perception of scenic layout. Cognitive Psychology, v. 47, n. 1, p. 43-86, 2003.

SCHELLING, H. Concept of distance in affine geometry and its applications in theories of vision. Journal of the Optical Society of America, v. 46, p. 309-315, 1956.

SCHOUMANS, N.; KAPPERS, A. M.; KOENDERINK, J. J. Scale invariance in near space: pointing under influence of context. Acta psychologica, v. 110, n. 1, p. 63-81, 2002.

SCHOUMANS, N.; KOENDERINK, J. J.; KAPPERS, A. M. Change in perceived spatial directions due to context. Perception E Psychophysics, v. 3, p. 532-539, 2000.

SEDGWICK, H. A. Space perception. In: BOFF, K.; KAUFMAN, L.; THOMAS, J. (Ed.). Handbook of Human Perception and Performance: Sensory Processes. New York: Wiley, 1986. v. 1, p. 21.1-21.57.

SHEPARD, R. N. Perceptual-cognitive universals as reflections of the world. Psychonomic Bulletin and Review, v. 1, p. 2-28, 1994.

SHEPARD, R. N.; METZLER, J. Mental rotation of three-dimensional objects. Science, v. 171, p. 701-703, 1971.

SIMONS, D. J.; WANG, R. F. Perceiving real-world viewpoint changes. Psychological Science, v. 9, p. 315-320, 1998.

SONG, J. H.; NAKAYAMA, K. Hidden cognitive states revealed in choice reaching tasks. Trends in Cognitive Sciences, v. 13, n. 8, p. 360-366, 2009.

STEVENS, S. S. Psychophysics: Introduction to its Perceptual, Neural, and Social Prospects. 2000. ed. New Brunswick: Transaction Books, 1975.

STRUIKSMA, M. E.; NOORDZIJ, M. L.; POSTMA, A. What is the link between language and spatial images? behavioral and neural findings in blind and sighted individuals. Acta psychologica, v. 132, n. 2, p. 145-156, 2009.

TEGHTSOONIAN, M.; TEGHTSOONIAN, R. Scaling apparent distance in natural indoor settings. Psychonomic Science, v. 16, n. 6, p. 281-283, 1969.

THOULESS, R. H. Phenomenal regression to the "real" object - I. British Journal Psychology, v. 21, p. 339-359, 1931.

TORRES, A. et al. Gender differences in cognitive functions and influence of sex hormones. Actas espanolas de psiquiatria, v. 34, n. 6, p. 408-415, 2006.

TOYE, R. C. The effect of viewing position on the perceived layout of space. Perception $\mathcal{E}$ Psychophysics, v. 40, n. 2, p. 85-92, 1986.

TVERSKY, B. Characterizing spatial cognition. International Journal of Psychology, v. 35, n. 3-4 Sp. Iss. SI, p. 3-3, 2000. 
WAGNER, H.; FINK, B. A.; ZADNIK, K. Sex- and gender-based differences in healthy and diseased eyes. Optometry, v. 79, n. 11, p. 636-652, 2008.

WAGNER, M. The metric of visual space. Perception \& Psychophysics, v. 38, p. 483-495, 1985.

WAGNER, M. The geometries of visual space. New Jersey: Lawrence Erlbaum Associates, 2005.

WANG, R. F.; SIMONS, D. J. Active and passive scene recognition across views. Cognition, v. 70, p. 191-210, 1999.

WARNER, L.; MCNEILL, M. E. Mental imagery and its potential for physical theraphy. Physical Therapy, v. 68, n. 4, p. 516-521, 1988.

WEINLAND, J. D. How to Think Straight. New Jersey: Rowman \& Allanheld, 1984.

WHO. Overcoming cataract blindness: A goal for the new millennium. Survey of Ophthalmology, v. 45, n. 1, p. S5-S6, 2000.

WOODS, R. L.; STRANG, N. C.; ATCHISON, D. A. Measuring contrast sensitivity with inappropiate optical correction. Ophthalmic and Physiological Optics, v. 20, n. 6, p. 442-451, 2000.

WOODWORTH, R. S.; SCHLOSBERG, H. Experimental Psychology. New York: Rinehart \& Winston, 1965.

WU, B.; KLATZKY, R. L.; SHELTON, D.; STETTEN, G. D. Psychophysical evaluation of in-situ ultrasound visualization. IEEE Transactions on Visualization and Computer Graphics, v. 11, n. 6, p. 684-693, 2005.

WU, B.; KLATZKY, R. L.; SHELTON, D.; STETTEN, G. Mental concatenation of perceptually and cognitively specified depth to represent locations in near space. Experimental Brain Research, v. 184, n. 3, p. 295-305, 2008.

YANG, Z.; PURVES, D. A statistical explanation of visual space. Nature Neuroscience, v. 6, n. 6, p. 632-640, 2003. 


\section{APÊNDICE A - Termo de Consentimento Livre e Esclarecido}

Exemplo de Termo de Consentimento livre e esclarecido empregado na coleta dos dados.

Estudo: "A métrica do espaço visual: julgamento de colinearidade para mensurar distância egocêntrica e exocêntrica".

Este estudo tem por objetivo abordar a questão da percepção de distância utilizando julgamento de colinearidade para mensurar a distância percebida. Esta será avaliada a partir de estimativas verbais feitas pelo observador das distâncias entre diferentes estímulos. A amostra desta pesquisa será composta por uma população universitária de ambos sexos e o estudo será conduzido sob condições de indícios visuais em campo aberto, isto é, em um ambiente de larga escala. Os benefícios advindos desta investigação consistem em propiciar uma melhor compreensão da percepção do espaço visual que, por sua vez, conduzirá a elucidação e obtenção de indícios sobre como a distância é mapeada em distância percebida. Quanto aos riscos, este projeto não expõe os participantes a nenhuma situação de estimulação física ou cognitiva que seja prejudicial ao seu organismo. Todos os participantes, após esta explanação, terão liberdade para aderir ou não à pesquisa, bem como iniciado o procedimento, interrompê-lo se assim desejar. A identidade dos colaboradores será mantida em sigilo.

1) Eu, abaixo assinado, concordei voluntariamente em participar do estudo acima.

2) Recebi informações detalhadas sobre a natureza e objetivos do estudo. 
3) Concordo em ser cooperativo nos procedimentos envolvidos.

4) Tenho conhecimento de que sou livre para desistir do estudo a qualquer momento, sem necessidade de justificar minha decisão. Caso isso ocorra, comprometo-me a avisar os pesquisadores o mais rápido possível.

5) Tenho conhecimento de que minha participação é sigilosa, isto é, de que meu nome não será divulgado em qualquer publicação, relatório ou comunicação científica referentes aos resultados da pesquisa. Além disso, eu autorizo o uso dos resultados obtidos, desde que eu não seja identificado como participante do estudo.

Nome:

Assinatura:

Data: ..../................

Confirmo ter explicado a natureza e os objetivos desse estudo ao voluntário acima. Coloco-me a disposição para outros esclarecimentos que se fizerem necessários.

Psic. Javier Enrique Santillán

Doutorando - PG em Psicobiologia

Contato: $3602-3835 / 3728$ 


\title{
APÊNDICE B - Instruções Experimento I
}

\author{
INSTRUÇão
}

Ajuste de Colinearidade

Este experimento requererá cerca de 20 minutos do seu tempo e você estará colaborando com a realização de nossa pesquisa. A identidade do participante será mantida em sigilo em caso de divulgação dos resultados para fins científicos. A tarefa que você realizará não é difícil. Todavia, caso você deseje interromper o experimento, avise-me e este será encerrado.

Inicialmente, gostaríamos que você observasse os alvos situados a sua frente e, com o queixo apoiado no suporte, alinhasse os quatro alvos móveis do centro com os quatros alvos fixos dos extremos. Primeiro os dois de uma diagonal e depois os outros dois até formar um " $\mathrm{X}$ ". Você poderá observar o esquema abaixo o qual apresenta graficamente a tarefa a ser realizada.
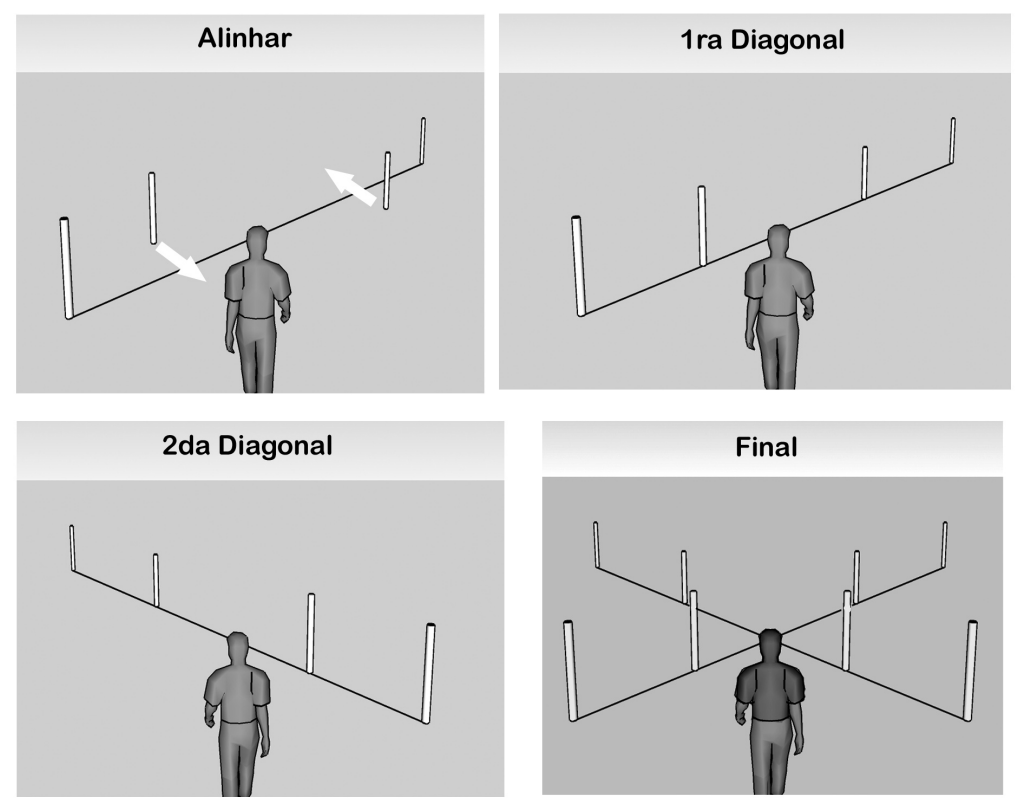

Durante a tarefa, você poderá observar os alvos, utilizando o suporte de queixo, o quanto for desejável e alterar o alinhamento o quanto necessário. Terminada a tarefa, por favor, avise o experimentador.

Alguma Questão? Muito Obrigado!. 


\section{APÊNDICE C - Protocolo coleta Exp. I}

\section{Experimento de Colinearidade} Protocolo de Coleta P1

Nome:

Data: / ।

(1)

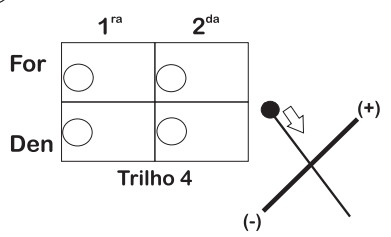

Clima: $\begin{aligned} & \text { sol } \\ & \text { Nublado }\end{aligned}$
Visão:

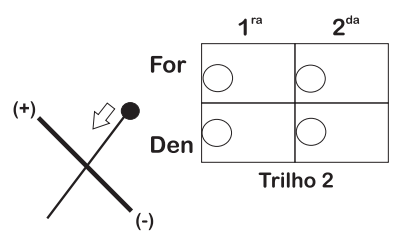

Identificação

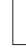

Edad:

Estratégia:
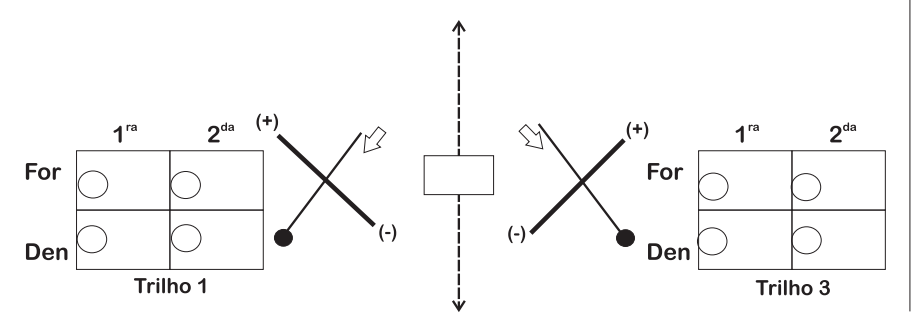

(2)

(3)
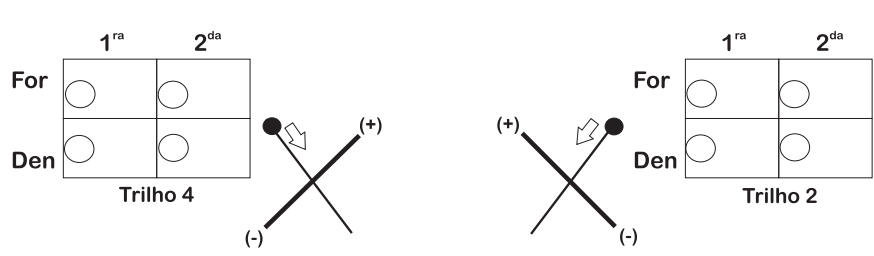

$X$
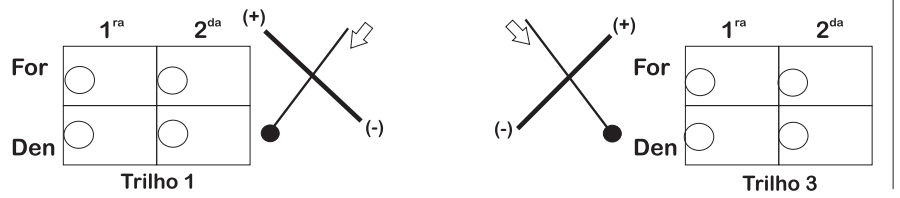


\title{
APÊNDICE D - Instruções Experimento II
}

\author{
INSTRUÇÃo \\ Julgamento de distâncias
}

Este experimento requererá cerca de 15 minutos do seu tempo e você estará colaborando com a realização de nossa pesquisa. A identidade do participante será mantida em sigilo em caso de divulgação dos resultados para fins científicos. A tarefa que você realizará não é difícil. Todavia, caso você deseje interromper o experimento, avise-me e este será encerrado.

Inicialmente, gostaríamos que você observasse os alvos situados a sua frente e, com o queixo apoiado no suporte, julgasse as distâncias que o experimentador ira apontando oportunamente e que poderão ser:

- Entre dois alvos

- Entre um alvo determinado e você

Sua tarefa será indicar verbalmente (em metros, ou centímetros ou uma combinação de ambos) ditas distâncias.

Alguma Questão? Muito Obrigado!. 


\section{APÊNDICE E - Protocolo coleta Exp. II}

\section{Experimento de Colinearidade \\ Protocolo de Coleta P2}

Nome:

Data: I I

Clima: Nol Nublado

Visão:

Identificação

Edad:

(1) Qual seria a distância em ( $\mathrm{m} / \mathrm{cm} / \mathrm{ambos})$ entre os dois alvos que vou sinalar?
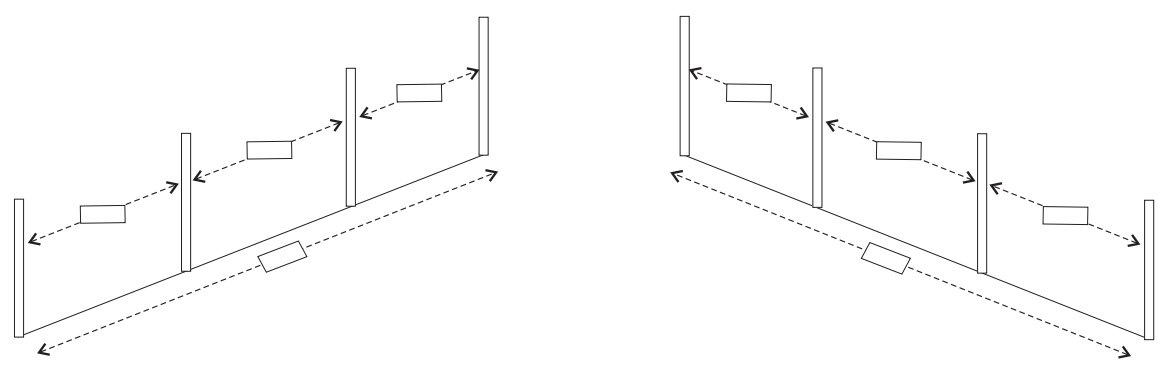

(2) Qual seria a distância em ( $\mathrm{m} / \mathrm{cm} / \mathrm{ambos})$ entre o alvo que vou sinalar e você?

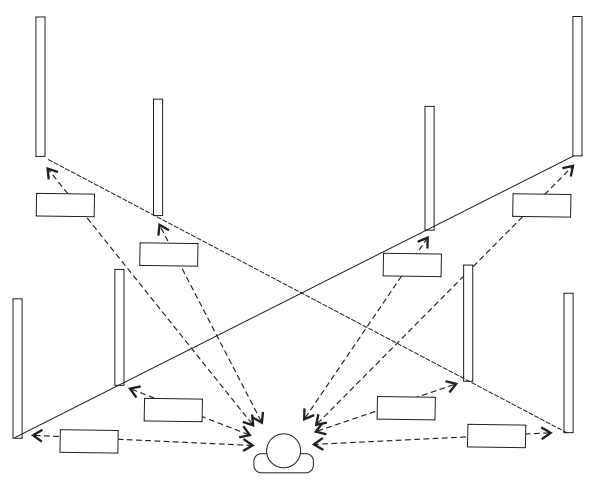

(3) Qual seria a distância em ( $\mathrm{m} / \mathrm{cm} / \mathrm{ambos})$ entre os dois alvos que vou sinalar na sua frente?

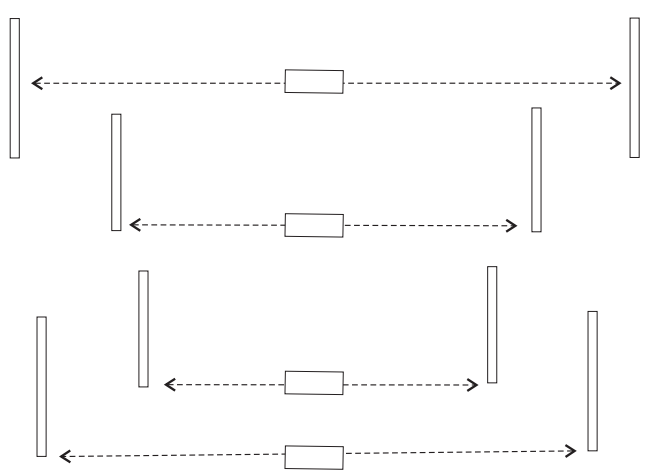




\title{
ANEXO A - Protocolo Comite Etica
}

\author{
UNIVERSIDADE DE SÃO PAULO \\ FACULDADE DE FILOSOFIA, CIENCIAS E LETRAS DE RIBEIRÃO PRETO \\ COMITE DE ÉTICA EM PESQUISA-CEP \\ Of.CEtP/109.2005-24/11/2005
}

Prezado(a) Senhor(a):

Comunicamos a V. Sa. que o trabalho intitulado "A MÉTRICA DA PERCEPÇÃO DO ESPAÇO VISUAL: CONSISTÊNCIA ENTRE INDICADORES DE DISTÂNCIA PERCEBIDA EGOCÊNTRICA E EXOCÊNTRICA EM AMBIENTE REAL, VIRTUAL E PICTÓRICO" foi analisado pelo Comitê de Ética em Pesquuisa da FFCLRP-USP, em sua $48^{\mathrm{a}}$ Reunião Ordinária realizada em 24/11/2005, e enquadrado na categoria: APROVADO de acordo com o Processo CEP-FFCLRP n 224/2005 2005.1.1657.59.0

Aproveitamos a oportunidade para apresentar nossos protestos de estima e consideração.

Atenciosamente,

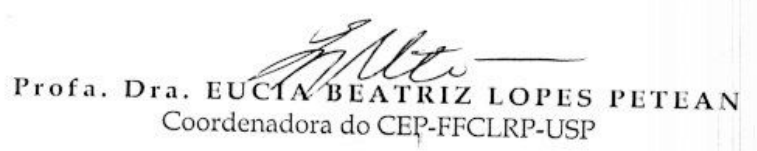

Ilustríssimo(a) Senhor(a)

Prof. Dr. JOSÉ APARECIDO DA SILVA

Docente do Departamento de Psicologia e Educação

desta FFCLRP-USP

CEP-FFCLRP-USP - Fone: (016) 602-3653 - Fax: (016) 633-5015 - E.mail: coetp@ffeIrp.usp.br - 